KARINA GORDON

\title{
Influência da transfusão de concentrado de hemácias na evolução pós-operatória de crianças submetidas a transplante hepático com doador vivo
}

Tese apresentada à Faculdade de Medicina da Universidade de São Paulo para obtenção do título de Doutora em Ciências

Programa de Anestesiologia

Orientador: Prof. Dr. Joel Avancini Rocha Filho

Coorientadora: Profa. Dra. Estela Regina Ramos Figueira

(Versão corrigida. Resolução CoPGr 6018/11, de 1 de novembro de 2011.

A versão original está disponível na Biblioteca da FMUSP)

São Paulo

2017 
Dados Internacionais de Catalogação na Publicação (CIP)

Preparada pela Biblioteca da

Faculdade de Medicina da Universidade de São Paulo

Creprodução autorizada pelo autor

\section{Gordon, Karina}

Influência da transfusão de concentrado de hemácias na evolução pósoperatória de crianças submetidas a transplante hepático com doador vivo / Karina Gordon -- São Paulo, 2017.

Tese(doutorado)--Faculdade de Medicina da Universidade de São Paulo.

Programa de Anestesiologia.

Orientador: Joel Avancini Rocha Filho.

Coorientadora: Estela Regina Ramos Figueira

Descritores: 1.Cirrose hepática 2.Transplante de fígado 3.Criança 4.Doadores vivos 5.Transfusão de eritrócitos 6.Complicações pós-operatórias 7.Sobrevivência pós-tratamento 8.Rejeição de enxerto 


\section{DEDICATÓRIA}

Este trabalho é dedicado:

Aos meus pais, Henry e Renata, que me ensinaram a importância do estudo, do respeito e da perseverança, guiando-me e incentivando-me, diariamente, desde a mais tenra infância.

Ao meu esposo, José Antônio, por testemunhar as incontáveis horas de sacrifício e dedicação, por zelar pela família e por seu amor incondicional.

Aos meus filhos, Mariana e Victor que, apesar do meu cansaço e impaciência frequentes, me compreenderam e me apoiaram até o fim. 


\section{AGRADECIMENTOS}

A Deus, pela graça da vida, da saúde, da família, do amparo, da misericórdia, por me guiar nas horas incertas e me fortalecer perante às dificuldades, me fazendo realizar este sonho.

Ao Prof. Dr. José Otávio Costa Auler Júnior, pela grande oportunidade proporcionada em minha vida profissional.

À Profa. Dra. Maria José Carvalho Carmona, coordenadora do Programa de Pós-Graduação em Anestesiologia da Faculdade de Medicina da Universidade de São Paulo, pela dedicação ao programa, pelas boas sugestões dadas à tese e pela oportunidade proporcionada em minha vida profissional.

Ao Prof. Dr. Joel Avancini Rocha Filho, pela orientação, pela experiência, pelo seu conhecimento e pelos valorosos ensinamentos, transmitidos na fundamentação e confecção desta tese.

À Profa. Dra. Estela Regina Ramos Figueira, pela coorientação, pela experiência, pela paciência, pelos conselhos e pela confiança transmitidas, na fundamentação e confecção desta tese.

Ao Prof. Dr. Paulo Chapchap, exímio cirurgião pediátrico, pioneiro deste notável programa e fundador do Departamento de Transplante Hepático, no AC Camargo Cancer Center e Hospital Sírio Libanês, por me despertar o interesse em conduzir a anestesia de crianças graves submetidas a transplante hepático e a cirurgias pediátricas oncológicas.

Ao Prof. Dr. Eduardo Caronne, exímio gastrocirurgião ex-chefe do Departamento de Transplante Hepático, no AC Camargo Cancer Center, por me orientar na prática anestésico-cirúrgica com seu jeito enérgico, porém, paternalista (in memoriam).

Ao Prof. Dr. Eduardo Antunes, gastrocirurgião e atual chefe do Departamento de Transplante Hepático, no AC Camargo Cancer Center, pelo respeito e anuência em relação a condução deste estudo.

Ao Prof. Dr. João Seda Neto, cirurgião pediátrico, pelo apoio, confiança e disponibilização de dados cirúrgicos fundamentais na elaboração deste estudo.

Aos Drs. Marcel Benavides, gastrocirurgião e Helry Cândido, cirurgião pediátrico, integrantes da equipe de Transplante Hepático, no AC Camargo Cancer Center, pelo respeito, coleguismo e dedicação aos pacientes.

À Profa. Dra. Renata Pugliese, hepatologista pediátrica, pela compreensão, presteza e disponibilização de dados clínicos fundamentais na elaboração deste estudo. 
À Dra. Massami Kayabashi, exímia intensivista pediátrica, pela assistência profissional, dedicação e carinho imensuráveis aos pacientes e pelos ensinamentos essenciais de terapia intensiva pediátrica.

Ao Dr. Eduardo Henrique Giroud Joaquim, professor e chefe do Departamento de Anestesiologia do AC Camargo Cancer Center, pelos ensinamentos, incentivo, confiança, oportunidade de aprendizado e aprimoramento profissional, em especial, ao que tangeu o desenvolvimento deste estudo.

Ao Dr. Luiz Antônio Mondadori, anestesiologista e grande amigo, pela inteligência, confiança, dedicação, altruísmo e, principalmente, pelo apoio logístico ilimitado na confecção do banco de dados que, efetivamente, viabilizou a execução deste estudo.

Ao Dr. Alex Madeira Vieira, anestesiologista, intensivista pediátrico e amigo, pela paixão e dedicação ao trabalho, além de "dividir o peso do piano" comigo.

Aos colegas anestesiologistas, pelo convívio prazeroso durante todos estes anos e pelas divertidas "conversas de corredor" que, acima de tudo, tornaram esta jornada muito mais leve.

Ao Departamento de Anestesiologia da Unidade de Fígado Queen Elizabeth Hospital de Birmingham (Reino Unido) e todo seu corpo clínico, que me acolheu como estagiária e contribuiu de maneira decisiva em minha formação profissional.

A todos os médicos, odontologistas, profissionais de enfermagem, psicólogos, fisioterapeutas, fonoaudiólogos, nutricionistas, assistentes sociais, escriturários, voluntários e demais colaboradores, envolvidos com os Departamentos de Anestesiologia, de Transplante Hepático, de Pediatria, de Estomatologia, centro cirúrgico, Unidade de Terapia Intensiva, enfermarias, ambulatórios, escola infantil e casas de apoio do AC Camargo Cancer Center.

Aos funcionários do Serviço de Arquivo Médico do AC Camargo Cancer Center pela agilidade e presteza, na disponibilização dos prontuários médicos ao longo de dezoito meses de pesquisa.

À bibliotecária, Isabel Figueiredo, da Divisão de Biblioteca e Documentação, pela elaboração da folha de rosto, ficha catalográfica e resumo e, ao funcionário, Josué Moreira, do setor de editoração da Faculdade de Medicina da Universidade de São Paulo pela formatação e encadernação.

Ao estatístico Vinicius Fernando Calsavara pela paciência, eficiência e solicitude na análise estatística deste estudo.

Aos doadores, exemplos de amor, dedicação e abnegação, e aos receptores, pela coragem no enfrentamento diário dos seus desafios, a todos que participaram efetivamente deste programa, corresponsáveis pelos bons resultados, minha admiração, meu respeito, e meus sinceros agradecimentos. 


\section{NORMALIZAÇÃO ADOTADA}

Esta dissertação está de acordo com as seguintes normas, em vigor no momento desta publicação

Referências: adaptado de International Committee of Medical Journals Editors (Vancouver).

Universidade de São Paulo. Faculdade de Medicina. Serviço de Biblioteca e Documentação. Guia de apresentação de dissertações, teses e monografias. Elaborado por Anneliese Carneiro da Cunha, Maria Julia de A.L. Freddi, Maria F. Crestana, Marinalva de Souza Aragão, Suely Campos Cadoso, Valéria Vilhena. $3^{a}$ Ed. São Paulo: Serviços de Biblioteca e Documentação; 2011.

Abreviaturas dos títulos dos periódicos de acordo com List of Journals Indexed in Index Medicus 


\section{SUMÁRIO}

Lista de símbolos e abreviaturas

Lista de siglas

Lista de figuras

Lista de tabelas

Resumo

Summary

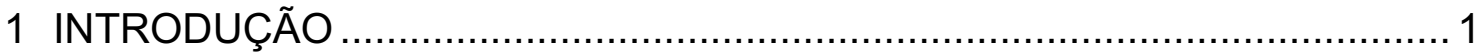

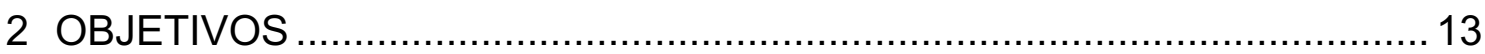

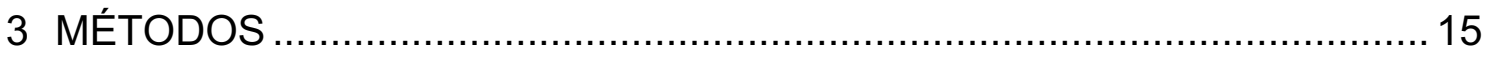

3.1 Critérios de elegibilidade .................................................... 16

3.1.1 Critérios de inclusão ........................................................ 16

3.1.2 Critérios de exclusão .......................................................... 16

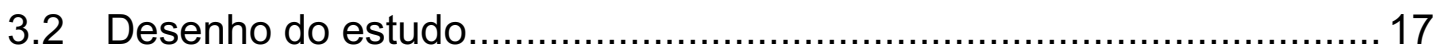

3.3 Classificação das complicações pós-operatórias de ClavienDindo $^{98}$ adaptada neste estudo para a população pediátrica e determinação das complicações graves........................................ 18

3.4 Variáveis estudadas ............................................................ 20

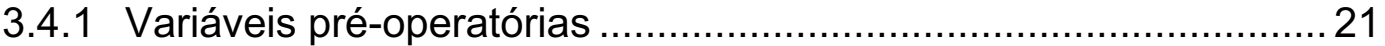

3.4.2 Variáveis intraoperatórias........................................................ 21

3.4.3 Variáveis pós-operatórias................................................... 22

3.4.4 Rejeição .............................................................................. 23

3.5 Complicações ....................................................................... 23

3.6 Tempo de internação e seguimento pós-alta hospitalar.....................27

3.7 Monitorização intraoperatória, técnica anestésica e técnica

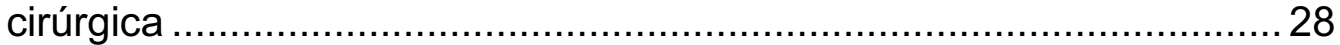

3.8 Análise estatística.................................................................... 31 
4.1 Participação do estudo

4.2 Características pré-operatórias da população geral e dos grupos

4.2.1 Características antropométricas e clínico-laboratoriais préoperatórias dos grupos de complicações maiores e menores

4.2.2 Características antropométricas e clínico-laboratoriais préoperatórias dos grupos de maior e menor volume transfusional de concentrado de hemácias no período perioperatório

4.2.3 Distribuição das etiologias das hepatopatias de base na amostra total e segundo os grupos de maior e menor volume transfusional de concentrado de hemácias.

4.3 Análise comparativa das variáveis clínico-laboratorias do intraoperatório e dos dados evolutivos do pós-operatório precoce dos grupos estudados de acordo com o volume concentrado de hemácias transfundido no perioperatório

4.4 Determinação dos fatores de risco independentes de transfusão de concentrado de hemácias no período perioperatório

4.5 Análise comparativa das complicações pós-operatórias entre os grupos com maior e menor volume de concentrado de hemácias transfundido no perioperatório.

4.5.1 Complicações do pós-operatório precoce utilizando a classificação de Clavien-Dindo adaptada e mortalidade pósoperatória de trinta dias após o transplante hepático dos grupos estudados de acordo com o volume de concentrado de hemácias transfundido no perioperatório

4.5.2 Complicações do pós-operatório precoce segundo tipo e gravidade dos grupos estudados de acordo com o volume de concentrado de hemácias transfundido no perioperatório

4.5.3 Complicações do pós-operatório tardio segundo tipo e gravidade dos grupos estudados de acordo com o volume de concentrado de hemácias transfundido no perioperatório

4.5.3.1 Complicações pós-operatórias até um ano após o transplante hepático segundo tipo e gravidade.

4.5.3.2 Complicações pós-operatórias até cinco anos após o transplante hepático segundo tipo e gravidade

4.5.3.3 Complicações pós-operatórias até dez anos após o transplante hepático segundo tipo e gravidade 
4.5.4 Análise gráfica das principais complicações pós-operatórias por períodos

4.6 Complicações imunológicas segundo grupos de maior e menor volume de concentrado de hemácias transfundido no perioperatório.

4.7 Complicações pós operatórias relacionadas ao enxerto e mortalidade de dez anos após o transplante hepático

4.8 Determinação dos fatores de risco independentes relacionados à mortalidade

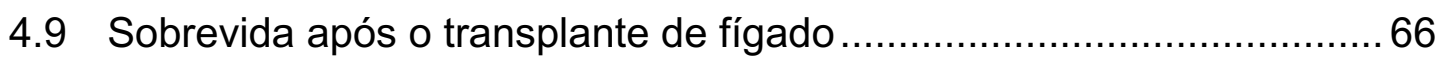

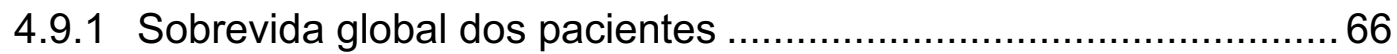

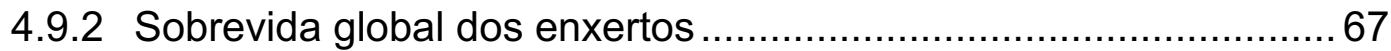

4.9.3 Análise da sobrevida de acordo com as complicações maiores.

4.9.3.1 Sobrevida dos pacientes de acordo com as complicações maiores ........................................................68

4.9.3.2 Sobrevida dos enxertos de acordo com as complicações maiores

4.9.4 Análise da sobrevida de acordo com o volume categorizado de concentrado de hemácias transfundido no perioperatório ...

4.9.4.1 Sobrevida dos pacientes de acordo com volume categorizado de concentrado de hemácias transfundido no perioperatório.

4.9.4.2 Sobrevida dos enxertos de acordo com volume categorizado de concentrado de hemácias transfundido no perioperatório.

5 DISCUSSÃO

6 CONCLUSÕES

7 ANEXOS

8 REFERÊNCIAS 


\section{LISTA DE SÍMBOLOS E ABREVIATURAS}

\begin{tabular}{|c|c|}
\hline$\%$ & Porcentagem \\
\hline ALT & alanina amino transaminase \\
\hline AST & aspartato amino transaminase \\
\hline BT & bilirrubina total \\
\hline Cai & cálcio iônico \\
\hline dL & Decilitro \\
\hline $\mathrm{Dr}$ & Doutor \\
\hline Dra & Doutora \\
\hline FA & fosfatase alcalina \\
\hline g & Grama \\
\hline GGT & $\begin{array}{l}\text { gamaglutamiltranspeptidase ou } \\
\text { gamaglutamiltransferase }\end{array}$ \\
\hline h & Hora \\
\hline Hb & Hemoglobina \\
\hline HR & hazard ratio ou razão de risco \\
\hline IC & Intervalo de confiança \\
\hline IOP & Intraoperatório \\
\hline kg & Quilograma \\
\hline $\mathbf{L}$ & Litro \\
\hline mcg & Micrograma \\
\hline $\mathrm{mEq}$ & Miliequivalente \\
\hline mg & Miligrama \\
\hline $\min$ & Minuto \\
\hline $\mathrm{mL}$ & Mililitro \\
\hline $\mathrm{mMol}$ & Milimol \\
\hline $\mathbf{N}$ ou $\mathbf{N}^{\circ}$ & Número \\
\hline OR & odds ratio ou razão de chance \\
\hline $\boldsymbol{p}$ & nível de significância \\
\hline Per & Perioperatório \\
\hline PO & pós-operatório \\
\hline Pré & pré-operatório \\
\hline Prof & Professor \\
\hline Profa & Professora \\
\hline Rel C/P & relação de TTPA controle para o paciente \\
\hline RNI & razão normalizada internacional \\
\hline
\end{tabular}




\section{LISTA DE SIGLAS}

ABO

$\mathrm{ACH}$ ou $\mathrm{HTr}$

ALT

AP

APC

AST

AVBEH

AVCI

$\mathrm{BCH}$ ou LTr

BT

CB

$\mathrm{CH}$

$\mathrm{CMa}$

$\mathrm{CMe}$

CMV

CP

CPRE

CPTH

CRIO

CTP

CTS

DCr ou

$\mathrm{ClCr}$

DM

EB

EBV

EDA

FB

GGT

HACC

$\mathrm{HC}$

HC/FMUSP

HLA

LDLT

MELD

MV2000

PELD

PFC

PLT sistema de antígenos de superfície das hemácias

alto volume de concentrado de hemácias transfundido no perioperatório ou high transfusion

alanina amino transaminase

atividade de protrombina

célula apresentadora de antígeno

aspartato amino transaminase

Atresia de Vias Biliares Extra-Hepáticas

acidente vascular cerebral isquêmico

baixo volume de concentrado de hemácias transfundido

no perioperatório oulow transfusion

bilirrubina total

complicações biliares

concentrado de hemácias

complicações maiores

complicações menores

Citomegalovírus

concentrado de plaquetas

colangiopancreatografia retrógrada endoscópica

colangiografia percutânea transhepática

concentrado de Crioprecipitado

Child-Turcotte-Pugh

Colaborative Transplant Study

depuração de creatinina ou clearance of creatinine

Diabetes mellitus

estenose biliar

Epstein-Barr virus

endoscopia digestiva alta

fístula biliar

gamaglutamiltranspeptidase ou gamaglutamiltransferase

AC Camargo Cancer Center

hemocomponente

Hospital das Clínicas da Faculdade de Medicina da

Universidade de São Paulo

sistema de antígenos de linfócitos humanos

Living Donor Liver Transplantation

Model of End-Stage Liver Disease

sistema operacional de banco de dados eletrônico do

HACC

Pediatric End-Stage Liver Disease

plasma fresco congelado

Pediatric Liver Transplantation 


$\begin{array}{ll}\text { PMN } & \text { Polimorfonucleares } \\ \text { PNF } & \text { Primary Non Function ou não funcionamento primário } \\ \text { POC } & \text { postopperative complications } \\ \text { PTLD } & \text { Post-Transplant Lymphoproliferative Disorders } \\ \text { PVC } & \text { pressão venosa central } \\ \text { RAC } & \text { rejeição aguda celular } \\ \text { RBC } & \text { red blood cells } \\ \text { Rel C/P } & \text { relação de TTPA controle para o paciente } \\ \text { RNI } & \text { razão normalizada internacional } \\ \text { RNM } & \text { ressonância nuclear magnética } \\ \text { ROC } & \text { receiver operating characteristic } \\ \text { ROTEM } & \text { tromboelastometria rotacional } \\ \text { RPIPP ou } & \text { relação do peso do implante para o peso do paciente ou } \\ \text { GBWR } & \text { graft-to-body-weight ratio } \\ \text { SDRA } & \text { Síndrome do Desconforto Respiratório Agudo } \\ \text { SNC } & \text { Sistema Nervoso Central } \\ \text { SO } & \text { sala operatória } \\ \text { SPLIT } & \text { Studies of Pediatric Liver Transplantation Research } \\ \text { TACO } & \text { Group } \\ \text { TC } & \text { Transfusion Associted Circulatory Overload } \\ \text { TEG } & \text { tomografia computadorizada } \\ \text { TH } & \text { tromboelastografia } \\ \text { THA } & \text { transplante hepático } \\ \text { THP } & \text { trombose de artéria hepática } \\ \text { TI } & \text { transplante hepático pediátrico } \\ \text { TRALI } & \text { tempo de internação } \\ \text { TRIM } & \text { Transfusion-Related Acute Lung Injury } \\ \text { TTPA } & \text { Transfusion-Related Immune Modulation } \\ \text { TVPo } & \text { tempo de tromboplastina parcialmente ativada } \\ \text { UNOS } & \text { trombose de veia porta } \\ \text { US } & \text { United Network for Organ Sharing } \\ \text { UTI } & \text { ultrassonografia } \\ \text { ZE/I ou } & \text { Unidade de Terapia Intensiva } \\ \text { ZLEN } & \text { z-escore de estatura para idade ou lenght-for-age z-score } \\ \text { ZIMC ou } & \text { z-escore de índice de massa corpórea para idade ou } \\ \text { ZBMI } & \text { body-mass-index-for-age z-score } \\ \text { ZP/E ou } & \text { z-escore de peso para estatura ou weight-for-length z- } \\ \text { ZWFL } & \text { score } \\ \text { ZP/l ou } & \text { z-escore de peso para idade ou weight-for-age z-score } \\ \text { ZWEI } & \\ & \\ & \end{array}$




\section{LISTA DE FIGURAS}

Figura 1. Curva ROC (Receiver Operating Characteristic) do volume de concentrado de hemácias transfundido no período perioperatório, de 24 $\mathrm{h}$ antes até $48 \mathrm{~h}$ após o transplante hepático e indexado pelo peso corpóreo $(\mathrm{CH})$.

Figura 2. Fluxograma dos pacientes incluídos no estudo 36

Figura 3. Complicações alérgicas maiores e menores nos grupos categorizados por volume de concentrado de hemácias transfundido no perioperatório, nos quatro períodos estudados, ao longo de dez anos de pós-operatório do transplante hepático

Figura 4. Complicações cardiovasculares maiores e menores nos grupos categorizados por volume de concentrado de hemácias transfundido no perioperatório, nos quatro períodos estudados, ao longo de dez anos de pós-operatório do transplante hepático

Figura 5. Complicações infecciosas maiores e menores nos grupos categorizados por volume de concentrado de hemácias transfundido no perioperatório, nos quatro períodos estudados, ao longo de dez anos de pós-operatório do transplante hepático

Figura 6. Complicações neoplásicas maiores e menores nos grupos categorizados por volume de concentrado de hemácias transfundido no perioperatório, nos quatro períodos estudados, ao longo de dez anos de pós-operatório do transplante hepático

Figura 7. Complicações relacionadas à rejeição maiores e menores nos grupos categorizados por volume de concentrado de hemácias transfundido no perioperatório, nos quatro períodos estudados, ao longo de dez anos de pós-operatório do transplante hepático

Figura 8. Complicações respiratórias maiores e menores nos grupos categorizados por volume de concentrado de hemácias transfundido no perioperatório, nos quatro períodos estudados, ao longo de dez anos de pós-operatório do transplante hepático

Figura 9. Complicações relacionadas a sangramento maiores e menores nos grupos categorizados por volume de concentrado de hemácias transfundido no perioperatório, nos quatro períodos estudados, ao longo de dez anos de pós-operatório do transplante hepático 
Figura 10. Curva de sobrevida de Kaplan-Meier com intervalo de confiança $95 \%$ de 240 pacientes submetidos a transplante hepático pediátrico com doador vivo

Figura 11. Curva de sobrevida de Kaplan-Meier do enxerto hepático com intervalo de confiança $95 \%$ de 240 pacientes submetidos a transplante hepático pediátrico com doador vivo

Figura 12. Curva de sobrevida de Kaplan-Meier do grupo CMe (109 pacientes sem nenhuma complicação ou com complicações menores grau I-Illa) e do grupo CMe (131 pacientes com ao menos uma complicação maior - grau IIlb-V )

Figura 13. Curva de sobrevida de Kaplan-Meier dos enxertos hepáticos do grupo CMe (109 pacientes sem nenhuma complicação ou com complicações menores, grau I-Illa) e do grupo CMa (131 pacientes com ao menos uma complicação maior, grau Illb-V).

Figura 14. Curva de sobrevida de Kaplan-Meier do grupo $\mathrm{BCH}$ (103 pacientes transfundidos no perioperatório com volume menor ou igual a $27,5 \mathrm{~mL} / \mathrm{kg}$ de concentrado de hemácias indexadas pelo peso corpóreo) e do grupo $\mathrm{ACH}$ (137 pacientes transfundidos no perioperatório com volume maior que $27,5 \mathrm{~mL} / \mathrm{kg}$ de concentrado de hemácias indexadas pelo peso corpóreo).

Figura 15. Curva de sobrevida de Kaplan-Meier dos enxertos hepáticos do grupo $\mathrm{BCH}$ (103 pacientes transfundidos no perioperatório com volume menor ou igual a $27,5 \mathrm{~mL} / \mathrm{kg}$ de concentrado de hemácias indexadas pelo peso corpóreo) e do grupo $\mathrm{ACH}$ (137 pacientes transfundidos no perioperatório com volume maior que $27,5 \mathrm{~mL} / \mathrm{kg}$ de concentrado de hemácias indexadas pelo peso corpóreo). 


\section{LISTA DE TABELAS}

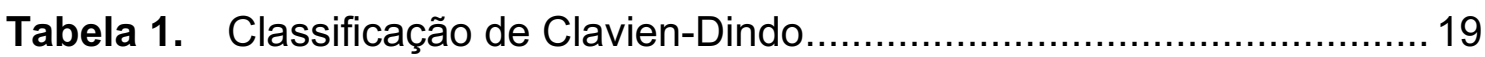

Tabela 2. Classificação de Clavien-Dindo adaptada para pacientes

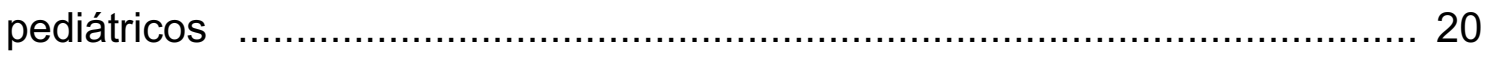

Tabela 3. Análise univariada e regressão logística múltipla dos dados perioperatórios segundo os grupos categorizados pela gravidade das complicações pós-operatórias

Tabela 4. Características dos pacientes e análises laboratoriais préoperatórias segundo o volume de concentrado de hemácias indexado pelo peso corpóreo e transfundido no perioperatório

Tabela 5. Classes das hepatopatias crônicas segundo transfusão perioperatória do volume de concentrado de hemácias indexado pelo peso

Tabela 6. Dados intraoperatórios e de pós-operatório precoce comparando os grupos de pacientes segundo transfusão perioperatória do volume de concentrado de hemácias indexado pelo peso

Tabela 7. Análise univariada e regressão logística múltipla de dados pré-operatórios e intraoperatórios dos grupos categorizados pelo volume transfusional de concentrado de hemácias perioperatório.

Tabela 8. Análise comparativa das complicações pós-operatórias da internação utilizando a classificação de Clavien-Dindo adaptada e mortalidade pós-operatória de 30 dias pós-transplante hepático segundo os grupos categorizados pelo volume de concentrado de hemácias perioperatório

Tabela 9. Classificação dos tipos e da gravidade das complicações pósoperatórias durante o período de internação pós-transplante hepático segundo os grupos categorizados pelo volume transfusional de concentrado de hemácias perioperatório

Tabela 10. Classificação dos tipos e da gravidade das complicações pósoperatórias até 1 ano pós-transplante hepático segundo os grupos categorizados pelo volume transfusional de concentrado de hemácias perioperatório

Tabela 11. Classificação dos tipos e da gravidade das complicações pósoperatórias até 5 anos pós-transplante hepático segundo os grupos 
categorizados pelo volume transfusional de concentrado de hemácias perioperatório

Tabela 12. Classificação dos tipos e da gravidade das complicações pósoperatórias até 10 anos pós-transplante hepático segundo os grupos categorizados pelo volume transfusional de concentrado de hemácias perioperatório

Tabela 13. Classificação dos tipos e da gravidade das complicações pós-operatórias imunológicas segundo os grupos categorizados pelo volume transfusional perioperatório de concentrado de hemácias indexado pelo peso ao longo dos quatro períodos analisados

Tabela 14. Dados de evolução pós-operatória de 2001 a 2011, segundo complicações relacionadas ao enxerto e mortalidade em 10 anos

Tabela 15. Fatores de risco independentes de óbito identificados por regressão de Cox simples e múltipla 


\section{RESUMO}

Gordon K. Influência da transfusão de concentrado de hemácias na evolução pósoperatória de crianças submetidas a transplante hepático com doador vivo [tese]. São Paulo: Faculdade de Medicina, Universidade de São Paulo; 2017.

Transfusão sanguínea tem sido associada ao aumento de complicações pósoperatórias (PO). Entretanto, há poucos estudos na área de transplante hepático pediátrico (THP). O objetivo do estudo foi avaliar o impacto da transfusão de concentrado de hemácias $(\mathrm{CH})$ no período perioperatório sobre as complicações e a sobrevida do THP. Este é um estudo observacional analítico retrospectivo que avaliou 240 crianças com peso $\leq 20 \mathrm{~kg}$, submetidos a THP, com doador vivo. As complicações PO foram avaliadas segundo a classificação de Clavien-Dindo, e os pacientes classificados segundo a presença ou ausência de complicações graves. Estes pacientes foram estudados de acordo com o volume de $\mathrm{CH}$ transfundido no perioperatório, sendo incluídos 103 pacientes no grupo de baixo volume de $\mathrm{CH}$ $(\mathrm{BCH}, \leq 27,5 \mathrm{~mL} / \mathrm{kg})$ e 137 , no grupo de alto volume de $\mathrm{CH}(\mathrm{ACH},>27,5 \mathrm{~mL} / \mathrm{kg})$. Os fatores independentes de risco para transfusão de $\mathrm{CH}$ perioperatório foram identificados por regressão logística multivariada e os de sobrevida, por regressão múltipla de Cox. As sobrevidas do enxerto e do paciente foram avaliadas pelo método de Kaplan-Meier e teste de Log-Rank. O nível de significância estatística considerado foi $p<0,05$. A transfusão de $\mathrm{CH}$ perioperatório foi o único fator de risco independente para complicação grave. No pré-operatório, o grupo $\mathrm{ACH}$ apresentou idade, peso, estatura, hemoglobina $(\mathrm{Hb})$, sódio $(\mathrm{Na})$ e depuração de creatinina $(\mathrm{DCr})$ menores, graus mais elevados de desnutrição e ascite, escore PELD (Pediatric EndStage Liver Disease) e RNI (razão normalizada internacional) maiores, do que o grupo $\mathrm{BCH}$. No intraoperatório, o grupo $\mathrm{ACH}$ apresentou $\mathrm{Hb}$ e $\mathrm{Na}$ menores e RNI, relação peso do implante para peso do paciente (RPIPP), tempos anestésico e cirúrgico, volumes de fluido e de diurese maiores, do que o grupo $\mathrm{BCH}$. No pósoperatório, o grupo $\mathrm{ACH}$ apresentou menor taxa de extubação precoce, intubação mais prolongada e períodos de internação em UTI e hospitalar maiores do que o grupo $\mathrm{BCH}$. Durante o período de internação pós-THP, o grupo $\mathrm{ACH}$ apresentou mais complicações por paciente, mais complicações graves, mais pacientes com, ao menos uma complicação grave, maior mediana de complicações graves, mais complicações cardiológicas, respiratórias, infecciosas maiores e sangramentos e menos complicações alérgicas e rejeições. $\mathrm{O}$ grupo $\mathrm{ACH}$ apresentou maior mortalidade até 30 dias pós-THP, diferentemente do grupo $\mathrm{BCH}$, que não apresentou nenhum óbito neste período. Até 10 anos, foram observadas mais complicações cardiovasculares, respiratórias, infecciosas maiores e neoplásicas menores e menos rejeições, além de maior número de óbitos no grupo $\mathrm{ACH}$, comparado ao grupo $\mathrm{BCH}$. Foram fatores independentes de risco para transfusão de $\mathrm{CH}$ perioperatório: zescore peso/estatura (ZP/E), PELD, DCr, Hb e Na pré-operatórios e RPIPP. Foram fatores de risco independentes de mortalidade: $\mathrm{DCr}(\mathrm{HR}=0,995 ; p=0,023)$ e $\mathrm{CH}$ $>27,5 \mathrm{~mL} / \mathrm{kg}(\mathrm{HR}=3,031 ; p=0,009)$. O grupo $\mathrm{ACH}$ apresentou sobrevida de enxerto e de paciente menores, em 1, 5 e 10 anos pós-THP do que o grupo $\mathrm{BCH}$. CONCLUSÃO: A transfusão de concentrado de hemácias no perioperatório do THP com doador vivo está diretamente associada ao aumento da morbidade e à redução da sobrevida do enxerto e do paciente.

Descritores: cirrose hepática; transplante de fígado; criança; doadores vivos; transfusão de eritrócitos; complicações pós-tratamento; sobrevivência póstratamento; rejeição de enxerto 


\section{SUMMARY}

Gordon K. Influence of red blood cells transfusion on postoperative outcome of pediatric living donor liver transplantation [thesis]. São Paulo: "Faculdade de Medicina, Universidade de São Paulo"; 2017.

Blood transfusion has been associated with an increase in postoperative complications (POC). However, there are few studies in the area of pediatric liver transplantation (PLT). The aim of the study was to evaluate the impact of perioperative red blood cells (RBC) transfusion on POC and PLT survival. This is an observational retrospective analytical study that evaluated 240 children weighing $\leq 20$ $\mathrm{kg}$, undergoing living donor liver transplantation (LDLT). POC were assessed according to the Clavien-Dindo classification, and the patients classified, whether they presented or not major complications. These patients were studied according to the perioperative transfused RBC volume, with 103 patients in the low transfusion group $(\mathrm{LTr}, \leq 27.5 \mathrm{~mL} / \mathrm{kg})$ and 137 in the high transfusion group $(\mathrm{HTr},>27.5 \mathrm{~mL} / \mathrm{kg})$. The independent risk factors of the perioperative RBC transfusion were identified by multivariate logistic regression and mortality independent risk factors, by multiple Cox regression. Graft and patient survival were assessed using the Kaplan-Meier method and Log-Rank test. Level of statistical significance was $p<0.05$. Perioperative RBC transfusion was the only independent risk factor for major complication. In the preoperative period, the HTr group presented lower age, weight, length, hemoglobin $(\mathrm{Hb})$, sodium $(\mathrm{Na})$ and creatinine clearance $(\mathrm{CrCl})$ and more severe malnutrition and ascites, higher PELD (Pediatric End-Stage Liver Disease) score and INR (International normalized ratio), than the LTr group. In the intraoperative period, the $\mathrm{HTr}$ group presented lower $\mathrm{Hb}$ and $\mathrm{Na}$ and higher INR levels, higher graft-to-bodyweight ratio (GBWR), longer anesthetic and surgical times and larger fluid and urine volumes, than the LTr group. In the postoperative period, the HTr group had a lower rate of early extubation, longer intubation period and longer ICU and hospitalization periods, than the LTr group. During the post-PLT hospitalization period, the HTr group presented more complications per patient, more major complications, more patients with at least one major complication and a higher median number of major complications, than the LTr group. Furthermore, the HTr group presented more major cardiovascular, respiratory, infectious and bleeding complications and less allergic and rejection complications than LTr group. The HTr group presented higher mortality up to 30 days post-PLT, unlike the LTr group, which did not present any deaths during this period. Up to 10 years, the $\mathrm{HTr}$ group presented more major cardiovascular, respiratory, infectious and minor neoplastic complications and less rejections besides, a higher mortality, compared to the LTr group. The independent risk factors for perioperative RBC transfusion were: z-score weight/length (ZWL), PELD score, $\mathrm{CrCl}$, preoperative $\mathrm{Hb}$ and $\mathrm{Na}$ and GBWR. The independent risk factors for mortality were: $\mathrm{CrCl}(\mathrm{HR}=0.995, p=0.023)$ and $\mathrm{RBC}$ volume $>27.5 \mathrm{~mL} / \mathrm{kg}(\mathrm{HR}=$ $3.031, p=0.009$ ). The HTr group presented lower graft and patient survival at 1,5 and 10 years post-PLT than the LTr group. CONCLUSION: The transfusion of red blood cells in the perioperative period of the pediatric LDLT is directly associated with increased morbidity and reduced graft and patient survival.

Descriptors: liver cirrhosis; liver transplantation; child; living donors; liver transplantation; erytrocyte transfusion; postoperative complications; disease-free survival; graft rejection 
1 INTRODUÇÃO 
Transplantar não é apenas uma cirurgia mas um complexo conjunto de medidas, envolvendo conhecimento teórico-prático, técnicas inovadoras, tecnologia avançada e cooperação profissional multidisciplinar, que permitam remover e transferir, com êxito, um órgão ou tecido, de um indivíduo para o outro, com um propósito terapêutico ${ }^{1}$.

A história dos transplantes de órgãos sólidos iniciou-se com o desenvolvimento de técnicas de sutura vascular, por Alexis Carrel, dando-lhe o Premio Nobel de Medicina, em 1912. Welch, em 1955, fez a primeira descrição científica de um transplante hepático $(\mathrm{TH})$ ectópico na cavidade abdominal ${ }^{2}$. Em 1958, Moore et al descrevaram a técnica de TH em cães. Starzl et al. ${ }^{3}$, em 1959, demonstraram técnicas de hepatectomia total que são utilizadas até hoje. No mesmo período, desenvolveu-se o conceito de que a perfusão hipotérmica intraportal com Ringer lactato e solução de Euro-Collins, poderia preservar o fígado por até 12 horas, permitindo a captação de enxertos em regiões mais distantes e facilitando a programação cirúrgica ${ }^{4-6}$. O primeiro TH ortotópico foi realizado em 1963, por Thomas Starzl, em uma criança de 3 anos com atresia de vias biliares que recebeu um enxerto hepático de doador falecido, também de 3 anos, portador de tumor cerebral de $3^{\circ}$ ventrículo. 0 receptor, porém, faleceu em sala operatória por hemorragia maciça ${ }^{7}$. Em 1967, foi feita nova tentativa, pelo mesmo cirurgião, em uma criança de 1 ano e meio, com hepatocarcinoma, que sobreviveu 400 dias $^{8,9}$. Durante o período de 1967 a 1972, diante dos resultados insatisfatórios, somente quatro grandes centros continuaram com seus programas de TH: o serviço de Thomas Starzl, em 
Pittsburgh (Estados Unidos); o de Roy Calne, em Cambridge (Inglaterra); o de Ruud Krom, em Gröningen (Holanda); e o de Rudolf Pichlmayr, em Hannover $(\text { Alemanha })^{10-12}$.

Até 1977 , duzentos TH haviam sido realizados no mundo e a sobrevida média era de 11 a $39 \%{ }^{11,13,14}$. As complicações infecciosas e a rejeição crônica eram, respectivamente, a causa de morte precoce e tardia mais frequentes. Com o surgimento da ciclosporina, em 1974, a sobrevida de $20 \%$ destes pacientes, saltou para $70 \%{ }^{15}$. Inicialmente utilizada em transplantes renais, foi usada por Calne, em 1979, pela primeira vez, em dois $\mathrm{TH}^{16,17}$. Strarzl et al. ${ }^{18}$, em 1981 , associaram a ciclosporina à prednisona com resultados animadores.

Em 1983, após 531 TH realizados, o Governo Americano promoveu uma reunião em Washington, que definiu consensualmente aspectos controversos sobre TH e o declarou como procedimento terapêutico e não mais experimental (National Institutes of Health Consensus Development Conference Statement, $1984)^{19,20}$.

Na América Latina, o primeiro $\mathrm{TH}$ foi realizado no Brasil por Marcel Cerqueira Cesar Machado em 1968, no Hospital das Clínicas da Faculdade de Medicina da Universidade de São Paulo (HC/FMUSP) ${ }^{21}$. O TH tornou-se um procedimento rotineiro no país, sendo realizado com sucesso em vários centros transplantadores. O Brasil participou ativamente da evolução mundial do $\mathrm{TH}$, e em 1988, Sivano Raia ${ }^{22}$ realizou no HC/FMUSP o primeiro TH com doador vivo do mundo, transplantando o segmento lateral esquerdo do fígado de um adulto em uma criança de 4 anos portadora de atresia de vias biliares, sendo que, no ano de 2012, figurava como segundo país com o maior número de $\mathrm{TH}$ realizados. O TH intervivos é uma terapia de sucesso e o Brasil tem posição de 
destaque, sendo líder na América Latina na realização do TH intervivos adulto e pediátrico, tendo realizado $2086 \mathrm{TH}$ intervivos até dezembro de $2014^{23}$. A Coreia é o representante de maior sucesso deste procedimento, tendo realizado até 2013 mais de 8 mil TH intervivos em seus 40 centros transplantadores ${ }^{24}$.

Decorridos mais de 40 anos do primeiro $\mathrm{TH}$, realizam-se, no mundo, na atualidade, mais de 10 mil TH por ano. Nas últimas décadas, grandes foram os avanços nas áreas de técnica anestésico-cirúrgica, no aprimoramento farmacológico da imunossupressão, bem como, no desenvolvimento de uma compreensão mais abrangente da fisiopatologia multifatorial da coagulopatia no hepatopata, o que permitiu o aumento da sobrevida dos pacientes submetidos a $\mathrm{TH}^{25-28}$. Atualmente, o $\mathrm{TH}$ é reconhecido como terapêutica de eleição da insuficiência hepática aguda ou crônica avançadas, em adultos e crianças. Na fase terminal da doença hepática, podem ocorrer complicações com risco de morte e que, normalmente, justificam o urgenciamento destes pacientes, como: encefalopatia hepática, hipertensão portal, sangramento digestivo, síndrome hepatopulmonar, hipertensão portopulmonar, síndrome hepatorrenal, ascite volumosa e incontrolável, prurido intenso, peritonites bacterianas espontâneas e colangites de repetição, coagulopatia, desnutrição proteico-calórica grave com sarcopenia ${ }^{29}$, distúrbios hidroeletrolíticos e metabólicos importantes. Estas complicações, em sua grande maioria, são reversíveis com o $\mathrm{TH}$, quando indicado no momento adequado ${ }^{30}$. Os pacientes que outrora tinham prognóstico fatal, no presente, são submetidos a TH adulto com taxas de sobrevida de $90 \%$ em 1 ano e de $80 \%$ em 5 anos $^{31,32}$.

O transplante hepático pediátrico (THP) é definido como o transplante hepático realizado em pacientes até 18 anos de idade. Devido a avanços 
tecnológicos e de técnicas intervencionistas e cirúrgicas, assim como, o aprimoramento da medicina intensiva neonatal e pediátrica, houve um aumento do número de THP realizados e uma redução na idade de sua indicação. Atualmente, cerca de $27 \%$ dos THP são realizados em crianças abaixo de 1 ano de vida ${ }^{33}$. Dentre os pacientes pediátricos, a sobrevida atingiu níveis de 95\% em 1 ano e $85 \%$ em 5 anos, dependendo da doença de base, podendo cair até 65 a 70\% em 1 ano na insuficiência hepática aguda ${ }^{34-37}$.

Frente ao descompasso entre uma alta demanda e uma baixa oferta de órgãos, sobretudo nesta faixa etária, relacionada a vários entraves sócioeconômicos, políticos, culturais e religiosos, principalmente devido a uma elevada taxa de recusa de doação, técnicas alternativas de obtenção de enxertos foram desenvolvidas, com a finalidade de encurtar o tempo de espera por um órgão, reduzir a morbimortalidade e melhorar o prognóstico destes pacientes. Em relação ao doador falecido, Broelsch e Bismuth, em 1980, utilizaram técnica de plastia ou redução do enxerto. Em 1988, Pichlmayr et al. ${ }^{19}$ fizeram o primeiro split (bipartição do enxerto), beneficiando desta maneira, dois receptores simultaneamente. Todavia, a utilização de fígado reduzido tem uma menor sobrevida do enxerto e do receptor, sendo recomendado priorizar o uso de split, em detrimento do reduzido. Não há evidência que indique o uso de doadores com critérios de doação extendidos para receptores pediátricos de $\mathrm{TH}^{38}$

Apesar da mudança no sistema de alocação ocorrida em 2006, permitindo a priorização das crianças no recebimento de órgãos ${ }^{39}$, o número de doadores falecidos passíveis de split, ainda é pequeno e doadores abaixo de 15 anos de idade são escassos ${ }^{33}$, fatores determinantes do crescente aumento de $\mathrm{TH}$ com 
doador vivo, na faixa pediátrica ${ }^{40}$. Os resultados de sobrevida dos paciente e dos diversos tipos de enxerto de doador falecido e doador vivo têm sido semelhantes, à exceção de receptores abaixo de dois anos, cuja sobrevida do paciente e do enxerto de doador vivo é maior, com menores índices de retransplante ${ }^{40,41}$.

O número de transplantes com doador vivo aparentado tem aumentado anualmente. No Ocidente, representa menos de $5 \%$ de todos os THP. Contrariamente no Oriente, particularmente no Japão, a maioria dos TH são realizados com doador vivo, uma vez que há entraves culturais e religiosos, quanto à aceitação de transplantes com doadores falecidos. Segundo banco de dados de um estudo colaborativo de transplante (CTS - Colaborative Transplant Study), realizado por um grupo chamado SPLIT (Studies of Pediatric Liver Transplantation), de 1985 até 2013, houve um aumento significativo, passando de zero para $33 \%$ dos THP, realizados em pacientes de 0 a 14 anos de idade. Segundo análise deste banco de dados, a sobrevida de 5 anos dos pacientes transplantados com doador vivo $(83,7 \%)$ vs. doador falecido $(81 \%)$ não mostrou diferença significativa. A sobrevida de 5 anos dos enxertos, no entanto, foi significativamente maior em THP com doador vivo $(78,2 \%)$, em relação ao doador falecido $(71,4 \%)^{33,42}$.

As indicações de THP podem ser divididas em classes de hepatopatias de base: 1) colestases extra-hepáticas: atresia de vias biliares extra-hepáticas (AVBEH) e cistos de colédocos; 2) colestases intra-hepáticas: síndrome de Alagile, hipoplasia de vias biliares não sindromática, colangite esclerosante primária e colangioesclerose intrahepática primária familiar; 3) doenças metabólicas: tirosinemia, deficiência de alfa-1 antitripsina, síndrome de CliggerNajar tipo 1, glicogenoses, defeitos do ciclo da ureia, oxalúria tipo I , acidemia 
orgânica, defeitos da lipase ácida, hipercolesterolemia familiar, hemofilias, porfiria, doença de Niemann-Pick, deficiência de proteína e fibrose cística; 4) Hepatites ou cirroses: virais, idiopáticas, autoimunes, criptogenéticas; 5) Insuficiência Hepática fulminante: doença de Wilson, síndrome de Duncan, agentes virais, drogas ou toxinas, ignorada; 6) Neoplásicas: hepatoblastoma, hepatocarcinoma, carcinoma fibrolamelar, sarcoma, hemangioma e hemangiendotelioma 7) Miscelânea: síndrome de Budd-Chiari, doença de Caroli secundária ao trauma ou à nutrição parenteral e fibroses a esclarecer ${ }^{43}$.

A AVBEH é a principal indicacção de TH na faixa etária pediátrica. A incidência atual é de 1 caso para cada 8.000 a 18.000 nascidos vivos ${ }^{44}$. As infecções virais causadas por citomegalovírus ${ }^{45}$, reovírus ${ }^{46}$ e rotavírus $^{47}$, têm sido estudadas como possíveis agentes desencadeadores de uma obstrução imunomediada $^{48-51}$ que, associada à suscetibilidade genética ${ }^{51}$ e às alterações do desenvolvimento embrionário da árvore biliar, são aspectos que podem participar da etiopatogênese da obliteração das vias biliares extra-hepáticas ${ }^{52}$. O prognóstico destas crianças, quando não tratadas, é a evolução para insuficiência hepática e óbito com 1 ano de idade, em 50 a $80 \%$ dos pacientes e até 3 anos, em 90 a $100 \%$ dos pacientes ${ }^{53}$. Ainda hoje, o único tratamento disponível é a portoenterostomia ou cirurgia de Kasai, cujos resultados são melhores quando realizada nos primeiros dois meses de vida, muito embora, mesmo realizada precocemente, os pacientes necessitam de $\mathrm{TH}$, em 70 a $80 \%$ dos casos durante as primeiras duas décadas de vida ${ }^{54,55}$.

Atualmente, acredita-se que a identificação precoce de fatores prognósticos de morbimortalidade deva ser o passo mais determinante para a redução da morbimortalidade perioperatória ${ }^{56-60}$. Neste contexto, a transfusão 
de hemocomponentes $(\mathrm{HC})$ tem sido amplamente associada ao aumento da morbimortalidade a curto, médio e longo prazos nos diferentes cenários cirúrgicos $^{61-65}$. Há vários estudos retrospectivos avaliando um grande número de pacientes oncológicos, demonstrando menor tempo de recorrência e aparecimento precoce de metástases de tumores de mama, de pulmão, hepatocarcinoma e carcinoma de reto, em pacientes transfundidos, quando comparados a pacientes que não receberam transfusão sanguínea ${ }^{64,} 65$. Em 2009, Shiba et al. ${ }^{64}$ mostraram que a transfusão de HC, em pacientes adultos submetidos à ressecção hepática por hepatocarcinoma, se correlacionou com o aumento da recidiva tumoral e diminuição de sobrevida. Este estudo, ratifica resultados anteriores semelhantes em cirurgias oncológicas colon-retais $^{61,66}$, gástricas ${ }^{67}$ e mamárias ${ }^{68}$.

$\mathrm{Na}$ área de $\mathrm{TH}$, a transfusão de $\mathrm{HC}$ como concentrado de hemácias $(\mathrm{CH})$, plasma fresco congelado (PFC) e plaquetas (CP), já foi identificada como fator prognóstico de morbimortalidade, portanto, existe uma crescente tendência atual de racionamento do uso de $\mathrm{HC}^{62,69,70}$.

As complicações mais frequentemente relacionadas à transfusão de HC incluem erros de identificação, reações alérgicas, sobrecarga volêmica, intoxicação por citrato, alterações eletrolíticas, infecções, aloimunização, imunomodulação, imunossupressão e maior recorrência de neoplasias ${ }^{65,71,72}$. O uso de $\mathrm{HC}$ parece ser importante fator prognóstico de morbimortalidade, aumentando o número de complicações perioperatórias como: edema pulmonar de origem cardiogênica por sobrecarga volêmica (TACO - Transfusion Associated Circulatory Overload) ou não cardiogênica relacionada à imunomodulação (TRIM - Transfusion Related Immune Modulation), por lesão 
pulmonar aguda pós-transfusional (TRALI - Transfusion Related Acute Lung Injury) e Síndrome do Desconforto Respiratório Agudo (SDRA), intubação prolongada, e maior período de ventilação mecânica. O uso de HC pode ainda, levar a ocorrência de íleo prolongado, insuficiência renal, sangramento, trombose, infecção, aumento do período de internação em unidade de terapia intensiva (UTI) e internação hospitalar, menor sobrevida do enxerto e menor sobrevida do paciente transplantado ${ }^{56,73,74}$.

Diversas estratégias tem sido adotadas para diminuir a transfusão de HC no período perioperatório. Essas medidas podem ser classificadas em medidas profiláticas, técnicas e farmacológicas. Como medidas profiláticas, tem-se o reconhecimento de grupos de risco para sangramento e a suspensão prévia de drogas que interfiram na coagulação. Como medidas técnicas, tem-se controle de pressão venosa central, a manobra de Pringle; o bisturi ultrassônico e de argônio; a captação e o reaproveitamento de sangue perdido no período intraoperatório (cell saver); a hipotensão controlada; a tromboelastografia $(T E G \circledast)$ ou a tromboelastometria rotacional (ROTEM®). Finalmente, tem-se as medidas farmacológicas, como o uso de eritropoetina, desmopressina, vasopressina, antifibrinolíticos, como o ácido épsilonaminocapróico e o ácido tranexâmico, o complexo protrombínico, fibrinogênio liofilizado, fator VIla recombinante e selantes de fibrina ${ }^{75-77}$.

No entanto, ainda existe uma ampla utilização de HC durante o período perioperatório do $\mathrm{TH}$, devido a fatores de risco pré-operatórios e intraoperatórios ${ }^{78}$.

Alguns estudos que avaliaram fatores preditores de necessidade transfusional foram realizados em pacientes submetidos a cirurgias cardiovasculares $^{79}$, oncológicas ${ }^{80,81}$ e por trauma ${ }^{82,83}$. 
$\mathrm{Na}$ área de $\mathrm{TH}$, a maioria dos estudos realizados para avaliação de fatores preditores de necessidade transfusional foi conduzida em adultos. McCluskey et al. ${ }^{84}$, em estudo com $460 \mathrm{TH}$, idealizaram um modelo preditor de risco de transfusão maciça, que consistiu de sete variáveis: idade superior a 40 anos; hemoglobina $(\mathrm{Hb})$ inferior a $10 \mathrm{~g} / \mathrm{dL}$; razão normalizada internacional (RNI) superior a 2,0; contagem de plaquetas inferior a 70.000; dosagem de creatinina sérica superior a $1,2 \mathrm{~g} / \mathrm{dL}$, em homens e superior a $1,1 \mathrm{~g} / \mathrm{dL}$, em mulheres; dosagem de albumina sérica inferior a $2,8 \mathrm{~g} / \mathrm{dL}$ e retransplante. Massicote et al. ${ }^{85}$, em 2004, identificaram três fatores preditores de transfusão de $\mathrm{CH}$ no intraoperatório em pacientes transplantados adultos: RNI inicial, número de plaquetas inicial e tempo de duração da cirurgia. Massicote et al. ${ }^{86}$, em 2009, em estudo com 505 pacientes, demonstraram que não houve diferença significativa no volume de transfusão de pacientes com escore de MELD (Model of End-Stage Liver Disease) mais elevado de (22 \pm 10$)$ em relação ao menos elevado, muito embora, a média transfusional tenha sido baixa. Por outro lado, Rana et al. ${ }^{87}$, em 2013, em estudo com $233 \mathrm{TH}$, demonstraram um risco aumentado de sangramento, com tempo de isquemia quente, cirúrgico e bilirrubina elevados, e cirurgia abdominal prévia. Mangus et al. ${ }^{88}$ realizaram estudo com $526 \mathrm{TH}$, no qual, também identificaram o escore MELD, além da Hb pré-operatória e o valor da pressão venosa central (PVC), como preditores de maior volume de transfusão intraoperatória de $\mathrm{CH}$. Fernandes et al. ${ }^{89}$, avaliando $341 \mathrm{TH}$, mostraram que a $\mathrm{Hb}$ baixa e o escore de MELD alto são fatores de risco para transfusão intraoperatória de $\mathrm{CH}$. Já Ghaffaripour et al. ${ }^{58}$, em estudo com $261 \mathrm{TH}$, não encontraram nenhum fator pré-operatório preditor de transfusão intraoperatória, embora houvesse uma 
redução significativa dos volumes de $\mathrm{CH}$ e PFC ao longo do tempo de experiência da equipe cirúrgica. Bang et al $^{90}$, em estudo envolvendo $555 \mathrm{TH}$ com doador vivo, identificaram como fatores de risco para uma perda sanguínea superior a $1000 \mathrm{~mL}$, o escore MELD, a albumina pré-operatória, a presença de ascite e o antecedente de cirurgia abdominal pregressa.

Assim sendo, o TH continua sendo uma das cirurgias de maior risco de transfusão de HC. O impacto negativo do uso de HC no TH é evidenciado em vários estudos $^{91-94}$. Existe, no entanto, uma enorme dificuldade em se identificar os fatores preditores de sangramento no $\mathrm{TH}$ e, nos estudos publicados recentemente, não existe consenso sobre o tema ${ }^{85,91,95}$.

A avaliação de fatores preditivos de risco de complicações em THP é também assunto de grande controvérsia, haja vista, a falta de homogeneidade das amostras estudadas, quanto a idade, peso, diagnósticos de base, técnica cirúrgica, tipo de doador, a falta de padronização de uma classificação de graduação de complicações pós-operatórias.

No início dos anos 90, houve uma redução expressiva na mortalidade perioperatória do THP, principalmente, pela redução drástica do sangramento perioperatório, com o advento de novos fármacos, exames diagnósticos, novas tecnologias e novas técnicas anestésicas e cirúrgicas, além de uma melhor compreensão da fisiopatologia das alterações hemostáticas no paciente hepatopata, particularmente na criança ${ }^{96}$. Estes avanços fizeram com que a preocupação primordial no THP se voltasse para a redução da morbidade pósoperatória.

As complicações pós-operatórias têm um caráter temporal de distribuição, quanto ao seu tipo e etiologia. Precocemente, até 30 dias de pós-operatório, 
tem-se uma maior frequência de complicações relacionadas à disfunção do enxerto, técnica cirúrgica, infecções nosocomiais e rejeição aguda. Aproximadamente 1 a 6 meses após o TH, surgem complicações relacionadas ao uso de imunossupressores, como: infecções oportunistas, rejeição aguda e crônica e efeitos colaterais dos medicamentos. A longo prazo, tem-se os desafios do manuseio dos imunossupressores tentando minimizar o aparecimento das comorbidades correlacionadas ao seu uso, os episódios de rejeição, a recorrência de patologias hepáticas de base e o aparecimento de novos tumores ${ }^{97}$.

As complicações a longo prazo são a nova fronteira do THP. Embora menos frequentes que no passado, ainda afetam 30 a $50 \%$ destas crianças $^{37}$. É necessário muito mais do que tem sido feito atualmente para se aprimorar a sobrevida e se evitar as comorbidades sistêmicas, pelo uso prolongado de imunossupressores. $\mathrm{Ng}$ et al. ${ }^{98}$, em estudo baseado nos registros do grupo de estudos chamado SPLIT, sobre 167 sobreviventes após 10 anos de THP, revelaram que apenas $32 \%$ destes apresentaram um perfil ideal, ou seja, portadores de primeiro enxerto, monoterapia imunossupressora em número e dose estável, crescimento pondero-estatural normal e ausência de efeitos colaterais comuns da terapia de imunossupressão. Qualidade de vida é uma medida de inclusão social que exigirá intervenções e abordagens inovadoras dos pacientes e de seu círculo de relacionamentos ${ }^{36}$.

Até o momento não há estudos publicados em TH com doador vivo que avaliem o impacto da transfusão de $\mathrm{CH}$ nas complicações pós-operatórias precoces e tardias. A hipótese é que a transfusão de $\mathrm{CH}$ no período perioperatório do THP, com doador vivo, esteja associada com o aumento da morbimortalidade pós-operatória nestes doentes. 
2 OBJETIVOS 


\section{Objetivos}

1. Avaliar a influência da transfusão perioperatória de concentrado de hemácias nas complicações pós-operatórias do transplante hepático pediátrico com doador vivo.

2. Identificar fatores de risco para transfusão perioperatória de concentrado de hemácias no transplante hepático pediátrico com doador vivo. 
3 MÉTODOS 
O projeto de pesquisa foi submetido ao Comitê de Ética em Pesquisa (CEP) do AC Camargo Cancer Center (HACC), aprovado sob o número 103.402 (Anexo A, pg 104) e ao Comitê de Ética para Análise de Projetos de Pesquisa do Hospital das Clínicas da Faculdade de Medicina da Universidade de São Paulo (HC/FMUSP), aprovado sob o número 243/12 (Anexo B, pg 106). Este estudo teve seu projeto realizado na instituição proponente o HC/FMUSP e seus dados coletados, com a anuênia da instituição coparticipante, o HACC (Anexo C, pg 107).

\subsection{Critérios de elegibilidade}

\subsubsection{Critérios de inclusão}

Foram incluídos no estudo pacientes submetidos a transplante hepático pediátrico, ou seja, abaixo de 18 anos de idade, com doador vivo com as seguintes características:

- peso menor ou igual a $20 \mathrm{~kg}$

- hepatopatia crônica

\subsubsection{Critérios de exclusão}

Foram excluídos deste estudo:

- Pacientes com hepatite fulminante 
- Retransplantes

- Pacientes com dados de prontuário incompletos

- Pacientes com perda de seguimento no primeiro ano

\subsection{Desenho do estudo}

Este é um estudo observacional retrospectivo analítico que avaliou 254 pacientes pediátricos submetidos a transplante hepático ortotópico com enxertos advindos de doadores vivos aparentados ou não, no período de 14 de maio de 2001 até 31 de dezembro de 2011. Todos os transplantes foram realizados utilizando a mesma técnica cirúrgica e anestésica em um único centro, o AC Camargo Cancer Center (HACC), de São Paulo.

Para avaliar a relação entre transfusão sanguínea e complicações pós-operatórias durante o período de internação foi utilizada a classificação de Clavien-Dindo ${ }^{99}$, adaptada neste estudo, para a população pediátrica, identificando-se os pacientes que apresentaram complicações maiores ou graves (Anexo G, pg 116).

Para construção dos grupos de estudos foi determinado o melhor ponto de corte da curva $\mathrm{ROC}$ em que o volume de $\mathrm{CH}$ transfundido no perioperatório se associava com o maior número de pacientes com complicações graves. A curva ROC apresentou AUC de 0,648 com $p<0,0001$ com maximização de sensibilidade de $68,7 \%$ e especificidade de $56,9 \%$, por meio do índice de Youden, chegando-se a um ponto de corte de $27,5 \mathrm{~mL} / \mathrm{kg}$ de $\mathrm{CH}$ perioperatório (Anexo H, pg 120). 
Os pacientes foram divididos em dois grupos de acordo com o volume de $\mathrm{CH}$ indexado pelo peso corpóreo, transfundido no período perioperatório, que compreende desde as 24 horas que antecedem a cirurgia até 48 horas após o término da cirurgia de TH (Anexo I, pg 121):

- Grupo de baixo volume de $\mathrm{CH}(\mathrm{BCH})$, que incluiu 103 pacientes que receberam volume menor ou igual a $27,5 \mathrm{~mL} / \mathrm{kg}$.

- Grupo de alto volume de $\mathrm{CH}(\mathrm{ACH})$, que incluiu 137 pacientes que receberam volume maior que $27,5 \mathrm{~mL} / \mathrm{kg}$.

\subsection{Classificação das complicações pós-operatórias de Clavien-Dindo ${ }^{99}$ adaptada neste estudo para a população pediátrica e determinação das complicações graves}

A classificação das complicações pós-operatórias de Clavien-Dindo é utilizada para avaliar complicações pós-operatórias e divide as complicações em cinco graus ( $\mathrm{I}$ a V) de gravidade progressiva (Tabela 1). Como esta classificação foi validada para pacientes adultos, houve a necessidade de adaptação, para os pacientes pediátricos. A subdivisão do grau III distingue-se pela complexidade dos procedimentos, de tal forma que, o grau Illa é composto de complicações que demandam procedimentos de menor complexidade e o grau IIIb, composto de complicações que demandam procedimentos de maior complexidade, independentes do tipo de anestesia empregada (Tabela 2). 
Foi definido para este estudo, fundamentado em estudo anterior em $\mathrm{TH}$ para receptor adulto ${ }^{100}$, como complicações maiores ou graves, aquelas classificadas em graus IIIb a $\mathrm{V}$, sendo que o sufixo d (disability), não foi empregado.

Tabela 1. Classificação de Clavien-Dindo

\begin{tabular}{|c|c|}
\hline Grau & Definição \\
\hline Grau I & $\begin{array}{l}\text { Complicação que exija o uso de analgésicos simples, antipiréticos, } \\
\text { antieméticos, diuréticos, eletrólitos e fisioterapia }\end{array}$ \\
\hline Grau II & $\begin{array}{l}\text { Complicação que exija outras drogas, distintas do grau I, } \\
\text { transfusão de hemoderivados ou nutrição parenteral }\end{array}$ \\
\hline Grau III & $\begin{array}{l}\text { Complicação que exija intervenção cirúrgica, endoscópica e/ou } \\
\text { radiológica }\end{array}$ \\
\hline IIla & Intervenção sem necessidade de anestesia geral \\
\hline IIIb & Intervenção com anestesia geral \\
\hline Grau IV & $\begin{array}{l}\text { Complicação com risco de vida (incluindo complicações do SNC)* } \\
\text { necessitando de UTI }\end{array}$ \\
\hline IVa & Disfunção de um único órgão (incluindo diálise) \\
\hline $\mathrm{IVb}$ & Disfunção de 2 ou mais órgãos \\
\hline Grau V & Óbito do paciente \\
\hline Sufixo "d" & $\begin{array}{l}\text { Se no momento da alta, o paciente ainda apresentar complicação que necessite } \\
\text { de acompanhamento, o sufixo "d" (for "disability") deve ser inserido ao respectivo } \\
\text { grau da complicação (ex: grau IVa-d). O sufixo "d" indica a necessidade de follow- } \\
\text { up para avaliação completa da complicação. }\end{array}$ \\
\hline \multicolumn{2}{|c|}{ * Hemorragia cerebral, $\mathrm{AVCl}$, sangramento subaracnoideo, excluindo isquemia cerebral transitória } \\
\hline
\end{tabular}


Tabela 2. Classificação de Clavien-Dindo adaptada para pacientes pediátricos

\begin{tabular}{|c|c|}
\hline Grau & Definição \\
\hline Grau I & $\begin{array}{l}\text { Complicação que exija o uso de analgésicos simples, antipiréticos, } \\
\text { antieméticos, diuréticos, eletrólitos e fisioterapia }\end{array}$ \\
\hline Grau II & $\begin{array}{l}\text { Complicação que exija outras drogas, distintas do grau I, transfusão } \\
\text { de hemoderivados ou nutrição parenteral }\end{array}$ \\
\hline Grau III & $\begin{array}{l}\text { Complicação que exija intervenção cirúrgica, endoscópica e/ou } \\
\text { radiológica }\end{array}$ \\
\hline IIla & $\begin{array}{l}\text { Procedimentos de pequeno porte ou baixa complexidade com ou sem } \\
\text { anestesia geral: EDA e colonoscopia com ou sem biópsia; US, TC e } \\
\text { RNM, com ou sem biópsia, CPRE, CPTH com passagem ou troca de } \\
\text { dreno biliar, arteriografia com ou sem angioplastia de Veia Porta, de } \\
\text { Veias Suprahepáticas ou ramos e de Artéria Hepática; biópsias, } \\
\text { extrações dentárias simples, drenagens, estomias e passagem de } \\
\text { cateter central para medicação, hemodiálise ou quimioterapia. }\end{array}$ \\
\hline IIIb & $\begin{array}{l}\text { Procedimentos de médio e grande porte ou de alta complexidade com } \\
\text { anestesia geral: extrações dentárias múltiplas, reanastomoses } \\
\text { vasculares ou biliodigestivas, laparotomias exploradoras e } \\
\text { toracotomias }\end{array}$ \\
\hline Grau IV & $\begin{array}{l}\text { Complicação com risco de vida (incluindo complicações do SNC)* } \\
\text { necessitando de UTI }\end{array}$ \\
\hline IVa & Disfunção de um único órgão (incluindo diálise) \\
\hline $\mathrm{IVb}$ & Disfunção de 2 ou mais órgãos \\
\hline Grau V & Óbito do paciente \\
\hline \multicolumn{2}{|c|}{$\begin{array}{l}\text { EDA, endoscopia digestiva alta; US, ultraassonografias; TC, tomografias computadorizadas, RNM, } \\
\text { ressonância nuclear magnética; CPRE, colangiopancreatografia retrógrada endoscópica; CPTH, } \\
\text { colangiografia percutânea transhepática; UTI, unidade de terapia intensiva }\end{array}$} \\
\hline \multicolumn{2}{|c|}{$\begin{array}{l}\text { * Hemorragia cerebral, } \mathrm{AVCl} \text { (acidente vascular cerebral isquêmico), sangramento subaracnoideo, } \\
\text { excluindo isquemia cerebral transitória }\end{array}$} \\
\hline
\end{tabular}

\subsection{Variáveis estudadas}

Foram analisados dados dos receptores de THP coletados dos prontuários médicos do Serviço de Arquivo Médico e dos registros da base de dados eletrônica do sistema MV2000 do HACC, relativos à evolução clínica e laboratorial dos pacientes transplantados entre maio de 2001 e dezembro de 2011 no HACC. 


\subsubsection{Variáveis pré-operatórias}

Foram analisados no período pré-operatório os seguintes parâmetros clínico-laboratoriais dos receptores de TH: idade, gênero, peso, altura, grau de nutrição (z-escores), escore PELD (Pediatric End Stage Liver Disease), etiologia da doença hepática, presença de ascite, hipertensão portal, encefalopatia hepática, sangramento digestivo, icterícia, síndrome hepatopulmonar, infecções prévias até 30 dias da data do $\mathrm{TH}$, antecedente de transfusão prévia, dosagens de $\mathrm{Hb}$, sódio, potássio, glicemia, creatinina séricos, lactato, aspartato aminotransferase (AST), alanina aminotransferase

$(\mathrm{ALT})$ gamaglutamiltransferase (GGT), fosfatase alcalina (FA), bilirrubina total (BT), albumina, plaquetas, RNI, relação do tempo de tromboplastina ativada controle para o paciente $(\operatorname{Rel} \mathrm{C} / \mathrm{P})$ e fibrinogênio. Foi analisado o volume transfundido de $\mathrm{CH}, \mathrm{PFC}, \mathrm{CP}$ e crioprecipitado (CRIO), no período de 24 horas que antecede a cirurgia. Foram registradas a data de internação e a data do transplante. Foi calculada a taxa de depuração da creatinina (DCr) estimada de cada paciente através da Fórmula de Schwartz simplificada ${ }^{101-103}=\mathrm{K} \times$ estatura $(\mathrm{cm}) /$ creatinina $(\mathrm{mg} / \mathrm{dL})$, onde $\mathrm{K}$ é uma constante igual a 0,413. A DCr estimada ou taxa de filtração glomerular ${ }^{104}$ para crianças maiores de 8 meses e menores de 2 anos é de $96 \pm 22 \mathrm{~mL} / \mathrm{min} / 1,73 \mathrm{~m}^{2}$ e para maiores de 2 anos até 12 anos é de $133 \pm 27 \mathrm{~mL} / \mathrm{min} / 1,73 \mathrm{~m}^{2}$

\subsubsection{Variáveis intraoperatórias}

Foram analisados no período intraoperatório, os seguintes dados: tempos de isquemia quente e fria, relação peso do implante para o peso do 
paciente (RPIPP), os tempos de duração dos procedimentos anestésico e cirúrgico, diurese, $\mathrm{Hb}$, plaquetas, RNI, Rel C/P, fibrinogênio, sódio, potássio, glicemia, lactato, albumina séricos, no início e final da cirurgia, e reposição volêmica: volume administrado de cristaloides, coloides, volumes de $\mathrm{CH}$, PFC, CP e CRIO. Foram avaliadas as seguintes complicações intraoperatórias: reações transfusionais agudas, síndrome de reperfusão, sangramento, instabilidade hemodinâmica (queda de pressão arterial média maior ou igual a $30 \%$ do basal com necessidade de drogas vasoativas em altas doses ou doses cresentes ou de outro suporte hemodinâmico), presença de broncoespasmo, derrame pleural ou pneumotórax, extubação em sala operatória (SO), necessidade de reintubação, arritmias e parada cardiorespiratória.

\subsubsection{Variáveis pós-operatórias}

Foram analisados no período pós-operatório, os seguintes dados: $\mathrm{Hb}$, plaquetas, RNI, Rel C/P, fibrinogênio, sódio, potássio, lactato, AST, ALT, GGT, FA, BT, creatinina, biópsia hepática, tempo de ventilação mecânica, tempo de internação na UTI e tempo total de internação hospitalar, data do óbito, e volume transfundido de $\mathrm{CH}, \mathrm{PFC}, \mathrm{CP}$ e $\mathrm{CRIO}$ até 48 horas após o término da cirurgia. As complicações pós-operatórias foram avaliadas durante o período pós-operatório precoce ou de internação do TH e durante o período de pósoperatório tardio ou até 1, 5 e 10 anos pós-TH, quanto à gravidade, de acordo com a classificação de Clavien-Dindo adaptada para THP, além de forma quantitativa e qualitativa, nos quatro períodos. 


\subsubsection{Rejeição}

Foram considerados episódios de rejeição: 1) diagnóstico clínico dado por aumento de transaminases e boa resposta ao tratamento de pulsoterapia com corticoide, chamada de pulsoterapia de prova ou; 2) diagnóstico anatomopatológico, dado através de biópsia hepática por trocater, guiada por ultrassonografia, caracterizada por uma rejeição aguda celular (RAC) e categorizado em três graus de gravidade: RAC 1 ou leve, RAC 2 ou moderado e RAC 3 ou grave. A RAC também foi avaliada conforme documentada na evolução clínica e baseada em laudos de exames anatomopatológicos. Todas as formas de rejeição foram analisadas quanto à frequência e à gravidade nos dois grupos estudados. A sobrevida do enxerto e do paciente foram avaliadas no primeiro, no quinto e no décimo anos pós-TH.

\subsection{Complicações}

Os pacientes foram classificados segundo o grau de gravidade da complicação pela classificação de Clavien-Dindo adaptada. A fim de não se hipervalorizar a gravidade destes pacientes, manteve-se a subdivisão da classificação de 2004 do grau III em Illa e IIIb, conforme já realizado para TH em adultos ${ }^{100}$

Considerou-se assim, procedimentos menos invasivos, como IIla e mais invasivos, como Illb e, os grupos foram criados a partir deste critério. O grupo de pacientes sem nenhuma complicação ou com complicações de grau I, II e 
Illa foi chamado de grupo de complicações menores (CMe), que incluiu 109 pacientes e o grupo de pacientes com ao menos uma complicação de grau IIIb, IVa, IVb ou V, que incluiu 131 pacientes, foi chamado de grupo de complicações maiores (CMa).

As complicações do período pós-operatório ao TH foram consideradas precoces, quando analisadas durante a internação e tardias, quando analisadas até 10 anos de pós-operatório do TH. Todas as complicações foram agrupadas por tipo de complicação, conforme a etiologia da mesma. Estas complicações foram agrupadas em catorze tipos quanto à sua etiopatogenia e classificadas qualitativamente em ordem alfabética:

1) Alérgica - manifestações alérgicas a drogas, alimentos, fatores ambientais sem história pregressa e relacionadas à transfusão de $\mathrm{HC}$;

2) Cardiovascular - hipertensão arterial sistêmica, alterações de ritmo cardíaco como, bradicardias, taquicardias, arritmias acompanhadas ou não de instabilidade hemodinâmica, edema pulmonar cardiogênico, insuficiência cardíaca e parada cardiorrespiratória;

3) Cirúrgica - deiscências de anastomoses com aparecimento de fístulas biliares (FB), estenose biliar (EB), estenoses vasculares, tromboses vasculares de influxo hepático, como trombose de artéria hepática (TAH) e trombose de veia porta (TVPo) e de efluxo hepático, como trombose de veias suprahepáticas, reanastomose bilio-digestivas, abdômen agudo com necessidade de laparotomia exploradora, herniações e retransplantes;

4) Endócrino-metabólica - alterações hidro-eletrolíticas como hiponatremia (sódio sérico < $133 \mathrm{mEq} / \mathrm{L}$ ), hipernatremia (sódio 
sérico $>147 \mathrm{mEq} / \mathrm{L}$ ), hipopotassemia (potássio sérico $<3,0 \mathrm{mEq} / \mathrm{L}$ ), hiperpotassemia (potássio sérico $>5,4 \mathrm{mEq} / \mathrm{l}$ ), hipocalcemia (cálcio iônico < 1,17 mMol/L), hipomagnesemia (magnésio sérico $<1,8 \mathrm{mg} / \mathrm{dL}$ ), hipofosfatemia (fósforo sérico $<2,5 \mathrm{mg} / \mathrm{dL}$ ), e ácidobásicas (gasometria arterial com $\mathrm{pH}<7,2$ na acidose e $\mathrm{pH}>7,5$ na alcalose), hiperlactatemia (lactato sérico $>22 \mathrm{mg} / \mathrm{dL}$ ), oligúria (diurese inferior a $0,5 \mathrm{ml} / \mathrm{kg} / \mathrm{h}$ ), insuficiência adrenal, diabetes mellitus (DM), déficit pondero-estatural (Z-score P/E $<-2$ desvios padrões) obesidade (ZIMC > 2 desvios padrões), dislipidemia (colesterol total sérico $>170 \mathrm{mg} / \mathrm{dL}$, fração LDL sérico $>130 \mathrm{mg} / \mathrm{dL}$ e triglicérides séricos > $130 \mathrm{mg} / \mathrm{dL}$ );

5) Gastrointestinal - desnutrição proteico-calórica (z-escore P/l ou E/I ou $P / E<-2$ desvios padrões), necessidade de dieta enteral ou parenteral, diarreia crônica (duração superior a 3 semanas), doença de refluxo gastroesofágico com ou sem broncoaspiração associada, visceromegalia ou ascite importante por hipertensão portal mantida;

6) Infecciosa - gastroenterocolites agudas, infecções de ferida operatória, cerato-conjuntivites, celulites, infecções dentárias, mastoidites, infecções de pele e anexos, de trato urinário, de ponta de cateter, colangites, hemoculturas positivas com sinais, sintomas ou alterações laboratoriais de sepse;

7) Miscelânea - patologias mais raras ou vinculadas a complicações de procedimentos relacionados ao $\mathrm{TH}$ (por exemplo: queimadura de terceiro grau, por infiltração acidental de cloreto de cálcio, no tecido 
celular subcutâneo, fratura óssea por restrição ou agitação psicomotora);

8) Neoplásica - doença linfoproliferativa pós-transplante (post-transplant limphoproliferative disorders - PTLD), linfomas, tumores de pele e recaídas de doenças de base (hepatoblastoma e hepatocarcinoma);

9) Neuro-psiquiátrica - cefaleia, vertigens, crises convulsivas, síndrome de abstinência à sedação, atraso de desenvolvimento neuropsicomotor, dificuldade de aprendizado escolar, alterações comportamentais com agitação psicomotora, déficit de atenção, labilidade emocional, quadros de ansiedade e depressão;

10) PNF - Primary Non Function - não funcionamento primário do enxerto acompanhado de sinais e sintomas de falência hepática aguda franca, excluindo-se casos de disfunção do enxerto e dúvida diagnóstica;

11) Rejeição - manifestações clínicas, laboratoriais, responsividade à pulsoterapia de prova com metilprednisolona ou documentação anátomo-patológica de rejeição aguda celular (RAC) ou rejeição crônica, de gravidades variáveis;

12) Renal - somente casos de insuficiência renal determinados por queda da função renal igual ou superior a $50 \%$ determinada por meio do cálculo de $\mathrm{DCr}$ estimada por meio de fórmula de Schwartz simplificada ${ }^{102}$.

13) Respiratória - quadros de broncoespasmo, infecções de via aérea superior (rinites, sinusites, otites, amigdalites, epiglotites e faringolaringites) e de via aérea inferior (traqueítes, broncopneumonias e 
pneumonias), intubações prolongadas (superiores a 48 horas), atelectasias, derrames, fístulas pleurais, hemotórax, pneumotórax, pneumomediastino, edemas não cardiogênicos e insuficiência respiratória aguda;

14) Sangramento - epistaxes, sangramentos digestivos, de ferida operatória, de drenos, e hemorragias sistêmicas, por hipertensão portal ou coagulopatia com ou sem necessidade de abordagem cirúrgica.

As complicações alérgicas, as infecciosas, as rejeições e as neoplásicas são complicações que dependem da integridade do sistema imune, tendo sido, neste estudo, classificadas como imunológicas.

\subsection{Tempo de internação e seguimento pós-alta hospitalar}

O tempo de internação de cada paciente foi variável dependendo de sua condição clínica de base, do procedimento anestésico cirúrgico e de sua evolução pós-operatória. Os pacientes foram acompanhados regularmente na pós-alta hospitalar em consultas de rotina semanais durante o primeiro mês, mensais até o terceiro mês, bimestrais até completar um ano e uma vez por ano, após o primeiro ano. Alguns pacientes tiveram parte de seu acompanhamento realizado em suas cidades de origem, ou seja, em outros serviços médicos à distância, havendo, no entanto, a manutenção das consultas anuais nas quais foram registradas intercorrências tratadas em outros serviços. A equipe de enfermagem do $\mathrm{TH}$ do $\mathrm{AC}$ Camargo Cancer Center participou ativamente da entrega de solicitações de coleta de exames 
de rotina periódicos, marcação de biópsias hepáticas de controle, cobrança de resultados, entrega de receituários de medicamentos de alto custo fornecidos pelo Sistema Único de Saúde, manutenção de drenos biliares e curativos em geral. Além disso, foram também realizados contatos telefônicos, abrangendo um questionário padronizado para verificação do estado geral dos pacientes, ingestão regular e adequada de medicamentos, checagem das doses de medicamentos calculadas segundo peso corpóreo e nível sérico, anotações a respeito da presença de alergias e efeitos colaterais aos medicamentos, atendimentos médicos de urgência, internações em outros serviços médicos, intercorrências e esclarecimento de dúvidas.

O seguimento dos pacientes pós-alta hospitalar foi iniciado em 14 de maio de 2001 e perpetuado até 31 de dezembro de 2014. Os pacientes que não retornaram ao ambulatório depois da alta hospitalar foram considerados com perda de seguimento.

\subsection{Monitorização intraoperatória, técnica anestésica e técnica cirúrgica}

A SO foi pré-aquecida a cerca de $24^{\circ} \mathrm{C}$, os pacientes foram posicionados sobre uma manta térmica pediátrica, tendo como meta manter temperatura de 36,5 a $37,7^{\circ} \mathrm{C}$, durante todo o procedimento anestésico-cirúrgico. Os pacientes foram monitorizados com eletrocardiografia contínua em 3 derivações, oximetria de pulso e manometria automática, a cada 3 minutos, de pressão não invasiva. Como estes pacientes vieram à SO com uma venóclise periférica para 
soro de manutenção e medicação profilática, esta via foi utilizada para ministração de medicação pré-anestésica (midazolam 0,1 a 0,2 mg/kg) para crianças com idade superior a 6 meses de vida. Após pré-oxigenação com fração inspirada de oxigênio $\left(\mathrm{FiO}_{2}\right)$ de $100 \%$ por 3 minutos, foi iniciada a indução anestésica endovenosa com fentanil 3 a $5 \mathrm{mcg} / \mathrm{kg}$, propofol 2,5 a 3,0 $\mathrm{mg} / \mathrm{kg}$ e o relaxamento muscular obtido com succinicolina 1,5 a $2,0 \mathrm{mg} / \mathrm{kg}$ no período de 2001 a 2007 e com rocurônio 1,5 a 2,0 mg/kg, de 2007 a 2011. Após a intubação traqueal, a ventilação mecânica foi mantida com uma $\mathrm{FiO}_{2}$ mínima de $40 \%$ objetivando-se uma relação adequada de $\mathrm{PaO}_{2} / \mathrm{FiO}_{2}$, em modalidade de pressão controlada para manter um volume corrente de 6 a $8 \mathrm{~mL} / \mathrm{kg}$ e frequência respiratória suficiente para manter normocapnia intraoperatória. A monitorização da temperatura foi realizada através de termômetro orofaríngeo, débito urinário através de sonda vesical siliconada e coletor infantil graduado, além de descompressão gástrica, através de sonda nasogástrica acoplada a um coletor. A manutenção anestésica endovenosa foi realizada com infusão contínua de alfentanil 0,5 a 2,0 mcg/kg/min de 2001 a 2005 e com remifentanil 0,20 a $1,0 \mathrm{mcg} / \mathrm{kg} / \mathrm{min}$ de 2005 a 2011 , propofol 75 a $150 \mathrm{mcg} / \mathrm{kg} / \mathrm{min}$ e o relaxamento muscular obtido com atracúrio 2 a $3 \mathrm{mcg} / \mathrm{kg} / \mathrm{min}$ de 2001 a 2006 e cisatracúrio 2 a 2,5 mcg/kg/min de 2006 a 2011. Foi realizada infusão de cloreto de cálcio a $10 \%$ de 40 a $100 \mathrm{mcg} / \mathrm{kg} / \mathrm{min}$, objetivando-se níveis de cálcio iônico de 1,17 a 1,32 mMol/L; infusão contínua de glicose a 50\% de 6,0 a $10,0 \mathrm{mg} / \mathrm{kg} / \mathrm{min}$, objetivando-se glicemia de 80 a $200 \mathrm{mg} / \mathrm{dL}$ e de manitol a $20 \%$ de 0,3 a $1,0 \mathrm{~mL} / \mathrm{kg} / \mathrm{min}$ objetivando-se diurese de 1 a $2 \mathrm{~mL} / \mathrm{kg} / \mathrm{min}$ e um melhor controle da reposição de fluidos, além do uso de drogas vasoativas quando necessário. 
Foi realizada punção da artéria radial para monitorização de pressão arterial invasiva e coleta de exames laboratoriais de hematimetria, bioquímica, avaliação de coagulação e gasometria arterial. A seguir, foi puncionado um novo acesso venoso periférico calibroso, preferencialmente em membros superiores, para reposição volêmica, em infusão contínua, com solução de cristaloide balanceada de $400 \mathrm{~mL}$ de Plasmalyte (Baxter®) associada a $100 \mathrm{~mL}$ de solução de albumina a $20 \%$, na velocidade aproximada de 10 a $15 \mathrm{~mL} / \mathrm{kg} / \mathrm{h}$. Por veia periférica, foi realizada infusão de drogas anestésicas, reposição de solução criataloide balanceada isolada ou associada a $\mathrm{HC}$, quando necessário. $\mathrm{O}$ acesso central foi realizado por veia jugular interna, preferencialmente à direita, por punção cervical anterior ou posterior, sem ultrassonografia, de 2001 a 2008 e, após 2008, por punção guiada por ultrassonografia, sempre seguida de radioscopia para posicionamento adequado do cateter. Pela veia central foi realizada reposição, em infusão contínua de, glicose, eletrólitos, diuréticos, drogas vasoativas, além da monitorização de PVC e coleta de exame de gasometria venosa. A reposição volêmica foi guiada pelo volume de ascite e de sangue aspirados, parâmetros hemodinâmicos, pelo débito urinário e por variáveis de perfusão tecidual (saturação venosa central de $\mathrm{O}_{2}$, diferença de pressão parcial de $\mathrm{CO}_{2}$ nas gasometria arterial e venosa e mensuração de lactato arterial). Foi procurado manter-se como alvo, um nível sérico de $\mathrm{Hb}$ entre 8,0 e 9,0 g/dL.

A técnica cirúrgica utilizada foi a de preservação de fluxo de veia cava inferior, conhecida por piggy-back, sem uso de bypass veno-venoso. A solução de Euro-Collins (Fresenius ${ }^{\circledR}$ ) foi a solução de preservação utilizada. Antes da reperfusão do enxerto, este foi irrigado com solução de soro fisiológico associado à albumina a $2 \%$, à temperatura ambiente, em um volume de $1 \mathrm{~mL} / \mathrm{kg}$ de 
solução para cada $1 \mathrm{~g}$ de massa de enxerto, através da veia cava infrahepática, a fim de eliminar debris, resíduos de solução de preservação contendo altos níveis de potássio, êmbolos gasosos e produtos do metabolismo anaeróbico produzidos pela isquemia e reperfusão. Todos os enxertos utilizados foram produtos de ressecção do segmento lateral esquerdo do fígado do doador.

\subsection{Análise estatística}

Uma análise preliminar da amostra geral foi realizada, em que foram apresentadas para as variáveis qualitativas, as frequências absolutas e relativas, Já para as variáveis quantitativas, foram apresentadas as medidas resumo como valores mínimo, máximo, média, mediana e desvio padrão.

Foi utilizada a classificação de graduação de complicações pósoperatórias modificada para faixa pediátrica, que denominamos de classificação de Clavien-Dindo adaptada, o que permitiu classificar todas as complicações no período de pós-operatório precoce ou de internação hospitalar e dividir a amostra, inicialmente, segundo a presença ou não de complicações graves. A mesma classificação foi aplicada no período de pósoperatório tardio, ou período de um, cinco e dez anos de pós-operatório do TH, permitindo análise de morbidade a curto, médio e longo prazo.

As comparações entre os grupos foram realizadas aplicando-se os Testes T de Student ou Mann-Whitney, para as variáveis quantitativas e os Testes Exato de Fisher ou Qui-quadrado, para as variáveis qualitativas, conforme necessidade.

Foram realizadas análises de regressão logística múltipla para identificar os fatores de risco para a ocorrência de complicação maior. Para a seleção das 
variáveis foi utilizado o método stepwise. Identificou-se uma única variável independente de risco para complicação grave que foi o volume médio de $\mathrm{CH}$ transfundido no perioperatório. Foi realizada a curva ROC (receiver operating characteristic) para a variável volume de $\mathrm{CH}$ perioperatório, em relação à presença de complicações maiores ou graves. A acurácia para a variável de volume de $\mathrm{CH}$ perioperatório foi de 0,648 (AUC = 0,648) com I.C. $(95 \%)=$ [0,578; 0,717]. A maximização simultânea da sensibilidade $(68,7 \%)$ e da especificidade $(56,9 \%)$, resultou em um ponto de corte de $27,5 \mathrm{~mL} / \mathrm{kg}$ de $\mathrm{CH}$ no perioperatório (Figura 1).

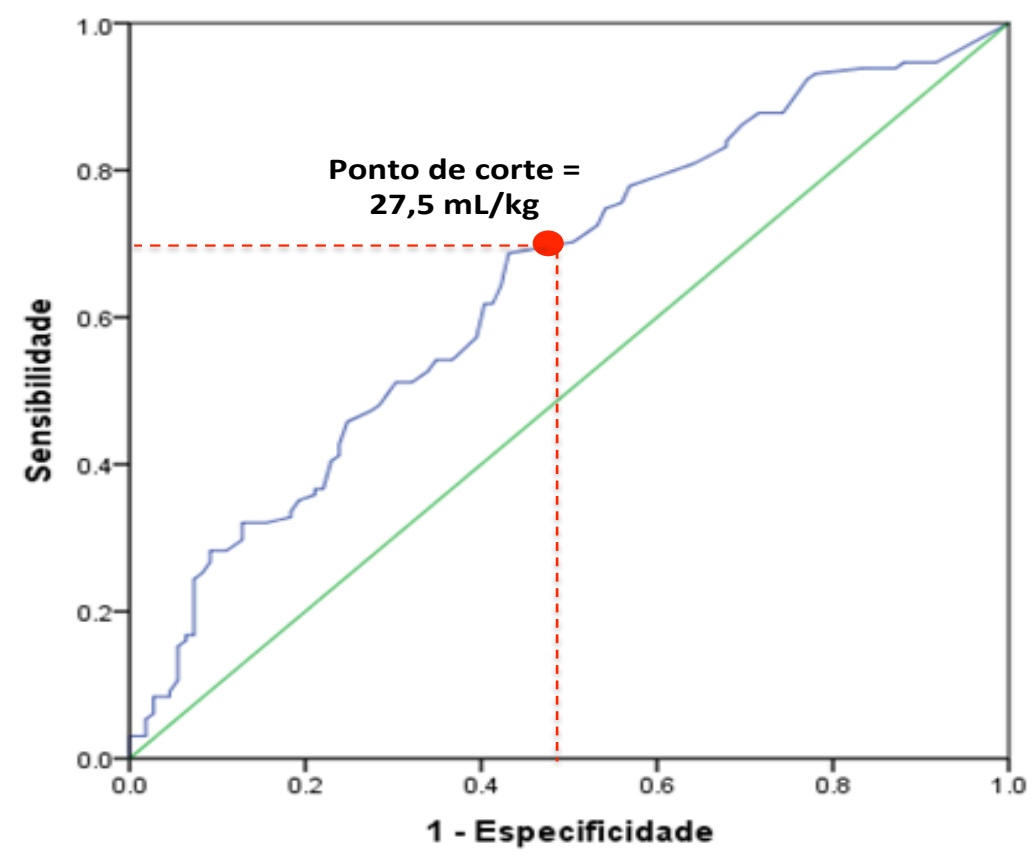

Figura 1. Curva ROC (Receiver Operating Characteristic) do volume de concentrado de hemácias transfundido no período perioperatório, de $24 \mathrm{~h}$ antes até $48 \mathrm{~h}$ após o transplante hepático e indexado pelo peso corpóreo $(\mathrm{CH})$. $A U C=0,648$; Intervalo de confiança (IC) de 95\% (0,578-0,717); $p<0,0001$. Sensibilidade $=68,7 \% \mathrm{e}$ Especificidade $=56,9 \%$. Ponto de corte $=27,5 \mathrm{~mL} / \mathrm{kg}$ de $\mathrm{CH}$ perioperatório 
A partir deste valor, a amostra foi finalmente dividida em dois grupos segundo o volume de $\mathrm{CH}$ do período perioperatório e realizadas análise univariada e regressão logística múltipla com o objetivo de identificar-se fatores de risco independentes para a transfusão de $\mathrm{CH}$ no período perioperatório.

As curvas de sobrevida global e específica dos pacientes e dos enxertos hepáticos foram obtidas por meio do estimador de Kaplan-Meier e comparadas entre si utilizando-se o teste Log-Rank (Mantel-Haenszel).

Foram utilizadas as regressões de Cox simples e múltipla, com o objetvo de determinar fatores de risco independentes de mortalidade dos pacientes ao longo de dez anos. Em todo o estudo foi fixado o nível de significância de 0,05.

Todos os dados coletados foram planilhados em programa Windows 8.0 com software Access (Microsoft ${ }^{\circledR}$ ), o que permitiu o cruzamento de dados. O software utilizado para realização das análises univariadas e regressões logísticas múltiplas foi o SPSS, versão 23 (2015). As regressões de Cox simples e múltipla foram realizadas com o programa R, versão 3.2.1 (2015). 
4 RESULTADOS 


\subsection{Participação do estudo}

No período de maio de 2001 a dezembro de 2011, foram realizados 354 THP no AC Camargo Cancer Center, dos quais, 296 foram com doador vivo e 58 com doador falecido. Dos 296 pacientes submetidos a THP com doador vivo, 254 pacientes apresentaram peso corpóreo até $20 \mathrm{~kg}$. Foram excluídos 14 pacientes, dos quais, 5 pacientes tinham hepatite fulminante, 3 pacientes perderam seguimento hospitalar ao longo do estudo, 3 pacientes haviam sido retransplantados e 3 pacientes tinham registros incompletos. Duzentos e quarenta pacientes foram incluídos no estudo, sendo divididos em dois grupos, segundo o volume de concentrado de hemácias indexado pelo peso corpóreo e transfundido no período perioperatório $(\mathrm{CH})$ : o grupo $\mathrm{BCH}$, com 103 pacientes que receberam baixo volume de $\mathrm{CH}$ (menor ou igual a $27,5 \mathrm{~mL} / \mathrm{kg}$ ) e um grupo $\mathrm{ACH}$, com 137 pacientes que receberam um alto volume de $\mathrm{CH}$ (maior que $27,5 \mathrm{~mL} / \mathrm{kg}$ ) (Figura 2). 


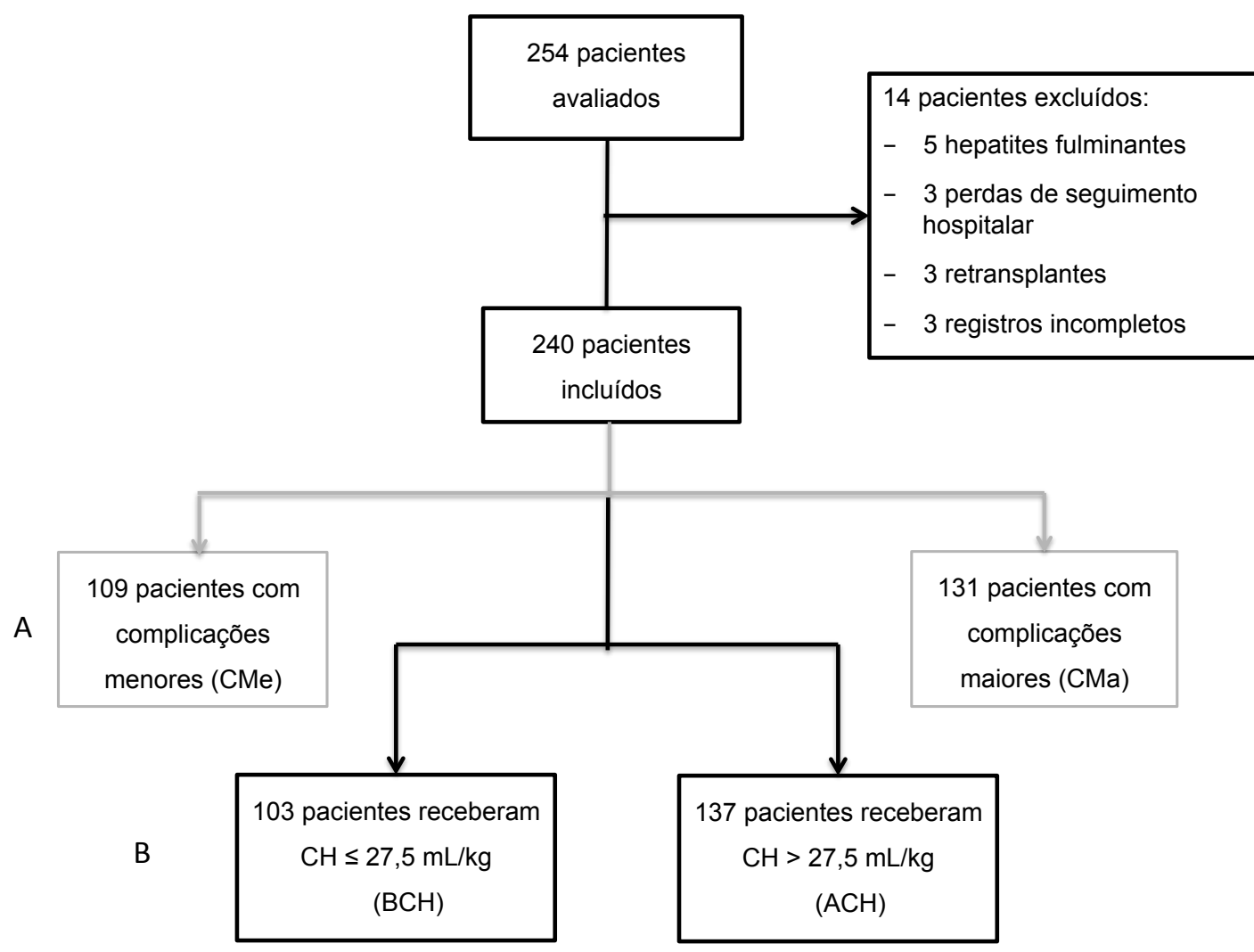

Figura 2. Fluxograma dos pacientes incluídos no estudo. A. Pacientes sem nenhuma complicação e com complicações menores ou não graves, I-Illa (grupo CMe) e pacientes com complicações maiores ou graves, IIlb-V (grupo CMa). B. Pacientes que receberam baixo volume de concentrado de hemácias no perioperatório, $\mathrm{CH} \leq 27,5$ $\mathrm{mL} / \mathrm{kg}$ (grupo $\mathrm{BCH}$ ) e pacientes que receberam alto volume de concentrado de hemácias no perioperatório $\mathrm{CH}>27,5 \mathrm{~mL} / \mathrm{kg}$ (grupo $\mathrm{ACH}$ ). 


\subsection{Características pré-operatórias da população geral e dos grupos}

\subsubsection{Características antropométricas e clínico-laboratoriais pré-operatórias dos grupos de complicações maiores e menores}

Dos 240 pacientes incluídos no estudo, 134 (55,8\%) eram do sexo feminino, com idade de 18,9 $\pm 15,8$ meses, peso de 9,08 $\pm 3,05 \mathrm{~kg}$ e estatura de $74 \pm 11,6 \mathrm{~cm}$. A pontuação do PELD puro pré-TH foi de $16( \pm 7,7)$. A indicação principal do TH foi AVBEH em 62,9\% sendo que a cirurgia de Kasai foi realizada, previamente, em $46,3 \%$ dos pacientes da amostra total.

A incidência de complicações maiores foi de $54,6 \%$ em 240 pacientes analisados. Os pacientes do grupo de complicações maiores (CMa) apresentaram idade $(17,1 \pm 16,5$ vs. $21,1 \pm 14,7$ meses $)$, peso $(8,61 \pm 3,09$ vs. $9,67 \pm 2,91 \mathrm{~kg})$ e estatura $(71,9 \pm 11,6$ vs. 76,6 \pm 11,2 cm) menores, em comparação ao grupo de complicações menores (CMe). Não houve diferença significativa, em relação ao gênero, entre os grupos CMa e CMe. A depuração de creatinina (193 \pm 109 vs. $\left.220 \pm 118 \mathrm{~mL} / \mathrm{min} / 1,73 \mathrm{~m}^{2}\right)$, a hemoglobina $(9,6 \pm 1,6$ vs. $9,9 \pm 1,5 \mathrm{~g} / \mathrm{dL})$, o sódio (135 \pm 4,4 vs. $136 \pm 3,0 \mathrm{mEq} / \mathrm{L})$, a glicemia ( $82 \pm 44$ vs. $113 \pm 73 \mathrm{mg} / \mathrm{dL})$ e a albumina séricas $(2,6 \pm 0,8$ vs. $2,8 \pm 0,9 \mathrm{~g} / \mathrm{dL})$, também foram menores, enquanto que, a bilirrubina total $(13,8 \pm 8,5$ vs. $11,3 \pm 7,8 \mathrm{~g} / \mathrm{dL})$ e a $\operatorname{RPIPP}(3,7 \pm 1,2$ vs. 3,3 $\pm 1,1 \%)$ foram maiores, em comparação ao grupo de complicações menores (CMe). Entretanto, o único fator de risco independente para complicações maiores foi o volume de $\mathrm{CH}$ transfundido no perioperatório (Tabela 3). 
Tabela 3. Análise univariada e regressão logística múltipla dos dados perioperatórios segundo os grupos categorizados pela gravidade das complicações pós-operatórias

\begin{tabular}{|c|c|c|c|c|c|c|c|}
\hline Variáveis & $\begin{array}{c}\text { CMe } \\
n=109\end{array}$ & $\begin{array}{c}\text { CMa } \\
n=131\end{array}$ & Estimativa & Valor $p$ & OR & IC (95\%) & Valor $p$ \\
\hline Gênero masculino & $54(49,5 \%)$ & $52(39,7 \%)$ & & 0,081 & & & \\
\hline Idade (meses) & $21,1 \pm 14,7$ & $17,1 \pm 16,5$ & & $<0,001$ & & & \\
\hline Peso (kg) & $9,67 \pm 2,91$ & $8,61 \pm 3,09$ & & $<0,001$ & & & \\
\hline Estatura $(\mathrm{cm})$ & $76,6 \pm 11,2$ & $71,9 \pm 11,6$ & & $<0,001$ & & & \\
\hline $\mathrm{ZP} / \mathrm{I}$ & $-1,28 \pm 1,24$ & $-1,49 \pm 1,31$ & & 0,105 & & & \\
\hline ZE/I & $-0,28 \pm 1,15$ & $-0,46 \pm 1,48$ & & 0,306 & & & \\
\hline ZP/E & $-2,03 \pm 1,41$ & $-2,15 \pm 1,48$ & & 0,313 & & & \\
\hline ZIMC & $-0,05 \pm 1,11$ & $-0,21 \pm 1,39$ & & 0,33 & & & \\
\hline Ascite & $78(71,6 \%)$ & $108(82,4 \%)$ & & 0,057 & & & \\
\hline PELD & $16,2 \pm 7,0$ & $17,8 \pm 8,2$ & & 0,14 & & & \\
\hline Cirurgia de Kasai & $50(45,9 \%)$ & $61(46,6 \%)$ & & 0,698 & & & \\
\hline Hipertensão portal & $97(88,9 \%)$ & $131(100,0 \%)$ & & 0,132 & & & \\
\hline $\begin{array}{l}\text { Síndrome } \\
\text { hepatopulmonar }\end{array}$ & $16(14,7 \%)$ & $15(11,5 \%)$ & & 0,414 & & & \\
\hline $\begin{array}{l}\text { Infecções até } 30 \text { dias } \\
\text { pré-TH }\end{array}$ & $0,4 \pm 0,6$ & $0,6 \pm 0,7$ & & 0,081 & & & \\
\hline $\mathrm{DCr}\left(\mathrm{mL} / \mathrm{min} / 1.73 \mathrm{~m}^{2}\right)^{*}$ & $220 \pm 118$ & $193 \pm 109$ & & 0,111 & & & \\
\hline Hemoglobina $(\mathrm{g} / \mathrm{dL})^{\star \star}$ & $9,9 \pm 1,5$ & $9,6 \pm 1,6$ & & 0,041 & & & \\
\hline Plaquetas $\left(\times 10^{3} / \mathrm{mm}^{3}\right)^{\star *}$ & $210 \pm 128$ & $183 \pm 110$ & & 0,304 & & & \\
\hline $\mathrm{RNI}^{* *}$ & $1,31 \pm 0,41$ & $1,44 \pm 0,51$ & & 0,212 & & & \\
\hline Sódio $(m E q / L))^{* *}$ & $136 \pm 3,0$ & $135 \pm 4,4$ & & 0,009 & & & \\
\hline Potássio $(\mathrm{mEq} / \mathrm{L})^{* *}$ & $4,4 \pm 0,5$ & $4,3 \pm 0,7$ & & 0,613 & & & \\
\hline Glicemia $(\mathrm{mg} / \mathrm{dL})^{\star *}$ & $113 \pm 73$ & $82 \pm 44$ & & 0,013 & & & \\
\hline Albumina $(\mathrm{g} / \mathrm{dL})^{\star *}$ & $2,8 \pm 0,9$ & $2,6 \pm 0,8$ & & 0,038 & & & \\
\hline Bilirrubina total $(\mathrm{g} / \mathrm{dL})^{\star *}$ & $11,3 \pm 7,8$ & $13,8 \pm 8,5$ & & 0,016 & & & \\
\hline RPIPP (\%) & $3,3 \pm 1,1$ & $3,7 \pm 1,2$ & & 0,035 & & & \\
\hline $\mathrm{CH}(\mathrm{mL} / \mathrm{kg})^{\star * *}$ & $31,1 \pm 25,4$ & $46,7 \pm 39,7$ & 0,018 & $<0,001$ & 1,018 & $1,007-1,028$ & 0,001 \\
\hline $\operatorname{PFC}(\mathrm{mL} / \mathrm{kg})^{* * *}$ & $0,3 \pm 2,6$ & $3,0 \pm 11,5$ & & 0,015 & & & \\
\hline $\mathrm{CP}(\mathrm{mL} / \mathrm{kg})^{* * *}$ & $0,1 \pm 0,8$ & $1,2 \pm 6,0$ & & 0,021 & & & \\
\hline CRIO $(\mathrm{mL} / \mathrm{kg})^{\star \star \star}$ & $0,0 \pm 0,0$ & $0,1 \pm 1,2$ & & 0,196 & & & \\
\hline \multicolumn{8}{|c|}{$\begin{array}{l}\text { CMe, grupo de complicações menores; CMa, grupo de complicações maiores;ZP/I, z-escore de peso para } \\
\text { idade;ZE/I, z-escore de estatura para idade; ZP/E, Z-escore de peso para estatura; ZIMC, z-escore de índice } \\
\text { de massa corpórea para idade; PELD, Pediatric End-Stage Liver Disease; TH, transplante hepático; DCr, } \\
\text { depuração de creatinina; RNI, razáo normalizada internacional; RPIPP, relação do peso do enxerto para o } \\
\text { peso do paciente; } \mathrm{CH} \text {, concentrado de hemácias; PFC, plasma fresco congelado; CP, concentrado de } \\
\text { plaquetas; CRIO, Crioprecipitado }\end{array}$} \\
\hline \multicolumn{8}{|c|}{ * Depuração de creatinina estimada pela Fórmula de Schwartz simplificada } \\
\hline \multicolumn{8}{|c|}{ ** Exames séricos coletados até $72 \mathrm{~h}$ antes da indução anestésica do transplante hepático } \\
\hline *** Volume transfusional c & e $24 \mathrm{~h}$ antes at & $48 \mathrm{~h}$ depois $\mathrm{dc}$ & transplar & hepátic & & & \\
\hline
\end{tabular}




\subsubsection{Características antropométricas e clínico-laboratoriais pré-operatórias dos grupos de maior e menor volume transfusional de concentrado de hemácias no período perioperatório}

Os pacientes do grupo ACH apresentaram idade (14 $\pm 11,7$ vs. $25,5 \pm$ 18,1 meses); peso $(7,88 \pm 2,29$ vs. $10,67 \pm 3,20 \mathrm{~kg})$ e estatura $(69,4 \pm 8,7$ vs. $80 \pm 12,1 \mathrm{~cm}$ ) menores, em comparação ao grupo $\mathrm{BCH}$.

Os pacientes do grupo $\mathrm{ACH}$ apresentaram z-escore de peso para idade ou ZP/I (-1,75 $\pm 1,21$ vs. $-0,90 \pm 1,20)$; z-escore de estatura para idade ou ZE/I $(-0,54 \pm 1,24$ vs. $-0,11 \pm 1,41) ;$-escore de peso para estatura ou ZP/E $(-2,43 \pm$

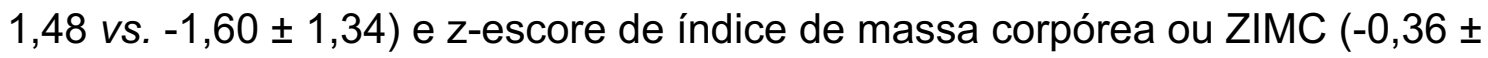
$1,39$ vs. $-0,20 \pm 1,20)$ menores, em comparação ao grupo $\mathrm{BCH}$. Não houve diferença significativa em relação ao gênero, entre os grupos $\mathrm{ACH}$ e $\mathrm{BCH}$ (Tabela 4).

Os pacientes do grupo $\mathrm{ACH}$ apresentaram grau de ascite $(83,9$ vs. $69,9 \%)$, PELD $(19,1 \pm 7,9$ vs. $14,2 \pm 6,4)$, frequência de cirurgia de Kasai $(54,0$ vs. $38,8 \%)$ e número médio de infecções até 30 dias antes do TH $(1 \pm 1$ vs. $0 \pm 1)$ maiores, em comparação ao grupo BCH. Não houve diferença significativa em relação à frequência de hipertensão portal, entre os grupos $\mathrm{ACH}$ e $\mathrm{BCH}$ (Tabela 4).

Os pacientes do grupo $\mathrm{ACH}$ apresentaram síndrome hepatopulmonar $(8,7$ vs. $18,4 \%)$ menos frequente, além de, níveis séricos de hemoglobina (9,3 $\pm 1,5$ vs. 10,2 $\pm 1,5 \mathrm{~g} / \mathrm{dL})$, sódio (135 $\pm 4,3$ vs. $137 \pm 2,7 \mathrm{mEq} / \mathrm{L})$, albumina (2,6 \pm 0,8 vs. $2,8 \pm 0,9 \mathrm{~g} / \mathrm{dL})$ e depuração de creatinina estimada (188 \pm 105 vs. $\left.229 \pm 121 \mathrm{~mL} / \mathrm{min} / 1,73 \mathrm{~m}^{2}\right)$ menores e $\mathrm{RNI}(1,49 \pm 0,56$ vs. $1,24 \pm 0,25)$ maior, em comparação ao grupo $\mathrm{BCH}$. Não houve diferença significativa em 
relação à contagem de plaquetas nem aos níveis séricos de potássio, glicemia e bilirrubina total, entre os grupos $\mathrm{ACH}$ e $\mathrm{BCH}$ (Tabela 4).

Tabela 4. Características dos pacientes e análises laboratoriais pré-operatórias segundo o volume de concentrado de hemácias indexado pelo peso corpóreo e transfundido no perioperatório

\begin{tabular}{|c|c|c|c|}
\hline Variáveis & $\begin{array}{c}\mathrm{BCH} \\
n=103\end{array}$ & $\begin{array}{c}\mathrm{ACH} \\
\mathrm{n}=137\end{array}$ & Valor $p$ \\
\hline Gênero masculino & $48(46,6 \%)$ & $58(42,3 \%)$ & 0,565 \\
\hline Idade (meses) & $25,5 \pm 18,1$ & $14,0 \pm 11,7$ & $<0,001$ \\
\hline Peso (g) & $10,67 \pm 3,20$ & $7,88 \pm 2,29$ & $<0,001$ \\
\hline Estatura (cm) & $80,0 \pm 12,1$ & $69,4 \pm 8,7$ & $<0,001$ \\
\hline ZP/I & $-0,90 \pm 1,20$ & $-1,75 \pm 1,21$ & $<0,001$ \\
\hline ZE/I & $-0,11 \pm 1,41$ & $-0,54 \pm 1,24$ & 0,012 \\
\hline $\mathrm{ZP} / \mathrm{E}$ & $-1,60 \pm 1,34$ & $-2,43 \pm 1,48$ & $<0,001$ \\
\hline ZIMC & $-0,20 \pm 1,20$ & $-0,36 \pm 1,39$ & 0,001 \\
\hline Ascite & $72(69,9 \%)$ & $115(83,9 \%)$ & 0,036 \\
\hline Ausente & $31(30,1 \%)$ & $22(16,0 \%)$ & \\
\hline Leve & $33(32,0 \%)$ & $36(26,3 \%)$ & \\
\hline Moderado & $25(24,3 \%)$ & $39(28,5 \%)$ & \\
\hline Grave & $14(13,6 \%)$ & $40(29,2 \%)$ & \\
\hline PELD & $14,1 \pm 6,2$ & $19,1 \pm 7,9$ & $<0,001$ \\
\hline Cirurgia de Kasai & $40(38,8 \%)$ & $74(54,0 \%)$ & 0,016 \\
\hline Hipertensão portal & $96(93,2 \%)$ & $132(96,3 \%)$ & 0,132 \\
\hline Síndrome hepatopulmonar & $19(18,4 \%)$ & $12(8,7 \%)$ & 0,043 \\
\hline Infecções até 30 dias pré-TH & $0 \pm 1$ & $1 \pm 1$ & 0,01 \\
\hline Hemoglobina $(g / d L)^{*}$ & $10,2 \pm 1,5$ & $9,3 \pm 1,5$ & $<0,001$ \\
\hline Plaquetas $\left(\times 10^{3} / \mathrm{mm}^{3}\right)^{*}$ & $196 \pm 112$ & $193 \pm 118$ & 0,789 \\
\hline $\mathrm{RNI}$ * & $1,24 \pm 0,25$ & $1,49 \pm 0,56$ & $<0,001$ \\
\hline Sódio $(\mathrm{mEq} / \mathrm{L})^{*}$ & $137 \pm 2,6$ & $135 \pm 4,4$ & $<0,001$ \\
\hline Potássio $(\mathrm{mEq} / \mathrm{L})^{*}$ & $4,3 \pm 0,5$ & $4,4 \pm 0,6$ & 0,613 \\
\hline Glicemia $(\mathrm{mg} / \mathrm{dL})^{*}$ & $104 \pm 59$ & $92 \pm 60$ & 0,313 \\
\hline Albumina $(g / d L)^{*}$ & $2,9 \pm 0,9$ & $2,5 \pm 0,8$ & 0,002 \\
\hline Bilirrubina total $(\mathrm{g} / \mathrm{dL})^{*}$ & $11,9 \pm 7,3$ & $13,4 \pm 8,8$ & 0,304 \\
\hline $\operatorname{DCr}\left(\mathrm{mL} / \mathrm{min} / 1,73 \mathrm{~m}^{2}\right)^{* *}$ & $229 \pm 121$ & $188 \pm 105$ & 0,006 \\
\hline \multicolumn{4}{|c|}{$\begin{array}{l}\mathrm{BCH} \text {, grupo de baixo volume transfusional de concentrado de hemácias perioperatório; } \mathrm{ACH} \text {, grupo de } \\
\text { alto volume transfusional de concentrado de hemácias perioperatório; ZP/l, z-escore de peso para } \\
\text { idade; ZE/I, z-escore de estatura para idade; ZP/E, z-escore de peso para estatura; ZIMC, z-escore de } \\
\text { índice de massa corporal para idade; PELD, Pediatric End-Stage Liver Disease, TH, transplante } \\
\text { hepático; RNI, razão normalizada internacional; DCr, depuração de creatinina. } \\
\text { " Exames séricos coletados até } 72 \mathrm{~h} \text { antes da indução anestésica }\end{array}$} \\
\hline \multicolumn{4}{|c|}{ ** Valor estimado ou calculado através de Fórmula de Schwartz simplificada } \\
\hline
\end{tabular}




\subsubsection{Distribuição das etiologias das hepatopatias de base na amostra total e segundo os grupos de maior e menor volume transfusional de concentrado de hemácias}

Quanto às classes de hepatopatias crônicas de base, a colestase extrahepática foi a classe de hepatopatias mais frequente e correspondeu a $70,8 \%$ da amostra total. Os pacientes do grupo $\mathrm{ACH}$ apresentaram colestase extrahepática $(76,6$ vs. $65,0 \%)$ mais frequente e colestase intra-hepática $(3,6$ vs. 12,6\%) menos frequente, em comparação ao grupo $\mathrm{BCH}$ (Tabela 5). Não houve diferença significativa entre os grupos $\mathrm{ACH}$ e $\mathrm{BCH}$ com relação à frequência de cirroses, doenças metabólicas, doenças neoplásicas ou miscelânea (Tabela 5).

As patologias de base encontradas dentre os 240 pacientes estudados distribuiram-se, segundo às classes já mencionadas, da seguinte maneira: 172 casos de colestases extra-hepáticas, sendo 151 (62,9\%) de AVBEH e 21 (8,8\%) de cisto de colédoco; 18 casos de colestases intra-hepáticas, sendo $6(2,5 \%)$ de síndrome de Alagille, $5(2,1 \%)$ de colestase intrahepática familiar progressiva, $4(1,7 \%)$ de hipoplasia de vias biliares e $3(1,3 \%)$ de colangite esclerosante primária; 18 casos de cirroses, sendo $8(3,3 \%)$ criptogenéticos $5(2,1 \%)$ casos autoimunes e $5(2,1 \%)$ casos idiopáticos; 17 casos de doenças metabólicas, sendo $6(2,5 \%)$ de tirosinemia, $5(2,1 \%)$ de deficiência de alfa-1 antitripsina, 3 $(1,3 \%)$ de doença de Cligger-Najar tipo $1,1(0,4 \%)$ caso de glicogenose IV, 1 $(0,4 \%)$ caso de defeito do ciclo da uréia (deficiência de ornitina-transcarbamilase e $1(0,4 \%)$ caso de oxalúria tipo $1 ; 10$ casos de doenças neoplásicas, sendo 9 
$(3,8 \%)$ casos de hepatoblastoma $1(0,4 \%)$ caso de hepatocarcinoma e 5 casos de miscelânea, sendo $3(1,3 \%)$ de fibrose a esclarecer, 1 (0,4\%) de Síndrome de Budd-Chiari e $1(0,4 \%)$ caso de hepatite de células gigantes. Não foi possível realizar a análise univariada de significância estatística das diferentes patologias, pela diversidade de diagnósticos (Tabela 5).

Tabela 5. Classes das hepatopatias crônicas segundo transfusão perioperatória do volume de concentrado de hemácias indexado pelo peso

\begin{tabular}{|c|c|c|c|}
\hline Variável & $\begin{array}{c}\text { Grupo BCH } \\
(n=103)\end{array}$ & $\begin{array}{c}\text { Grupo ACH } \\
(n=137)\end{array}$ & Valor $p$ \\
\hline Colestase extra-hepática & $67(65,0 \%)$ & $105(76,6 \%)$ & 0,029 \\
\hline Colestase intra-hepática & $13(12,6 \%)$ & $5(3,6 \%)$ & 0,002 \\
\hline Cirroses & $6(5,8 \%)$ & $12(8,8 \%)$ & 0,373 \\
\hline Doenças metabólicas & $7(6,8 \%)$ & $10(7,3 \%)$ & 0,852 \\
\hline Doenças neoplásicas & $7(6,8 \%)$ & $3(2,2 \%)$ & 0,159 \\
\hline Miscelânea & $3(2,9 \%)$ & $2(1,5 \%)$ & 0,751 \\
\hline \multicolumn{4}{|c|}{$\begin{array}{l}\text { ACH, grupo de alto volume transfusional de concentrado de hemácias perioperatório; } \mathrm{BCH} \text {, grupo de baixo } \\
\text { volume transfusional de concentrado de hemácias perioperatório; Colestase extra-hepática (atresia de vias } \\
\text { biliares extra-hepáticas, cisto de colédoco); Colestase intra-hepática (síndrome de Alagille, hipoplasia de } \\
\text { vias biliares não sindromática, colangite esclerosante primária, colestase familiar intra-hepática } \\
\text { progressiva); Cirroses criptogenética, autoimune e idiopática); Doenças metabólicas (glicogenoses, } \\
\text { Cligger-Najar, tirosinemia, fibrose cística, deficiência de alfa-1 antitripsina, defeitos do ciclo da uréia, } \\
\text { oxalúria tipo I); Doenças neoplásicas (hepatoblastoma e hepatocarcinoma) e Miscelânea (síndrome de } \\
\text { Budd-Chiari, Doença de Caroli, hepatite de células gigantes, fibroses a esclarecer). }\end{array}$} \\
\hline
\end{tabular}




\subsection{Análise comparativa das variáveis clínico-laboratorias do intraoperatório e dos dados evolutivos do pós-operatório precoce dos grupos estudados de acordo com o volume concentrado de hemácias transfundido no perioperatório}

Os pacientes do grupo $\mathrm{ACH}$ apresentaram níveis séricos de hemoglobina (7,6 $\pm 1,2$ vs. $8,6 \pm 1,5 \mathrm{~g} / \mathrm{dL})$ e sódio (134 \pm 5 vs. $135 \pm 8 \mathrm{mEq} / \mathrm{L})$ menores e RNI $(1,67 \pm 0,75$ vs.1,23 $\pm 0,42)$ maior, em comparação ao grupo BCH. Não houve diferença significativa entre os grupos, em relação à contagem de plaquetas, potássio, glicemia, albumina e lactato séricos (Tabela 6).

Os pacientes do grupo $\mathrm{ACH}$ apresentaram tempo de anestesia $(10,8 \pm 1,9$ vs. $9,7 \pm 1,6 h)$, tempo de cirurgia $(9,0 \pm 1,9$ vs. $7,8 \pm 1,4 h)$ e a relação do peso do implante para o peso do paciente ou RPIPP $(3,9 \pm 1,1$ vs. $2,9 \pm 1,0 \%)$ maiores, em comparação ao grupo $\mathrm{BCH}$. Não houve diferença significativa entre os grupos, em relação aos tempos de isquemia quente e fria (Tabela 6).

Os pacientes do grupo $\mathrm{ACH}$ tiveram, no intraoperatório, volumes indexados médios de criataloide $(251,2 \pm 104,8$ vs. $179,4 \pm 67,3 \mathrm{~mL} / \mathrm{kg})$, de colóide $(43,1 \pm 19,7$ vs. $33,6 \pm 20,8 \mathrm{~mL} / \mathrm{kg})$ e de diurese $(61,3 \pm 36,6$ vs. $47,5 \pm 22,9 \mathrm{~mL} / \mathrm{kg}$ ) maiores, em comparação ao grupo BCH (Tabela 6).

Os pacientes do grupo $\mathrm{ACH}$ apresentaram taxa de extubação em sala operatória (11,7 vs. 23,3 \%) menor e frequência de intubação prolongada (24,1 vs. 5,8 \%) maior, em comparação ao grupo $\mathrm{BCH}$ (Tabela 6).

Os pacientes do grupo $\mathrm{ACH}$ apresentaram períodos de internação em UTI ( $8 \pm 13$ vs. $4 \pm 5$ dias $)$ e hospitalar ( $23 \pm 21$ vs. $17 \pm 13$ dias $)$ maiores, em comparação ao grupo BCH (Tabela 6). 
Tabela 6. Dados intraoperatórios e de pós-operatório precoce comparando os grupos de pacientes segundo transfusão perioperatória do volume de concentrado de hemácias indexado pelo peso

\begin{tabular}{|c|c|c|c|}
\hline Variável & $\begin{array}{c}\text { Grupo BCH } \\
n=103\end{array}$ & $\begin{array}{c}\text { Grupo ACH } \\
n=137\end{array}$ & Valor $p$ \\
\hline Hemoglobina $(\mathrm{g} / \mathrm{dL})^{*}$ & $8,6 \pm 1,5$ & $7,6 \pm 1,2$ & $<0,001$ \\
\hline Plaquetas $\left(\times 10^{3} / \mathrm{mm}^{3}\right)^{*}$ & $158 \pm 98,7$ & $153 \pm 92,2$ & 0,863 \\
\hline $\mathrm{RNI}^{*}$ & $1,23 \pm 0,42$ & $1,67 \pm 0,75$ & $<0,001$ \\
\hline Sódio $(\mathrm{mEq} / \mathrm{L})^{*}$ & $135 \pm 8$ & $134 \pm 5$ & 0,002 \\
\hline Potássio $(\mathrm{mEq} / \mathrm{L})^{*}$ & $3,6 \pm 0,6$ & $3,7 \pm 0,6$ & 0,431 \\
\hline Glicemia $(\mathrm{mg} / \mathrm{dL})^{*}$ & $88 \pm 25$ & $103 \pm 54$ & 0,067 \\
\hline Albumina $(g / d L)^{*}$ & $2,6 \pm 0,7$ & $2,3 \pm 0,7$ & 0,057 \\
\hline Lactato $(\mathrm{mg} / \mathrm{dL})^{*}$ & $11,1 \pm 5,7$ & $12,0 \pm 5,9$ & 0,553 \\
\hline Tempo de isquemia quente (min) & $42,2 \pm 12,8$ & $42,9 \pm 11,6$ & 0,537 \\
\hline Tempo de isquemia fria (min) & $53,0 \pm 34,8$ & $67,5 \pm 56,3$ & 0,084 \\
\hline Tempo de anestesia $(\mathrm{h})$ & $9,7 \pm 1,6$ & $10,8 \pm 1,9$ & $<0,001$ \\
\hline Tempo de cirurgia (h) & $7,8 \pm 1,4$ & $9,0 \pm 1,9$ & $<0,001$ \\
\hline RPIPP (\%) & $2,9 \pm 1,0$ & $3,9 \pm 1,1$ & $<0,001$ \\
\hline Volume de cristaloide (mL/kg) & $179,4 \pm 67,3$ & $251,2 \pm 104,8$ & 0,015 \\
\hline Volume de coloide $(\mathrm{mL} / \mathrm{kg})$ & $33,6 \pm 20,8$ & $43,1 \pm 19,7$ & $<0,001$ \\
\hline Diurese $(\mathrm{mL} / \mathrm{kg})$ & $47,5 \pm 22,9$ & $61,3 \pm 36,6$ & 0,013 \\
\hline Extubação em SO & $24(23,3 \%)$ & $16(11,7 \%)$ & 0,008 \\
\hline Intubação superior a $48 \mathrm{~h}$ & $6(5,8 \%)$ & $33(24,1 \%)$ & $<0,001$ \\
\hline TI em UTI (dias) & $4 \pm 5$ & $8 \pm 13$ & 0,001 \\
\hline TI hospitalar (dias) & $17 \pm 13$ & $23 \pm 21$ & 0,01 \\
\hline \multicolumn{4}{|c|}{$\begin{array}{l}\mathrm{BCH} \text {, grupo de baixo volume transfusional de concentrado de hemácias perioperatório; } \mathrm{ACH} \text {, grupo de alto } \\
\text { volume transfusional de concentrado de hemácias perioperatório; RNI, razão normalizada internacional; } \\
\text { RPIPP, relação do peso do implante para o peso corpóreo do paciente; SO, sala operatória; TI, tempo de } \\
\text { internação; UTI, unidade de terapia intensiva }\end{array}$} \\
\hline \multicolumn{4}{|c|}{${ }^{*}$ Exames séricos coletados até $2 \mathrm{~h}$ após a indução anestésica } \\
\hline
\end{tabular}

\subsection{Determinação dos fatores de risco independentes de transfusão} de concentrado de hemácias no período perioperatório

Com o objetivo de identificar fatores de risco independentes para a transfusão perioperatória de um alto volume de $\mathrm{CH}$ ou seja, um volume maior que $27,5 \mathrm{~mL} / \mathrm{kg}$, foram selecionadas variáveis de relevância estatística dos 
períodos pré-operatório e intraoperatório e submetidas à regressão logística multivariada (Tabela 7). Foram identificadas como variáveis independentes de risco de transfusão de $\mathrm{CH}$ no período perioperatório o z-escore de peso para estatura (ZP/E), o PELD escore, a depuração de creatinina (DCr) estimada, os níveis séricos de hemoglobina e de sódio pré-operatórios e a relação do peso do implante para o peso do paciente (RPIPP) (Tabela 7).

Tabela 7. Análise univariada e regressão logística múltipla de dados pré-operatórios e intraoperatórios dos grupos categorizados pelo volume transfusional de concentrado de hemácias perioperatório

\begin{tabular}{|c|c|c|c|c|c|c|}
\hline Variáveis & $\begin{array}{c}\mathrm{BCH} \\
\mathrm{n}=103\end{array}$ & $\begin{array}{c}\mathrm{ACH} \\
\mathrm{n}=137\end{array}$ & Valor $p$ & Estimativa & OR & IC (95\%) \\
\hline ZP/I & $-0,90 \pm 1,20$ & $-1,75 \pm 1,21$ & $<0,001$ & & & \\
\hline ZE/I & $-0,11 \pm 1,41$ & $-0,54 \pm 1,24$ & 0,012 & & & \\
\hline ZP/E & $-1,60 \pm 1,34$ & $-2,43 \pm 1,48$ & $<0,001$ & $-0,49$ & 0,613 & $0,414-0,906$ \\
\hline Ascite & $72(69,9 \%)$ & $115(83,9 \%)$ & 0,036 & & & \\
\hline PELD & $14,1 \pm 6,2$ & $19,1 \pm 7,9$ & $<0,001$ & 0,083 & 1,087 & $1,012-1,167$ \\
\hline $\begin{array}{l}\text { Colestase extra- } \\
\text { hepática }\end{array}$ & $67(65,0 \%)$ & $105(76,6 \%)$ & 0,029 & & & \\
\hline Cirurgia de Kasai & $40(38,8 \%)$ & $74(54,0 \%)$ & 0,016 & & & \\
\hline $\begin{array}{l}\text { Síndrome } \\
\text { hepatopulmonar }\end{array}$ & $19(43 \%)$ & $12(8,7 \%)$ & 0,043 & & & \\
\hline $\begin{array}{l}\text { Infecções até } 30 \\
\text { dias pré-TH }\end{array}$ & $0 \pm 1$ & $1 \pm 1$ & 0,010 & & & \\
\hline $\begin{array}{l}\mathrm{DCr} \\
\left(\mathrm{mL} / \mathrm{min} / 1,73 \mathrm{~m}^{2}\right)^{*}\end{array}$ & $229 \pm 121$ & $188 \pm 105$ & 0,006 & $-0,005$ & 0,995 & $0,991-0,999$ \\
\hline $\begin{array}{l}\text { Hemoglobina } \\
(\mathrm{g} / \mathrm{dL})^{\star *}\end{array}$ & $10,2 \pm 1,5$ & $9,3 \pm 1,5$ & $<0,001$ & $-0,347$ & 0,706 & $0,517-0,966$ \\
\hline $\mathrm{RNI}$ ** & $1,24 \pm 0,25$ & $1,49 \pm 0,56$ & $<0,001$ & & & \\
\hline Sódio $(\mathrm{mEq} / \mathrm{L})^{* *}$ & $137 \pm 2,6$ & $135 \pm 4,4$ & $<0,001$ & $-0,173$ & 0,842 & $0,711-0,996$ \\
\hline Albumina $(\mathrm{g} / \mathrm{dL})^{* *}$ & $2,9 \pm 0,9$ & $2,5 \pm 0,8$ & 0,002 & & & \\
\hline RPIPP $(\%)^{* * *}$ & $2,9 \pm 1,0$ & $3,9 \pm 1,1$ & $<0,001$ & 0,948 & 2,58 & $1,615-4,121$ \\
\hline $\begin{array}{l}\text { Volume de } \\
\text { cristaloide } \\
(\mathrm{mL} / \mathrm{kg})^{\star * *}\end{array}$ & $179,4 \pm 67,3$ & $\begin{array}{c}251,2 \pm \\
104,8\end{array}$ & 0,015 & & & \\
\hline $\begin{array}{l}\text { Volume de coloide } \\
(\mathrm{mL} / \mathrm{kg})^{\star * *}\end{array}$ & $33,6 \pm 20,8$ & $43,1 \pm 19,7$ & $<0,001$ & & & \\
\hline \multicolumn{7}{|c|}{$\begin{array}{l}\mathrm{BCH} \text {, grupo de baixo volume transfusional de concentrado de hemácias perioperatório; } \mathrm{ACH} \text {, grupo de alto volume } \\
\text { transfusional de concentrado de hemácias perioperatório; ZP/l, z-escore de peso para idade; ZE/l, z-escore de } \\
\text { estatura para idade; ZP/E, z-escore de peso para estatura; ZIMC, Z-escore de índice de massa corporal para idade; } \\
\text { PELD, Pediatric End-Stage Liver Disease; DCr, depuração de creatinina; RNI, razão normalizada internacional; } \\
\text { RPIPP, relação do peso do implante para o peso do paciente }\end{array}$} \\
\hline \multicolumn{7}{|c|}{ * Depuração de creatinina estimada pela Fórmula de Schwartz simplificada } \\
\hline \multicolumn{7}{|c|}{ ** Exames séricos coletadas até $72 \mathrm{~h}$ antes da indução anestésica do transplante hepático } \\
\hline *** Dados referentes & eríodo Intraope & & & & & \\
\hline
\end{tabular}




\subsection{Análise comparativa das complicações pós-operatórias entre os grupos com maior e menor volume de concentrado de hemácias transfundido no perioperatório}

4.5.1 Complicações do pós-operatório precoce utilizando a classificação de Clavien-Dindo adaptada e mortalidade pós-operatória de trinta dias após o transplante hepático dos grupos estudados de acordo com o volume de concentrado de hemácias transfundido no perioperatório

No período de internação ou período de pós-operatório precoce, dos 240 pacientes da amostra total, 13 pacientes não tiveram nenhuma complicação e 227 tiveram algum tipo de complicação. Destes 227 pacientes, 132 pertenciam ao grupo $\mathrm{ACH}$ e 95 ao grupo $\mathrm{BCH}$, sem diferença significativa entre os grupos, quanto ao total de pacientes com uma complicação qualquer (Tabela 8).

O grupo $\mathrm{ACH}$ apresentou mais pacientes com complicações maiores ou grau IIlb-V (65,7 vs. 39,8\%), uma maior média de complicações por paciente (3,8 $\pm 3,6$ vs. $2,5 \pm 1,7)$, uma maior porcentagem de complicações maiores, no total de complicações $(39,7$ vs. $20,6 \%)$, uma mediana do maior grau de complicação mais elevada (IVa vs. Illa) e, apesar do mesmo grau mediano de complicação por paciente (II), apresentou variabilidade maior de graus de complicações (I-V vs. I-IIlb), em comparação ao grupo BCH (Tabela 8). Houve maior taxa de mortalidade pós-operatória de 30 dias pós-TH no grupo $\mathrm{ACH}$ (6,6 vs. $0 \%$ ) sem nenhum registro de óbito no grupo $\mathrm{BCH}$ (Tabela 8 ). 
Tabela 8. Análise comparativa das complicações pós-operatórias da internação utilizando a classificação de Clavien-Dindo adaptada e mortalidade pós-operatória de 30 dias pós-transplante hepático segundo os grupos categorizados pelo volume de concentrado de hemácias perioperatório

\begin{tabular}{|c|c|c|c|}
\hline Variáveis & $\begin{array}{c}\mathrm{BCH} \\
n=103\end{array}$ & $\begin{array}{c}\mathrm{ACH} \\
\mathrm{n}=137\end{array}$ & Valor $p$ \\
\hline Pacientes com qualquer complicação & $95(92,2 \%)$ & $132(96,4 \%)$ & 0,264 \\
\hline Pacientes com complicações maiores (IIIlb-V) & $41(39,8 \%)$ & $90(65,7 \%)$ & $<0,001$ \\
\hline Média de complicações por paciente & $2,5 \pm 1,7$ & $3,8 \pm 3,6$ & 0,007 \\
\hline $\begin{array}{l}\text { Número de complicações maiores (IIIlb-V) no } \\
\text { total de complicações em cada grupo }\end{array}$ & $54 / 262(20,6 \%)$ & $207 / 521(39,7 \%)$ & $<0,001$ \\
\hline Mediana do maior grau de complicação & IIla (I - IVb) & $\mathrm{IVa}(\mathrm{I}-\mathrm{V})$ & $<0,001$ \\
\hline Grau mediano de complicação por paciente & II (I - IIIb) & II $(\mathrm{I}-\mathrm{V})$ & $<0,001$ \\
\hline Mortalidade pós-operatória de 30 dias & $0(0)$ & $9(6,6)$ & 0,008 \\
\hline
\end{tabular}

\subsubsection{Complicações do pós-operatório precoce segundo tipo e gravidade} dos grupos estudados de acordo com o volume de concentrado de hemácias transfundido no perioperatório

No período de internação após o TH, houve 783 complicações pósoperatórias sendo $66,5 \%$ no grupo $\mathrm{ACH}$ e $33,5 \%$ no grupo $\mathrm{BCH}$. O grupo $\mathrm{ACH}$, apresentou maior porcentagem de complicações maiores $(39,7$ vs. $20,6 \%)$ e menor porcentagem de complicações menores, em comparação ao $\mathrm{BCH}$ (60,3 vs. $79,4 \%)$ (Tabela 9$)$.

No grupo $\mathrm{ACH}$, as complicações cardiovasculares e infecciosas maiores e as complicações respiratórias e sangramentos, em geral, foram mais frequentes, já as complicações alérgicas e as rejeições foram menos frequentes, em comparação ao BCH (Tabela 9).

Não houve diferença significativa entre os grupos $\mathrm{ACH}$ e $\mathrm{BCH}$, em relação às complicações endócrino-metabólicas, cirúrgicas, gastrointestinais, 
miscelânea, neoplásicas, neuropsiquiátricas, PNF ou renais, durante o período de internação após o TH (Tabela 9).

Tabela 9. Classificação dos tipos e da gravidade das complicações pós-operatórias durante o período de internação pós-transplante hepático segundo os grupos categorizados pelo volume transfusional de concentrado de hemácias perioperatório

\begin{tabular}{|c|c|c|c|c|}
\hline \multicolumn{5}{|c|}{ Complicações na internação } \\
\hline Tipo & Grau & $\mathrm{BCH}$ & $\mathrm{ACH}$ & Valor $p$ \\
\hline \multirow{3}{*}{ Alérgica (\%) } & Menor (I - IIIa) & $9(3,4)$ & $5(1,0)$ & 0,093 \\
\hline & Maior (IIlb - V) & $0(0)$ & $1(0,2)$ & 1 \\
\hline & Subtotal & $9(3,4)$ & $6(1,2)$ & 0,049 \\
\hline \multirow{4}{*}{ Cardiovascular (\%) } & Menor (I - IIla) & $17(6,5)$ & $29(5,6)$ & 0,754 \\
\hline & Maior (IIIb - V) & $0(0)$ & $17(3,3)$ & 0,028 \\
\hline & Subtotal & $17(6,5)$ & $46(8,9)$ & 0,319 \\
\hline & Menor (I - IIla) & $8(3,1)$ & $9(1,8)$ & 0,617 \\
\hline \multirow[t]{3}{*}{ Cirúrgica (\%) } & Maior (IIIb - V) & $10(3,8)$ & $44(8,4)$ & 0,711 \\
\hline & Subtotal & $18(6,9)$ & $53(10,2)$ & 0,166 \\
\hline & Menor (I - IIIa) & $86(32,8)$ & $134(25,7)$ & 0,786 \\
\hline \multirow{3}{*}{ Endócrino-metabólica (\%) } & Maior (IIIb - V) & $1(0,4)$ & $0(0)$ & 0,207 \\
\hline & Subtotal & $87(33,2)$ & $134(25,7)$ & 0,085 \\
\hline & Menor (I - IIIa) & $5(1,9)$ & $13(2,5)$ & 0,336 \\
\hline \multirow[t]{3}{*}{ Gastrointestinal (\%) } & Maior (IIllb - V) & $0(0)$ & $1(0,2)$ & 1 \\
\hline & Subtotal & $5(1,9)$ & $14(2,7)$ & 0,627 \\
\hline & Menor (I - IIIa) & $21(8)$ & $32(6,1)$ & 1 \\
\hline \multirow[t]{3}{*}{ Infecciosa (\%) } & Maior (IIIb - V) & $32(12,2)$ & $82(15,8)$ & 0,013 \\
\hline & Subtotal & $53(20,2)$ & $114(21,9)$ & 0,66 \\
\hline & Menor (I - IIIa) & $8(3,1)$ & $25(4,8)$ & 0,067 \\
\hline \multirow[t]{3}{*}{ Miscelânea (\%) } & Maior (IIlb - V) & $1(0,4)$ & $5(1,0)$ & 1 \\
\hline & Subtotal & $9(3,5)$ & $30(5,8)$ & 0,217 \\
\hline & Menor (I - IIIa) & $0(0)$ & $0(0)$ & 1 \\
\hline \multirow[t]{3}{*}{ Neoplásica (\%) } & Maior (IIIb - V) & $0(0)$ & $0(0)$ & 1 \\
\hline & Subtotal & $0(0)$ & $0(0)$ & 1 \\
\hline & Menor (I - IIIa) & $3(1,1)$ & $2(0,4)$ & 0,391 \\
\hline \multirow[t]{3}{*}{ Neuropsiquiátrica (\%) } & Maior (IIIb - V) & $1(0,4)$ & $1(0,2)$ & 0,371 \\
\hline & Subtotal & $4(1,5)$ & $3(0,6)$ & 0,169 \\
\hline & Menor (I - IIIa) & $0(0)$ & $0(0)$ & 1 \\
\hline \multirow[t]{3}{*}{ PNF (\%) } & Maior (IIlb - V) & $0(0)$ & $5(1,0)$ & 0,587 \\
\hline & Subtotal & $0(0)$ & $5(1,0)$ & 0,175 \\
\hline & Menor (I - IIIa) & $40(15,3)$ & $32(6,1)$ & 0,004 \\
\hline \multirow[t]{3}{*}{ Rejeição (\%) } & Maior (IIlb - V) & $0(0)$ & $1(0,2)$ & 1 \\
\hline & Subtotal & $40(15,3)$ & $33(6,3)$ & $<0,001$ \\
\hline & Menor (I - IIla) & $2(0,8)$ & $3(0,6)$ & 1 \\
\hline \multirow[t]{3}{*}{ Renal (\%) } & Maior (IIIb - V) & $2(0,8)$ & $5(1,0)$ & 0,637 \\
\hline & Subtotal & $4(1,6)$ & $8(1,6)$ & 1 \\
\hline & Menor (I - IIIa) & $8(3,1)$ & $24(4,6)$ & 0,093 \\
\hline \multirow[t]{3}{*}{ Respiratória (\%) } & Maior (IIIb - V) & $7(2,7)$ & $36(6,9)$ & 0,539 \\
\hline & Subtotal & $15(5,8)$ & $60(11,5)$ & 0,014 \\
\hline & Menor (I - IIIa) & $1(0,4)$ & $6(1,1)$ & 0,252 \\
\hline \multirow[t]{2}{*}{ Sangramento (\%) } & Maior (IIlb - V) & $0(0)$ & $9(1,8)$ & 0,211 \\
\hline & Subtotal & $1(0,4)$ & $15(2,9)$ & 0,016 \\
\hline \multirow{2}{*}{ Qualquer complicação (\%) } & Minor (I - IIla) & $208(79,4)$ & $314(60,3)$ & \multirow{2}{*}{$<0,001$} \\
\hline & Major (IIIb - V) & $54(20,6)$ & $207(39,7)$ & \\
\hline \multicolumn{2}{|c|}{ Complicações totais por grupo $(\%)$} & $262(33,5)$ & $521(66,5)$ & \\
\hline \multicolumn{2}{|c|}{ Complicações totais por período (\%) } & \multicolumn{2}{|c|}{$783(30,8)$} & \\
\hline
\end{tabular}




\subsubsection{Complicações do pós-operatório tardio segundo tipo e gravidade dos grupos estudados de acordo com o volume de concentrado de hemácias transfundido no perioperatório}

\subsubsection{Complicações pós-operatórias até um ano após o transplante hepático segundo tipo e gravidade}

No período até 1 ano após o TH, houve 1407 complicações pósoperatórias, sendo $62,3 \%$ no grupo $\mathrm{ACH}$ e $37,7 \%$ no grupo $\mathrm{BCH}$. O grupo $\mathrm{ACH}$ apresentou maior porcentagem de complicações maiores $(30,7$ vs. $15,1 \%)$ e menor porcentagem de complicações menores (69,3 vs. 84,9\%), em comparação ao $\mathrm{BCH}$ (Tabela 10).

No grupo $\mathrm{ACH}$, as complicações cardiovasculares e infecciosas maiores e a miscelânea menor foram mais frequentes, enquanto, as complicações alérgicas e as rejeições foram menos frequentes, em comparação ao $\mathrm{BCH}$ (Tabela 10).

Não houve diferença significativa entre os grupos $\mathrm{ACH}$ e $\mathrm{BCH}$, em relação às complicações endócrino-metabólicas, cirúrgicas, gastrointestinais, neoplásicas, neuropsiquiátricas, PNF, renais, respiratórias ou sangramentos, durante o período até 1 ano após o TH (Tabela 10). 
Tabela 10. Classificação dos tipos e da gravidade das complicações pósoperatórias até 1 ano pós-transplante hepático segundo os grupos categorizados pelo volume transfusional de concentrado de hemácias perioperatório

\begin{tabular}{|c|c|c|c|c|}
\hline \multicolumn{5}{|c|}{ Complicações até 1 ano } \\
\hline \multirow[t]{2}{*}{ Tipo } & Grau & $\mathrm{BCH}$ & $\mathrm{ACH}$ & Valor $p$ \\
\hline & Menor (I - IIIa) & $25(4,7)$ & $16(1,8)$ & 0,009 \\
\hline \multirow[t]{3}{*}{ Alérgica (\%) } & Maior (IIIb - V) & $1(0,2)$ & $1(0,1)$ & 0,406 \\
\hline & Subtotal & $26(4,9)$ & $17(1,9)$ & 0,003 \\
\hline & Menor (I - IIIa) & $19(3,6)$ & $32(3,6)$ & 0,662 \\
\hline \multirow[t]{3}{*}{ Cardiovascular (\%) } & Maior (IIIb - V) & $0(0)$ & $18(2,0)$ & 0,017 \\
\hline & Subtotal & $19(3,6)$ & $50(5,8)$ & 0,098 \\
\hline & Menor (I - IIla) & $19(3,6)$ & $23(2,6)$ & 0,631 \\
\hline \multirow[t]{3}{*}{ Cirúrgica (\%) } & Maior (IIIb - V) & $12(2,3)$ & $51(5,8)$ & 0,509 \\
\hline & Subtotal & $31(5,9)$ & $74(8,4)$ & 0,092 \\
\hline & Menor (I - IIla) & $89(16,8)$ & $140(16,0)$ & 0,494 \\
\hline \multirow[t]{3}{*}{ Endócrino-metabólica (\%) } & Maior (IIIb - V) & $2(0,4)$ & $0(0)$ & 0,052 \\
\hline & Subtotal & $91(17,2)$ & $140(16,0)$ & 0,605 \\
\hline & Menor (I - IIla) & $15(2,8)$ & $30(3,4)$ & 0,353 \\
\hline \multirow[t]{3}{*}{ Gastrointestinal (\%) } & Maior (IIIb - V) & $1(0,2)$ & $4(0,5)$ & 1 \\
\hline & Subtotal & $16(3,0)$ & $34(3,9)$ & 0,488 \\
\hline & Menor (I - IIla) & $86(16,2)$ & $116(13,2)$ & 0,577 \\
\hline \multirow[t]{3}{*}{ Infecciosa (\%) } & Maior (IIIb - V) & $43(8,1)$ & $106(12,1)$ & 0,028 \\
\hline & Subtotal & $129(24,3)$ & $222(25,3)$ & 0,729 \\
\hline & Menor (I - IIla) & $30(5,7)$ & $48(5,5)$ & $<0,001$ \\
\hline \multirow[t]{3}{*}{ Miscelânea (\%) } & Maior (IIIb - V) & $3(0,6)$ & $7(0,8)$ & 0,702 \\
\hline & Subtotal & $33(6,3)$ & $55(6,3)$ & 1 \\
\hline & Menor (I - IIIa) & $4(0,8)$ & $9(1,0)$ & 0,576 \\
\hline \multirow[t]{3}{*}{ Neoplásica (\%) } & Maior (IIIb - V) & $4(0,8)$ & $3(0,3)$ & 0,058 \\
\hline & Subtotal & $8(1,6)$ & $12(1,4)$ & 1 \\
\hline & Menor (I - IIla) & $7(1,3)$ & $4(0,5)$ & 0,135 \\
\hline \multirow[t]{3}{*}{ Neuropsiquiátrica (\%) } & Maior (IIIb - V) & $1(0,2)$ & $1(0,1)$ & 0,406 \\
\hline & Subtotal & $8(1,5)$ & $5(0,6)$ & 0,134 \\
\hline & Menor (I - IIIa) & $0(0)$ & $0(0)$ & 1 \\
\hline \multirow[t]{3}{*}{ PNF (\%) } & Maior (IIIb - V) & $0(0)$ & $5(0,6)$ & 0,593 \\
\hline & Subtotal & $0(0)$ & $5(0,6)$ & 0,164 \\
\hline & Menor (I - IIla) & $73(13,8)$ & $66(7,5)$ & 0,003 \\
\hline \multirow[t]{3}{*}{ Rejeição (\%) } & Maior (IIIb - V) & $1(0,2)$ & $4(0,5)$ & 1 \\
\hline & Subtotal & $74(14,0)$ & $70(8,0)$ & $<0,001$ \\
\hline & Menor (I - IIla) & $3(0,6)$ & $3(0,3)$ & 0,693 \\
\hline \multirow[t]{3}{*}{ Renal (\%) } & Maior $(I I I b-V)$ & $2(0,4)$ & $7(0,8)$ & 1 \\
\hline & Subtotal & $5(1,0)$ & $10(1,1)$ & 0,796 \\
\hline & Menor (I - IIla) & $75(14,2)$ & $110(12,6)$ & 0,934 \\
\hline \multirow[t]{3}{*}{ Respiratória (\%) } & Maior (IIIb - V) & $9(1,7)$ & $53(6,0)$ & 0,096 \\
\hline & Subtotal & $84(15,9)$ & $163(18,6)$ & 0,217 \\
\hline & Menor (I - IIla) & $5(0,9)$ & $11(1,3)$ & 0,61 \\
\hline \multirow[t]{2}{*}{ Sangramento (\%) } & Maior (IIIb - V) & $1(0,2)$ & $9(1,0)$ & 0,465 \\
\hline & Subtotal & $6(1,1)$ & $20(2,3)$ & 0,178 \\
\hline \multirow{2}{*}{ Qualquer complicação (\%) } & Minor (I - IIla) & $450(84,9)$ & $608(69,3)$ & \multirow{2}{*}{$<0,001$} \\
\hline & Major $(\mathrm{IIIb}-\mathrm{V})$ & $80(15,1)$ & $269(30,7)$ & \\
\hline \multicolumn{2}{|c|}{ Complicações totais por grupo (\%) } & $530(37,7)$ & $877(62,3)$ & \\
\hline \multicolumn{2}{|c|}{ Complicações totais por período (\%) } & \multicolumn{2}{|c|}{$1407(55,3)$} & \\
\hline \multicolumn{5}{|c|}{$\begin{array}{l}\mathrm{ACH}, \text { grupo de alto volume transfusional de concentrado de hemácias perioperatório; } \mathrm{BCH} \text {, grupo de baixo volume } \\
\text { transfusional de concentrado de hemácias perioperatório; PNF, "primary non-function" ou não funcionamento primári } \\
\text { do enxerto }\end{array}$} \\
\hline
\end{tabular}




\subsubsection{Complicações pós-operatórias até cinco anos após o transplante hepático segundo tipo e gravidade}

No período até 5 anos após o TH, houve 2330 complicações pósoperatórias, sendo $60,3 \%$ no grupo $\mathrm{ACH}$ e $39,7 \%$ no grupo $\mathrm{BCH}$. O grupo $\mathrm{ACH}$ apresentou maior porcentagem de complicações maiores (25 vs.13,6\%) e menor porcentagem de complicações menores (75 vs. 86,4\%), em comparação ao $\mathrm{BCH}$ (Tabela 11).

No grupo $\mathrm{ACH}$, as complicações cardiovasculares, infecciosas e respiratórias maiores foram mais frequentes, enquanto, as rejeições foram menos frequentes, em comparação ao BCH (Tabela 11).

Não houve diferença significativa entre os grupos $\mathrm{ACH}$ e $\mathrm{BCH}$, em relação às complicações alérgicas, cirúrgicas, endócrino-metabólicas, gastrointestinais, miscelânea, neoplásicas, neuropsiquiátricas, PNF, renais, ou sangramentos, durante o período até 5 anos após o TH (Tabela 11). 
Tabela 11. Classificação dos tipos e da gravidade das complicações pósoperatórias até 5 anos pós-transplante hepático segundo os grupos categorizados pelo volume transfusional de concentrado de hemácias perioperatório

\begin{tabular}{|c|c|c|c|c|}
\hline \multicolumn{5}{|c|}{ Complicações até 5 anos } \\
\hline Tipo & Grau & $\mathrm{BCH}$ & $\mathrm{ACH}$ & Valor $p$ \\
\hline \multirow{3}{*}{ Alérgica (\%) } & Menor (I - IIIa) & $52(5,6)$ & $58(4,1)$ & 0,322 \\
\hline & Maior (IIIb - V) & $7(0,8)$ & $10(0,7)$ & 0,168 \\
\hline & Subtotal & $59(6,4)$ & $68(4,8)$ & 0,134 \\
\hline \multirow{3}{*}{ Cardiovascular (\%) } & Menor (I - IIla) & $24(2,6)$ & $39(2,8)$ & 0,518 \\
\hline & Maior (IIIb - V) & $0(0)$ & $18(1,3)$ & 0,005 \\
\hline & Subtotal & $24(2,6)$ & $57(4,1)$ & 0,075 \\
\hline \multirow{3}{*}{ Cirúrgica (\%) } & Menor (I - IIIa) & $33(3,6)$ & $49(3,5)$ & 0,732 \\
\hline & Maior (IIIb - V) & $20(2,2)$ & $56(4,0)$ & 1 \\
\hline & Subtotal & $53(5,8)$ & $105(7,5)$ & 0,118 \\
\hline \multirow{3}{*}{ Endócrino-metabólica (\%) } & Menor (I - IIla) & $96(10,4)$ & $146(10,4)$ & 0,329 \\
\hline & Maior (IIlb - V) & $2(0,2)$ & $0(0)$ & 0,069 \\
\hline & Subtotal & $98(10,6)$ & $146(10,4)$ & 0,942 \\
\hline \multirow{3}{*}{ Gastrointestinal (\%) } & Menor (I - IIIa) & $30(3,3)$ & $44(3,1)$ & 0,721 \\
\hline & Maior (IIIb - V) & $3(0,3)$ & $6(0,5)$ & 0,704 \\
\hline & Subtotal & $33(3,6)$ & $50(3,6)$ & 1 \\
\hline \multirow{3}{*}{ Infecciosa (\%) } & Menor (I - IIIa) & $188(20,3)$ & $235(16,7)$ & 0,434 \\
\hline & Maior (IIIb - V) & $56(6,0)$ & $132(9,4)$ & 0,020 \\
\hline & Subtotal & $244(26,3)$ & $367(26,1)$ & 0,948 \\
\hline \multirow{3}{*}{ Miscelânea (\%) } & Menor (I - IIIa) & $66(7,2)$ & $71(5,1)$ & 0,179 \\
\hline & Maior (IIlb - V) & $4(0,4)$ & $14(1,0)$ & 0,792 \\
\hline & Subtotal & $70(7,6)$ & $85(6,1)$ & 0,180 \\
\hline \multirow{3}{*}{ Neoplásica (\%) } & Menor (I - IIla) & $13(1,4)$ & $32(2,3)$ & 0,067 \\
\hline & Maior (IIIb - V) & $9(1,0)$ & $13(0,9)$ & 0,137 \\
\hline & Subtotal & $22(2,4)$ & $45(3,2)$ & 0,296 \\
\hline \multirow{3}{*}{ Neuropsiquiátrica (\%) } & Menor (I - IIIa) & $17(1,8)$ & $14(1,0)$ & 0,200 \\
\hline & Maior (IIIb - V) & $1(0,1)$ & $1(0,1)$ & 0,459 \\
\hline & Subtotal & $18(1,9)$ & $15(1,1)$ & 0,116 \\
\hline \multirow{3}{*}{ PNF (\%) } & Menor (I - IIIa) & $0(0)$ & $0(0)$ & 1 \\
\hline & Maior (IIIb - V) & $0(0)$ & $5(0,4)$ & 0,332 \\
\hline & Subtotal & $0(0)$ & $5(0,4)$ & 0,164 \\
\hline \multirow{3}{*}{ Rejeição (\%) } & Menor (I - IIla) & $111(12,0)$ & $102(7,3)$ & 0,106 \\
\hline & Maior (IIIb - V) & $4(0,4)$ & $8(0,6)$ & 0,526 \\
\hline & Subtotal & $115(12,4)$ & $110(7,9)$ & $<0,001$ \\
\hline \multirow{3}{*}{ Renal (\%) } & Menor (I - IIla) & $4(0,4)$ & $3(0,2)$ & 0,469 \\
\hline & Maior (IIlb - V) & $5(0,5)$ & $9(0,7)$ & 0,535 \\
\hline & Subtotal & $9(0,9)$ & $12(0,9)$ & 0,945 \\
\hline \multirow{3}{*}{ Respiratória (\%) } & Menor (I - IIla) & $161(17,4)$ & $247(17,6)$ & 0,141 \\
\hline & Maior (IIIb - V) & $14(1,5)$ & $70(5,0)$ & 0,029 \\
\hline & Subtotal & $175(18,9)$ & $317(22,6)$ & 0,038 \\
\hline \multirow{3}{*}{ Sangramento (\%) } & Menor (I - IIla) & $5(0,5)$ & $13(0,9)$ & 0,237 \\
\hline & Maior (IIIb - V) & $1(0,1)$ & $9(0,7)$ & 0,467 \\
\hline & Subtotal & $6(0,6)$ & $22(1,6)$ & 0,052 \\
\hline \multirow{2}{*}{ Qualquer complicação (\%) } & Minor (I - IIla) & $800(86,4)$ & $1053(75,0)$ & \multirow{2}{*}{$<0,001$} \\
\hline & Major (IIIb - V) & $126(13,6)$ & $351(25,0)$ & \\
\hline \multicolumn{2}{|c|}{ Complicações totais por grupo (\%) } & $926(39,7)$ & $1404(60,3)$ & \\
\hline \multicolumn{2}{|c|}{ Complicações totais por período (\%) } & \multicolumn{2}{|c|}{$2330(91,5)$} & \\
\hline
\end{tabular}




\subsubsection{Complicações pós-operatórias até dez anos após o transplante hepático segundo tipo e gravidade}

No período até 10 anos após o TH, houve 2546 complicações pósoperatórias, sendo $60 \%$ no grupo $\mathrm{ACH}$ e $40 \%$ no grupo $\mathrm{BCH}$. O grupo $\mathrm{ACH}$ em comparação ao $\mathrm{BCH}$ apresentou maior porcentagem de complicações maiores (23,3 vs. $13,4 \%)$ e menor porcentagem de complicações menores (76,7 vs. $86,6 \%)$ (Tabela 12).

No grupo $\mathrm{ACH}$, as complicações cardiovasculares, infecciosas, respiratórias maiores e neoplásicas menores foram mais frequentes, enquanto, as rejeições foram menos frequentes, em comparação ao $\mathrm{BCH}$ (Tabela 12).

Não houve diferença significativa entre os grupos $\mathrm{ACH}$ e $\mathrm{BCH}$, em relação às complicações alérgicas, cirúrgicas, endócrino-metabólicas, gastrointestinais, neuropsiquiátricas, PNF, renais, miscelânea ou sangramentos, durante o período até 10 anos após o TH (Tabela 12). 
Tabela 12. Classificação dos tipos e da gravidade das complicações pósoperatórias até 10 anos pós-transplante hepático segundo os grupos categorizados pelo volume transfusional de concentrado de hemácias perioperatório

\begin{tabular}{|c|c|c|c|c|}
\hline \multicolumn{5}{|c|}{ Complicações até 10 anos } \\
\hline \multirow[t]{2}{*}{ Tipo } & Grau & $\mathrm{BCH}$ & $\mathrm{ACH}$ & Valor $p$ \\
\hline & Menor (I - IIla) & $59(5,8)$ & $71(4,6)$ & 0,583 \\
\hline \multirow[t]{3}{*}{ Alérgica (\%) } & Maior (IIIb - V) & $8(0,8)$ & $10(0,7)$ & 0,114 \\
\hline & Subtotal & $67(6,6)$ & $81(5,3)$ & 0,209 \\
\hline & Menor (I - IIIa) & $25(2,5)$ & $42(2,7)$ & 0,381 \\
\hline \multirow[t]{3}{*}{ Cardiovascular (\%) } & Maior (IIIb - V) & $0(0)$ & $18(1,2)$ & 0,005 \\
\hline & Subtotal & $25(2,5)$ & $60(3,9)$ & 0,282 \\
\hline & Menor (I - IIIa) & $43(4,2)$ & $66(4,3)$ & 0,487 \\
\hline \multirow[t]{3}{*}{ Cirúrgica (\%) } & Maior (IIllb - V) & $20(2,0)$ & $58(3,8)$ & 0,682 \\
\hline & Subtotal & $63(6,2)$ & $124(8,1)$ & 0,079 \\
\hline & Menor (I - IIIa) & $102(10,0)$ & $151(9,9)$ & 0,416 \\
\hline \multirow[t]{3}{*}{ Endócrino-metabólica (\%) } & Maior (IIIb - V) & $2(0,2)$ & $0(0)$ & 0,077 \\
\hline & Subtotal & $104(10,2)$ & $151(9,9)$ & 0,846 \\
\hline & Menor (I - IIla) & $33(3,2)$ & $49(3,2)$ & 0,650 \\
\hline \multirow[t]{3}{*}{ Gastrointestinal (\%) } & Maior (IIIb - V) & $3(0,3)$ & $6(0,4)$ & 0,713 \\
\hline & Subtotal & $36(3,5)$ & $55(3,6)$ & 1 \\
\hline & Menor (I - IIla) & $207(20,3)$ & $257(16,8)$ & 0,394 \\
\hline \multirow[t]{3}{*}{ Infecciosa (\%) } & Maior (IIIb - V) & $60(5,9)$ & $133(8,7)$ & 0,022 \\
\hline & Subtotal & $267(26,2)$ & $390(25,5)$ & 0,743 \\
\hline & Menor (I - IIIa) & $73(7,2)$ & $74(4,8)$ & 0,100 \\
\hline \multirow[t]{3}{*}{ Miscelânea (\%) } & Maior (IIIb - V) & $5(0,5)$ & $14(0,9)$ & 1 \\
\hline & Subtotal & $78(7,7)$ & $88(5,8)$ & 0,070 \\
\hline & Menor (I - IIIa) & $13(1,3)$ & $35(2,3)$ & 0,027 \\
\hline \multirow[t]{3}{*}{ Neoplásica (\%) } & Maior (IIIb - V) & $11(1,1)$ & $14(0,9)$ & 0,070 \\
\hline & Subtotal & $24(2,4)$ & $49(3,2)$ & 0,253 \\
\hline & Menor (I - IIIa) & $24(2,4)$ & $23(1,5)$ & 0,297 \\
\hline \multirow[t]{3}{*}{ Neuropsiquiátrica (\%) } & Maior (IIIb - V) & $2(0,2)$ & $1(0,1)$ & 0,188 \\
\hline & Subtotal & $26(2,6)$ & $24(1,6)$ & 0,109 \\
\hline & Menor (I - IIIa) & $0(0)$ & $0(0)$ & 1 \\
\hline \multirow[t]{3}{*}{ PNF (\%) } & Maior (IIIb - V) & $0(0)$ & $5(0,3)$ & 0,329 \\
\hline & Subtotal & $0(0)$ & $5(0,3)$ & 0,164 \\
\hline & Menor (I - IIla) & $117(11,5)$ & $125(8,2)$ & 0,030 \\
\hline \multirow[t]{3}{*}{ Rejeição (\%) } & Maior (IIIb - V) & $5(0,5)$ & $8(0,5)$ & 0,363 \\
\hline & Subtotal & $122(12,0)$ & $133(8,7)$ & $<0,001$ \\
\hline & Menor (I - IIla) & $4(0,4)$ & $4(0,3)$ & 0,731 \\
\hline \multirow[t]{3}{*}{ Renal (\%) } & Maior (IIIb - V) & $5(0,5)$ & $9(0,6)$ & 0,547 \\
\hline & Subtotal & $9(0,9)$ & $13(0,9)$ & 1 \\
\hline & Menor (I - IIla) & $177(17,4)$ & $261(17,1)$ & 0,106 \\
\hline \multirow[t]{3}{*}{ Respiratória (\%) } & Maior (IIIb - V) & $15(1,5)$ & $71(4,7)$ & 0,017 \\
\hline & Subtotal & $192(18,9)$ & $332(21,8)$ & 0,041 \\
\hline & Menor (I - IIla) & $5(0,5)$ & $13(0,9)$ & 0,236 \\
\hline \multirow[t]{2}{*}{ Sangramento (\%) } & Maior (IIllb - V) & $1(0,1)$ & $9(0,6)$ & 0,297 \\
\hline & Subtotal & $6(0,6)$ & $22(1,4)$ & 0,068 \\
\hline \multirow{2}{*}{ Qualquer complicação (\%) } & Minor (I - IIIa) & $882(86,6)$ & $1171(76,7)$ & \multirow{2}{*}{$<0,001$} \\
\hline & Major (IIIb - V) & $137(13,4)$ & $356(23,3)$ & \\
\hline \multicolumn{2}{|c|}{ Complicações totais por grupo (\%) } & $1019(40,0)$ & $1527(60,0)$ & \\
\hline \multicolumn{2}{|c|}{ Complicações totais por período (\%) } & \multicolumn{2}{|c|}{$2546(100)$} & \\
\hline \multicolumn{5}{|c|}{$\begin{array}{l}\text { ACH, grupo de alto volume transfusional de concentrado de hemácias perioperatório; } \mathrm{BCH} \text {, grupo de baixo } \\
\text { volume transfusional de concentrado de hemácias perioperatório; PNF, "primary non-function" ou não } \\
\text { funcionamento primário do enxerto }\end{array}$} \\
\hline
\end{tabular}




\subsubsection{Análise gráfica das principais complicações pós-operatórias por períodos}

As complicações alérgicas foram menos frequentes no grupo $\mathrm{ACH}$, em comparação ao grupo $\mathrm{BCH}$, nos períodos de internação e até 1 ano pós-TH. Neste último período, relacionado às complicações menores (Figura 3).

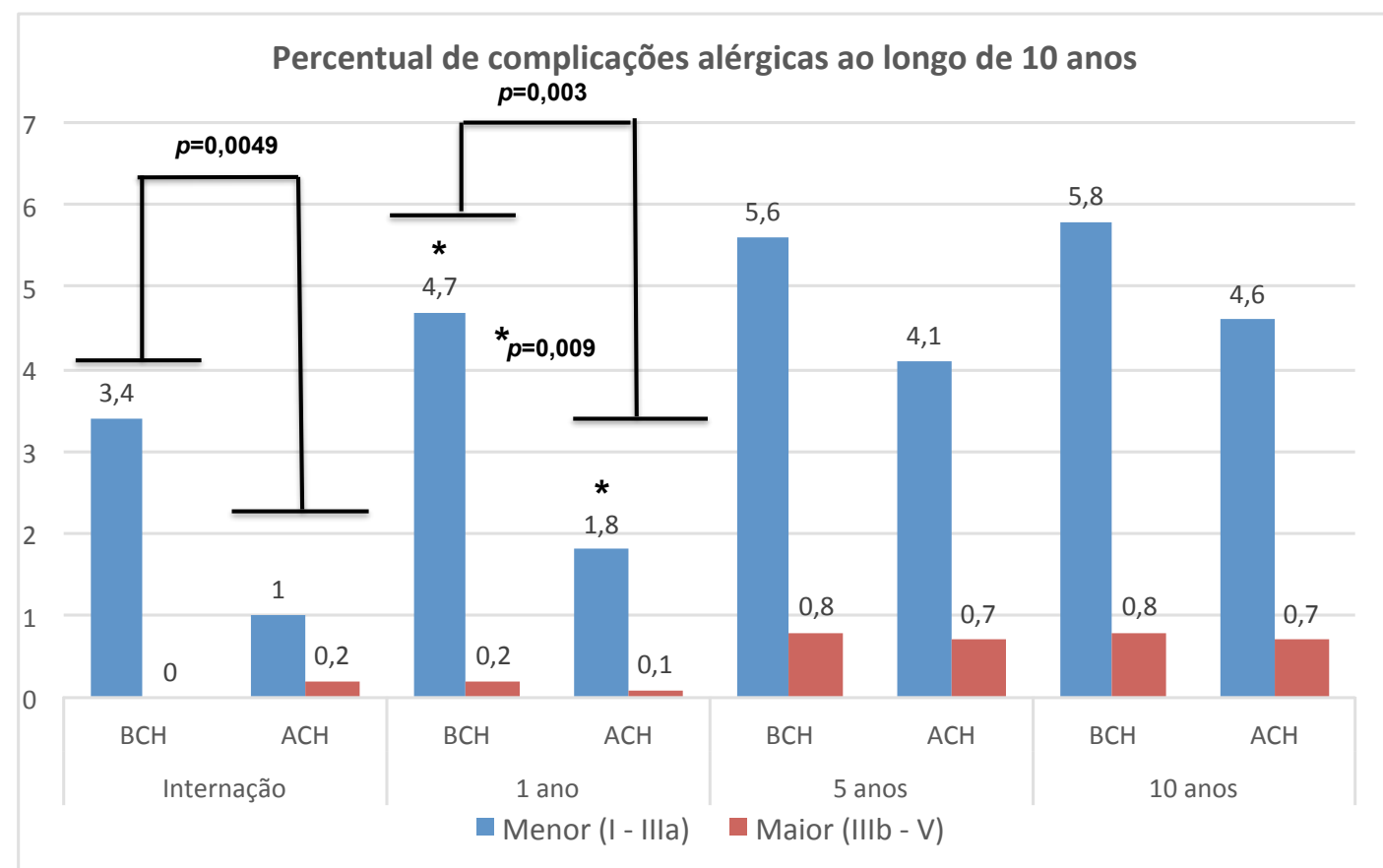

$\boldsymbol{p}=\mathbf{0 , 0 4 9}$ significância estatística entre complicações alérgicas em geral, na internação $\boldsymbol{p}=\mathbf{0 , 0 0 3}$ significância estatística entre complicações alérgicas em geral, no período de 1 ano pós-transplante hepático

* $p=0,009$ significância estatística entre complicações alérgicas menores, no período de 1 ano pós-transplante hepático

Figura 3. Complicações alérgicas maiores e menores nos grupos categorizados por volume de concentrado de hemácias transfundido no perioperatório, nos quatro períodos estudados, ao longo de dez anos de pós-operatório do transplante hepático 
As complicações cardiovasculares maiores foram mais frequentes no grupo $\mathrm{ACH}$, em comparação ao $\mathrm{BCH}$, nos períodos de internação, 1 ano, 5 anos e 10 anos pós-TH (Figura 4).

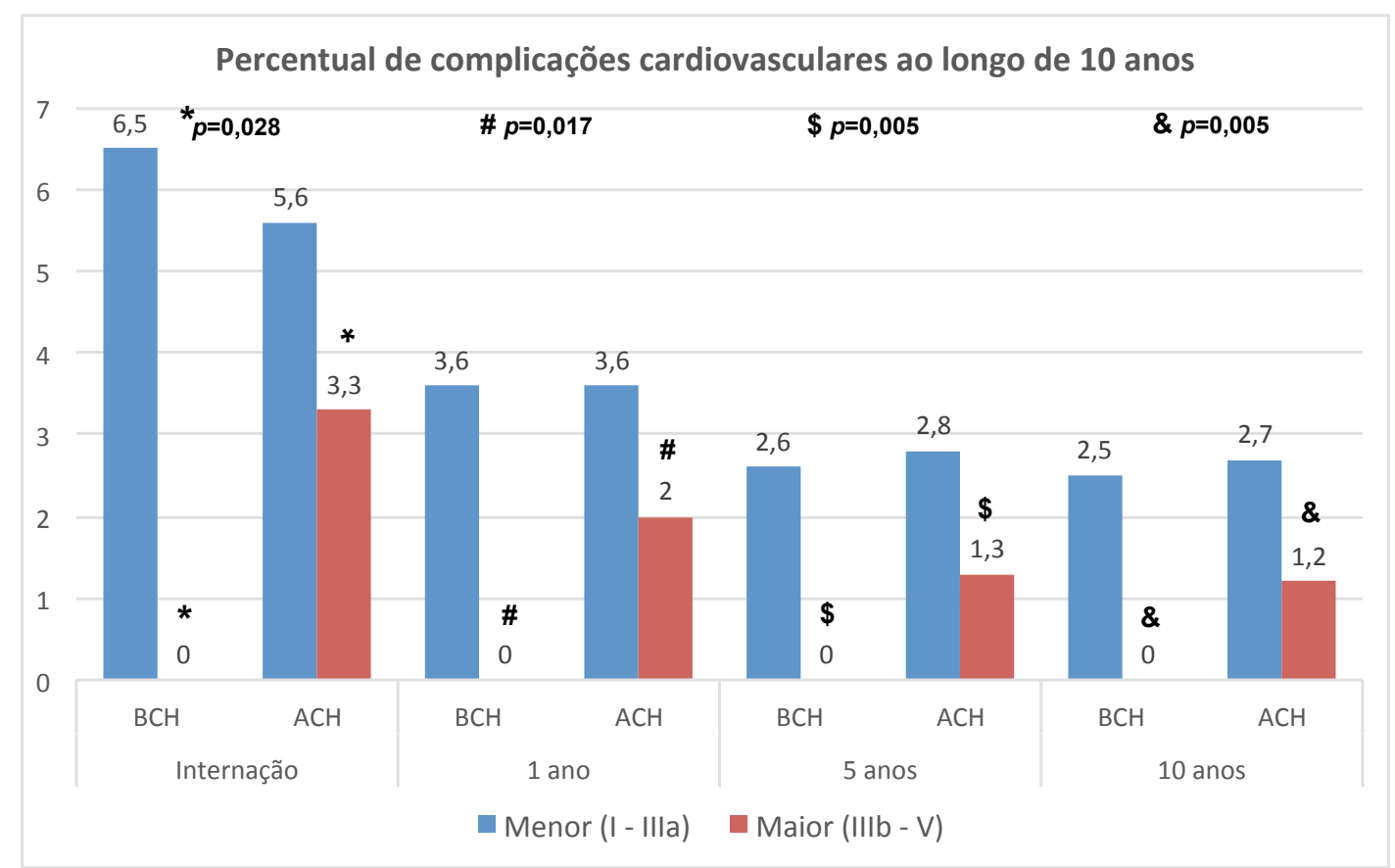

${ }^{*} \boldsymbol{p}=\mathbf{0 , 0 2 8}$ significância estatística entre complicações cardiovasculares maiores, no período de internação

\# $p=0,017$ significância estatística entre complicações cardiovasculares maiores, no período de 1 ano pós-transplante hepático

$\$ p=0,005$ significância estatística entre complicações cardiovasculares maiores, no período de 5 anos pós-transplante hepático

$\& p=0,005$ significância estatística entre complicações cardiovasculares maiores, no período de 10 anos pós-transplante hepático

Figura 4. Complicações cardiovasculares maiores e menores nos grupos categorizados por volume de concentrado de hemácias transfundido no perioperatório, nos quatro períodos estudados, ao longo de dez anos de pós-operatório do transplante hepático 
As complicações infecciosas maiores foram mais frequentes no grupo $\mathrm{ACH}$, em comparação ao $\mathrm{BCH}$, nos períodos de internação, 1 ano, 5 anos e 10 anos pós-TH (Figura 5).

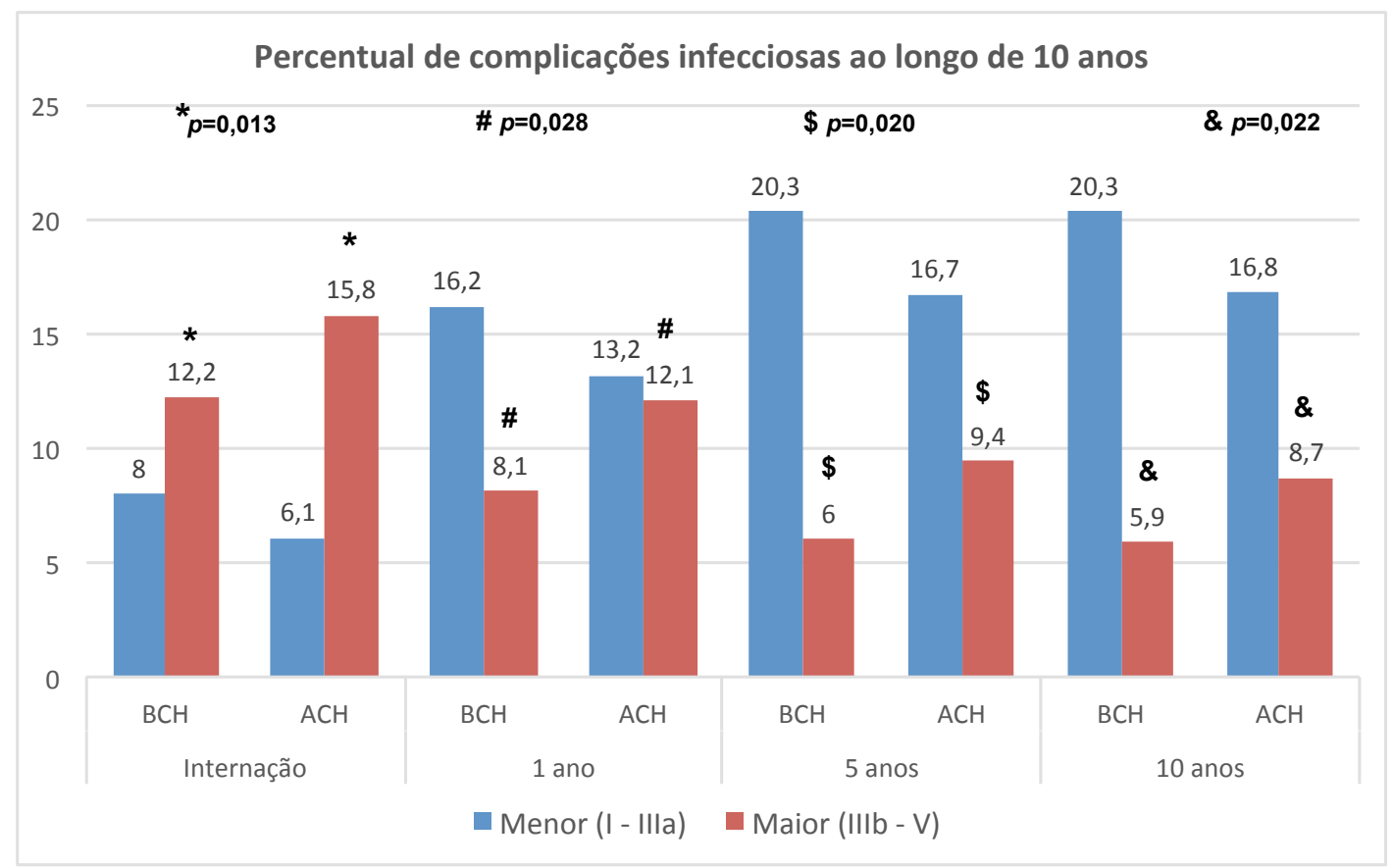

* $p=0,013$ significância estatística entre complicações infecciosas maiores, no período de internação

\# $\boldsymbol{p = 0 , 0 2 8}$ significância estatística entre complicações infecciosas maiores, no período de 1 ano pós-transplante hepático

$\$ p=0,020$ significância estatística entre complicações infecciosas maiores, no período de 5 anos pós-transplante hepático

\& $\boldsymbol{p}=\mathbf{0 , 0 2 2}$ significância estatística entre complicações infecciosas maiores, no período de 10 anos pós-transplante hepático

Figura 5. Complicações infecciosas maiores e menores nos grupos categorizados por volume de concentrado de hemácias transfundido no perioperatório, nos quatro períodos estudados, ao longo de dez anos de pós-operatório do transplante hepático 
As complicações neoplásicas menores foram mais frequentes no grupo $\mathrm{ACH}$, em comparação ao $\mathrm{BCH}$, no período até 10 anos pós-TH (Figura 6).

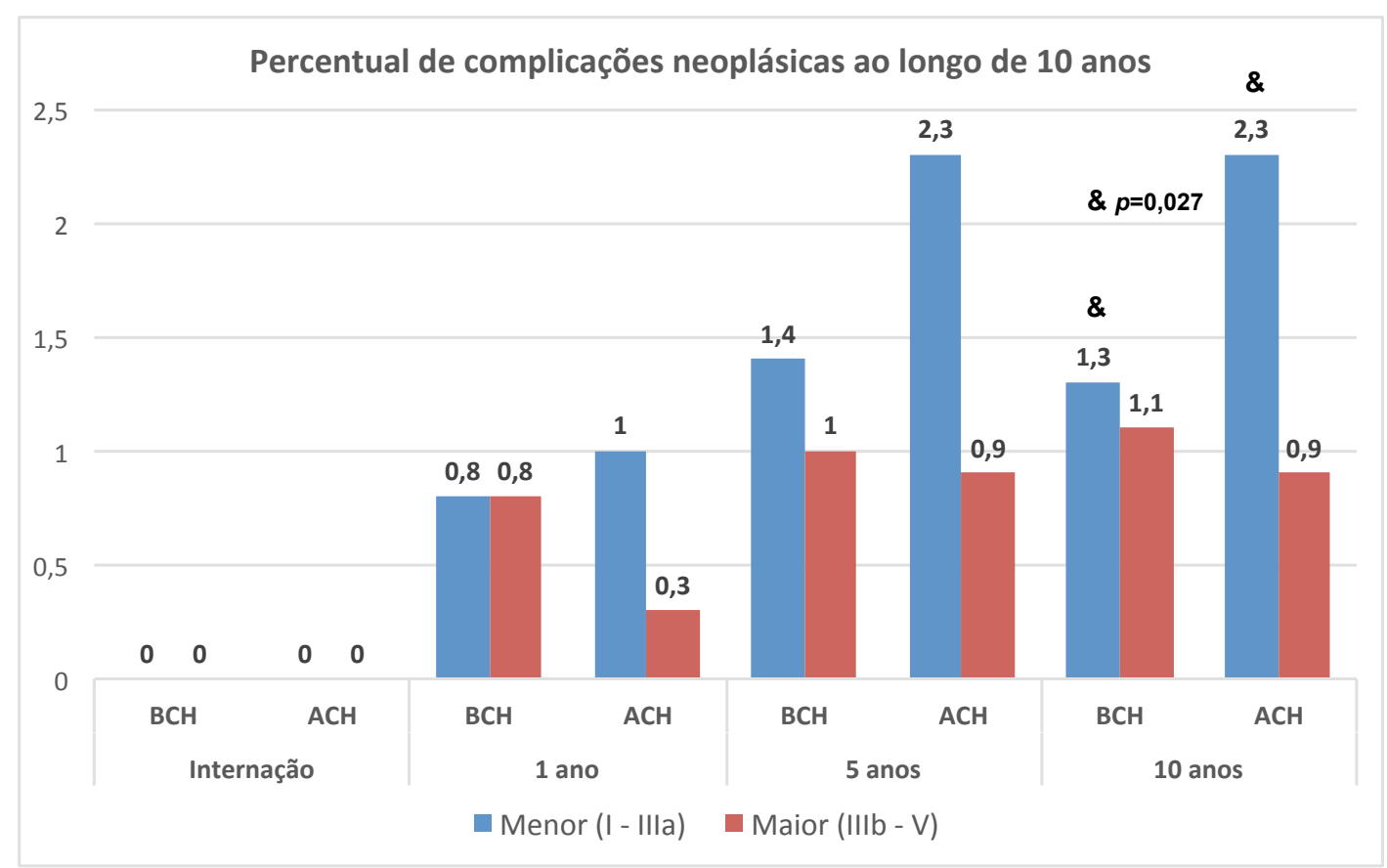

$\& p=0,027$ significância estatística entre complicações neoplásicas menores, no período até 10 anos pós-transplante hepático

Figura 6. Complicações neoplásicas maiores e menores nos grupos categorizados por volume de concentrado de hemácias transfundido no perioperatório, nos quatro períodos estudados, ao longo de dez anos de pós-operatório do transplante hepático 
As complicações referentes à rejeição foram menos frequentes no grupo $\mathrm{ACH}$, em comparação ao $\mathrm{BCH}$, nos quatro períodos, sendo que, nos períodos de internação, até 1 ano e até 10 anos pós-TH, relacionados às complicações menores (Figura 7).

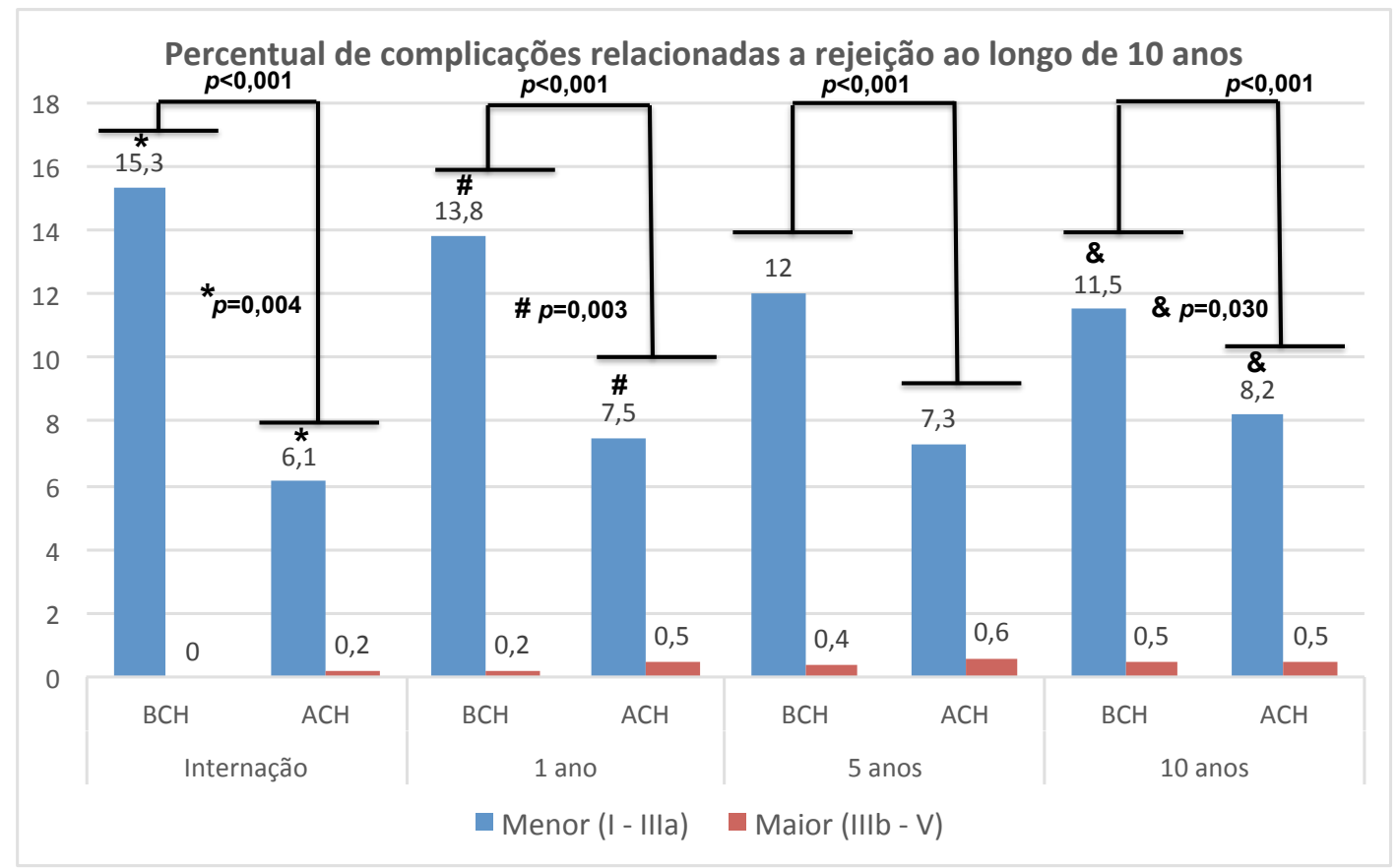

$p<0,001$ significância estatística entre rejeições em geral, durante os quatro períodos analisados; internação, 1 ano, 5 anos e 10 anos pós-transplante hepático

* $p=0,004$ significância estatística entre complicações relacionadas a rejeições menores, no período de internação

\# $\boldsymbol{p}=\mathbf{0 , 0 0 3}$ significância estatística entre complicações relacionadas a rejeições menores, no período de 1 ano pós-transplante hepático

\& $p=0,030$ significância estatística entre complicações relacionadas a rejeições menores, no período de 10 anos pós-transplante hepático

Figura 7. Complicações relacionadas à rejeição maiores e menores nos grupos categorizados por volume de concentrado de hemácias transfundido no perioperatório, nos quatro períodos estudados, ao longo de dez anos de pós-operatório do transplante hepático 
As complicações respiratórias foram mais frequentes no grupo $\mathrm{ACH}$, em comparação ao $\mathrm{BCH}$, na internação, até 5 anos e até 10 anos pós-TH. Nestes dois últimos períodos, relacionados às complicações maiores (Figura 8).

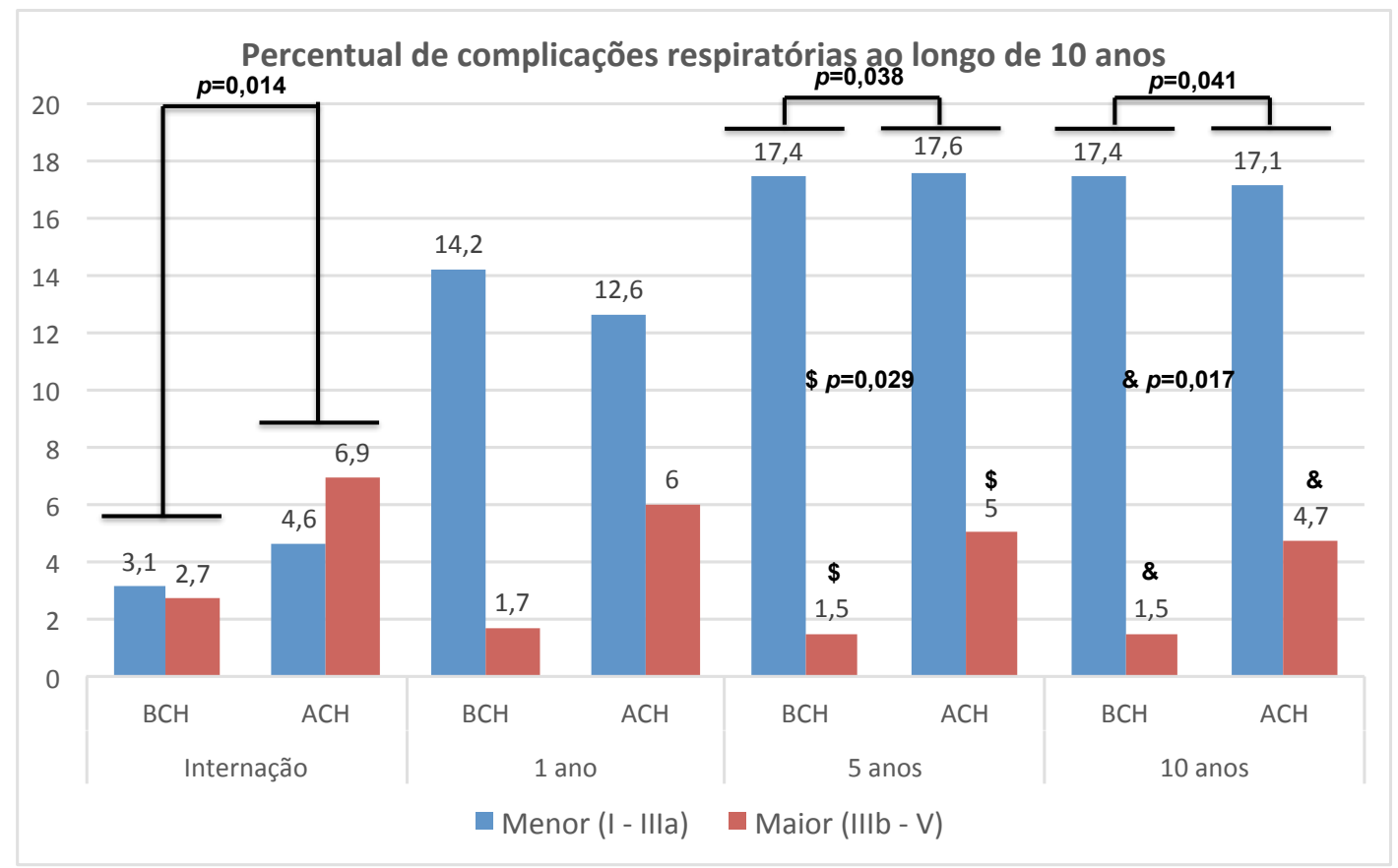

$p=0,014$ significância estatística entre complicações respiratórias em geral, na internação $p=0,038$ significância estatística entre complicações respiratórias em geral, no período de 5 anos pós-transplante hepático

$\$ p=0,029$ signifância estatística entre complicações respiratórias maiores, no período de 5 anos pós-transplante hepático

$\boldsymbol{p}=\mathbf{0 , 0 4 1}$ significância estatística entre complicações respiratórias em geral, no período de 10 anos pós-transplante hepático

\& $p=0,017$ significância estatística entre complicações respiratórias maiores, no período de 10 anos pós-transplante hepático

Figura 8. Complicações respiratórias maiores e menores nos grupos categorizados por volume de concentrado de hemácias transfundido no perioperatório, nos quatro períodos estudados, ao longo de dez anos de pós-operatório do transplante hepático 
As complicações referentes a sangramento foram mais frequentes no grupo $\mathrm{ACH}$, em comparação ao $\mathrm{BCH}$, no período de internação pós-TH (Figura 9)

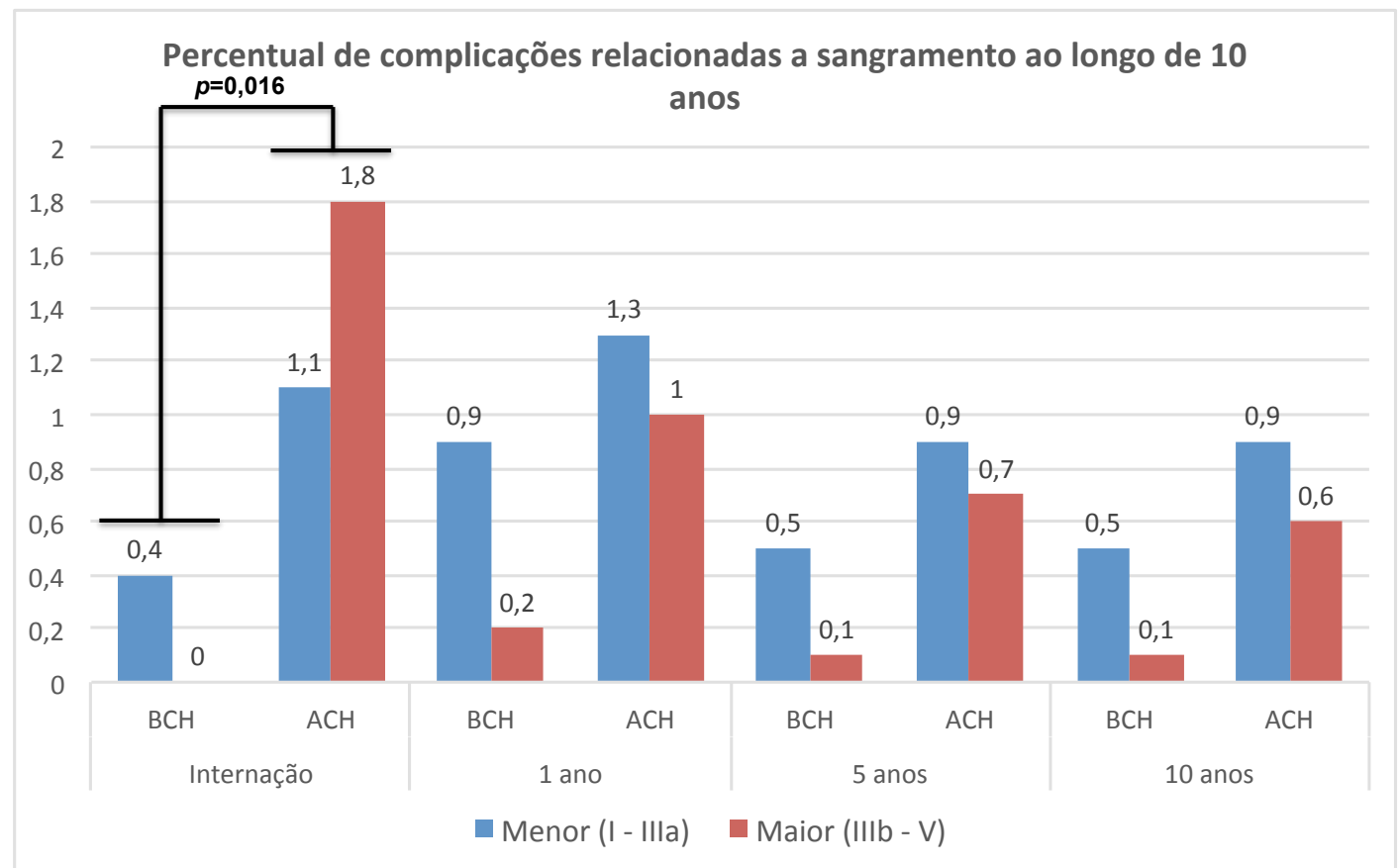

$\boldsymbol{p}=\mathbf{0 , 0 1 6}$ significância estatística entre complicações relacionadas a sangramentos em geral, durante o período de internação

Figura 9. Complicações relacionadas a sangramento maiores e menores nos grupos categorizados por volume de concentrado de hemácias transfundido no perioperatório, nos quatro períodos estudados, ao longo de dez anos de pós-operatório do transplante hepático

\subsection{Complicações imunológicas segundo grupos de maior e menor volume de concentrado de hemácias transfundido no perioperatório}

Nos períodos de internação até 10 anos de pós-operatório, o grupo $\mathrm{ACH}$ apresentou mais complicações infecciosas maiores e neoplásicas menores e menos complicações alérgicas e relacionadas às rejeições, em comparação ao $\mathrm{BCH}$ (Tabela 13). 
Tabela 13. Classificação dos tipos e da gravidade das complicações pós-operatórias imunológicas segundo os grupos categorizados pelo volume transfusional perioperatório de concentrado de hemácias indexado pelo peso ao longo dos quatro períodos analisados

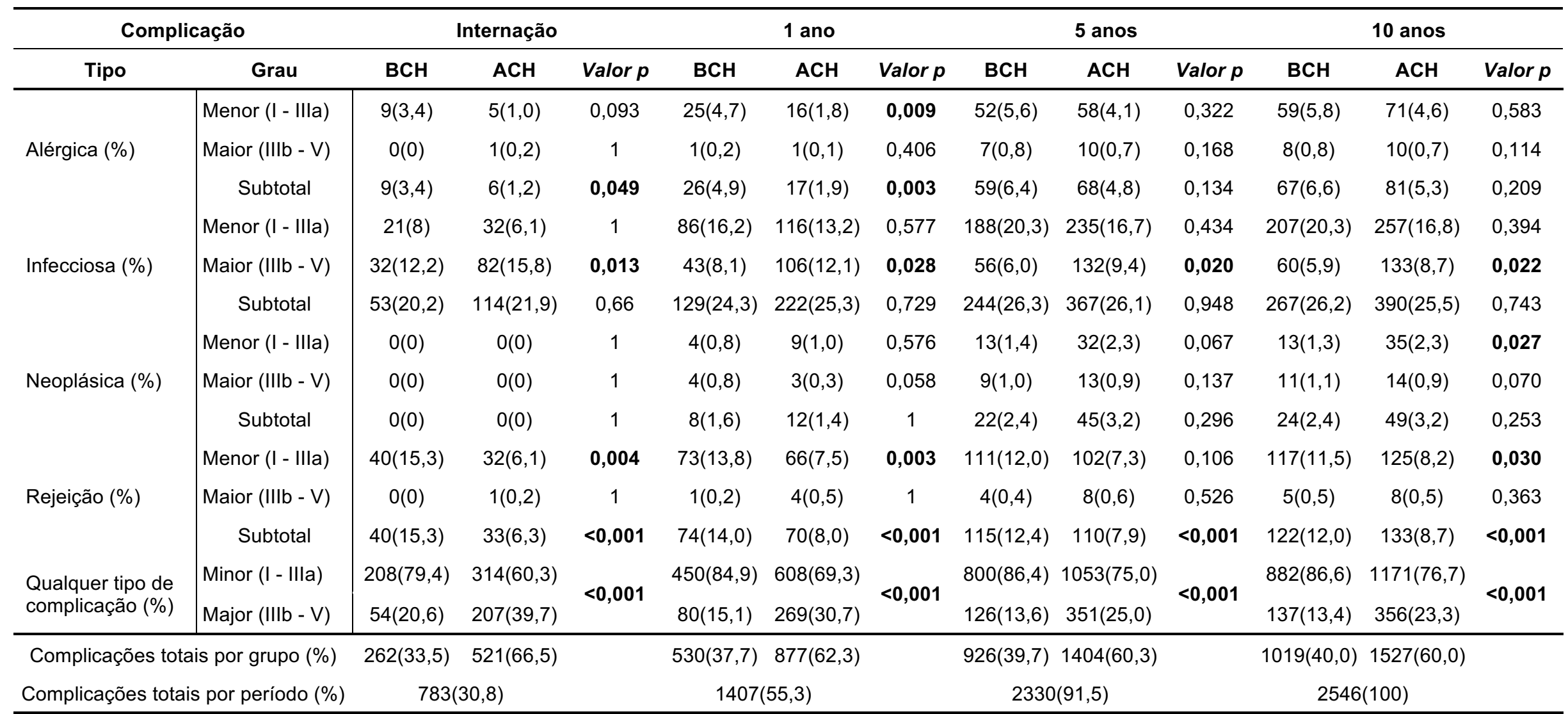

$\mathrm{BCH}$, grupo de baixo volume transfusional de concentrado de hemácias perioperatório; $\mathrm{ACH}$, grupo de alto volume transfusional de concentrado de hemácias perioperatório; PNF, "primary nonfunction" ou não funcionamento primário do enxerto 


\subsection{Complicações pós-operatórias relacionadas ao enxerto e mortalidade de dez anos após o transplante hepático}

Ao longo de dez anos de acompanhamento da amostra total, a incidência de fístula biliar (FB) foi de $6,2 \%$, de estenose biliar (EB) foi de $12,1 \%$, de trombose de artéria hepática (TAH) foi de $4,6 \%$, de trombose de veia porta (TVPo) foi de $12,9 \%$ e de retransplantes foi de $3,8 \%$, sem diferença entre os grupos ACH e BCH (Tabela 14).

Os pacientes do grupo ACH tiveram incidência de reoperações $(36,5$ vs. $15,5 \%)$ e taxa de mortalidade em dez anos ( 25,5 vs. $7,8 \%)$ significativamente maiores, em comparação ao grupo $\mathrm{BCH}$ (Tabela 14).

Tabela 14. Dados de evolução pós-operatória de 2001 a 2011, segundo complicações relacionadas ao enxerto e mortalidade em 10 anos

\begin{tabular}{lccc}
\hline \multicolumn{1}{c}{ Complicações pós-operatórias } & $\mathbf{B C H}$ & $\mathbf{A C H}$ & Valor $\boldsymbol{p}$ \\
& $\mathbf{n = 1 0 3}$ & $\mathbf{n = 1 3 7}$ & \\
\hline Fístula biliar & $4(3,9 \%)$ & $11(8,0 \%)$ & 0,282 \\
Estenose biliar & $15(14,6 \%)$ & $14(10,2 \%)$ & 0,241 \\
Trombose de Artéria Hepática & $2(1,9 \%)$ & $9(6,6 \%)$ & 0,122 \\
Trombose de Veia Porta & $9(8,6 \%)$ & $22(16,1 \%)$ & 0,12 \\
Reoperação & $13(12,6 \%)$ & $49(36,5 \%)$ & $<\mathbf{0 , 0 0 1}$ \\
Retransplante & $2(1,9 \%)$ & $7(5,1 \%)$ & 0,306 \\
Mortalidade pós-operatória em 10 anos & $8(7,8 \%)$ & $35(25,5 \%)$ & $<\mathbf{0 , 0 0 1}$ \\
\hline $\begin{array}{l}\text { BCH, grupo baixo volume transfusional de concentrado de hemácias perioperatório; ACH, grupo de alto volume } \\
\text { transfusional de concentrado de hemácias perioperatório }\end{array}$ & & \\
\hline
\end{tabular}




\subsection{Determinação dos fatores de risco independentes relacionados à mortalidade}

Com o objetivo de identificar fatores de risco independentes para a mortalidade dos pacientes submetidos ao THP com doador vivo, foram selecionadas variáveis de relevância estatística e clínica e realizadas as regressões simples e múltipla de Cox. Foram encontradas duas variáveis independentes de risco de mortalidade: a depuração de creatinina estimada no período pré-operatório $(\mathrm{HR}=0,995$ e valor $p=0,023)$ e o volume de concentrado de hemácias indexado pelo peso corpóreo superior a $27,5 \mathrm{~mL} / \mathrm{kg}$ no período perioperatório ( $\mathrm{HR}=3,031$ e valor $p=0,009$ ) (Tabela 15). 
Tabela 15. Fatores de risco independentes de óbito identificados por regressão de Cox simples e múltipla

\begin{tabular}{|c|c|c|c|c|c|c|}
\hline Variável & Estimativa & $\begin{array}{c}\text { Hazard } \\
\text { ratio (HR) } \\
\text { univariada }\end{array}$ & IC (95\%) & $\begin{array}{l}\text { Valor } \\
p\end{array}$ & $\begin{array}{c}\text { Hazard ratio } \\
\text { (HR) } \\
\text { multivariada }\end{array}$ & $\begin{array}{l}\text { Valor } \\
p\end{array}$ \\
\hline Gênero masculino & $-0,062$ & 0,94 & $0,514-1,718$ & 0,841 & & \\
\hline Idade (meses) & $-0,024$ & 0,977 & $0,950-1,004$ & 0,095 & & \\
\hline Peso (g) & $-0,17$ & 0,844 & $0,738-0,964$ & 0,012 & & \\
\hline Estatura $(\mathrm{cm})$ & $-0,044$ & 0,957 & $0,924-0,990$ & 0,013 & & \\
\hline $\mathrm{ZP} / \mathrm{I}$ & $-0,243$ & 0,784 & $0,623-0,986$ & 0,037 & & \\
\hline ZE/I & $-0,085$ & 0,918 & $0,734-1,148$ & 0,455 & & \\
\hline ZP/E & $-0,235$ & 0,791 & $0,649-0,963$ & 0,019 & & \\
\hline ZIMC & $-0,084$ & 0,919 & $0,723-1,168$ & 0,49 & & \\
\hline PELD & 0,022 & 1,022 & $0,982-1,064$ & 0,282 & & \\
\hline Cirurgia de Kasai & $-0,214$ & 0,808 & $0,440-1,483$ & 0,491 & & \\
\hline $\mathrm{N}^{\circ}$ Infecções pré até 30 dias & 0,348 & 1,416 & $1,023-1,960$ & 0,036 & & \\
\hline $\mathrm{DCr}\left(\mathrm{mL} / \mathrm{min} / 1,73 \mathrm{~m}^{2}\right)^{*}$ & $-0,005$ & 0,995 & $0,991-0,999$ & 0,01 & 0,995 & 0,023 \\
\hline Tempo de cirurgia (horas) & 0,012 & 1,013 & $0,856-1,197$ & 0,884 & & \\
\hline Hemoglobina $(\mathrm{g} / \mathrm{dL})^{* *}$ & $-0,206$ & 0,814 & $0,657-1,008$ & 0,059 & & \\
\hline $\mathrm{RNI}^{* *}$ & 0,259 & 1,295 & $0,722-2,322$ & 0,386 & & \\
\hline Sódio $(\mathrm{mEq} / \mathrm{L})^{* *}$ & $-0,014$ & 0,986 & $0,916-1,061$ & 0,704 & & \\
\hline Albumina $(\mathrm{g} / \mathrm{dL})^{\star *}$ & $-0,116$ & 0,89 & $0,615-1,290$ & 0,539 & & \\
\hline Lactato $(\mathrm{mmol} / \mathrm{L})^{* * *}$ & $-0,021$ & 0,979 & $0,914-1,048$ & 0,541 & & \\
\hline RPIPP (\%) & 0,149 & 1,16 & $0,909-1,481$ & 0,232 & & \\
\hline Diagnóstico de base (AVBH) & $-0,426$ & 0,653 & $0,357-1,195$ & 0,167 & & \\
\hline $\begin{array}{l}\text { Alto volume transfusional }(\mathrm{CH} \\
>27,5 \mathrm{~mL} / \mathrm{kg})\end{array}$ & 1,316 & 3,73 & $1,730-8,042$ & 0,001 & 3,031 & 0,009 \\
\hline $\begin{array}{l}\text { Presença de complicação } \\
\text { maior }\end{array}$ & 0,384 & 1,469 & $0,799-2,701$ & 0,261 & & \\
\hline \multicolumn{7}{|c|}{$\begin{array}{l}\text { ZP/I, z-score de peso para idade; ZE/I, z-score de estatura para idade; ZP/E, z-score de peso para estatura; ZIMC, z- } \\
\text { score de índice de massa corporal para idade; PELD, Pediatric End-Stage Liver Disease; No , número; Dep creat, } \\
\text { depuração de creatinina sérica; RNI, Razão Normalizada Internacional; RPIPP, relação de peso do implante e peso do } \\
\text { paciente.AVBH atresia de vias biliares extra-hepáticas; } \mathrm{CH}>27,5 \mathrm{~mL} / \mathrm{kg} \text { alto volume transfusional ou volume de } \\
\text { concentrado de hemácias transfundido no período perioperatório de } 24 \mathrm{~h} \text { antes até } 48 \mathrm{~h} \text { depois do transplante hepático }\end{array}$} \\
\hline \multicolumn{7}{|c|}{ * Valor estimado ou calculado através de fórmula de Scwartz } \\
\hline \multicolumn{7}{|c|}{ ** Exames séricos coletados até $72 \mathrm{~h}$ antes do procedimento anestésico } \\
\hline${ }^{* * *}$ Exame sérico coletado até 2 & a induc & tésic & lante he & & & \\
\hline
\end{tabular}




\subsection{Sobrevida após o transplante de fígado}

\subsubsection{Sobrevida global dos pacientes}

A sobrevida global dos 240 pacientes, ao longo de 1 ano, foi de $87,1 \%$ com IC 95\% (82,7 a 91,8\%), ao longo de 5 anos, foi de $81,5 \%$ com IC $95 \%$ (76,1 a $87,2 \%)$ e ao longo de 10 anos, foi de $80,3 \%$ com IC 95\% (74,6 a $86,5 \%)$. A sobrevida média dos pacientes da amostra total foi de $53,1 \pm 36,7$ meses (Figura 10).

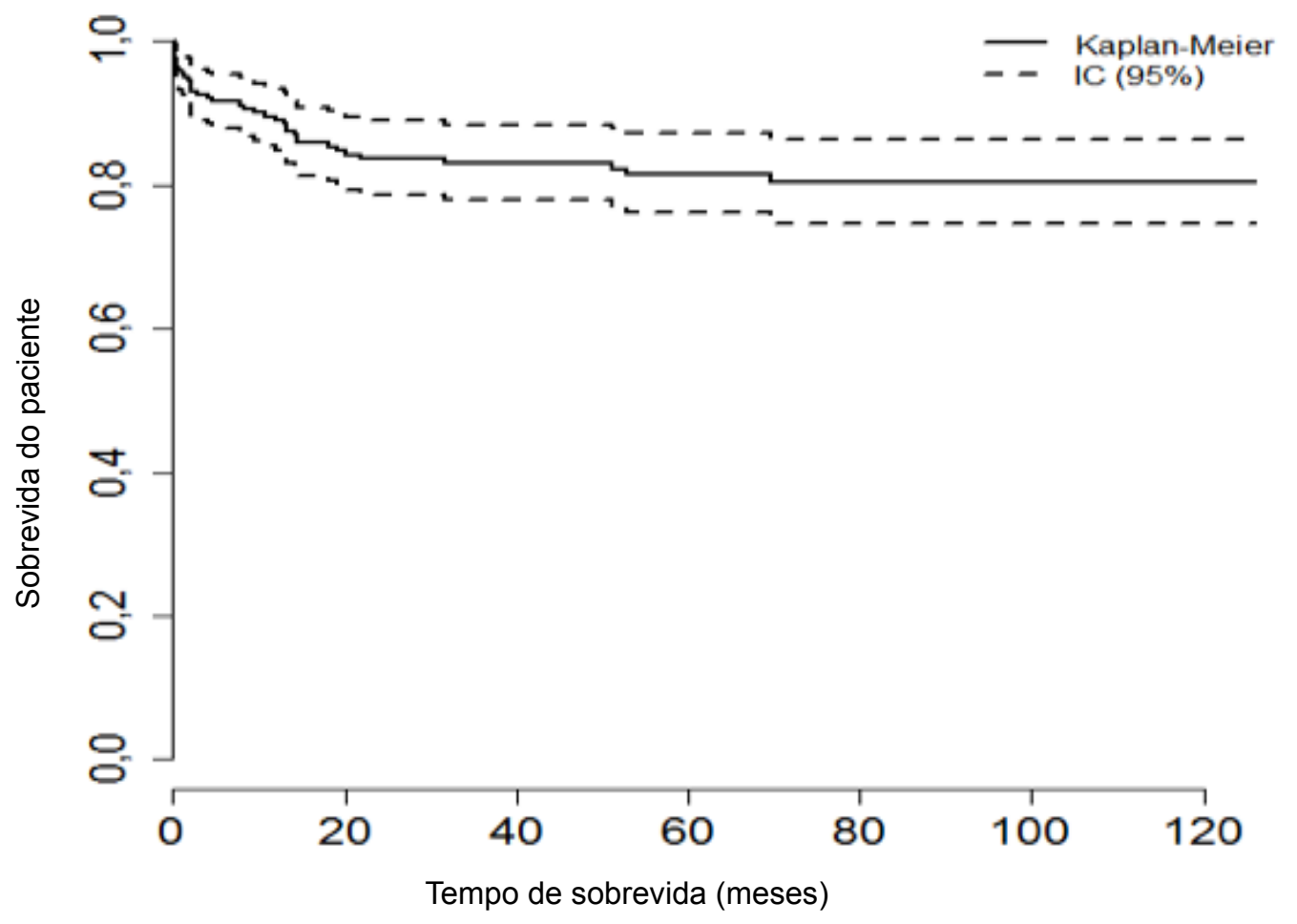

Figura 10. Curva de sobrevida de Kaplan-Meier com intervalo de confiança $95 \%$ de 240 pacientes submetidos a transplante hepático pediátrico com doador vivo 


\subsubsection{Sobrevida global dos enxertos}

A sobrevida global dos 240 enxertos hepáticos, ao longo de 1 ano, foi de $87,1 \%$ com IC $95 \%$ (82,7 a $91,8 \%)$, ao longo de 5 anos, foi de $77,7 \%$ com IC $95 \%(72,0$ a $84,0 \%)$ e ao longo de 10 anos, foi de $75,6 \%$ com IC 95\% (69,3 a $82,4 \%$ ). A sobrevida media dos enxertos hepáticos da amostra total foi de $51,35 \pm 36,9$ meses (Figura 11).

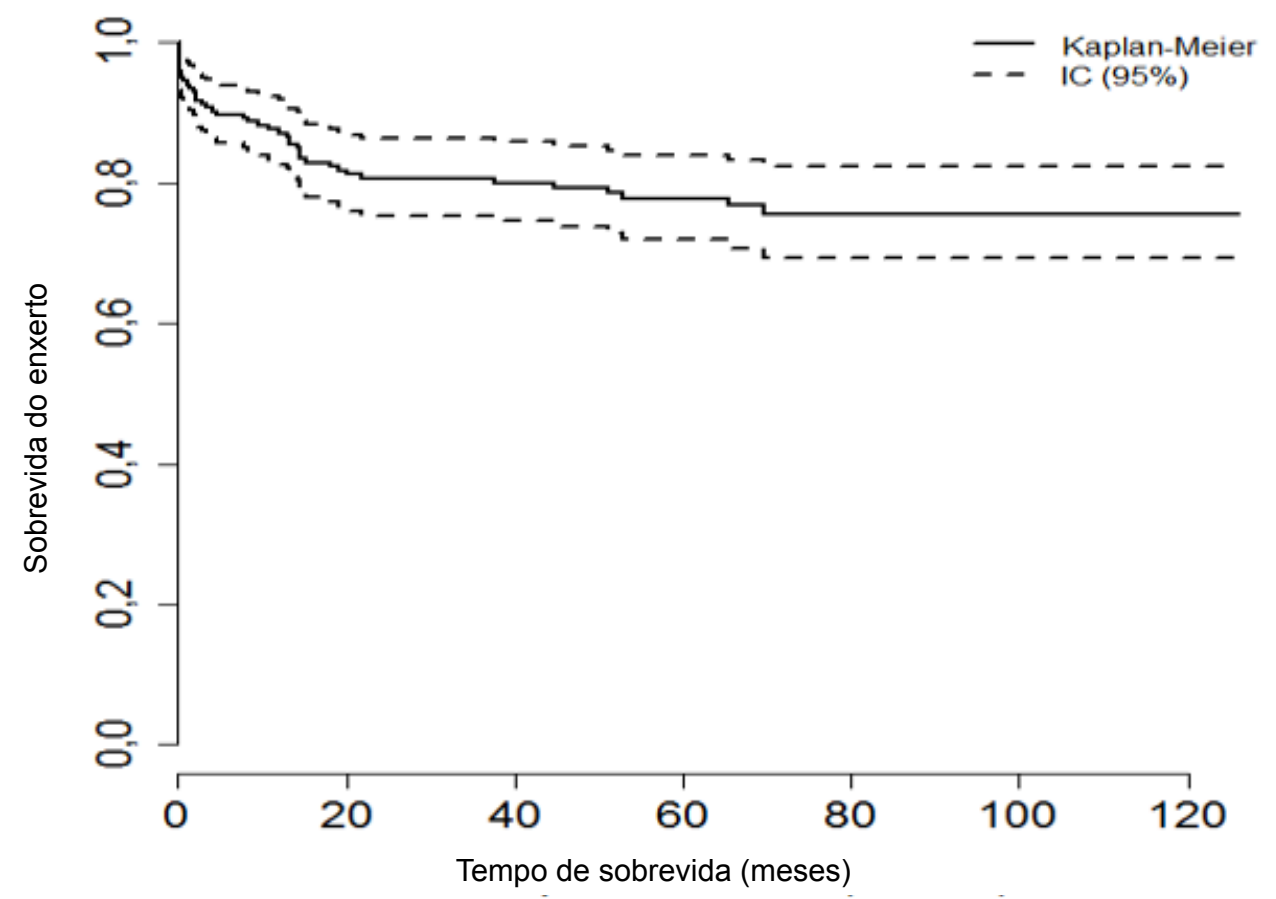

Figura 11. Curva de sobrevida de Kaplan-Meier do enxerto hepático com intervalo de confiança $95 \%$ de 240 pacientes submetidos a transplante hepático pediátrico com doador vivo 


\subsubsection{Análise da sobrevida de acordo com as complicações maiores 4.9.3.1 Sobrevida dos pacientes de acordo com as complicações maiores}

A sobrevida dos 109 pacientes do grupo CMe, ao longo de um ano, foi de $94,4 \%$ com IC de $95 \%$ (89,8 a $99,3 \%$ ), ao longo de cinco anos, foi de $85,7 \%$ com IC de $95 \%$ (78,4 a 93,6\%) e, ao longo de dez anos, foi de $83,6 \%$ com IC de $95 \%$ (75,7 a 92,4\%). A sobrevida dos 131 pacientes do grupo CMa, ao longo de um ano, foi de $84,9 \%$ com IC de $95 \%$ (78,6 a 91,6\%) e, ao longo de cinco anos e de dez anos, foi de $78,6 \%$ com IC de $95 \%$ (71,2 a $86,7 \%)$. Os pacientes do grupo CMa e os pacientes do grupo CMe não tiveram diferença significativa de sobrevida, quanto à presença de complicações maiores ou graves (Figura 12).

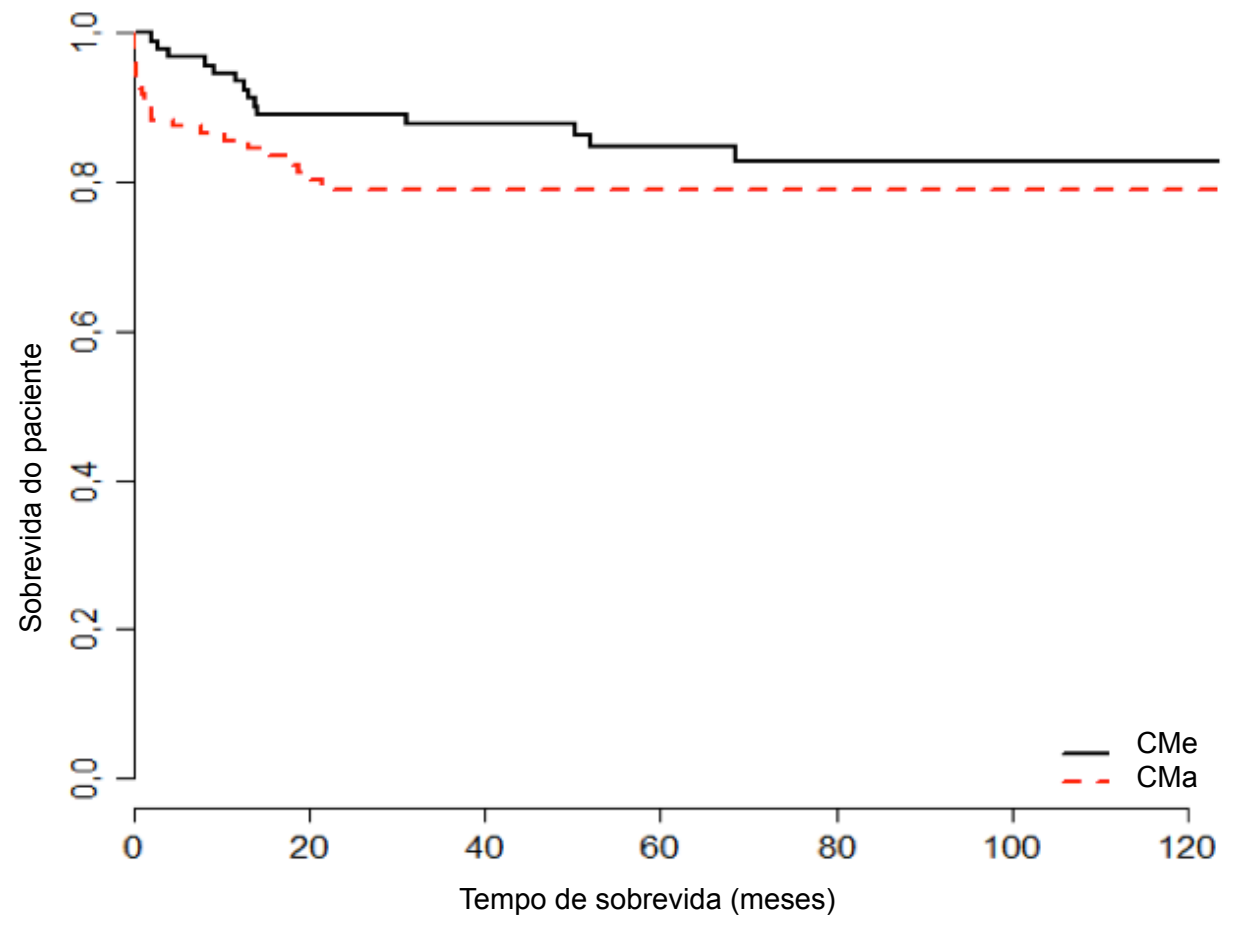

Figura 12. Curva de sobrevida de Kaplan-Meier do grupo CMe (109 pacientes sem nenhuma complicação ou com complicações menores - grau I-IIla) e do grupo CMa (131 pacientes com ao menos uma complicação maior - grau Illb-V ). Teste Log-Rank (Mantel-Haenszel): Qui-quadrado $=12,6 ;$ graus de liberdade $=1 ; p=0,12$ 


\subsubsection{Sobrevida dos enxertos de acordo com as complicações maiores}

A sobrevida dos 109 enxertos hepáticos do grupo CMe, ao longo de um ano, foi de $94,4 \%$ com IC de $95 \%$ (89,8 a $99,3 \%$ ), ao longo de cinco anos, foi de $84,6 \%$ com IC de $95 \%$ (77,3 a 92,8\%) e ao longo de dez anos, foi de $81,0 \%$ com IC de 95\% (72,6 a 90,4\%). A sobrevida dos 131 enxertos hepáticos do grupo CMa, ao longo de um ano, foi de $81,5 \%$ com IC de $95 \%(74,8$ a $88,8 \%)$, ao longo de cinco anos e de dez anos, foi de $72,2 \%$ com IC de 95\% $(63,9$ a 81,5\%). Os pacientes do grupo CMa tiveram uma sobrevida do enxerto, significativamente menor, em relação ao grupo $\mathrm{CMe}$, quanto à presença de complicações maiores ou graves (Figura 13).

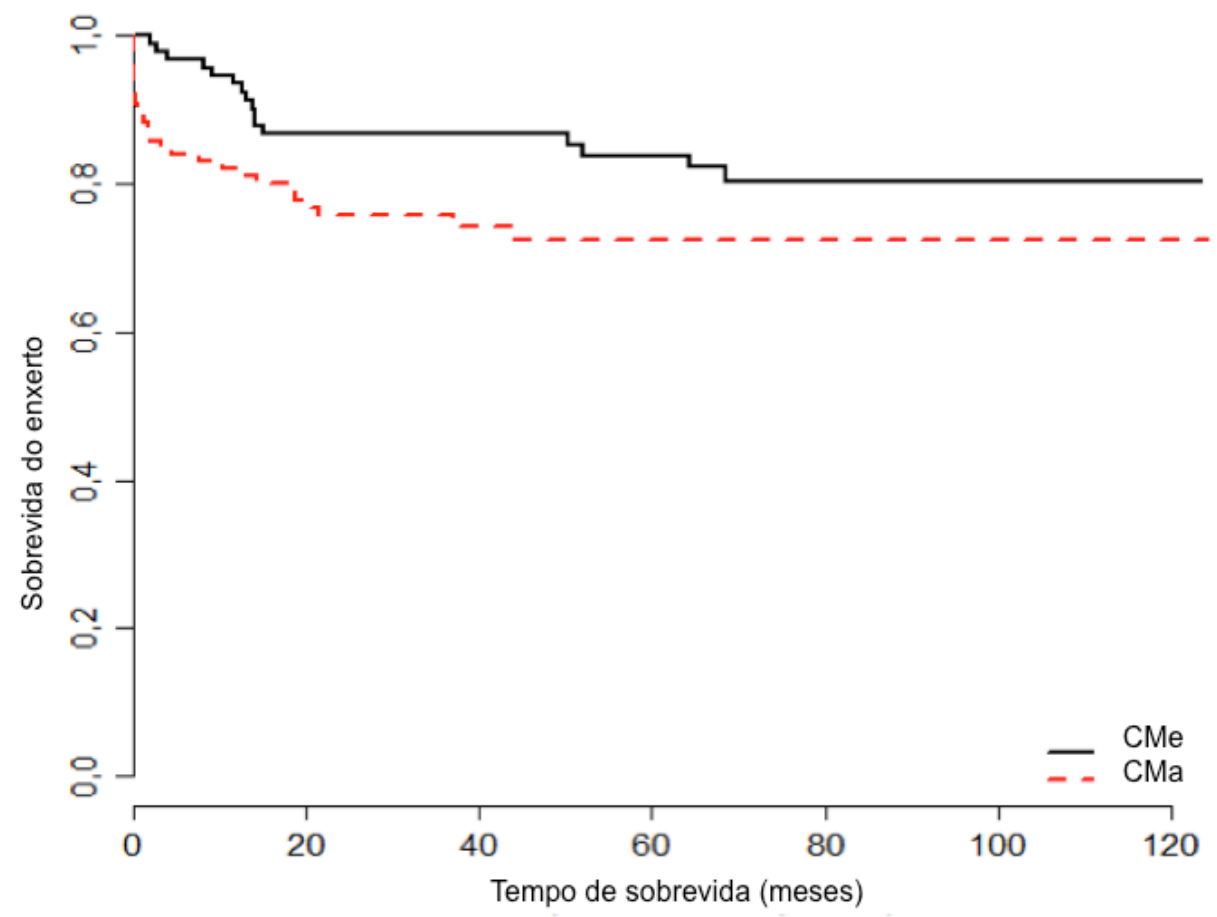

Figura 13. Curva de sobrevida de Kaplan-Meier dos enxertos hepáticos do grupo CMe (109 pacientes sem nenhuma complicação ou com complicações menores, grau I-Illa) e do grupo CMa (131 pacientes com ao menos uma complicação maior, grau Illb-V). Teste Log-Rank (Mantel-Haenszel): Qui-quadrado $=14,6 ;$ graus de liberdade $=1 ; p=0,03$ 


\subsubsection{Análise da sobrevida de acordo com o volume categorizado de concentrado de hemácias transfundido no perioperatório}

\subsubsection{Sobrevida dos pacientes de acordo com volume categorizado de concentrado de hemácias transfundido no perioperatório}

A sobrevida dos 103 pacientes do grupo $\mathrm{BCH}$, ao longo de um ano, foi de $97,7 \%$ com IC de $95 \%$ (94,6 a 100\%), ao longo de cinco anos, foi de $93,8 \%$ com IC de $95 \%(88,6$ a $99,2 \%)$ e, ao longo de dez anos, foi de $90,9 \%$ com IC de $95 \%$ (83,5 a 98,8\%). A sobrevida dos 137 pacientes do grupo $\mathrm{ACH}$, ao longo de um ano, foi de $82,7 \%$ com IC de $95 \%$ (76,2 a 89,7\%), ao longo de cinco anos, foi de $73,9 \%$ com IC de $95 \%(66,2$ a $82,5 \%)$ e, ao longo de dez anos, foi de $72,6 \%$ com IC de $95 \%$ (64,7 a $81,5 \%)$. Os pacientes do grupo $\mathrm{ACH}$ tiveram uma sobrevida, significativamente menor, em relação ao grupo $\mathrm{BCH}$, quanto ao volume de $\mathrm{CH}$ transfundido no perioperatório (Figura 14).

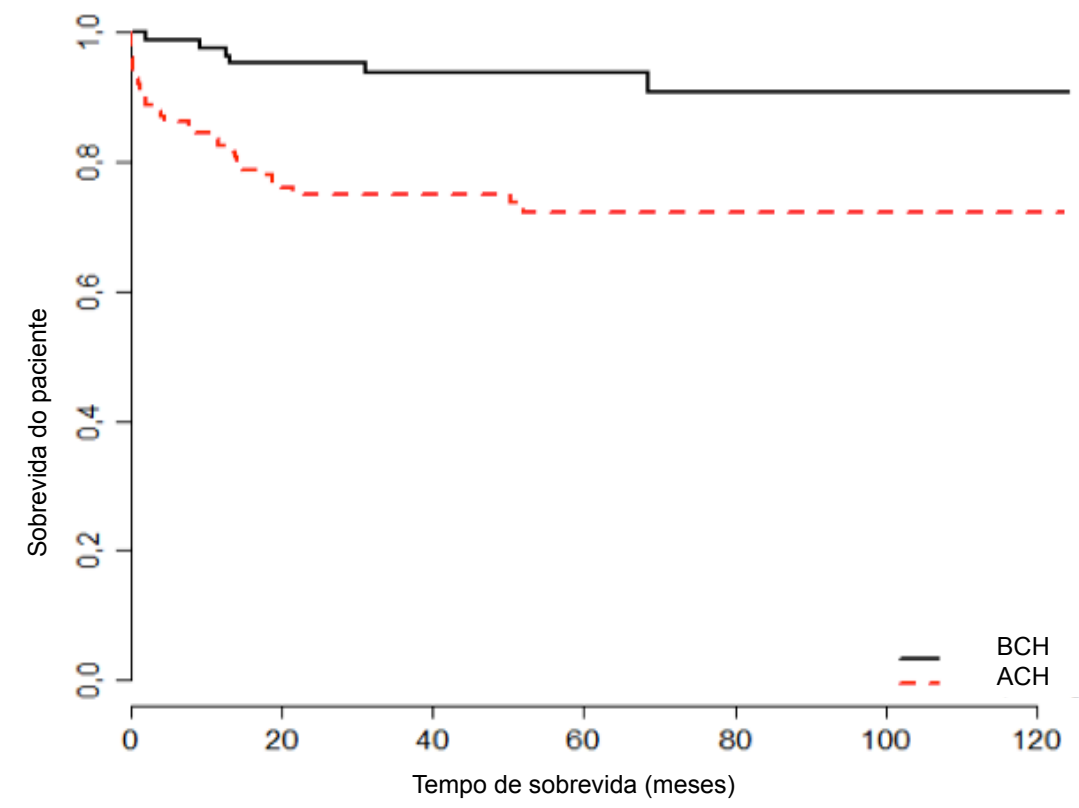

Figura 14. Curva de sobrevida de Kaplan-Meier do grupo $\mathrm{BCH}$ (103 pacientes transfundidos no perioperatório com volume menor ou igual a $27,5 \mathrm{~mL} / \mathrm{kg}$ de concentrado de hemácias indexadas pelo peso corpóreo) e do grupo $\mathrm{ACH}$ (137 pacientes transfundidos no perioperatório com volume maior que $27,5 \mathrm{~mL} / \mathrm{kg}$ de concentrado de hemácias indexadas pelo peso corpóreo). Teste Log-Rank (MantelHaenszel): Qui-quadrado $=12,6$; graus de liberdade $=1 ; p<0,001$ 


\subsubsection{Sobrevida dos enxertos de acordo com volume categorizado de concentrado de hemácias transfundido no perioperatório}

A sobrevida dos 103 enxertos hepáticos do grupo $\mathrm{BCH}$, ao longo de um ano, foi de $97,7 \%$ com IC de $95 \%$ (94,6 a 100\%), ao longo de cinco anos, foi de $92,3 \%$ com IC de $95 \%(86,5$ a $98,5 \%)$ e ao longo de dez anos, foi de $87,0 \%$, com IC de 95\% (78,3 a 96,6\%). A sobrevida dos 137 enxertos hepáticos do grupo $\mathrm{ACH}$, ao longo de um ano, foi de $79,5 \%$ com IC de $95 \%(72,6$ a $87,0 \%)$ e ao longo de cinco anos e de dez anos, foi de $67,2 \%$ com IC de $95 \%$ (58,9 a $76,7 \%)$. Os pacientes do grupo $\mathrm{ACH}$ tiveram uma sobrevida do enxerto, significativamente menor, em relação ao grupo $\mathrm{BCH}$, quanto ao volume de $\mathrm{CH}$ transfundido no perioperatório (Figura 15).

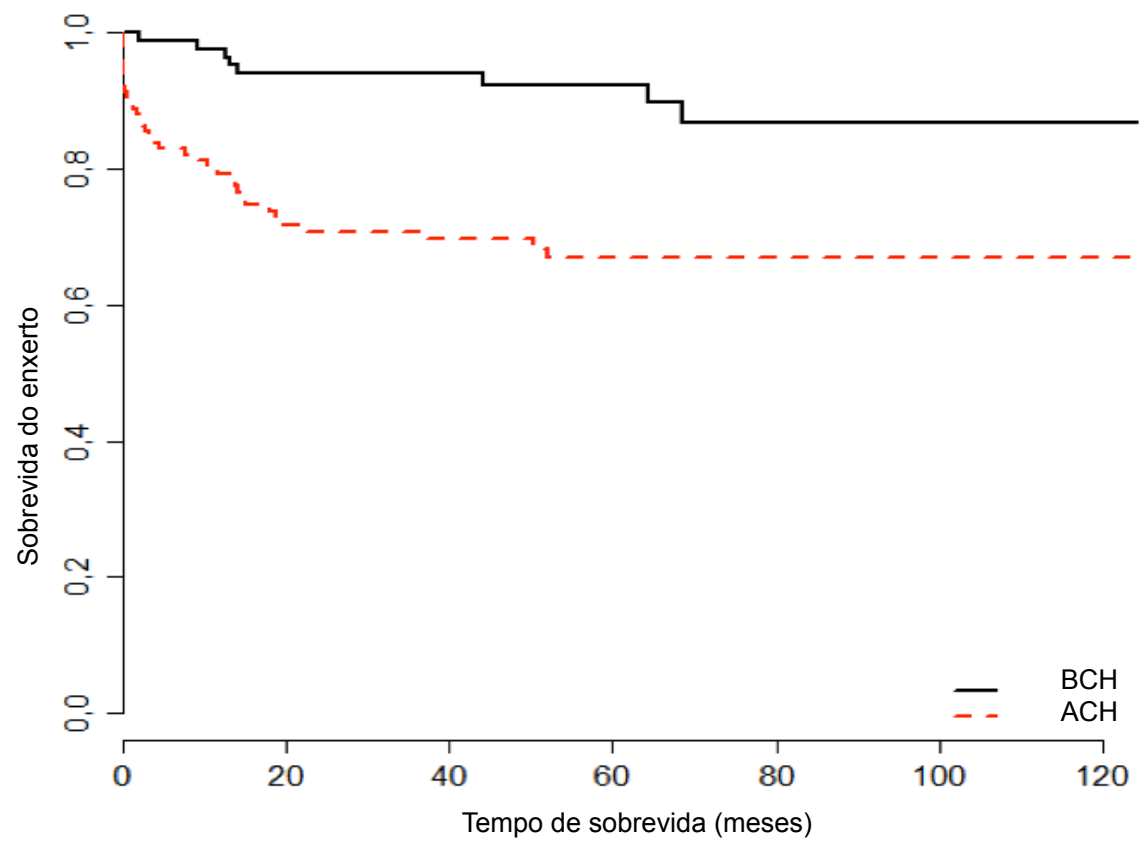

Figura 15. Curva de sobrevida de Kaplan-Meier dos enxertos hepáticos do grupo $\mathrm{BCH}$ (103 pacientes transfundidos no perioperatório com volume menor ou igual a $27,5 \mathrm{~mL} / \mathrm{kg}$ de concentrado de hemácias indexadas pelo peso corpóreo) e do grupo $\mathrm{ACH}$ (137 pacientes transfundidos no perioperatório com volume maior que 27,5 $\mathrm{mL} / \mathrm{kg}$ de concentrado de hemácias indexadas pelo peso corpóreo). Teste Log-Rank (Mantel- Haenszel): Qui-quadrado = 14,6; graus de liberdade $=1 ; p<0,001$ 
5 DISCUSSÃO 
Apesar dos grandes avanços nos últimos quarenta anos, elevando a sobrevida destes pacientes a um nível acima de $90 \%$ em 1 ano e acima de $80 \%$ em cinco anos ${ }^{34,105}$, ainda há um longo caminho a ser trilhado para reduzir as complicações perioperatórias, que tem impacto na sobrevida pós$\mathrm{TH}$, do paciente e do enxerto.

A transfusão sanguínea, apesar de reconhecida como importante fator de impacto na morbimortalidade pós-operatória no $\mathrm{TH}$ e nas mais diversas áreas cirúrgicas, a despeito de todos os avanços tecnológicos e da experiência adquirida pelas equipes de anestesia e cirurgia, ainda é largamente utilizada no período perioperatório do $\mathrm{TH}^{78}$. Entretanto, há uma crescente tendência de racionamento do uso de $\mathrm{HC}$, com maior restrição das indicações transfusionais ${ }^{69,106,107 .}$

A identificação de fatores preditivos de complicações em TH pode ser dificultada, pela heterogeneidade das amostras e pela falta de uma classificação padronizada que defina as complicações. Os estudos publicados até a atualidade envolvem pequenas amostras e revelam uma grande variabilidade nos resultados. Este é o primeiro estudo incluindo 240 crianças de pouca idade, submetidas exclusivamente a THP com doador vivo, com o objetivo de avaliar a associação de transfusão sanguínea perioperatória com complicação pós-operatória. A amostra é homogênea, visto que foram excluídos pacientes acima de $20 \mathrm{~kg}$, com diagnósticos de base agudos e retransplantes, além disso todos os procedimentos foram realizados pela mesma equipe anestésico- 
cirúrgica. Paralelamente, o fato do AC Camargo Cancer Center contar com ambulatórios de Hepatologia, Pediatria, Cirurgia Pediátrica, Transplante Hepático, subespecialidades oncológicas e um serviço assistencial de casas de apoio para estadia de pacientes e familiares, contribuiu para a fidelização ao serviço onde fora realizado o procedimento do $\mathrm{TH}$. O acompanhamento pré e pós-operatório destes pacientes foi minucioso e prolongado, dado que as suas cidades de origem nem sempre dispunham de serviço especializado.

As complicações pós-operatórias foram graduadas, por meio da classificação de Clavien-Dindo ${ }^{99}$. Clavien et al. ${ }^{108}$ criaram, em 1992, uma classificação de graduação de gravidade das complicações pós-operatórias baseada em quatro graus de complicação. As vantagens desta classificação eram criar uma uniformidade no relato de resultados, comparar resultados de dois períodos distintos em um mesmo centro, comparar resultados cirúrgicos em centros diferentes, comparar resultados de condutas cirúrgicas versus e não cirúrgicas, capacitar a elaboração de metanálises, avaliar fatores de risco pré-operatório e estabelecer no pré-operatório escores de prognóstico A primeira utilização desta classificação em TH foi feita em 1994, em um estudo multicêntrico, analisando 215 TH ortotópicos de adultos ${ }^{109}$.

Clavien \& Dindo ${ }^{99}$ publicaram, em 2004, uma reformulação da classificação para aumentar sua acurácia e sua aceitação no meio cirúrgico. Esta nova classificação mais simplificada ficou conhecida como classificação de Clavien-Dindo, composta de cinco graus de complicações com apenas 2 subdivisões, dos graus III e IV, sendo considerada muito mais lógica, compreensível, útil e reprodutível, na prática clínica. No mesmo ano, Broering et al. ${ }^{110}$ publicaram uma análise das complicações em doadores vivos 
aparentados de TH, utilizando a nova classificação que correlacionou negativamente a morbidade pós-operatória com a experiência da equipe cirúrgica, alertando para a necessidade de aprimoramento da proficiência da técnica cirúrgica em hepatectomia direita, previamente ao procedimento de $\mathrm{TH}$, para evitar-se complicações relacionadas à curva de aprendizado. Em 2009, Beatrice et al. ${ }^{100}$ realizaram um estudo multicêntrico internacional com a participação do HC/FMUSP sobre a influência do sevoflurano no condicionamento hepático e na evolução do $\mathrm{TH}$ em adultos com doador falecido. Neste estudo, os pacientes foram categorizados em dois grupos, segundo a presença de complicações menores (I-IIla) e complicações maiores (IIlb-V), o que serviu de base para a categorização de gravidade das crianças deste estudo.

No paciente pediátrico, a maioria dos exames diagnósticos, como biópsias, inserção de cateteres, procedimentos endoscópicos, cirúrgicos e radiológicos, que se fazem necessários ao longo do período de pós operatório de um $\mathrm{TH}$, precisam ser realizados sob anestesia geral, a fim de garantir a imobilidade e a segurança do paciente. Alguns trabalhos em cirurgia pediátrica utilizam a classificação de Clavien-Dindo com adaptações, levando em consideração procedimentos peculiares das diferentes especialidades, ora considerando o grau III como uma complicação grave, ora não grave. A incorporação do conceito de sequela (disability) nos pacientes pediátricos também não é abordada em todos os estudos. ${ }^{111-113}$ Originalmente, classifica as complicações pós-operatórias no período de internação hospitalar para a realização do procedimento cirúrgico em questão, podendo ser utilizada por períodos maiores no pós-operatório ${ }^{114,115}$. 
Não há uma classificação de gravidade específica para avaliação de pacientes no pós-operatório de THP. Considerando-se a necessidade de anestesia geral para a execução de quase todos os procedimentos, além de uma maior incidência de complicações biliares $^{36}$ e vasculares ${ }^{116}$, necessitando de procedimentos de radiologia invasiva com maior frequência, inclusive com melhores resultados do que em adultos, foi realizada uma adaptação da classificação de Clavien-Dindo, vinculada à complexidade do procedimento. Desta maneira, o grau Illa incluiu complicações de menor complexidade que exigiram intervenção endoscópica, radiológica ou cirúrgica de pequeno porte e o grau Illb, complicações de maior complexidade, como cirurgias de médio e grande porte.

Neste estudo, os participantes foram, inicialmente, alocados em dois grupos, de acordo com a presença ou ausência de complicação maior. Este estudo demonstrou que a transfusão perioperatória de $\mathrm{CH}$ foi o único fator de risco independente para complicações pós-operatórias maiores ou graves.

Há várias definições de hemorragia maciça em Pediatria. Usualmente, é definida como a perda de uma volemia no período de $24 \mathrm{~h}$. No entanto, a maioria dos participantes deste estudo não preencheu critérios de transfusão maciça e, a fim de se evitar qualquer tipo de arbitrariedade na escolha de um limiar de transfusão, optou-se pela realização de uma curva ROC. A média de transfusão de $\mathrm{CH}$ perioperatório no grupo mais transfundido $(\mathrm{ACH})$ foi de 58 $\mathrm{mL} / \mathrm{kg}$ em um período de $96 \mathrm{~h}$. Somente 16 pacientes do estudo não receberam nenhuma transfusão (Figura 2). Dos 224 pacientes transfundidos, 7,1\% receberam $\mathrm{CH}$ no período pré-operatório, 98,8\% no intraoperatório e 37,5\% no pós-operatório. Dentre as hepatopatias crônicas encontradas na amostra geral, 71,7\% pertenciam à classe colestase extra-hepática. A patologia 
mais frequente de toda a amostra foi a $A V B E H$, que teve uma incidência de $62,5 \%$. A incidência relatada na literatura é de 30 a $50 \%{ }^{96}$, tendo sido superior neste estudo, provavelmente, por se tratar de serviço de referência nacional de THP. O grupo $\mathrm{ACH}$ apresentou significativamente mais pacientes com classes de colestase extra-hepática e, menos, com colestase intra-hepática, em comparação ao $\mathrm{BCH}$. Não houve diferença entre os grupos de maior e menor volume transfusional quanto às outras classes de hepatopatias.

Quanto ao período pré-operatório, de maneira interessante, os altos volumes transfusionais foram associados à pouca idade, baixa estatura, baixo peso, enxertos maiores, graus maiores de ascite, PELD mais elevado mas não aos antecedentes de cirurgia de Kasai, hipertensão portal ou de síndrome hepato-pulmonar, o que contrasta com os achados de Fana et al. ${ }^{117}$. Além disso, os pacientes do grupo $\mathrm{ACH}$, apresentaram uma hemoglobina, sódio, albumina médias e taxa de depuração de creatinina estimada menores e um RNI maior, em relação ao grupo $\mathrm{BCH}$. Não houve diferença entre os grupos no que concerne o gênero, exames de contagem de plaquetas, níveis séricos de glicose e BT. O grupo que recebeu maior volume transfusional era de maior gravidade clínica da hepatopatia prévia, maior grau de desnutrição e piores funções pulmonar e renal. Roullet et al. ${ }^{118}$, em 2011 demonstrou que o escore de CTP e não o de MELD, foi preditor independente de risco de transfusão, o que foi validado posteriormente, em 2014, por De Santis et al. ${ }^{119}$.

Quanto ao período intraoperatório; os pacientes do grupo $\mathrm{ACH}$ apresentaram menor hemoglobina e sódio e maiores $\mathrm{RNI}$, os tempos médios de anestesia e cirurgia, relação do peso do implante para o peso do paciente, além de, volumes de criataloide, colóide e diurese indexados pelo peso 
corpóreo, maiores em relação ao grupo $\mathrm{BCH}$. Esta duração maior do procedimento anestésico-cirúrgico no grupo de maior volume transfusional pode ser atribuída à maior dificuldade técnica, estruturas menores, mais frágeis e presença de bridas abdominais por cirurgias e infecções pregressas. A utilização de enxertos mais volumosos implica em um maior "roubo" de volemia, uma vez que são implantados enxertos repletos de solução de preservação e, após a reperfusão, são totalmente preenchidos por sangue do receptor. Maiores volumes de criataloide e colóide podem ser responsáveis por um maior volume urinário, desde que ocorra a elevação da pré-carga no compartimento central com consequente aumento do ritmo de filtração glomerular.

Quanto ao período pós-operatório, os pacientes do grupo ACH tiveram menor taxa de extubação em SO, permaneceram intubados em ventilação mecânica por período mais prolongado, além de um período maior de internação em UTI e hospitalar, em relação ao grupo $\mathrm{BCH}$. Li et al. ${ }^{69}$, também observaram um aumento no número de infecções pós-operatórias, bem como, aumento do tempo de internação em UTI e hospitalar em pacientes que receberam maiores volumes de $\mathrm{CH}$, em $\mathrm{TH}$ com doador vivo. Pereboom et al. $^{107}$ demonstraram que a transfusão plaquetária está associada a um aumento de mortalidade e à uma prevalência maior de TRALI e Benson et al. ${ }^{120}$ mostraram que produtos contendo grande quantidade de plasma como PFC e plaquetas estavam associados a um risco aumentado de TRALI. Contudo, a transfusão de $\mathrm{CH}$ mostrou-se associada ao risco aumentado de desenvolver infecção de maneira dose dependente. A infecção hospitalar e a 
TRALI estão associadas a um maior tempo de internação hospitalar e a uma maior mortalidade intra-hospitalar.

Durante o período de internação ou pós-operatório precoce, dentre os 240 pacientes analisados, foram observadas complicações pós-operatórias em 94,6\% destes, dos quais, 54,6\% tiveram complicações maiores ou graves, associadas com taxas maiores de mortalidade e de perda de enxertos. Nos pacientes do grupo $\mathrm{ACH}$, a incidência de complicações graves foi 2,19 vezes maior, em comparação ao grupo $\mathrm{BCH}$. Houve registro de óbitos até 30 dias pós-TH, exclusivamente, no grupo de maior volume transfusional. Este período correspondeu a $30,8 \%$ do total de complicações observadas em 10 anos. O grupo $\mathrm{ACH}$ apresentou mais complicações cardiológicas, infecciosas, respiratórias maiores e sangramentos, em geral, e menos complicações alérgicas e rejeições, em comparação ao $\mathrm{BCH}$.

O período de pós-operatório tardio ou até 1, 5 e 10 anos pós-TH, correspondeu a $69,2 \%$ do total de complicações observadas em 10 anos, tendo a maior parte destas ocorrido até o primeiro ano pós-TH. Todos os períodos analisados revelaram uma maior frequência de complicações graves de qualquer tipo no grupo $\mathrm{ACH}$, em comparação ao $\mathrm{BCH}$. Até 10 anos pós-TH, o grupo $\mathrm{ACH}$ apresentou mais complicações cardiológicas, infecciosas e respiratórias maiores e mais neoplásicas menores e menos rejeições, em comparação ao BCH.

Em 2013, Feltraco et al. ${ }^{121}$ publicaram uma revisão sobre complicações pulmonares precoces, no pós-operatório de TH em adultos, onde foram identificados fatores de risco pré, intra e pós-operatórios. Dentre vários fatores pré-operatórios, ressaltou-se: maior idade do receptor, gênero feminino, história 
de tabagismo, hipoxemia moderada, anormalidades pregressas como broncoespasmo e insuficiência cardíaca, renal, diabetes e enxerto de doador falecido. Dentre fatores intraoperatórios, relatou-se: grandes incisões e perdas volêmicas e excesso de infusões de fluidos e hemocomponentes. Quanto a fatores pós-operatórios, detectou-se: excessiva administração de fluidos, maior duração da ventilação mecânica, paralisia diafragmática direita, insuficiência cardíaca, insuficiência renal aguda, exposição a agentes infecciosos hospitalares, imunossupressão e complicações cirúrgicas. As complicações pulmonares mais relevantes relatadas tiveram uma frequência variável segundo o centro onde havia sido realizado o $\mathrm{TH}$, derrames pleurais (32 a $47 \%$ ), edema pulmonar (4 a 47\%), pneumonias (5 a $38 \%$ ), atelectasias (5 a 29\%) e SARA (0,8 a 42\%). Neste estudo, as complicações respiratórias maiores, como SARA e pneumonias graves com necessidade de ventilação mecânica, tenderam a ser mais frequentes no grupo ACH durante a internação, em 5 e 10 anos de evolução pós- $\mathrm{TH}$, em relação ao $\mathrm{BCH}$. A frequência de complicações respiratórias foi maior no grupo $\mathrm{ACH}$, em quase todos os períodos analisados, exceto até 1 ano pós-TH.

Quanto às complicações endócrino-metabólicas, já no período préoperatório, nota-se uma dificuldade de manejo de fluidos, por alguns fatores conhecidos, como a alteração da composição do glicocálice ${ }^{122}$, a hipertensão portal, a hipoalbuminemia e a síndrome hepatocirculatória. Esta última, referese a um desbalanço de substâncias vasoativas, dentre as principais, a endotelina-1 e o óxido nítrico, levando à vasoconstricção arterial intra-hepática e à vasodilatação arterial do compartimento esplâncnico e periférico, resultando em diminuição do compartimento central e um aumento do 
compartimento esplâncnico $^{123}$. Esta remodelagem, ativa o sistema nervoso autônomo simpático, o sistema renina angiotensina e aldosterona, a liberação de hormônio antidiurético, levando à oligúria, retenção de água e sal, edemas de graus variáveis até anasarca e formação de ascite no perioperatório. Os imunossupressores, principalmente altas doses de corticoides, a curto prazo, podem levar a insuficiência de adrenal por inibirem o eixo hipotálamo-hipofisário e, a longo prazo, associada a hábitos sedentários, resistência insulínica com intolerância à glicose e, consequentemente, diabetes mellitus, dislipidemia e obesidade. Pode-se encontrar um déficit pondero-estatural significativo, principalmente, em crianças transplantadas acima de 2 anos de idade submetidas a mais de 18 meses de corticoterapia pós $\mathrm{TH}$, com diagnósticos pré-operatórios de doenças metabólicas ou não colestáticas ${ }^{124}$. Estão ainda descritos efeitos colaterais dos imunossupressores como, puberdade precoce, fraturas associadas à osteopenia, pelo uso dos corticoides; gota e disfunções da paratireoide, pelo uso de inibidores de calcineurina ${ }^{97}$. As complicações endócrino-metabólicas foram as mais frequentes do pós-operatório precoce, constituindo $28,2 \%$ do total de complicações no período de internação sem, no entanto, apresentar associação com o volume transfusional.

A insuficiência renal aguda pode ocorrer em decorrência de várias razões como, disfunção renal prévia, síndrome hepatorrenal, instabilidade hemodinâmica com necessidade de drogas vasoativas no perioperatório, uso de drogas nefrotóxicas, como imunossupressores inibidores da calcineurina (ciclosporina e tacrolimus), antibióticos, antifúngicos e sepse ${ }^{125}$. $\mathrm{Na}$ faixa pediátrica, a incidência de redução de função renal é de 17 a $32 \%{ }^{33}$. 
Não houve diferença significativa na frequência das complicações renais quanto ao volume transfusional.

As complicações infecciosas são a maior causa de mortalidade entre os pacientes pediátricos. Os fatores considerados de risco para infecção, incluem pouca idade, grau de desnutrição, insuficiência orgânica subjacente, presença de cateteres centrais, duração da intubação traqueal, duração da internação hospitalar, duração do ato operatório e os esquemas imunossupressores ${ }^{126}$. Estas complicações podem ocorrer precocemente, sendo as mais frequentes as bacteremias, pneumonias, infecções urinárias, infecções de ferida operatória e de cateteres. Até um mês de pós-operatório, as infecções nosocomiais bacterianas por germes de pele (stafilococos e streptococos) e da flora intestinal (enterococos e gram negativos) e fúngicas (candidíases) são mais prevalentes. De dois a seis meses, fazem-se mais presentes as infecções oportunistas, como as virais, principalmente por citomegalovírus (CMV), Ebstein-Barr vírus (EBV), vírus da herpes virus humanus, papiloma virus humanus; rotavirus, adenovírus, influenza e parainfluenza vírus; as infecções por protozoários, como Pneumocistis carinii e jenovecii), Toxoplasma gondi, Toxocara canis; fungos, como Aspergilus fumigates e bactérias, como Listeria monocytogenes e Mycobacterium tuberculosis. Outras infecções, acima de seis meses de pós-operatório como, por Criptococcus neoformans e Nocardia asteroides, podem ocorrer em vigência de disfunção do enxerto ou de níveis séricos elevados de imunossupressores ${ }^{126,127}$. O TH é o transplante de órgãos sólidos com a maior incidência de infecção por Candida sp. variando de 16 a $42 \%$ dos THP, sendo que o volume de $\mathrm{CH}$ transfundido no intraoperatório foi um dos fatores de risco independentes para sua ocorrência ${ }^{128}$. As viroses são as infecções mais prevalentes no TH, particularmente, no THP ${ }^{129}$. 
Os vírus de maior relevância, CMV e EBV, manifestam-se de maneiras diferentes. Desde a soroconversão assintomática até os casos de viroses inespecíficas, quadros similares à mononucleose, pneumonites, hepatites, doenças gastrointestinais, miocardites, encefalites ou corioretinites. O EBV está associado à doença linfoproliferativa pós-transplante (PTLD) e o CMV aumenta o risco de contrair outras infecções oportunistas. Há que se lembrar que, especificamente a hepatite causada por $\mathrm{CMV}$, pode levar à destruição do enxerto hepático ${ }^{130}$. As infecções respiratórias virais, contribuem para a disfunção do enxerto hepático, para um aumento das hospitalizações e um aumento da morbimortalidade. A transfusão de $\mathrm{CH}$ tem sido correlacionada, como fator independente de risco de infecção pós-operatória ${ }^{120,131}$. Neste estudo, a frequência de infecções, em geral, variou de 21,3 a 25,8\%, sendo a complicação mais frequente do período de pósoperatório tardio, sem diferença significativa entre os grupos, quanto ao volume transfusional. Todavia, houve uma maior frequência de complicações graves, como sepse grave, no grupo de maior volume transfusional, nos quatro períodos analisados. Segundo Starczewska et al. $^{132}$, o número de unidades de $\mathrm{CH}$ transfundidas durante o TH é um preditor de reoperações precoces e aumenta o risco de mortalidade, em até 3 vezes. Segundo os autores do estudo, a transfusão de $\mathrm{CH}$, também se correlaciona negativamente com a sobrevida dos enxertos durante o primeiro e quinto anos de acompanhamento pós-operatório, de maneira muito similar a este estudo.

A disfunção do enxerto é uma complicação mediada pela lesão por isquemia e reperfusão e é de gravidade variável. Pode manifestar-se, desde um quadro leve com febre e dor abdominal acompanhadas de elevação de enzimas AST e ALT, sem nenhuma causa técnico-cirúrgica aparente, até 
quadro grave, o não funcionamento primário do enxerto ou PNF, com insuficiência hepática aguda grave e necessidade de retransplante urgente. Não há tratamento específico, no entanto, parece estar relacionada a alguns fatores de risco como, idade avançada do doador ${ }^{133,134}$, enxerto com alto grau de esteatose $e^{133-135}$ e tempo de isquemia prolongado ${ }^{43,136,137}$. A incidência de PNF em THP é de 0,9 a 8,5\%, neste estudo foi de 2,1\%, incidência mais baixa, provavelmente, pela seleção prévia de doadores adequados e pelo pequeno tempo de isquemia envolvido no THP com doador vivo. Apesar de todos os casos de PNF terem sido registrados no grupo de maior volume transfusional, não houve diferença significativa entre os grupos $\mathrm{ACH}$ e $\mathrm{BCH}$.

As complicações cirúrgicas são decorrentes da somação de fatores relacionados ao receptor, ao doador, e à técnica operatória, dentre outros. A TAH é a complicação mais frequente na faixa pediátrica. Pode ocorrer em 5 a 18\% dos THP sendo que, sua incidência é cerca de 3 a 4 vezes maior na criança, em relação ao adulto ${ }^{43,96}$. Ocorre frequentemente nos primeiros 30 dias de pós-operatório e os fatores de risco para sua ocorrência são: doadores de idade inferior a 6 meses de vida, TH realizados em centros de pequeno volume de transplantes, receptores de pouca idade com vasos de pequeno calibre, enxerto de lobo hepático direito, enxerto de órgão inteiro, necessidade de enxerto arterial, tempo de isquemia fria prolongado, estado de hipercoagulabilidade e ascite volumosa do receptor $^{36}$. O uso de suturas microscópicas reduziram a incidência de TAH para até 3,8\%, em centros de grande volume de transplantes. TAH tardia é muito mais rara pois a maioria incide nos primeiros 30 dias. Aparentemente, se deve muito mais, à falta de reconhecimento precoce, do que por surgimento tardio. A mortalidade por TAH 
precoce, em THP, é de 30 a $40 \%{ }^{36,96}$. A taxa de retransplante pós-TAH, na faixa pediátrica, é de $62 \%^{116}$. O prognóstico da criança é superior em relação ao adulto, principalmente quando o diagnóstico é precoce, com boa evolução em $92 \%$ dos $\operatorname{casos}^{116}$. A incidência de TAH na amostra total foi de $4,6 \%$.

A trombose de veia porta (TVPo) tem uma incidência de 5 a 10\%, na faixa pediátrica ${ }^{36}$. A incidência de TVPo, na amostra total, foi de 12,9\%, provavelmente mais elevada por se tratarem, em sua maioria, de pacientes com AVBEH com inerente hipoplasia prévia de veia porta, alguns casos inclusive, necessitando de técnicas de anastomoses complexas com uso de interposições de enxertos vasculares ${ }^{43,138}$.

A incidência de fístulas biliares na amostra total foi de $6,2 \%$ e de estenoses biliares foi de $12,1 \%$, perfazendo $18,3 \%$ de complicações biliares na amostra total. As complicações biliares (CB) têm uma incidência de 5 a $25 \%$ na faixa pediátrica, dependendo do tipo de enxerto utilizado ${ }^{36}$. Nos THP, com doador vivo, a incidência de CB é de 4 até 45\%, constituindo-se na complicação de terapêutica mais prolongada. Enquanto na faixa etária adulta, 30 a $50 \%$ dos pacientes com CB necessitam de retransplantes, na faixa pediátrica, $70 \%$ destas complicações são resolvidas por endoscopia ou radiologia intervencionista,. A sobrevida dos enxertos hepáticos é de cerca de $80 \%$, após 5 anos e de $60 \%$, após 10 anos de THP. Isso resulta em uma meia-vida de, aproximadamente, 10 a 13 anos $^{36,139}$.

A incidência de retransplantes da amostra total foi de $3,8 \%$, inferior à relatada, na faixa pediátrica que, historicamente varia de 9 a $29 \%{ }^{140}$. O retransplante, quando indicado por falência hepática aguda, tem uma 
sobrevida superior a $80 \%$, em contrapartida, quando indicado tardiamente, por rejeição crônica, habitualmente associada à falência multiorgânica, a sobrevida cai para aproximadamente $50 \%{ }^{43}$.

A incidência de reoperações, na amostra total, foi de $27,5 \%$. As reoperações têm uma incidência de 8 a 29\%, independente do tipo de enxerto, ocorrendo, na maioria das vezes, por sangramento, lesões intestinais secundárias a aderências, sepse, hérnias incisionais, TAH, PNF, rejeição crônica e complicações biliares $^{36}$. Complicações vasculares e biliares são mais frequentes em crianças abaixo de $10 \mathrm{~kg}$ e menores de 1 ano de vida ${ }^{37}$. Não houve diferença com relação a incidência de complicações específicas, relacionadas ao enxerto, como $\mathrm{FB}, \mathrm{EB}, \mathrm{TAH}$, TVPo e retransplante entre os grupos $\mathrm{ACH}$ e $\mathrm{BCH}$. Houve contudo, no grupo de maior volume transfusional, uma maior incidência de reoperações e de óbitos, ao longo de dez anos. A frequência de complicações cirúrgicas, em geral, não mostrou diferença significativa entre os grupos $\mathrm{ACH}$ e $\mathrm{BCH}$, provavelmente por englobar todos os procedimentos cirúrgicos realizados no pós-operatório, e não somente, procedimentos cirúrgicos relativos ao enxerto hepático.

As complicações neuropsiquiátricas, mais comumente relatadas, foram crises convulsivas (pela neurotoxicidade dos imunossupressores e por alterações hidroeletrolíticas), síndromes de abstinência por sedação prolongada na UTI, principalmente com opioides e benzodiazepínicos e alterações neurocognitivas. Em uma revisão sistemática, realizada por Moser ${ }^{141}$, em 2013, as alterações neurocognitivas se devem ao atraso do desenvolvimento neuropsicomotor com quociente de inteligência reduzido, dificuldade de aprendizado, dificuldade de aquisição de linguagem oral e escrita, leitura, 
raciocínio matemático, pela hepatopatia crônica prévia e por falta de condições de acompanhamento escolar adequado. Houve uma maior frequência de dificuldade de concentração, humor lábil, irritabilidade, ansiedade, depressão, menor maturidade intelectual, emocional e qualidade de vida inferior dos hepatopatas crônicos submetidos a $\mathrm{TH}$, em relação a crianças não hepatopatas da mesma idade. As alterações cognitivas foram mais importantes em crianças que desenvolveram a hepatopatia abaixo de 1 ano de idade ${ }^{142}$ e que tiveram um período de permanência em UTI mais prolongado e um número maior de internações ${ }^{143}$. Um estudo realizado para identificar fatores preditivos de função cognitiva, em THP, mostrou que menor idade e maior altura, foram fatores determinantes de melhores resultados em testes cognitivos ${ }^{144}$. Neste estudo, não houve diferença significativa na frequência de complicações neuropsiquiátricas entre os grupos $\mathrm{ACH}$ e $\mathrm{BCH}$.

Quanto às complicações cardiovasculares, os distúrbios hidroeletrolíticos podem levar a alterações do ritmo cardíaco, desde bradicardias assintomáticas, arritmias acompanhadas de instabilidade hemodinâmica, até parada cardiorrespiratória por depressão miocárdica, toxicidade medicamentosa e falência hepática aguda. A hipertensão arterial sistêmica (HAS), pode ocorrer no intraoperatório, logo após a anastomose da $\mathrm{AH}$, quando se verifica uma diminuição dos níveis de fator natriurético e um aumento nos níveis de vasopressina, que pode ser agravada pela sobrecarga de volume e de sódio administrados nesta fase. Já no período pós-operatório, os imunossupressores são responsáveis pelo aparecimento de HAS, pois ativam o sistema renina-angiotensina-aldosterona e o sistema nervoso autônomo simpático, liberam endotelina e inibem a produção de óxido nítrico, 
levando a uma vasoconstricção sistêmica, deflagrada principalmente pelos inibidores de calcineurina, além da retenção de água e sal, característica dos corticoides. A incidência de HAS, no THP, é de 15 a 30\%, a depender do esquema de imunossupressão ${ }^{33}$. Neste estudo, a frequência de complicações cardiovasculares maiores, como instabilidade hemodinâmica com necessidade de altas doses de drogas vasoativas e parada cardiorrespiratória, foi maior no grupo $\mathrm{ACH}$, nos quatro períodos analisados, quando comparada ao grupo $\mathrm{BCH}$.

O pós-opertório é uma fase de catabolismo intenso, adicionam-se a este, outros, como náuseas e vômitos, dificuldade de realimentação, íleo prolongado, reoperações, dor, astenia, febre, diarreias e infecções. As complicações gastrointestinais, muitas vezes, já presentes no pré-operatório, podem se agravar ainda mais no pós-operatório, como é o caso da desnutrição proteico-calórica grave. Esta última, por si só, dificulta o desmame ventilatório, a cicatrização de feridas e exige a introdução de suplementação alimentar enteral ou parenteral, conforme a necessidade. Esta suplementação é responsável por várias outras complicações como, intolerância à dieta com náuseas, vômitos, diarreia, doença de refluxo gastroesofágico com ou sem broncoaspiração, síndromes desabsortivas, dislipidemia, entre outras ${ }^{1,145}$. Não houve diferença significativa na frequência das complicações gastro-intestinais, entre os grupos $\mathrm{ACH}$ e $\mathrm{BCH}$, em nenhum dos períodos analisados.

Apesar da discordância entre os estudos realizados, em relação a fatores de risco de morbimortalidade, a transfusão intraoperatória parece ser uma unanimidade, como fator determinante de mau prognóstico ${ }^{56,92,93,146,147 .}$ Isto se deve às reações transfusionais, contaminações infecciosas de HC e pela imunomodulação ${ }^{56}$. 
As complicações relacionadas à resposta imune, são as alérgicas, as infecções, as rejeições e as neoplásicas. A fim de uma melhor discriminação destas complicações, neste estudo, foi feita a análise, separadamente. As complicações alérgicas foram consideradas como, todas as manifestações, inexistentes previamente ao $\mathrm{TH}$, relacionadas à hipersensibilidade de fatores ambientais como poeira, temperatura, umidade, a alimentos, a transfusões e a drogas como antibióticos. As complicações por rejeições englobaram as rejeições celulares agudas e crônicas e as complicações neoplásicas englobaram recidiva de tumor de base e novas neoplasias.

Complicações alérgicas são comuns após $\mathrm{O} T \mathrm{TH}$, podendo ter manifestações cutâneas (eritemas, rushes, pápulas, placas, lesões liquenificadas); manifestações respiratórias (broncoespasmo, hipertrofia adenoamigdaliana com obstrução de via aérea) e até manifestações sistêmicas com reações anafilático-anafilactóides. As complicações alérgicas foram menos frequentes no grupo $\mathrm{ACH}$ no período de internação e até 1 ano pós-TH, quando comparado ao $\mathrm{BCH}$.

Complicações por uso de imunossupressores são comuns com o uso de inibidores de calcineurina, porém mais evidentes com a ciclosporina: hirsutismo, hiperplasia gengival, fissuras periorais e em língua. Já com tacrolimus pode-se ter náusea e vômitos, diarreia, cefaleia, tremores, e ambos podem levar à HAS, hipercalemia, hipomagnesemia e insuficiência renal. Os corticoides podem levar a mudanças de status mental, dificuldade de cicatrização de ferida operatória, úlceras, miopatias, catarata, Síndrome de Cushing. Podem ainda levar à hiperglicemia, dislipidemia, obesidade e HAS, constituindo a síndrome metabólica, que está fortemente associada a 
hipertrofia ventricular esquerda ${ }^{148}$ e à doença ateroesclerótica, elevando o risco cardiovascular em $64 \%$, nestes pacientes ${ }^{127,}{ }^{149}$. O micofenolato pode levar a náuseas e vômitos, diarreia, perda de peso, anemia, leucopenia e trombocitopenia. As globulinas antitimocíticas podem acarretar febre, tremores manifestações alérgicas de pele e até instabilidade hemodinâmica. A rapamicina pode levar à anemia, leucopenia, trombocitopenia, hipercolesterolemia, hipertrigliceremia, deiscência de ferida operatória, edema periférico e doença pulmonar intersticial. Os anticorpos monoclonais anti-infócitos $\mathrm{T}$, também podem causar febre, tremores, dor no peito, dispneia e rigidez. A manifestação de efeitos adversos é multifatorial, podendo ocorrer por hipersensibilidade, toxicidade ou idiossincrasia. Neste estudo não foram separadas reações por imunossupressores especificamente, no entanto, foram contempladas, quanto ao tipo de manifestação nos 14 diferentes tipos.

Quanto às rejeições, podem ser de vários tipos. A rejeição hiperaguda ou humoral ocorre minutos ou horas após o transplante, dependendo do tipo e concentração de anticorpos anti-HLA presentes na circulação. Rara no $\mathrm{TH}$, caracteriza-se pela presença de um grande número de células polimorfonucleares (PMN) na vasculatura, mas ausentes no interstício, com intenso acúmulo de plaquetas e formação de microtrombos, levando à isquemia severa e necrose do enxerto. Os pacientes de maior risco, são os politransfundidos, as multíparas e transplantados prévios. Uma vez que, não há terapêutica para sua interrupção, a conduta se restringe à prevenção pela escolha cuidadosa do doador e através da histocompatibilidade $A B O$ e das provas cruzadas negativas $^{150}$. Neste estudo não houve relato de rejeição hiperaguda. 
A rejeição aguda celular (RAC) é a forma mais comum de rejeição com incidência de 60\%, podendo ocorrer em dias ou até semanas após o transplante. Caracteriza-se por uma reação aguda celular com presença de macrófagos e linfócitos $\mathrm{T}$, no interstício do enxerto, com raros PMN. A lesão vascular característica é a necrose vascular com inflamação aguda. No caso do transplante ortotópico, os próprios leucócitos do enxerto, como linfócitos T e B, monócitos, macrófagos, e células dendríticas, funcionam tanto como antígenos, quanto como células apresentadoras de antígenos, estimulando diretamente o sistema imune do receptor. A RAC é subdividida, segundo os "Critérios de Banff"151, pela extensão do infiltrado inflamatório, em: grau 1 ou leve; 2 ou moderada e 3 ou grave, quando transcende os espaços porta e região perivenular com necrose hepatocítica ${ }^{152}$. Pode ser evitada com o uso de um esquema imunossupressor regular, composto por duas ou três drogas em doses adequadas, levando em conta, peso corpóreo, comorbidades e monitoramento do nível sérico em exames periódicos. A primeira linha de drogas a ser usada são os corticoides (prednisolona e prednisona) em altas doses por dois ou três dias consecutivos e mantidos, posteriormente, por até seis meses, em doses progressivamente decrescentes.

A rejeição crônica ou aguda tardia, habitualmente, manifesta-se após três meses de transplante, com incidência de $10 \%{ }^{36}$. Caracteriza-se, por uma diminuição progressiva do lúmen vascular arterial, devido ao crescimento das células endoteliais. Acredita-se que seja decorrente de reatividade humoral e celular, a antígenos menores de histocompatibilidade, como o sistema endotelial monocitário, que provoquem lesões leves no endotélio, seguidas de reparo ou decorrentes da liberação de interleucina-1 pelos monócitos e de fatores de 
crescimento pelas plaquetas. Inicialmente assintomática ou indistinguível da rejeição aguda, gradativamente, encontra-se, presença de infiltrado linfocitário, espessamento fibroso da íntima arterial e redução da luz vascular progressiva, evoluindo para isquemia e perda da função do órgão, com necessidade de retransplante $^{152}$. As alterações enzimáticas e a leucocitose com eosinofilia são suspeitas de rejeição, embora não haja consenso de sua magnitude, nem sejam alterações patognomômicas. Uma vez descartadas outras causas de alteração funcional do enxerto, tais como, causas vasculares, biliares e infecciosas, recomenda-se a realização de uma biópsia hepática, a fim de se obter certeza diagnóstica, grau de gravidade e implementação de tratamento adequado precocemente $^{153}$.

Neste estudo, o grupo $\mathrm{ACH}$ teve menos rejeições, nos quatro períodos analisados, quando comparado ao $\mathrm{BCH}$. Em transplante renal, este assunto fora estudado, anteriormente. Há contudo, poucas evidências de que transfusão de $\mathrm{CH}$ esteja relacionada com menor taxa de rejeição renal, mesmo quando realizada no período pré-operatório, o que aumentaria a sensibilização ao sistema HLA. Em uma revisão, publicada em 2012, sobre o impacto da transfusão de $\mathrm{HC}$ na rejeição de enxertos renais, foi inconclusivo se houve efeito positivo, nulo ou negativo sobre taxa de rejeição até 30 dias e até 1 ano póstransplante, devido ao reduzido número de trabalhos analisados ${ }^{154}$. Na área de TH, não há evidência clínica de correlação entre maior volume transfusional e menor número de episódios ou menor gravidade de rejeição em humanos, tendo sido sugerido um mecanismo de imunomodulação, em trabalho experimental ${ }^{155}$.

Quanto às complicações neoplásicas, a mais prevalente é a PTLD, uma linfoproliferação exacerbada onde $85 \%$ dos casos, se originam de linfócito B e 
$80 \%$ dos casos estão relacionados ao EBV. Dos $15 \%$ que se originam em linfócitos $\mathrm{T}$, apenas $30 \%$, estão relacionados ao EBV. Varia desde uma hiperplasia policlonal reacional até um linfoma de alto grau com proliferação monoclonal e manifestações extra-nodais. Os imunossupressores diminuem o número e o efeito da resposta específica contra o EBV dos linfócitos citotóxicos. Os casos de post-transplant lymphoproliferative disorders (PTLD) não relacionados ao EBV, não tem seu mecanismo de ação conhecido e são de pior prognóstico. Os fatores de risco para desenvolver PTLD são idade menor ou igual a 18 anos, grau e tipo de imunossupressão, incompatibilidade de anticorpos anti-EBV, entre receptor EBV negativo e doador EBV positivo. A incidência de PTLD no TH adulto é de $2,8 \%$, enquanto no pediátrico, é de até $15 \%{ }^{156}$. A mortalidade relacionada à PTLD é de até $50 \%$. A frequência de complicações neoplásicas menores foi maior no grupo $\mathrm{ACH}$, até 10 anos pós$\mathrm{TH}$, em comparação ao grupo BCH.

A transfusão de $\mathrm{CH}$ tem sido relacionada ao aumento do risco de recidiva de câncer, sendo estimado aumento do risco relativo de recidiva em 2,1 vezes, após transfusão de 3 unidades, em cirurgia de trato digestivo. A probabilidade de recidiva é maior quando o sangue é administrado no intraoperatório em relação ao pré e pós-operatório ${ }^{157}$. Van de Vatering et al. ${ }^{158}$ mostraram aumento da recidiva local de câncer colon-retal, no grupo de pacientes transfundidos. Dentre vários efeitos, a transfusão leva a alterações inflamatórias e imunomoduladoras que podem ser responsáveis pela recorrência da doença oncológica ${ }^{157}$.

Os fatores de risco transfusionais intraoperatórios, no $\mathrm{TH}$, referem-se à presença de hipertensão portal e formação de uma rica circulação colateral, à 
circulação hiperdinâmica e à resposta alterada à expansão volêmica com circulação esplâncnica aumentada, em detrimento da circulação sistêmica. Referem-se ainda, ao porte cirúrgico e às notórias alterações pré-existentes na hemostasia primária destes pacientes, porém, agravadas pelo procedimento anestésico-cirúrgico, por hemodiluição, por compressão, pela presença de adesões cicatriciais abdominais prévias, presença de trombose venosa de porta (TVPo), inexperiência da equipe cirúrgica e duração prolongada do procedimento $^{91}$.

A determinação de fatores de risco independentes para transfusão de $\mathrm{CH}$ perioperatório, neste estudo, identificou quatro fatores inversamente relacionados, o ZP/E, a depuração de creatinina estimada, o sódio e a hemoglobina préoperatórios; e dois fatores diretamente relacionados, o PELD e a RPIPP.

A dosagem de $\mathrm{Hb}$ pré-operatória, demonstrou ser um importante fator preditor de transfusão intraoperatório, em vários estudos de $\mathrm{TH}$ adultos e pediátricos $^{92,159-161}$, o que foi corroborado por este estudo, onde o maior volume de transfusão de $\mathrm{HC}$ ocorreu no período intraoperatório.

Curiosamente, as variáveis encontradas em outros estudos de THP, como peso inferior a $10 \mathrm{~kg}^{162}$, menor idade ${ }^{163,164}$, os níveis pré-operatórios elevados de $\mathrm{RNI}^{165}$ e reduzidos de plaquetas ${ }^{166,167}$ e fibrinogênio ${ }^{88,159}$ e o antecedente de cirugia de $\mathrm{Kasai}^{117}$, não se mostraram como fatores independentes de risco para transfusão de $\mathrm{CH}$ perioperatório, neste estudo. Deve ser lembrado, todavia, que a relação do z-escore se mostrou significativa quando correlacionou peso e estatura (ZP/E) para a mesma idade, nos grupos de maior e menor volume transfusional. 
O valor do sódio pré-operatório e o tamanho do enxerto ${ }^{146}$ foram relatados anteriormente como fatores de risco independentes de sobrevida do enxerto. Neste estudo, o sódio pré-operatório e a razão peso do implante para peso do paciente foram identificados como fatores de risco independentes de transfusão de $\mathrm{CH}$ perioperatório. No entanto, um maior volume de $\mathrm{CH}$ perioperatório $(>27,5 \mathrm{~mL} / \mathrm{kg})$, por sua vez, implicou em uma menor sobrevida do enxerto e do paciente, em todos os períodos analisados.

O conceito de hemorragia maciça em crianças é variável, podendo ser definido, como a perda de $100 \%$ da volemia em 24 horas, de $50 \%$ da volemia em 3 horas ou de $10 \%$ da volemia por minuto ${ }^{168}$. Consequentemente, o conceito de transfusão maciça é mutável, pois é embasado no cálculo da volemia que, por sua vez, depende da faixa etária e do peso do paciente ${ }^{168}$.

Em 2013, Huang et al. ${ }^{165}$ publicaram um estudo, envolvendo 198 pacientes pediátricos, procurando identificar, fatores de risco preditores, da necessidade de transfusão maciça, durante o THP com doador vivo. O conceito de transfusão maciça utilizado foi a administração de volume total de $\mathrm{HC}$ superior a uma volemia do paciente. Os pacientes que mais necessitaram de hemotransfusão foram os de menor idade, menor peso e com RNI mais prolongado. O único fator preditivo de risco independente identificado para transfusão maciça, naquele estudo, foi o valor de RNI. Para elevação de cada 0,1 unidade, do valor do $\mathrm{RNI}$, foi constatado um aumento de risco de ocorrência de transfusão maciça de 1,083 vezes.

Em recente publicação, realizada por Jin et al. ${ }^{166}$, envolvendo 249 THP, realizados em um único centro, durante 20 anos consecutivos, com doadores vivos e falecidos, os autores estudaram fatores de risco relacionados à 
transfusão maciça. Esta, foi arbitrariamente definida, como a administração de volume de $\mathrm{CH} \geq 100 \%$ do total da volemia, considerada como $70 \mathrm{~mL} / \mathrm{kg}$ para todos os pacientes, de 3 meses a 17 anos de idade. Não houve diferença significativa na sobrevida de 6 meses pós-TH, entre o grupo que recebeu transfusão maciça, quando comparado ao que não recebeu. Os fatores de risco pré-operatórios independentes de transfusão maciça encontrados foram a leucocitose, a plaquetopenia e o doador falecido.

A predição do risco de transfusão, antes da cirurgia, é um passo crítico para a otimização da terapêutica transfusional e o gerenciamento adequado do uso de $\mathrm{HC}$, recursos preciosos e cada vez mais escassos em nosso meio. Todavia, este é um assunto polêmico, uma vez que envolve estratégias específicas que podem variar de acordo com as características individuais de cada serviço, como: perfil do paciente, técnicas cirúrgicas e anestésicas, diferentes gatilhos transfusionais institucionais, infraestrutura e aparato tecnológico, grau de experiência e colaboração entre as equipes envolvidas. A adoção de valores de referência que sejam efetivos em um centro, podem falhar completamente em outro, conforme a diversidade destas características ${ }^{169}$.

Foi evidenciado neste estudo, uma forte associação entre volume transfusional e maior frequência e maior gravidade das complicações pósoperatórias, em geral. Os pacientes que receberam maior volume transfusional tiveram menor taxa de extubação, períodos de intubação mais prolongados, maior taxa de reoperações, tempo de internação em UTI e hospitalar maiores, número mais elevado de complicações maiores totais e por paciente, uma maior variabilidade de complicações, além de uma mortalidade maior no pósoperatório precoce, até 30 dias, e em todos os períodos do pós-operatorio 
tardio, até 1 ano, 5 anos e 10 anos. Estes achados são contundentes com estudos pregressos de correlação entre transfusão de HC e complicações pósoperatórias e de identificação de fatores de risco para mortalidade ${ }^{94,106,117,166}$.

Ramos et al. ${ }^{92}$, em 2003, realizaram estudo prospectivo com $122 \mathrm{TH}$ adultos, no qual se demonstrou que a transfusão intraoperatória de 3 ou mais unidades de $\mathrm{CH}$, prolongou o tempo de internação hospitalar. As variáveis de risco de mortalidade incluídas na análise multivariada foram o escore de ChildTurcotte-Pugg (CTP), o estado físico segundo a classificação UNOS (United Network for Organ Sharing $)^{170}$ e a transfusão de 6 ou mais unidades de $\mathrm{CH}$, sendo que, apenas a última, foi o único fator preditor de mortalidade.

Boyd et al. ${ }^{56}$, em 2007, avaliando 209 TH adultos, encontraram três fatores independentes associados a mortalidade: número de $\mathrm{CH}$ transfundidos no intraoperatório, presença de anticorpos por aloimunização, por transfusão prévia ou gestação, e esquema de imunossupressão com duas ou mais drogas distintas.

De Boer et al. ${ }^{91}$, em 2008, avaliando 433 TH adultos, identificaram três fatores de risco independentes, para sobrevida do enxerto hepático, após 1 ano de $\mathrm{TH}$ : diagnóstico de base, número de unidades de $\mathrm{CH}$ e de $\mathrm{CP}$ transfundidas. Além disso, identificaram quatro fatores de risco independentes para sobrevida do enxerto, após 5 anos de $\mathrm{TH}$ : número de unidades de $\mathrm{CH}$ e de CP transfundidas, tempo de isquemia fria e época de realização do transplante, relacionada à experiência da equipe.

Boin et al. ${ }^{171}$, em 2008, realizaram um estudo tipo coorte, onde analisaram $232 \mathrm{TH}$ em adultos, que tiveram transfusão maciça no intraoperatório. O grupo de pacientes que recebeu maior volume transfusional ( $\geq 6$ unidades de $\mathrm{CH}$ ) apresentou escore de CTP, de MELD, peso corpóreo, tempo cirúrgico e de 
isquemia quente superiores, em relação ao grupo que recebeu menor volume transfusional (<6 unidades de $\mathrm{CH}$ ). Foram identificados dois fatores de risco independentes de mortalidade: o nível de sódio sérico e a idade do doador.

Pereboom et al. ${ }^{107}$, em 2009, avaliaram os efeitos do uso de HC em 148 TH adultos, na sobrevida de 90 dias e de 1 ano. Houve redução significativa da sobrevida de pacientes e enxertos, com o uso de CP, comparado ao grupo que não utilizou plaquetas. Houve uma incidência maior de TRALI, relacionada ao uso de CRIO e de PFC, em relação ao uso exclusivo de $\mathrm{CH}$. As alterações inflamatórias causadas pelos HC são agravadas pela lesão de isquemia e reperfusão do enxerto. Ocorre liberação de debris celulares e endotoxinas do enxerto isquêmico, com aumento de permeabilidade vascular pulmonar, ligação de anticorpos de leucócitos citotóxicos, microagregação plaquetária e ativação do sistema complemento com deflagração de resposta inflamatória ${ }^{172}$. Nestes pacientes, foi observada menor sobrevida, pois houve maior incidência de falência respiratória com enxertos funcionantes.

Lopéz Santamaría et al. ${ }^{106}$, em 2005, estudaram fatores prognósticos que interferem na sobrevida do enxerto hepático em 292 THP com doador falecido, realizados em 234 crianças, durante um período de 15 anos e, apesar de encontrarem 11 variáveis na análise univariada, como, z-escore de peso para estatura (ZP/E), necessidade de retransplante, transfusão intra-operatória de $\mathrm{CH}$, de $\mathrm{CP}$, peso do doador inferior a $10 \mathrm{~kg}$; na análise multivariada, identificaram apenas quatro variáveis independentes: idade inferior a 3 anos, classificação de UNOS, o momento do procedimento cirúrgico, relacionada à curva de aprendizado e ganho de proficiência da equipe e o diagnóstico de base (cirrose autoimune ou criptogenética). 
Já Nacoti et al. ${ }^{94}$, em 2012, realizaram um estudo tipo coorte com 243 pacientes submetidos a THP com doador falecido, no qual foi avaliada a associação entre transfusão e sobrevida de enxertos e pacientes. O risco de morte dos pacientes que receberam, no intraoperatório, três ou mais unidades de $\mathrm{CH}$ foi 3,15 vezes maior e os que receberam três ou mais unidades de PFC foi 3,35 vezes maior, quando comparados aos que receberam uma ou nenhuma unidade, do $\mathrm{HC}$ respectivo.

Neste estudo, identificou-se dois fatores independentes de risco de mortalidade, que foram a DCr estimada no pré-operatório e um volume transfucional de $\mathrm{CH}>27,5 \mathrm{~mL} / \mathrm{kg}$, no período perioperatório. A fórmula de Schwartz simplificada utilizada, pode superestimar valores pelas baixas dosagens de creatinina sérica, habitualmente vistas em pacientes muito desnutridos pela hepatopatia crônica, podendo justificar seu menor impacto como um fator de risco independente de mortalidade, uma vez que não foi mensurado em urina de $24 \mathrm{~h}$, no pré-operatório. Já a transfusão de $\mathrm{CH}$, foi forte fator de risco independente de mortalidade, fato concordante com outros estudos realizados em $\mathrm{TH}_{\text {adulto }}^{92,146}$ e pediátrico $^{173,174}$.

A sobrevida global dos pacientes ao longo de 1 ano, 5 anos e 10 anos pó-TH foi, respectivamente, de $87,1 \% ; 81,5 \%$ e $80,3 \%$ e a sobrevida global dos enxertos foi, respectivamente, de $87,1 \% ; 77,7 \%$ e $75,6 \%$, valores compatíveis com resultados obtidos em outros grandes centros ${ }^{33,37}$. A análise comparativa entre as curvas de sobrevida de pacientes e enxertos, demonstrou uma menor sobrevida de ambos ao longo de 1, 5 e 10 anos no grupo $\mathrm{ACH}$, em comparação ao grupo $\mathrm{BCH}$, confirmando relatos prévios de que a transfusão de $\mathrm{CH}$ aumenta o número de complicações pós-operatórias, bem como, abrevia a sobrevida de pacientes e enxertos $92,93,146,147,175$. 
O THP deixou de ser medida heróica para se destacar como tratamento de eleição de um crescente de pacientes com doença hepática terminal. Este cenário inclui, não somente, redução de complicações de longo prazo e da recorrência da patologia de base, mas melhorias na qualidade de vida, bem como, a inserção social destas crianças e adolescentes, tornando-se um desafio à sociedade moderna.

As limitações deste estudo foram, o fato de ser retrospectivo, os dados referentes às complicações e à sobrevida terem sido avaliados, desde o início da implantação do programa de TH, envolvendo uma curva de aprendizado, a qual pode ter influenciado os resultados.

Este estudo, que incluiu 240 crianças pequenas, evidenciou associação de transfusão de $\mathrm{CH}$ com aumento das complicações de ordem infecciosa, cardiovascular, respiratória, neoplásica e de sangramento, e redução de complicações por alergia e rejeição. Os seus resultados reforçam a necessidade da adoção de medidas que possibilitem restringir o uso de $\mathrm{CH}$ neste grupo de pacientes, o que parece apresentar um efeito imunomodulatório persistente a longo prazo, merecendo maior elucidação em novos estudos. Deve-se dar atenção especial, no pré-operatório, à otimização da relação peso/estatura da criança e da função renal, ao tratamento das condições com impacto no PELD, no sódio e na anemia e, no intraoperatório, avaliar criteriosamente a relação do peso do implante para o peso do paciente. Outros estudos se fazem necessários no transplante hepático intervivos pediátrico para complementar os resultados deste trabalho, visando a dimuição da morbimordalidade que ainda acompanha este procedimento complexo que envolve crianças e um doador vivo saudável. 
6 CONCLUSÕES 
1 - Pacientes que receberam maior volume de concentrado de hemácias no período perioperatório do transplante hepático pediátrico (THP) com doador vivo apresentaram maior incidência e maior gravidade de complicações pós-operatórias e menor sobrevida precoce e tardia, tanto do enxerto quanto dos pacientes.

2 - O z-escore de peso para altura, o escore de gravidade PELD, a depuração de creatinina, os níveis pré-operatórios de sódio e de hemoglobina e a relação do peso do implante para o peso do paciente foram indicadores independentes do risco de transfusão de concentrado de hemácias no período perioperatório do THP com doador vivo. 
7 ANEXOS 


\title{
Anexo A. Aprovação no Comitê de Ética em Pesquisa do AC Camargo Cancer Center (HACC)
}

\author{
FUNDAÇÃO ANTÔNIO \\ PRUDENTE-HOSPITAL DO \\ CÂNCER A C CAMARGO
}

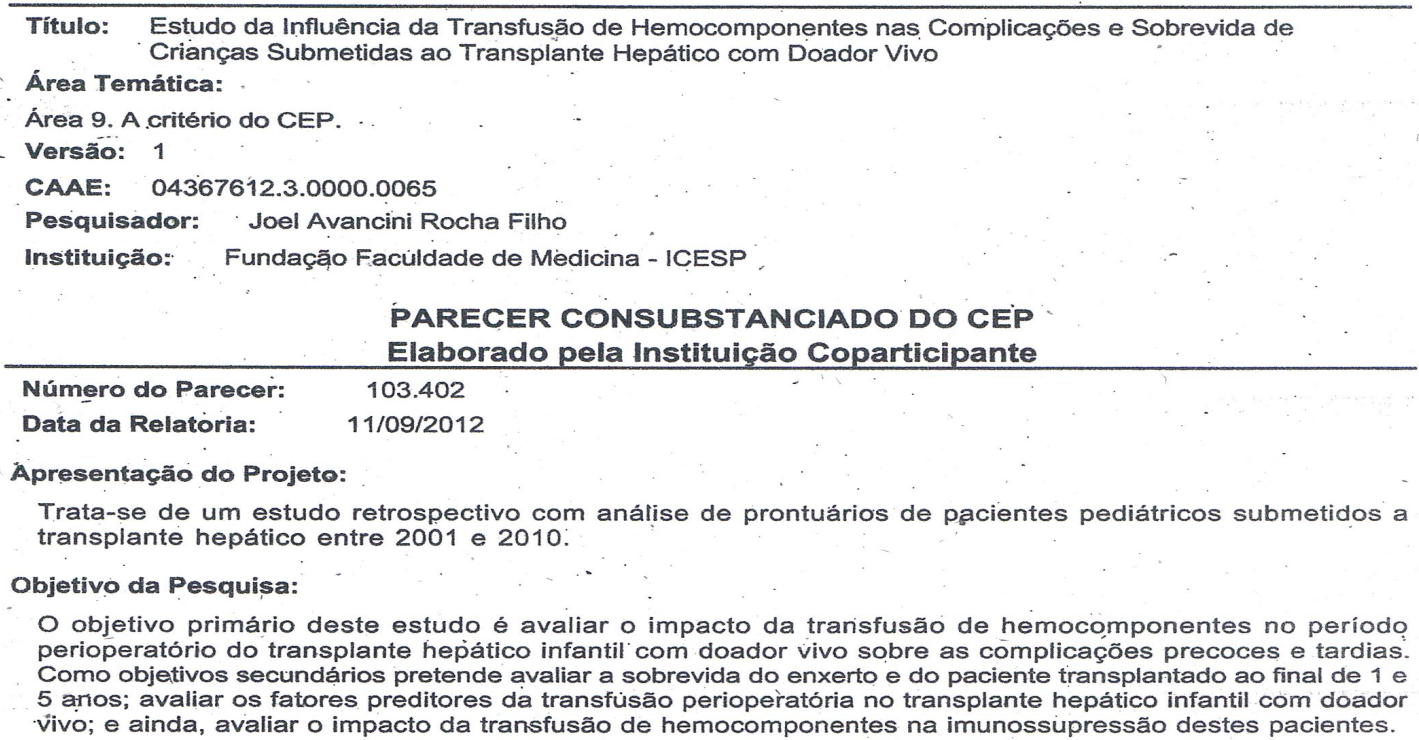

Avaliação dos Riscos e Beneficios:

Não há riscos uma vez que se trata de um estudo retrospectivo com analise de prontuários.

Comentários e Consideraçöes sobre a Pesquisa:

Trata-se de um estudo observacional e retrospectivo. Serão analisados 254 pacientes com diagnóstico de doença hepatopática crônica e peso menor ou igual a $20 \mathrm{~kg}$, submetidos a

transplante hepático com doador vivo, realizados no Hospital A.C. Camargo, no periodo de maio de 2001 a dezembro de 2011.

Os pacientes serão alocados em 3 grupos de acordo cỏm o volume total de hemocomponentes transfundidos no período de 24 horas antes do transplante até 48 horas após o final da anestesia: grupo 1, pacientes não transfundidos; grupo 2, pacientes que receberam até $20 \mathrm{mi} / \mathrm{kg}$ de hemocomponentes (CH, PFC, CPP e CRP); grupo 3, pacientes que receberam mais do que $20 \mathrm{ml} / \mathrm{kg}$ de hemocomponentes.

Serão coletadas váriáveis demográficas; dados do procedimento cirúrgico e do periodo peri-operatório bem como da evolução clínica e desfechó de 1 e 5 anos de sobrevida.

Considerações sobre os Termos de apresentação obrigatória:

Apresentados de maneira adequada.

Endereço: Rua Professor Antônio Prudente, 211 Bairro: Liberdade

UF: SP - Município:

Telefone: (111)189-5020
CEP: $01.509-900$

Fax: (111)189--5020

E-mail: cep·hcancer@hcancer.org.br; Ip-kowalski@uol.com.br 
Anexo A. Aprovação no Comitê de Ética em Pesquisa do AC Camargo

Cancer Center (HACC) (continuação)

\section{FUNDAÇÃO ANTÔNIO \\ PRUDENTE-HOSPITAL DO \\ CÂNCER A C CAMARGO}

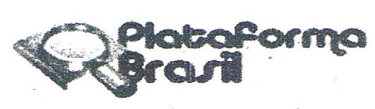

Recomendações:

Nenhuma.

Conclusōes ou Pendências e Lista de Inadequaçōes:

Projeto bem estruturado, com objetivos claros e delineamento adequado.

Situação do Parecer:

Aprovado

Necessita Apreciação da CONEP:

Não

Consideraçōes Finais a critério do CEP:

Análise da Comissão de Pesquisa (COPE): aprovado com sugestões.

Sugestão COPE: Em relação à análise estátística, é importante descrever os procedimentos para escolha das variáveis identificadas na análise univariada e que integrarão o modelo múltiplo (exemplo, $p<0,20$ ?)

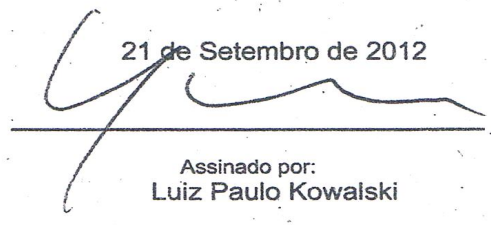

Endereço: Rua Professor Antônio Prudente, 211

Bairro: Liberdade

Telefone: (111)189-5020 Fax: (111)189-5020 . E-mail: cep_hcancer@hcancer.org.br; Ip-kowalski@uol.com.br 
Anexo B. Aprovação no Comitê de Ética em Pesquisa da Faculdade de Medicina da Universidade de São Paulo (FMUSP)

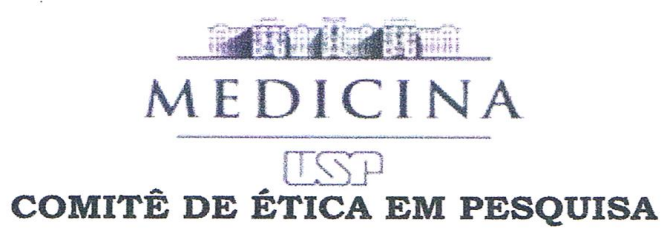

\section{APROVAÇÃo}

O Comitê de Ética em Pesquisa da Faculdade de Medicina da Universidade de São Paulo, em sessão de o8/o8/2012, APROVOU o Protocolo de Pesquisa $n^{\circ}$ 243/12 intitulado: "ESTUDO DA INFLUÊNCIA DA TRANSFUSÃO DE HEMOCOMPONENTES NAS COMPLICAÇÕES E SOBREVIDA DE CRIANÇAS SUBMETIDAS AO TRANSPLANTE HEPÁTICO COM DOADOR VIVO" apresentado pelo Departamento de CIRURGIA

Cabe ao pesquisador elaborar e apresentar ao CEPFMUSP, os relatórios parciais e final sobre a pesquisa (Resolução do Conselho Nacional de Saúde $n^{\circ}$ 196, de 10/10/1996, inciso IX.2, letra "c").

Pesquisador (a) Responsável: Joel Avancini Rocha Filho

Pesquisador (a) Executante: Karina Gordon

CEP-FMUSP, 09 de Agosto de 2012.

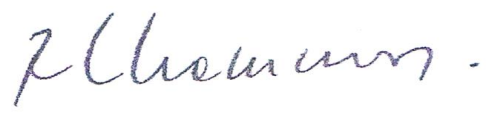

Prof. Dr. Roger Chammas Coordenador

Comitê de Etica em Pesquisa 


\section{Anexo C. Carta de Anuência da realização do estudo em questão do Chefe do Departamento de Transplante do AC Camargo Cancer Center (HACC)}

Ao

Comitê de Ética em Pesquisa

Faculdade de Medicina da Universidade de São Paulo

CEP. FMUSP

Pela presente, a Fundação Antonio Prudente - Hospital A. C. Camargo manifesta sua anuencia ao desenvolvimento do Projeto de Pesquisa intitulado "ESTUDO DA INFLUENCIA DA TRANSFUSÃO DE HEMOCOMPONENTES NAS COMPLICAÇŌES E SOBREVIDA DE CRIANÇAS SUBMETIDAs AO TRANSPLANTE HEPÁTICO COM DOADOR VIVO" a ser desenvolvido pela pesquisadora executante Karina Gordon (como tese de doutorado) e orientado pelo pesquisador responsavel Joel Avancini Rocha Filho da Faculdade de Medicina da Universidade de São Paulo.

Atenciosamente,

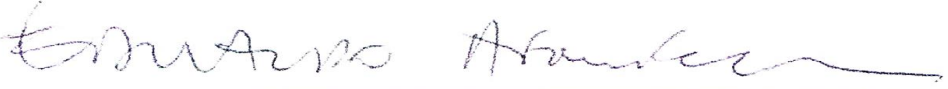

Dr Eduardo Antunes da Fonseca Chefe do Depto de Transplante Hepático do HACCamargo 
Anexo D. Apresentações do estudo em congressos nacionais e internacionais

1. Blood Transfusion Increases the Risk of Portal Vein Thrombosis in Pediatric Living Donor Liver Transplantation

Apresentação em português de estudo com resultados parciais em formato de aula expositiva em Fórum Internacional de Transplantes do Aparelho Digestivo - FITx de 12 a 14 de novembro de 2014. Evento no qual recebeu prêmio de $1^{\circ}$ lugar como melhor trabalho.

2. Blood Transfusion Increases the Risk of Portal Vein Thrombosis in Pediatric Living Donor Liver Transplantation

Apresentação em inglês de estudo com resultados parciais em formato de pôster eletrônico durante o Annual Meeting of the American Society of Anesthesiology (ASA) de 11 a 15 de outubro de 2014.

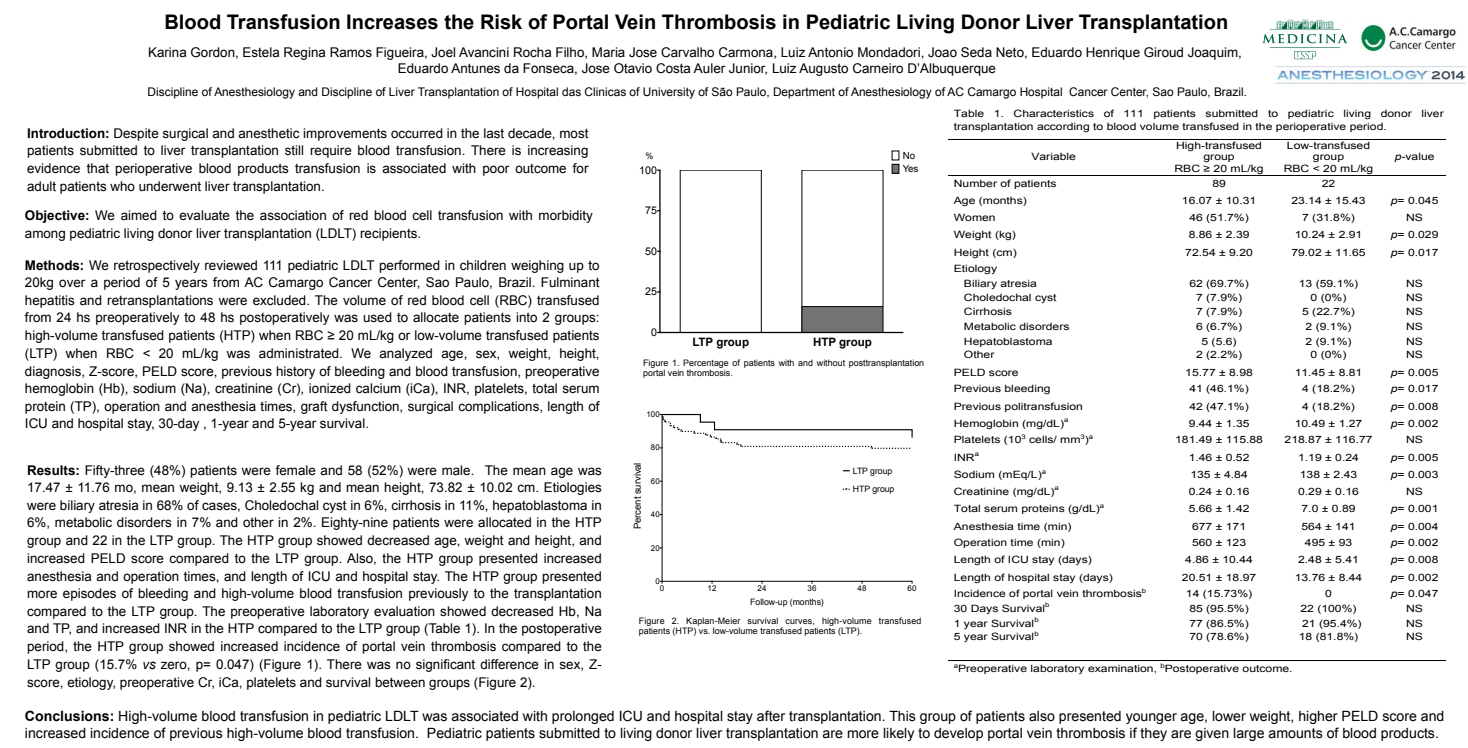




\section{Blood Transfusion Is Risk Factor For Short-Term Postoperative Major}

\section{Complications In Pediatric Living Donor Liver Transplantation}

Apresentação em inglês, realizada pela Profa.Dra. Estela Regina Ramos

Figueira, de estudo com resultados parciais em formato de pôster eletrônico

com apresentação oral longa, durante o Annual Meeting of the Americas

Hepato-Pancreato-Biliary Association (AHPBA) de 29 de março a 02 de abril de

2017.

\section{LONG ORAL SESSION ABSTRACTS}

\section{LO 20 - BLOOD TRANSFUSION IS RISK FACTOR FOR SHORT-TERM POSTOPERATIVE MAJOR COMPLICATIONS IN PEDIATRIC LIVING DONOR LIVER TRANSPLANTATION}

J.A. Rocha-Filho, E.R.R. Figueira, K. Gordon, M.J.C. Carmona, E.H.G. Joaquim, L.A. Mondadori, J. Seda-Neto, E.A. Fonseca, J.O.C. Auler-Jr and L.A.C. D’Albuquerque

Hospital das Clinicas from University of Sao Paulo, Sao Paulo, Brazil

Objective: Our aim was to evaluate if perioperative red blood cells (RBC) transfusion during pediatric living donorliver transplantation (PLDLT) increases postoperative complications and, if so, to investigate risk factors for transfusion. Methods: We retrospectively evaluated 240 children with up to 20 $\mathrm{kg}$, who underwent elective PLDLT in one single center. Patients were divided according to grade of postoperative (30days) complications (modified Clavien-Dindo classification). In LCo ( $\mathrm{n}=103$ ), patients presented lower grade complications ( 0 -IIIa), and in HCo group ( $\mathrm{n}=137)$, major complications (IIIb-V). Cut-point of RBC transfusion volume $(27.5 \mathrm{~mL} / \mathrm{kg})$ related to major complications was calculated with ROC curve and patients were evaluated according to volume of RBC transfusion in low transfusion (LRBC $\leq 27.5 \mathrm{~mL} / \mathrm{kg}$ ) and high transfusion (HRBC $>27.5 \mathrm{~mL} / \mathrm{kg}$ ) groups. Results: HCo group showed increased $\mathrm{RBC}$, fresh frozen plasma, and platelets transfusion, preoperative bilirubin, intraoperative lactate, and ICU and hospital stay, and decreased height, weight, and age, preoperative glucose and sodium, perioperative hemoglobin, and albumin, compared to LCo group. Multiple logistic regression identified perioperative transfusion and height as significant variables. Pearson's coefficient analysis showed high RBC transfusion positive correlation with preoperative PELD, intraoperative crystalloid infusion and lactate, and graft-to-recipient-body-weight-ratio and negative correlation with height, weight, age and preoperative sodium and lactate.
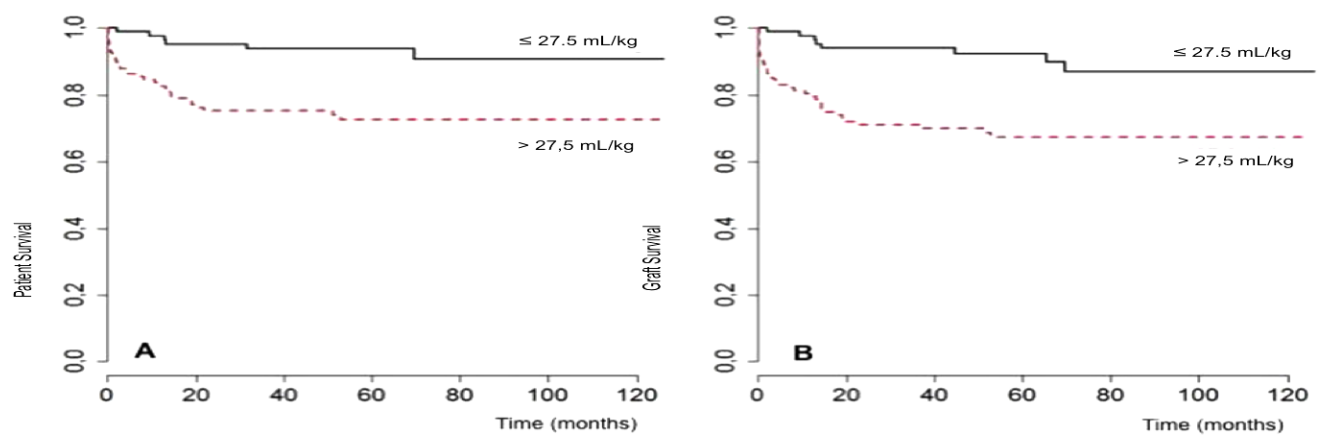


\section{Anexo E. Formulário de coleta de dados do doador}

FOLHA DE COLETA DE DADOS - DOADOR

NOME

$\mathrm{RGH}$

SEXO $M() \quad F()$

DATA NASC

PESO

ALT

IMC

GRUPO SG

TRANSFUSÃO SIM ( ) NÃO ( ) GESTAÇÃO SIM ( ) NÃO ( )

CIRURGIA PRÉVIA

PARENTESCO SIM( ) NÃO( ) GRAU

DATA TX HEP_ I_ I_ TIPO INTERVIVOS ( ) CADÁVER ( )

ANESTESIA INÍCIO__

CIRURGIA INÍCIO__ H_ MIN TÉRMINO__ H_ MIN

INTERNAÇÃO : UTI ENTRADA_I_I_SAÍDA_____DIAS _ _ _ _

HOSPITALAR ENTRADA_I_ _ SAÍDA _ _ I_DIAS

ASA COMORBIDADES

PRÉ -TX Hb:__ / Htc:__ Na:__ K:__ U:_ /Cr:__ GLI:_

PÓs -TX Hb:__ / Htc:__ Na:__ K:__ U:__ / $\mathrm{Cr}$

TIPO DE ENXERTO

PESO DO ENXERTO: g

SOLUÇÃO DE PRESERVAÇÃO:

COMPLICAÇÕES

EXTUBAÇÃO EM SO SIM( ) NÃO( )

A. GERAL ( ) PERI CONT ( ) PCA EV ( )

OBSERVAÇÕES: 


\section{Anexo F. Formulário de coleta de dados do receptor}

FOLHA DE COLETA DE DADOS - RECEPTOR

PRÉ-OPERATÓRIO

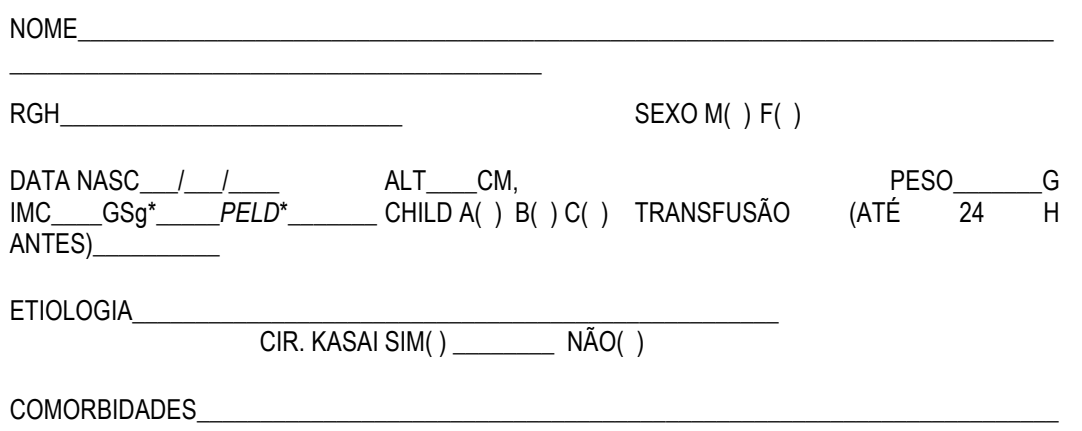

MEDICAÇÃO PRÉ -

TRANSPLANTE

DNPM

NUTRIÇÃO

ECO

PARTO

NORMAL ( )

CESÁREA ( )

PREMATURO ( )

$\operatorname{GEMELAR}()$

OBSERVAÇÕES
$\mathrm{Hb}^{*} \_\mathrm{HtC} \_\mathrm{PQT} \_$_

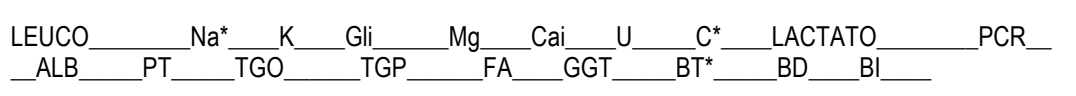
FOLHA DE COLETA DE DADOS - RECEPTOR
INTRAOPERATÓRIO

ANESTESIA:
TÉRMINO____MIN
CIRURGIA:
TÉRMINO_____CIO_MIN

EXAMES 
CLAMPEAMENTO DOADOR:___

CLAMPEAMENTO RECEPTOR: _

INÍCIO DAS ANASTOMOSES:__

TÉRMINO DAS ANASTOMOSES E REPERFUSÃO H_ MIN

TEMPO ISQUEMIA FRIA: INÍCIO__ TÉRMINO__

TEMPO ISQUEMIA QUENTE: INÍCIO__ H__ MIN TÉRMINO__ PESO EXPLANTE G IMPLANTE G DIURESE ML

VOL CRIATALOIDE ML COLÓIDE ML HEMOCOMPONENTES

DROGAS NORA( ) ADR( ) EFED( ) DOPA( ) DOBUTA( )

ANTIBIOTICOPROFILAXIA/TERAPIA: AMPICILINA ( ) CEFTRIAXONE ( ) CEFOTAXIMA ( ) CEFTAZIDIME ( ) FLUCONAZOL ( ) GANCICLOVIR( ) BACTRIM ( ) ACICLOVIR ()

OUTROS

HEPARINA_APRO__IPSILON_ MANITOL__ FUROSEMIDA

INTERCORRÊNCIAS:

\section{FOLHA DE COLETA DE DADOS- INTRAOPERATÓRIO}

\section{EXAMES LABORATORIAIS}

FASE 1- PRIMEIRA

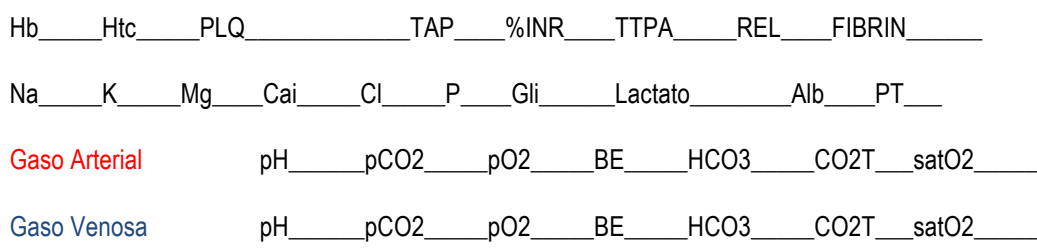

FASE 1- SEGUNDA

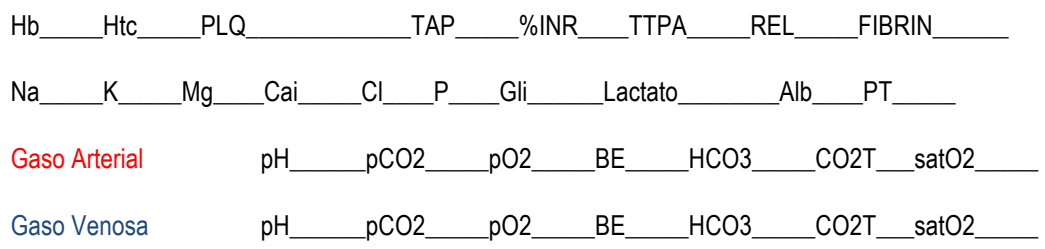


FOLHA DE COLETA DE DADOS- INTRAOPERATÓRIO

FASE 2

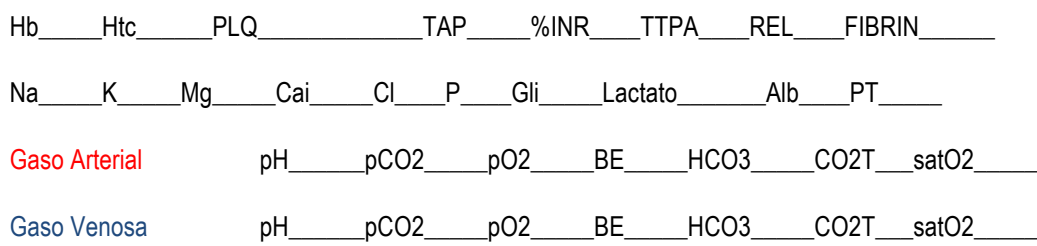

FASE 3 - PRIMEIRA

$\mathrm{Hb} \_$Htc__PLQ__
Gaso Arterial
Gaso Venosa

FASE 3 - ÚLTIMA

Gaso Arterial
Gaso Venosa
EXTUBAÇÃO EM SO
OBSERVAÇÕES

FOLHA DE COLETA DE DADOS

PÓS-OPERATÓRIO - EXS LABORATORIAIS

ENTRADA DE UTI (POI)
Gaso Arterial
Gaso Venosa


$1^{\circ} \mathrm{PO}$

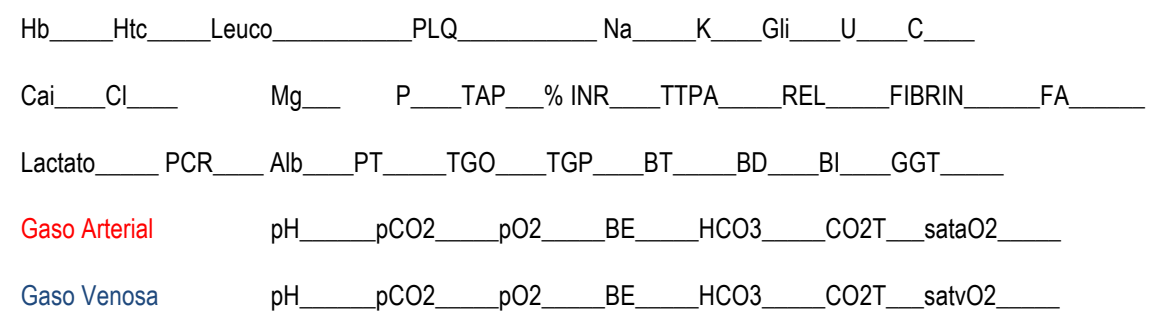

\section{ALTA DA UTI}

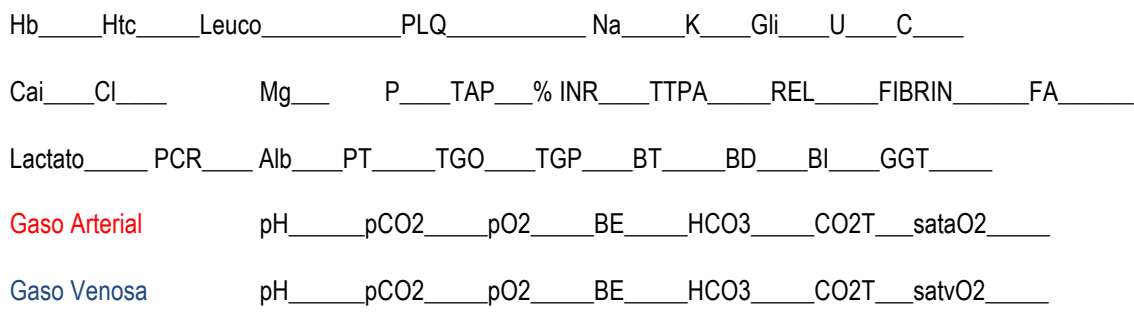

\section{PÓS-OPERATÓRIA - COMPLICAÇÕES}

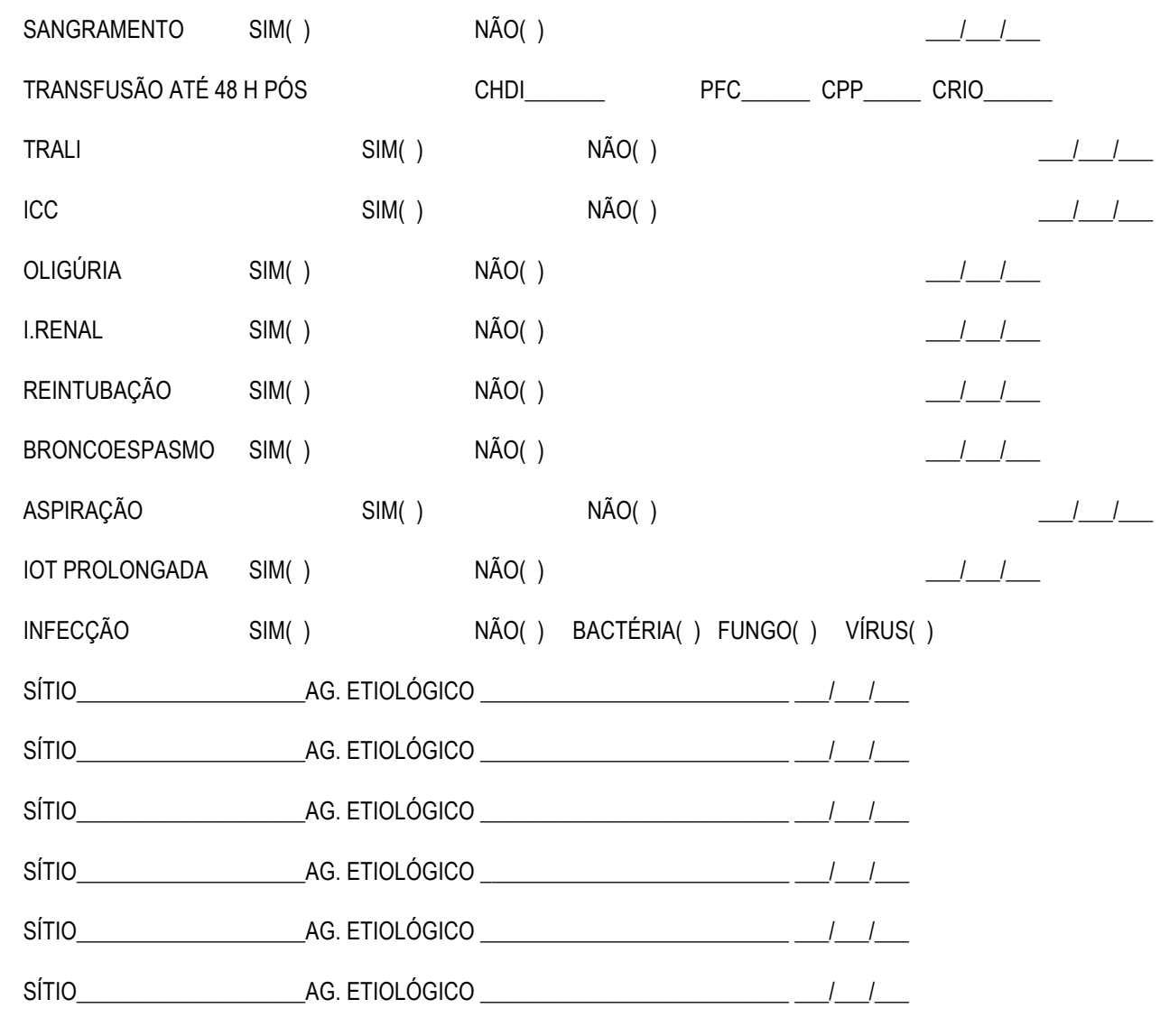

OBSERVAÇÕES 


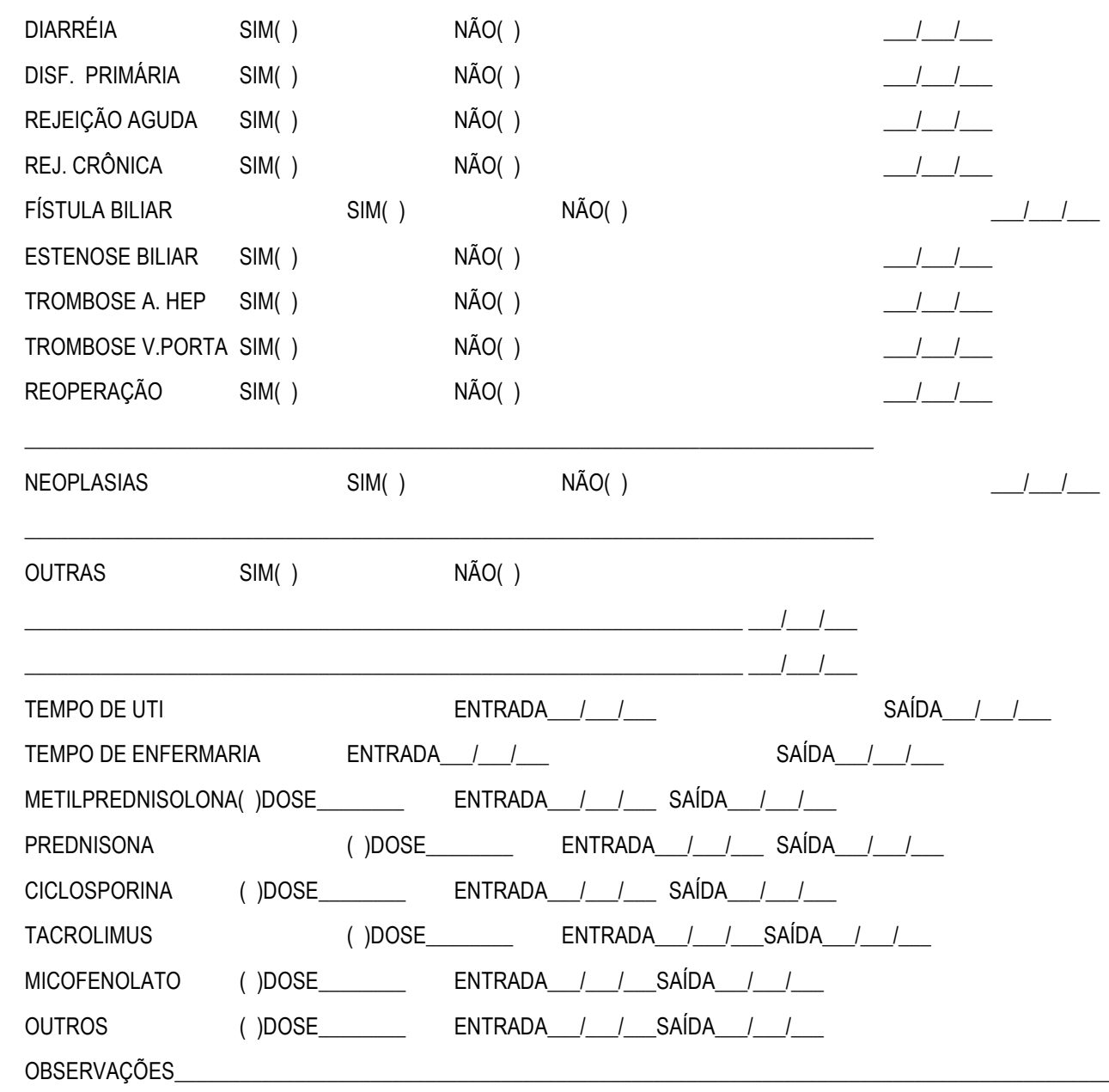

\begin{tabular}{|c|c|c|c|}
\hline ÓBITO & $\operatorname{SIM}()$ & DATA I I I & NÃO( ) \\
\hline AUSA & & & \\
\hline
\end{tabular}

ÚLTIMA CONSULTA DATA_L_L

\section{ENDEREÇO}

TELEFONE ( )

CELULAR ( ) 
Anexo G. Análise univariada dos grupos de complicações menores (ausentes ou grau l-IIla) e maiores (grau IIlb-V)

\begin{tabular}{|c|c|c|c|c|c|c|c|c|c|c|c|c|c|c|c|c|c|c|c|}
\hline \multirow{2}{*}{ Complicações } & \multicolumn{6}{|c|}{ Cme (menores) } & \multicolumn{6}{|c|}{ Cma(maiores) } & \multicolumn{6}{|c|}{ Total } & \multirow{2}{*}{ Valor $p$} \\
\hline & $\mathrm{N}$ & Minimum & Mean & Median & Maximum & SD & $\mathrm{N}$ & Minimum & Mean & Median & Maximum & SD & $\mathrm{N}$ & Minimum & Mean & Median & Maximum & SD & \\
\hline$I \operatorname{Rx}(d)$ & 109 & 174,0 & 632,9 & 461,0 & 2131,0 & 439,6 & 131 & 136,0 & 512,4 & 316,0 & 3046,0 & 497,0 & 240 & 136,0 & 567,13 & 372,0 & 3046,0 & 474,66 & ,000 \\
\hline$P \operatorname{Rx}(g)$ & 109 & 5000,0 & 9661,4 & 9140,0 & 18100,0 & 2913,8 & 131 & 4850,0 & 8611,3 & 7650,0 & 20000,0 & 3085,4 & 240 & 4850,0 & 9088,22 & 8072,5 & 20000,0 & 3047,85 & ,000 \\
\hline P Rx(kg) & 109 & 5,0 & 9,6 & 9,1 & 18,1 & 3,0 & 131 & 4,9 & 8,6 & 7,7 & 20,0 & 3,1 & 240 & 4,9 & 9,06 & 8,1 & 20,0 & 3,07 & ,001 \\
\hline $\mathrm{E} \operatorname{Rx}(\mathrm{cm})$ & 109 & 60,0 & 76,6 & 74,0 & 112,0 & 11,5 & 131 & 54,0 & 71,9 & 68,0 & 120,0 & 11,2 & 240 & 54,0 & 73,97 & 70,0 & 120,0 & 11,55 & ,000 \\
\hline Zscore P/I & 109 & $-4,580$ & $-1,3$ & $-1,230$ & 1,930 & 1,2 & 131 & $-4,530$ & $-1,5$ & $-1,380$ & 2,210 & 1,3 & 230 & $-4,6$ & $-1,41$ & $-1,3$ & 2,2 & 1,28 & , 105 \\
\hline Zscore E/l & 109 & $-3,220$ & $-0,3$ & $-0,160$ & 2,300 & 1,2 & 131 & $-6,020$ & $-0,5$ & $-0,365$ & 3,710 & 1,5 & 230 & $\begin{array}{l}-6,020 \\
\end{array}$ & $-0,39$ & $-0,260$ & 3,710 & 1,35 & 0,306 \\
\hline Zscore P/E & 106 & $-5,600$ & $-2,0$ & $-1,695$ & 0,430 & 1,4 & 124 & $-7,090$ & $-2,1$ & $-2,080$ & 1,380 & 1,5 & 230 & $-7,090$ & $-2,10$ & $-1,950$ & 1,380 & 1,45 & 0,313 \\
\hline ZBMI (IMC) & 109 & $-3,140$ & 0,0 & 0,080 & 2,640 & 1,1 & 131 & $-3,320$ & $-0,2$ & $-0,2$ & 3,9 & 1,4 & 240 & $-3,320$ & $-0,14$ & $-0,060$ & 3,940 & 1,28 & 0,330 \\
\hline IMC & 109 & 12,6 & 16,2 & 16,3 & 19,6 & 1,5 & 131 & 12,6 & 16,3 & 16,4 & 22,5 & 1,8 & 240 & 12,6 & 16,25 & 16,3 & 22,5 & 1,66 & ,777 \\
\hline PELD_Pré & 96 & 1,0 & 16,2 & 15,5 & 34,0 & 7,0 & 129 & 1,0 & 17,8 & 17,0 & 45,0 & 8,2 & 225 & 1,0 & 17,07 & 16,0 & 45,0 & 7,69 & 140 \\
\hline $\begin{array}{l}\text { No.HDA_Pré } \\
\text { (hemorragia) }\end{array}$ & 103 & 0,0 & 0,7 & 0,0 & 5,0 & 1,2 & 129 & 0,0 & 0,8 & 0,0 & 9,0 & 1,4 & 232 & 0,0 & 0,73 & 0,0 & 9,0 & 1,30 & ,507 \\
\hline DV Kasai_Pré & 45 & 45,0 & 110,2 & 101,0 & 365,0 & 54,6 & 59 & 49,0 & 99,7 & 93,0 & 181,0 & 29,5 & 104 & 45,0 & 104,25 & 98,0 & 365,0 & 42,28 &, 555 \\
\hline No.Inf 30d_Pré & 109 & 0,0 & 0,4 & 0,0 & 3,0 & 0,6 & 131 & 0,0 & 0,6 & 0,0 & 4,0 & 0,7 & 240 & 0,0 & 0,47 & 0,0 & 4,0 & 0,68 & ,081 \\
\hline $\begin{array}{c}\text { TA_IOP } \\
\text { (anestesia) }\end{array}$ & 100 & 1,2 & 10,3 & 10,0 & 19,4 & 2,0 & 122 & 6,8 & 10,4 & 10,2 & 16,0 & 1,7 & 222 & 1,2 & 10,33 & 10,1 & 19,4 & 1,84 &, 791 \\
\hline $\begin{array}{l}\text { TC_IOP } \\
\text { (cirurgia) }\end{array}$ & 100 & 5,3 & 8,6 & 8,5 & 17,6 & 1,8 & 122 & 5,5 & 8,6 & 8,3 & 14,6 & 1,7 & 222 & 5,3 & 8,61 & 8,5 & 17,6 & 1,77 & 810 \\
\hline $\begin{array}{c}\text { TIT_IOP } \\
\text { (isquemia total) }\end{array}$ & 92 & 55,0 & 101,6 & 91,0 & 270,0 & 37,4 & 119 & 50,0 & 105,4 & 90,0 & 505,0 & 56,6 & 211 & 50,0 & 103,72 & 90,0 & 505,0 & 49,08 &, 619 \\
\hline TIF_IOP(fria) & 88 & 10,0 & 56,5 & 43,5 & 225,0 & 39,6 & 111 & 5,0 & 64,9 & 47,0 & 445,0 & 54,8 & 199 & 5,0 & 61,21 & 45,0 & 445,0 & 48,72 & 298 \\
\hline TIQ_IOP(quente) & 93 & 22,0 & 45,0 & 45,0 & 80,0 & 12,7 & 119 & 20,0 & 40,7 & 40,0 & 80,0 & 11,2 & 212 & 20,0 & 42,59 & 40,0 & 80,0 & 12,05 & ,012 \\
\hline Diurese_IOP & 80 & 108 & 522,8 & 495 & 1950 & 329,3 & 110 & 110 & 480,2 & 425 & 1635 & 292,3 & 190 & 108 & 498,13 & 438 & 1950 & 308,33 & ,573 \\
\hline Criataloide_IOP & 84 & 550,00 & 1898,0 & 1865,00 & 5100,00 & 810,0 & 115 & 500,00 & 1923,2 & 1850,00 & 4600,00 & 832,1 & 199 & 500,00 & 1912,59 & 1865,00 & 5100,00 & 820,89 & 949 \\
\hline Colóide_IOP & 85 & 50,00 & 358,4 & 300,00 & 1350,00 & 241,7 & 114 & 100,00 & 335,0 & 300,00 & 1300,00 & 193,8 & 199 & 50,00 & 345,02 & 300,00 & 1350,00 & 215,29 & ,755 \\
\hline Diurese_IOP ind & 80 & 10,4 & 54,6 & 46,7 & 210 & 34,3 & 110 & 15,9 & 55,9 & 48,2 & 186 & 33,5 & 180 & 10 & 55,43 & 48 & 210 & 32,72 & ,627 \\
\hline $\begin{array}{l}\text { Criataloide_IOP } \\
\text { ind }\end{array}$ & 86 & 80,4 & 199,7 & 194,6 & 523,5 & 83,1 & 113 & 65,4 & 237,0 & 209,4 & 614,6 & 104,0 & 180 & 65,4 & 220,86 & 201,5 & 614,6 & 96,95 & ,015 \\
\hline Colóide_IOP ind & 85 & 5,7 & 39,1 & 33,3 & 112,5 & 23,4 & 114 & 8,9 & 39,9 & 36,3 & 104 & 22,5 & 192 & 5,7 & 39,50 & 35,4 & 112,5 & 20,69 & ,385 \\
\hline $\begin{array}{c}\text { Peso } \\
\text { Implante_IOP }\end{array}$ & 109 & 155 & 300,7 & 300 & 468 & 60,6 & 131 & 120 & 289,0 & 290 & 520 & 68,9 & 239 & 120 & 294,26 & 300 & 520 & 65,42 & , 159 \\
\hline RPI/PP ( \%) & 109 & 1,5 & 3,3 & 3,3 & 6,8 & 1,1 & 131 & 0,9 & 3,7 & 3,5 & 7,2 & 1,2 & 239 & 0,90 & 3,5 & 3,5 & 7,2 & 1,20 & ,035 \\
\hline Crio_Pré & 109 & 0,0 & 0,0 & 0,0 & 0,0 & 0,0 & 131 & 0,0 & 0,0 & 0,0 & 0,0 & 0,0 & 240 & 0,0 & 0,00 & 0,0 & 0,0 & 0,00 & 1,000 \\
\hline PFC_Pré & 109 & 0,0 & 0,0 & 0,0 & 0,0 & 0,0 & 131 & 0,0 & 0,0 & 0,0 & 0,0 & 0,0 & 240 & 0,0 & 0,00 & 0,0 & 0,0 & 0,00 & 1,000 \\
\hline Plaq_Pré & 109 & 0,0 & 0,0 & 0,0 & 0,0 & 0,0 & 131 & 0,0 & 0,0 & 0,0 & 0,0 & 0,0 & 240 & 0,0 & 0,00 & 0,0 & 0,0 & 0,00 & 1,000 \\
\hline
\end{tabular}


Anexo G. Análise univariada dos grupos de complicações menores (ausentes ou grau I-IIla) e maiores (grau IIIb-V) (continuação)

\begin{tabular}{|c|c|c|c|c|c|c|c|c|c|c|c|c|c|c|c|c|c|c|c|}
\hline \multirow[b]{2}{*}{ Complicações } & \multicolumn{6}{|c|}{ Cme (menores) } & \multicolumn{6}{|c|}{ Cma(maiores) } & \multicolumn{6}{|c|}{ Total } & \multirow{2}{*}{ Valor $p$} \\
\hline & $\mathrm{N}$ & Minimum & Mean & Median & Maximum & SD & $\mathrm{N}$ & Minimum & Mean & Median & Maximum & SD & N & Minimum & Mean & Median & Maximum & SD & \\
\hline $\begin{array}{l}\text { CHDI_IOP } \\
\end{array}$ & 109 & 0,0 & 213,9 & 200,0 & 903,0 & 163,5 & 131 & 0,0 & 289,0 & 218,0 & 1636,0 & 243,6 & 240 & 0,0 & 255,53 & 201,0 & 1636,0 & 214,53 & ,002 \\
\hline Crio_IOP & 109 & 0,0 & 0,0 & 0,0 & 0,0 & 0,0 & 131 & 0,0 & 0,5 & 0,0 & 70,0 & 6,1 & 240 & 0,0 & 0,29 & 0,0 & 70,0 & 4,52 & ,370 \\
\hline PFC_IOP & 109 & 0,0 & 1,7 & 0,0 & 180,0 & 17,4 & 131 & 0,0 & 14,3 & 0,0 & 458,0 & 62,8 & 240 & 0,0 & 8,67 & 0,0 & 458,0 & 48,47 & ,025 \\
\hline Plaq_IOP & 109 & 0,0 & 0,6 & 0,0 & 64,0 & 6,2 & 131 & 0,0 & 4,6 & 0,0 & 272,0 & 26,3 & 240 & 0,0 & 2,84 & 0,0 & 272,0 & 20,08 & ,064 \\
\hline $\begin{array}{l}\text { CHDI_Pós (ate } \\
48 \mathrm{~h})\end{array}$ & 109 & 0,0 & 44,7 & 0,0 & 410,0 & 86,0 & 131 & 0,0 & 74,7 & 0,0 & 1008,0 & 129,7 & 240 & 0,0 & 61,32 & 0,0 & 1008,0 & 113,13 & ,031 \\
\hline Crio_Pós & 109 & 0,0 & 0,0 & 0,0 & 0,0 & 0,0 & 131 & 0,0 & 0,8 & 0,0 & 108,0 & 9,4 & 240 & 0,0 & 0,45 & 0,0 & 108,0 & 6,97 & ,370 \\
\hline PFC_Pós & 109 & 0,0 & 1,4 & 0,0 & 150,0 & 14,5 & 131 & 0,0 & 11,5 & 0,0 & 494,0 & 55,3 & 240 & 0,0 & 7,01 & 0,0 & 494,0 & 42,55 & ,025 \\
\hline Plaq_Pós & 109 & 0,0 & 0,0 & 0,0 & 0,0 & 0,0 & 131 & 0,0 & 4,4 & 0,0 & 307,0 & 30,5 & 240 & 0,0 & 2,42 & 0,0 & 307,0 & 22,79 & ,071 \\
\hline $\begin{array}{c}\text { CHDI_Per } \\
\text { (pre+intratpos) }\end{array}$ & 109 & 0,0 & 269,1 & 239,0 & 1035,0 & 196,1 & 131 & 0,0 & 366,7 & 300,0 & 2287,0 & 322,2 & 240 & 0,0 & 323,18 & 300,0 & 2287,0 & 277,04 & ,004 \\
\hline Crio_Per & 109 & 0,0 & 0,0 & 0,0 & 0,0 & 0,0 & 131 & 0,0 & 1,3 & 0,0 & 108,0 & 11,1 & 240 & 0,0 & 0,74 & 0,0 & 108,0 & 8,29 & ,204 \\
\hline PFC_Per & 109 & 0,0 & 3,1 & 0,0 & 180,0 & 22,5 & 131 & 0,0 & 25,8 & 0,0 & 648,0 & 98,9 & 240 & 0,0 & 15,68 & 0,0 & 648,0 & 75,87 & ,017 \\
\hline Plaq_Per & 109 & 0,0 & 0,6 & 0,0 & 64,0 & 6,2 & 131 & 0,0 & 9,0 & 0,0 & 372,0 & 43,9 & 240 & 0,0 & 5,26 & 0,0 & 372,0 & 33,12 & ,024 \\
\hline $\begin{array}{l}\text { CHDI_Per_Ind } \\
\text { (volume/peso) }\end{array}$ & 109 & 0,0 & 31,1 & 26,6 & 141,8 & 25,4 & 131 & 0,0 & 46,7 & 38,3 & 305,5 & 39,7 & 240 & 0,0 & 39,67 & 31,3 & 305,9 & 34,76 & ,000 \\
\hline Crio_Per_Ind & 109 & 0,0 & 0,0 & 0,0 & 0,0 & 0,0 & 131 & 0,0 & 0,1 & 0,0 & 14,0 & 1,2 & 240 & 0,0 & 0,07 & 0,0 & 14,0 & 0,92 & 196 \\
\hline PFC_Per_Ind & 109 & 0,0 & 0,3 & 0,0 & 24,0 & 2,6 & 131 & 0,0 & 3,0 & 0,0 & 79,0 & 11,5 & 240 & 0,0 & 1,83 & 0,0 & 79,0 & 8,79 & ,015 \\
\hline Plaq_Per_Ind & 109 & 0,0 & 0,1 & 0,0 & 8,0 & 0,8 & 131 & 0,0 & 1,2 & 0,0 & 50,0 & 6,0 & 240 & 0,0 & 0,71 & 0,0 & 50,0 & 4,52 & ,021 \\
\hline ?T UTI & 109 & 1,0 & 2,1 & 1,0 & 21,0 & 2,6 & 131 & 1,0 & 9,1 & 4,0 & 77,0 & 13,3 & 240 & 1,0 & 5,93 & 2,0 & 77,0 & 10,53 & ,000 \\
\hline ?T Hosp & 109 & 5,0 & 13,4 & 12,0 & 41,0 & 6,4 & 131 & 6,0 & 26,6 & 20,5 & 174,0 & 22,3 & 240 & 5,0 & 20,52 & 15,0 & 174,0 & 18,12 & ,000 \\
\hline Dias PNF_Pós & & & & & & & 4 & 1,0 & 2,3 & 2,0 & 4,0 & 1,5 & 4 & 1,0 & 2,25 & 2,0 & 4,0 & 1,50 & , 102 \\
\hline Dias FB_Pós & 1 & 2648,0 & 2648,0 & 2648,0 & 2648,0 & . & 13 & 1,0 & 7,8 & 7,0 & 21,0 & 7,2 & 14 & 1,0 & 196,43 & 7,0 & 2648,0 & 705,65 & ,529 \\
\hline Dias EB_Pós & 14 & 24,0 & 974,2 & 726,5 & 2885,0 & $\begin{array}{l}991,6 \\
991\end{array}$ & 11 & 35,0 & 1078,2 & 1093,0 & 2202,0 & 830,7 & 25 & 24,0 & 1019,96 & 757,0 & 2885,0 & $\begin{array}{l}907,14 \\
\end{array}$ & ,033 \\
\hline Dias TAH_Pós & 2 & 0,0 & 0,0 & 0,0 & 0,0 & 0,0 & 9 & 4,0 & 61,2 & 11,0 & 365,0 & 117,7 & 11 & 0,0 & 50,09 & 9,0 & 365,0 & 108,16 & ,284 \\
\hline Dias TVP_Pós & 5 & 0,0 & 1568,4 & 2130,0 & 2879,0 & 1461,7 & 27 & 0,0 & 353,2 & 6,0 & 2473,0 & 675,0 & 32 & 0,0 & 543,09 & 6,0 & 2879,0 & 926,68 & ,000 \\
\hline Dias Neopl_Pós & 21 & 7,0 & 906,8 & 497,0 & 2401,0 & 759,1 & 15 & 87,0 & 811,5 & 944,0 & 1447,0 & 511,4 & 36 & 7,0 & 867,08 & 799,0 & 2401,0 & 660,41 & ,619 \\
\hline $\begin{array}{c}\text { Contagem de } \\
\text { obitos }\end{array}$ & 17 & 3,0 & 18,6 & 15,0 & 41,0 & 11,7 & 26 & 1,0 & 24,2 & 26,5 & 43,0 & 12,8 & 43 & 1,0 & 22,00 & 22,0 & 43,0 & 12,56 & , 150 \\
\hline Dias Óbito_Pós & 17 & 85,0 & 911,4 & 433,0 & 2827,0 & 811,8 & 26 & 5,0 & 265,6 & 60,5 & 1699,0 & 391,8 & 43 & 5,0 & 520,88 & 320,0 & 2827,0 & 666,70 & ,001 \\
\hline Dias ReTx_Pós & 2 & 465,0 & 469,0 & 4699,0 & 473,0 & 5,7 & 7 & 7,0 & 388,3 & 44,0 & 1342,0 & 597,7 & 9 & 7,0 & 406,22 & 112,0 & 1342,0 & 518,89 & ,380 \\
\hline Dias PT Prova & 52 & 4,0 & 29,8 & 5,0 & 1100,0 & $\begin{array}{ll}152,2 \\
\end{array}$ & 47 & 2,0 & 7,5 & 5,0 & 99,0 & 13,8 & 99 & 2,0 & 19,23 & 5,0 & 1100,0 & 110,73 & ,181 \\
\hline Dias RAC1_Pós & 19 & 8,0 & 466,4 & 258,0 & 1593,0 & 502,7 & 17 & 18,0 & 687,2 & 462,0 & 1910,0 & 587,5 & 36 & 8,0 & 570,67 & 398,0 & 1910,0 & 547,94 & ,178 \\
\hline
\end{tabular}


Anexo G. Análise univariada dos grupos de complicações menores (ausentes ou grau I-IIla) e maiores (grau IIlb-V) (continuação)

\begin{tabular}{|c|c|c|c|c|c|c|c|c|c|c|c|c|c|c|c|c|c|c|c|}
\hline \multirow{2}{*}{ Complicações } & \multicolumn{6}{|c|}{ Cme (menores) } & \multicolumn{6}{|c|}{ Cma(maiores) } & \multicolumn{6}{|c|}{ Total } & \multirow{2}{*}{ Valor $p$} \\
\hline & $\mathrm{N}$ & Minimum & Mean & Median & Maximum & SD & $\mathrm{N}$ & Minimum & Mean & Median & Maximum & SD & $\mathrm{N}$ & Minimum & Mean & Median & Maximum & SD & \\
\hline Dias RAC2_Pós & 29 & 5,0 & 658,7 & 279,0 & 2641,0 & 814,9 & 33 & 7,0 & 644,7 & 344,0 & 3552,0 & 827,7 & 62 & 5,0 & 651,24 & 299,0 & 3552,0 & 814,99 & ,927 \\
\hline Dias RAC3_Pós & 25 & 5,0 & 479,1 & 171,0 & 2131,0 & 643,4 & 28 & 4,0 & 481,1 & 90,0 & 3250,0 & 751,3 & 53 & 4,0 & 480,15 & 109,0 & 3250,0 & 695,81 & ,755 \\
\hline Hbo_Pré & 107 & 7,0 & 9,9 & 10,1 & 13,5 & 1,5 & 127 & 7,3 & 9,6 & 9,3 & 14,5 & 1,6 & 234 & 7,0 & 9,73 & 9,5 & 14,5 & 1,55 & ,041 \\
\hline Hb1_IOP & 82 & 5,6 & 8,3 & 8,2 & 13,6 & 1,5 & 103 & 5,2 & 7,8 & 7,6 & 11,9 & 1,3 & 185 & 5,2 & 8,03 & 7,9 & 13,6 & 1,43 & ,011 \\
\hline Hb7_Pós & 94 & 5,6 & 9,2 & 9,1 & 12,5 & 1,4 & 109 & 2,4 & 8,6 & 8,6 & 14,5 & 1,7 & 203 & 2,4 & 8,86 & 8,9 & 14,5 & 1,58 & ,012 \\
\hline Hb8_Pós & 58 & 6,6 & 9,1 & 9,1 & 11,8 & 1,1 & 131 & 6,9 & 9,0 & 8,7 & 12,0 & 1,3 & 100 & 6,6 & 9,07 & 8,9 & 12,0 & 1,21 & ,472 \\
\hline Htc0_Pré & 105 & 20,0 & 29,7 & 30,0 & 40,0 & 4,5 & 131 & 21,0 & 28,7 & 28,0 & 44,0 & 4,6 & 234 & 20,0 & 29,14 & 28,5 & 44,0 & 4,58 & ,030 \\
\hline Htc1_IOP & 81 & 17,0 & 24,7 & 24,0 & 33,0 & 4,1 & 104 & 14,0 & 23,5 & 23,0 & 35,0 & 4,0 & 185 & 14,0 & 24,01 & 24,0 & 35,0 & 4,05 & ,060 \\
\hline Htc7_Pós & 94 & 16,0 & 27,1 & 27,0 & 36,0 & 4,1 & 108 & 7,0 & 25,7 & 26,0 & 42,0 & 4,8 & 202 & 7,0 & 26,32 & 26,0 & 42,0 & 4,56 & ,023 \\
\hline Htc8_Pós & 57 & 20,0 & 26,8 & 27,0 & 37,0 & 3,4 & 42 & 20,0 & 26,8 & 25,8 & 37,0 & 4,1 & 99 & 20,0 & 26,83 & 26,0 & 37,0 & 3,68 & 691 \\
\hline Plq0_Pré & 56 & 50000 & 210375,0 & 173000 & 584000 & 127932,9 & 87 & 30000 & 182965,5 & 163000 & 488000 & 110210,9 & 143 & 30000 & 193699,30 & 167000 & 584000 & 117795,61 & ,304 \\
\hline Plq1_IOP & 63 & 49000 & 154650,8 & 136000 & 584000 & 86257,0 & 97 & 18000 & 159319,6 & 136000 & 670000 & 102559,5 & 160 & 18000 & 157481,25 & 136000 & 670000 & 96214,51 & ,903 \\
\hline Plq7_Pós & 88 & 24000 & 120931,8 & 107000 & 310000 & 64348,4 & 107 & 17000 & 116780,4 & 101000 & 428000 & 77124,4 & 195 & 17000 & 118653,85 & 104000 & 428000 & 71492,97 & ,378 \\
\hline Plq8_Pós & 56 & 17000 & 123455,4 & 108000 & 329000 & 63864,9 & 41 & 8400 & 111839,0 & 93000 & 306000 & 72409,5 & 97 & 8400 & 118545,36 & 103000 & 329000 & 67488,35 & ,131 \\
\hline NaO_Pré & 104 & 125,0 & 136,3 & 136,0 & 143,0 & 3,0 & 125 & 108,0 & 135,2 & 135,0 & 149,0 & 4,4 & 229 & 108,0 & 136,70 & 136,0 & 149,0 & 3,85 & ,009 \\
\hline Na1_IOP & 80 & 115,0 & 135,1 & 135,0 & 143,0 & 3,6 & 98 & 66,0 & 133,6 & 135,0 & 142,0 & 8,2 & 178 & 66,0 & 134,27 & 135,0 & 143,0 & 6,56 & ,092 \\
\hline Na7_Pós & 90 & 129,0 & 138,7 & 138,5 & 156,0 & 4,2 & 103 & 125,0 & 140,3 & 140,0 & 158,0 & 4,7 & 193 & 125,0 & 139,55 & 139,0 & 158,0 & 4,52 & ,005 \\
\hline Na8_Pós & 55 & 124,0 & 136,4 & 137,0 & 144,0 & 4,2 & 42 & 127,0 & 136,8 & 138,0 & 143,0 & 3,7 & 97 & 124,0 & 136,61 & 137,0 & 144,0 & 3,95 & ,775 \\
\hline KO_Pré & 59 & 3,2 & 4,4 & 4,4 & 5,0 & 0,5 & 72 & 3,0 & 4,3 & 4,0 & 5,7 & 0,7 & 131 & 3,0 & 4,31 & 4,0 & 5,9 & 0,62 & ,613 \\
\hline K1_IOP & 81 & 3,0 & 3,8 & 4,0 & 5,0 & 0,5 & 98 & 1,0 & 3,6 & 4,0 & 5,0 & 0,7 & 179 & 1,0 & 3,69 & 4,0 & 5,0 & 0,63 & , 176 \\
\hline K7_Pós & 90 & 2,0 & 3,7 & 4,0 & 5,0 & 0,6 & 104 & 3,0 & 3,8 & 4,0 & 6,0 & 0,6 & 194 & 2,0 & 3,75 & 4,0 & 6,0 & 0,61 & ,801 \\
\hline K8_Pós & 56 & 3,0 & 4,0 & 4,0 & 6,0 & 0,6 & 42 & 2,0 & 4,2 & 4,0 & 6,0 & 0,7 & 98 & 2,0 & 4,09 & 4,0 & 6,0 & 0,66 & , 115 \\
\hline Glio_Pré & 32 & 39 & 112,7 & 80 & 378 & 72,6 & 40 & 19 & 82,5 & 72 & 251 & 43,7 & 72 & 19 & 95,89 & 76 & 378 & 59,82 & ,013 \\
\hline Gli1_IOP & 65 & 36 & 97,8 & 93 & 245 & 38,3 & 92 & 20 & 99,0 & 92 & 319 & 50,8 & 157 & 20 & 98,51 & 92 & 319 & 45,93 &, 543 \\
\hline Gli7_IOP & 57 & 32 & 154,3 & 146 & 358 & 57,0 & 80 & 38 & 146,4 & 134 & 404 & 58,4 & 137 & 32 & 149,64 & 137 & 404 & 57,77 & ,269 \\
\hline Gli8_IOP & 28 & 46 & 152,3 & 142 & 298 & 62,2 & 26 & 90 & 179,6 & 148 & 820 & 140,3 & 54 & 46 & 165,44 & 144 & 820 & 106,97 & ,585 \\
\hline La1_IOP & 67 & 0,8 & 10,3 & 10,1 & 26,4 & 5,3 & 87 & 0,9 & 12,6 & 12,1 & 42,0 & 6,0 & 154 & 0,8 & 11,63 & 11,0 & 42,0 & 5,81 & ,010 \\
\hline La7_Pós & 77 & 0,0 & 22,2 & 14,0 & 407,0 & 46,6 & 86 & 3,0 & 18,8 & 12,0 & 276,0 & 37,0 & 163 & 0,0 & 20,40 & 13,0 & 407,0 & 41,73 & ,082 \\
\hline La8_Pós & 28 & 3,0 & 16,1 & 14,0 & 34,0 & 9,3 & 32 & 2,0 & 15,7 & 15,5 & 35,0 & 8,5 & 60 & 2,0 & 15,85 & 15,0 & 35,0 & 8,80 & ,941 \\
\hline RNIO_Pré & 85 & 0,93 & 1,3 & 1,19 & 3,82 & 0,4 & 117 & 0,74 & 1,4 & 1,29 & 3,86 & 0,5 & 202 & 0,74 & 1,38 & 1,25 & 3,86 & 0,48 &, 212 \\
\hline
\end{tabular}


Anexo G. Análise univariada dos grupos de complicações menores (ausentes ou grau I-IIla) e maiores (grau IIlb-V) (conclusão)

\begin{tabular}{|c|c|c|c|c|c|c|c|c|c|c|c|c|c|c|c|c|c|c|c|}
\hline \multirow{2}{*}{ Complicações } & \multicolumn{6}{|c|}{ Cme (menores) } & \multicolumn{6}{|c|}{ Cma(maiores) } & \multicolumn{6}{|c|}{ Total } & \multirow{2}{*}{ Valor $p$} \\
\hline & $\mathrm{N}$ & Minimum & Mean & Median & Maximum & SD & $\mathrm{N}$ & Minimum & Mean & Median & Maximum & SD & $\mathrm{N}$ & Minimum & Mean & Median & Maximum & SD & \\
\hline RNI1_IOP & 72 & 1,00 & 1,3 & 1,00 & 3,00 & 0,5 & 94 & 1,00 & 1,6 & 1,00 & 5,00 & 0,8 & 166 & 1,00 & 1,48 & 1,00 & 5,00 & 0,68 & ,056 \\
\hline RNI7_Pós & 78 & 1,00 & 2,3 & 2,00 & 4,00 & 0,6 & 96 & 1,00 & 2,5 & 2,00 & 6,00 & 0,8 & 174 & 1,00 & 2,39 & 2,00 & 6,00 & 0,69 & , 061 \\
\hline RNI8_Pós & 36 & 1,00 & 1,9 & 2,00 & 5,00 & 0,8 & 34 & 1,00 & 1,9 & 2,00 & 5,00 & 0,9 & 70 & 1,00 & 1,93 & 2,00 & 5,00 & 0,84 & , 892 \\
\hline Rel0_Pré & 47 & 1,00 & 1,2 & 1,00 & 2,00 & 0,4 & 61 & 1,00 & 1,5 & 1,00 & 7,00 & 0,9 & 108 & 1,00 & 1,35 & 1,00 & 7,00 & 0,75 & , 142 \\
\hline Rel1_IOP & 70 & 1,00 & 1,4 & 1,00 & 5,00 & 0,7 & 87 & 1,00 & 1,5 & 1,00 & 7,00 & 0,9 & 157 & 1,00 & 1,48 & 1,00 & 7,00 & 0,80 & ,255 \\
\hline Rel7_Pós & 71 & 1,00 & 2,1 & 2,00 & 5,00 & 0,9 & 86 & 1,00 & 2,7 & 2,00 & 50,00 & 5,2 & 157 & 1,00 & 2,41 & 2,00 & 50,00 & 3,92 & ,471 \\
\hline Rel8_Pós & 35 & 1,00 & 2,5 & 1,00 & 37,00 & 6,1 & 31 & 1,00 & 1,6 & 1,00 & 5,00 & 1,0 & 66 & 1,00 & 2,08 & 1,00 & 37,00 & 4,45 & ,822 \\
\hline Cai0_Pré & 33 & 1,0 & 1,0 & 1,0 & 1,0 & 0,0 & 38 & 1,0 & 1,0 & 1,0 & 1,0 & 0,0 & 71 & 1,0 & 1,00 & 1,0 & 1,0 & 0,00 & 1,000 \\
\hline Cai1_IOP & 75 & 1,0 & 1,0 & 1,0 & 2,0 & 0,2 & 96 & 1,0 & 1,0 & 1,0 & 3,0 & 0,2 & 171 & 1,0 & 1,03 & 1,0 & 3,0 & 0,20 & ,812 \\
\hline Cai7_Pós & 35 & 0,0 & 4,2 & 1,0 & 112,0 & 18,8 & 45 & 1,0 & 1,0 & 1,0 & 1,0 & 0,0 & 80 & 0,0 & 2,39 & 1,0 & 112,0 & 12,41 & ,507 \\
\hline Cai8_Pós & 8 & 1,0 & 1,0 & 1,0 & 1,0 & 0,0 & 16 & 1,0 & 1,0 & 1,0 & 1,0 & 0,0 & 24 & 1,0 & 1,00 & 1,0 & 1,0 & 0,00 & 1,000 \\
\hline Alb0_Pré & 101 & 1,0 & 2,8 & 3,0 & 5,0 & 0,9 & 116 & 1,0 & 2,6 & 2,0 & 5,0 & 0,8 & 217 & 1,0 & 2,70 & 3,0 & 5,0 & 0,86 & ,038 \\
\hline Alb1_IOP & 66 & 2,0 & 2,6 & 2,0 & 4,0 & 0,7 & 90 & 1,0 & 2,3 & 2,0 & 4,0 & 0,8 & 156 & 1,0 & 2,44 & 2,0 & 4,0 & 0,74 & ,034 \\
\hline Alb7_Pós & 76 & 1,2 & 2,8 & 2,8 & 4,6 & 0,6 & 82 & 1,5 & 2,9 & 2,8 & 4,8 & 0,7 & 158 & 1,2 & 2,82 & 2,8 & 4,8 & 0,67 & ,427 \\
\hline Alb8_Pós & 14 & 1,2 & 2,5 & 2,6 & 3,2 & 0,6 & 28 & 1,3 & 2,6 & 2,5 & 6,5 & 1,0 & 42 & 1,2 & 2,58 & 2,6 & 6,5 & 0,85 & ,883 \\
\hline ASTO_Pré & 43 & 29,0 & 308,6 & 237,0 & 2965,0 & 446,7 & 45 & 55,0 & 267,0 & 226,0 & 745,0 & 167,1 & 88 & 29,0 & 287,33 & 236,5 & 2965,0 & 333,00 & ,723 \\
\hline AST7_Pós & 73 & 55,0 & 378,6 & 353,0 & 1612,0 & 212,6 & 92 & 20,0 & 510,1 & 326,0 & 5627,0 & 740,1 & 165 & 20,0 & 451,95 & 335,0 & 5627,0 & 572,74 & ,963 \\
\hline AST8_Pós & 52 & 36,0 & 286,6 & 171,5 & 3112,0 & 455,7 & 39 & 20,0 & 330,6 & 169,0 & 3398,0 & 633,0 & 91 & 20,0 & 305,46 & 170,0 & 3398,0 & 536,01 & 633 \\
\hline ALTO_Pré & 43 & 30,0 & 173,6 & 122,0 & 1268,0 & 205,0 & 45 & 13,0 & 194,6 & 157,5 & 733,0 & 139,9 & 88 & 13,0 & 184,35 & 136,5 & 1268,0 & 174,08 & ,073 \\
\hline ALT7_Pós & 74 & 64,0 & 409,2 & 370,5 & 1769,0 & 228,4 & 92 & 54,0 & 605,3 & 384,0 & 7561,0 & 952,1 & 166 & 54,0 & 517,88 & 380,5 & 7561,0 & 729,76 & ,553 \\
\hline ALT8_Pós & 52 & 133,0 & 438,1 & 306,0 & 4507,0 & 621,0 & 39 & 54,0 & 549,3 & 291,0 & 5233,0 & 948,5 & 91 & 54,0 & 485,77 & 300,0 & 5233,0 & 775,52 & ,597 \\
\hline BT0_Pré & 91 & 0,2 & 11,3 & 11,3 & 32,2 & 7,8 & 111 & 0,3 & 13,8 & 13,4 & 38,4 & 8,5 & 202 & 0,2 & 12,70 & 12,6 & 38,4 & 8,26 & ,016 \\
\hline BT7_Pós & 79 & 0,3 & 4,3 & 3,7 & 14,9 & 3,2 & 95 & 0,5 & 5,2 & 4,1 & 33,0 & 4,5 & 174 & 0,3 & 4,81 & 3,8 & 33,0 & 3,97 & 193 \\
\hline BT8_Pós & 54 & 0,4 & 3,8 & 2,8 & 31,1 & 4,4 & 43 & 0,6 & 3,6 & 2,8 & 22,2 & 3,5 & 97 & 0,4 & 3,71 & 2,8 & 31,1 & 4,00 & ,738 \\
\hline Cro_Pré & 99 & 0,0 & 0,0 & 0,0 & 1,0 & 0,1 & 116 & 0,0 & 0,0 & 0,0 & 1,0 & 0,1 & 215 & 0,0 & 0,01 & 0,0 & 1,0 & 0,12 & ,657 \\
\hline Cl Cro_Pré(DCr) & 101 & 0,0 & 219,6 & 168,9 & 528,0 & 117,7 & 114 & 0,0 & 193,5 & 152,5 & 566,5 & 108,9 & 215 & 0,0 & 205,78 & 157,5 & 566,5 & 113,59 & 1111 \\
\hline $\begin{array}{l}\text { Menor Grau de } \\
\text { Complicą̧ão }\end{array}$ & 107 & 0,0 & 1,3 & 1,0 & 2,0 & 0,7 & 133 & 1,0 & 1,9 & 2,0 & 7,0 & 1,2 & 240 & 0,0 & 1,65 & 2,0 & 7,0 & 1,02 & ,001 \\
\hline $\begin{array}{l}\text { Maior Grau de } \\
\text { Complicaçãoo }\end{array}$ & 107 & 0,0 & 1,7 & 2,0 & 3,0 & 0,8 & 133 & 2,0 & 5,3 & 5,0 & 7,0 & 0,9 & 240 & 0,0 & 3,71 & 4,0 & 7,0 & 2,00 &, 000 \\
\hline
\end{tabular}


Anexo H - Dados de sensibilidade e de especificidade da curva ROC do volume de concentrado de hemácias transfundido no perioperatório

\begin{tabular}{|c|c|c|}
\hline Positivo se maior ou igual $a^{a}$ & Sensibilidade & 1 - Especificidade \\
\hline 53,00 & 1,000 & 1,000 \\
\hline 56,50 & ,992 & 1,000 \\
\hline 59,50 & ,985 & 1,000 \\
\hline 60,50 & ,947 & 1,000 \\
\hline 61,50 & ,932 & 1,000 \\
\hline 62,50 & 879 & ,989 \\
\hline 63,50 & 848 & 947 \\
\hline 64,50 & ,758 & ,905 \\
\hline 65,50 & 674 & ,884 \\
\hline 66,50 & ,576 & ,811 \\
\hline 67,50 &, 538 &, 747 \\
\hline 68,50 & ,470 & 684 \\
\hline 69,50 & ,417 & ,632 \\
\hline 70,50 & ,379 &, 579 \\
\hline 71,50 & ,341 &, 568 \\
\hline 72,50 & ,303 &, 516 \\
\hline 73,50 & ,295 & ,484 \\
\hline 74,50 & ,265 & ,442 \\
\hline 75,50 & ,258 & ,432 \\
\hline 76,50 & ,242 & ,389 \\
\hline 77,50 & ,227 & ,389 \\
\hline 78,50 & 197 & ,358 \\
\hline 79,50 & ,197 & ,337 \\
\hline 80,50 & ,189 & ,295 \\
\hline 81,50 & 174 & ,295 \\
\hline 82,50 & 152 & 295 \\
\hline 83,50 & 144 & 274 \\
\hline 84,50 & 144 & 242 \\
\hline 85,50 & 137 & 232 \\
\hline 86,50 & 129 & 221 \\
\hline 87,50 & ,098 & 179 \\
\hline 89,00 & 091 & 179 \\
\hline 90,50 & ,068 & ,168 \\
\hline 91,50 & ,068 & 158 \\
\hline 92,50 & ,068 & 147 \\
\hline 93,50 & ,068 & 137 \\
\hline 94,50 & ,045 & 105 \\
\hline 95,50 & ,045 & ,084 \\
\hline 97,00 & ,045 & ,042 \\
\hline 98,50 & ,038 & ,042 \\
\hline 100,00 & ,038 & ,032 \\
\hline 102,00 & ,030 & ,032 \\
\hline 103,50 & ,023 & ,032 \\
\hline 103,50 & ,023 & ,021 \\
\hline 105,50 & ,023 & 011 \\
\hline 106,50 & ,015 & 011 \\
\hline 109,50 & ,008 & ,011 \\
\hline 116,00 & ,008 & 0,000 \\
\hline 121,00 & 0,000 & 0,000 \\
\hline
\end{tabular}


Anexo I. Análise univariada dos grupos de menor $(\mathrm{BCH})$ e maior $(\mathrm{ACH})$ volume transfusional perioperatório de concentrado de hemácias indexado pelo peso corporeo

\begin{tabular}{|c|c|c|c|c|c|c|c|c|c|c|c|c|c|c|c|c|c|c|c|}
\hline \multirow{2}{*}{ CHDI_Per_Ind_ROC } & \multicolumn{6}{|c|}{$\mathrm{BCH}<=27,5$} & \multicolumn{6}{|c|}{$\mathrm{ACH}>27,5$} & \multicolumn{6}{|c|}{ Total } & \multirow[t]{2}{*}{ Valor $p$} \\
\hline & $\mathrm{N}$ & Minimum & Mean & Median & Maximum & SD & N & Minimum & Mean & Median & Maximum & SD & $\mathrm{N}$ & Minimum & Mean & Median & Maximum & SD & \\
\hline $\operatorname{Rx}(\mathrm{d})$ & 103 & 183,0 & 763,6 & 572 & 2566 & 544,1 & 137 & 136 & 419,4 & 314 & 3046 & 350,3 & 240 & 136,0 & 567 & 372 & 3046 & 475 & $<0,001$ \\
\hline P Rx (g) & 103 & 5510,0 & 10672,5 & 10310 & 18100 & $\begin{array}{c}3194 \\
7\end{array}$ & 137 & 4850 & 7882,1 & 7400 & 20000 & 2292,5 & 240 & 4850,0 & 9088 & 8073 & 20000 & 3048 & $<0,001$ \\
\hline$P R x(k g)$ & 103 & 6,0 & 10,6 & 10 & 18 & 3,2 & 137 & 5 & 7,9 & 7 & 20 & 2,3 & 240 & 5,0 & 9 & 8 & 20 & 3 & $<0,001$ \\
\hline $\mathrm{ERx}(\mathrm{cm})$ & 103 & 60,0 & 80,0 & 78,0 & 112,0 & 12,1 & 137 & 54,0 & 69,4 & 68,0 & 120,0 & 8,7 & 240 & 54,0 & 74,0 & 70,0 & 120,0 & 11,6 & $<0,001$ \\
\hline Zscore P/I & 103 & $-3,8$ & $-0,9$ & $-0,82$ & 2,21 & 1,2 & 137 & $-4,58$ & $-1,7$ & $-1,75$ & 1,54 & 1,2 & 240 & $-4,6$ & $-1,38$ & $-1,24$ & 2,21 & 1,27 & $<0,001$ \\
\hline Zscore E/l & 103 & $-6,0$ & $-0,1$ & 0,03 & 3,71 & 1,4 & 137 & $-4,50$ & $-0,5$ & $-0,43$ & 3,06 & 1,2 & 240 & $-6,0$ & $-0,36$ & $-0,22$ & 3,71 & 1,33 & 0,005 \\
\hline Zscore P/E & 96 & $-4,6$ & $-1,6$ & $-1,41$ & 0,96 & 1,3 & 137 & $-7,09$ & $-2,4$ & $-2,48$ & 1,38 & 1,4 & 233 & $-7,1$ & $-2,09$ & $-1,99$ & 1,38 & 1,46 & $<0,001$ \\
\hline ZBMI (IMC) & 103 & $-2,6$ & 0,2 & 0,19 & 3,94 & 1,2 & 137 & $-3,32$ & $-0,4$ & $-0,28$ & 3,94 & 1,3 & 240 & $-3,3$ & $-0,12$ & $-0,05$ & 3,94 & 1,26 & 0,001 \\
\hline IMC & 103 & 13,1 & 16,4 & 16,5 & 22,2 & 1,7 & 137 & 12,6 & 16,1 & 16,1 & 22,5 & 1,6 & 240 & 12,6 & 16,3 & 16,3 & 22,5 & 1,7 & , 131 \\
\hline PELD_Pré & 90 & 1,0 & 14,1 & 14,0 & 30,0 & 6,2 & 135 & 1,0 & 19,1 & 19,0 & 45,0 & 7,9 & 228 & 1,0 & 17,1 & 16,0 & 45,0 & 7,7 & ,000 \\
\hline $\begin{array}{l}\text { No.HDA_Pré } \\
\text { (hemorragia) }\end{array}$ & 102 & 0,0 & 0,7 & 0,0 & 5,0 & 1,2 & 132 & 0,0 & 0,8 & 0,0 & 9,0 & 1,4 & 234 & 0,0 & 0,7 & 0,0 & 9,0 & 1,3 & ,917 \\
\hline DV Kasai_Pré & 35 & 45,0 & 95,5 & 91,0 & 258,0 & 38,2 & 69 & 49,0 & 108,7 & 99,0 & 365,0 & 43,8 & 104 & 45,0 & 104,3 & 98,0 & 365,0 & 42,3 & ,078 \\
\hline No.Inf 30d_Pré & 103 & 0,0 & 0,3 & 0,0 & 2,0 & 0,5 & 137 & 0,0 & 0,6 & 0,0 & 4,0 & 0,8 & 240 & 0,0 & 0,5 & 0,0 & 4,0 & 0,7 & , 028 \\
\hline TA_IOP (anestesia) & 95 & 1,2 & 9,7 & 9,6 & 13,7 & 1,6 & 127 & 6,8 & 10,8 & 10,5 & 19,4 & 1,9 & 222 & 1,2 & 10,3 & 10,2 & 19,4 & 1,8 & ,000 \\
\hline TC_IOP (cirurgia) & 95 & 5,3 & 8,1 & 7,8 & 12,2 & 1,5 & 127 & 5,5 & 9,0 & 8,7 & 17,6 & 1,9 & 222 & 5,3 & 8,6 & 8,5 & 17,6 & 1,8 & ,001 \\
\hline TIT_IOP (isquemia total) & 89 & 50,0 & 95,6 & 86,0 & 240,0 & 36,2 & 122 & 50,0 & 109,6 & 92,0 & 505,0 & 56,1 & 211 & 50,0 & 103,7 & 90,0 & 505,0 & 49,1 & ,071 \\
\hline TIF_IOP(fria) & 85 & 10,0 & 53,3 & 40,0 & 185,0 & 34,9 & 114 & 5,0 & 67,1 & 46,0 & 445,0 & 56,3 & 199 & 5,0 & 61,2 & 45,0 & 445,0 & 48,7 & ,118 \\
\hline TIQ_IOP(quente) & 90 & 21,0 & 42,2 & 40,0 & 80,0 & 12,9 & 122 & 20,0 & 42,9 & 40,5 & 80,0 & 11,4 & 212 & 20,0 & 42,6 & 40,0 & 80,0 & 12,0 & .515 \\
\hline Diurese_IOP & 84 & 110,0 & 518,8 & 465 & 1635 & 292,3 & 108 & 108 & 500,9 & 422 & 2190 & 359,3 & 192 & 108,0 & 509 & 443 & 2190 & 331 & 284 \\
\hline Criataloide_IOP & 85 & 600,0 & 1932,5 & 1958 & 4500 & 784,4 & 117 & 500 & 1915,0 & 1730 & 5100 & 846,1 & 202 & 500,0 & 1922 & 1883 & 5100 & 819 & 690 \\
\hline Colóide_IOP & 86 & 100,0 & 349,3 & 301 & 1200 & 222,9 & 116 & 50 & 341,1 & 300 & 1350 & 208,2 & 202 & 50,0 & 345 & 300 & 1350 & 214 & ,948 \\
\hline Diurese_IOP ind & 83 & 10,4 & 47,5 & 45,48 & 113,73 & 22,9 & 107 & 15,32 & 61,3 & 54,63 & 209,62 & 36,6 & 190 & 10,4 & 55,28 & 47,81 & 209,62 & 32,04 & 0,013 \\
\hline Criataloide_IOP ind & 84 & 80,4 & 179,4 & 172,45 & 453,72 & 67,3 & 115 & 65,36 & 251,2 & 234,92 & 614,56 & 104,8 & 199 & 65,4 & 220,88 & 201,51 & 614,56 & 96,95 & 0,015 \\
\hline Colóide_IOP ind & 85 & 5,7 & 33,6 & 27,40 & 106,04 & 20,8 & 114 & 5,72 & 43,1 & 39,16 & 112,50 & 19,7 & 199 & 5,7 & 39,02 & 35,17 & 112,50 & 20,65 & $<0,001$ \\
\hline Peso Implante_IOP & 103 & 120,0 & 292,9 & 300 & 520 & 72,0 & 137 & 122,0 & 293,9 & 300,0 & 450,0 & 60,5 & 239 & 120,0 & 293,4 & 300,0 & 520,0 & 65,5 & ,719 \\
\hline RPI/PP ( \%) & 103 & 0,0 & 2,9 & 2,7 & 6,2 & 1,00 & 137 & $1,5 \%$ & $3,9 \%$ & $3,9 \%$ & $7,2 \%$ & 1,10 & 240 & $0,9 \%$ & 3,50 & $3,5 \%$ & $7,2 \%$ & $1,2 \%$ & $<0,001$ \\
\hline Crio_Pré & 103 & 0,0 & 0,0 & 0,0 & 0,0 & 0,0 & 137 & 0,0 & 0,0 & 0,0 & 0,0 & 0,0 & 240 & 0,0 & 0,0 & 0,0 & 0,0 & 0,0 & 1,000 \\
\hline PFC_Pré & 103 & 0,0 & 0,0 & 0,0 & 0,0 & 0,0 & 137 & 0,0 & 0,0 & 0,0 & 0,0 & 0,0 & 240 & 0,0 & 0,0 & 0,0 & 0,0 & 0,0 & 1,000 \\
\hline
\end{tabular}


Anexo I. Análise univariada dos grupos de menor $(\mathrm{BCH})$ e maior $(\mathrm{ACH})$ volume transfusional perioperatório de concentrado de hemácias indexado pelo peso corporeo (continuação)

\begin{tabular}{|c|c|c|c|c|c|c|c|c|c|c|c|c|c|c|c|c|c|c|c|}
\hline \multirow{2}{*}{ CHDI_Per_Ind_ROC } & \multicolumn{6}{|c|}{$\mathrm{BCH}<=27,5$} & \multicolumn{6}{|c|}{$\mathrm{ACH}>27,5$} & \multicolumn{6}{|c|}{ Total } & \multirow[t]{2}{*}{ Valor $p$} \\
\hline & $\mathrm{N}$ & Minimum & Mean & Median & Maximum & SD & $\mathrm{N}$ & Minimum & Mean & Median & Maximum & SD & $\mathrm{N}$ & Minimum & Mean & Median & Maximum & SD & \\
\hline Plaq_Pré & 103 & 0,0 & 0,0 & 0,0 & 0,0 & 0,0 & 137 & 0,0 & 0,0 & 0,0 & 0,0 & 0,0 & 240 & 0,0 & 0,0 & 0,0 & 0,0 & 0,0 & 1,000 \\
\hline CHDI_IOP & 103 & 0,0 & 135,9 & 107,0 & 400,0 & 95,5 & 137 & 100,0 & 344,5 & 300,0 & 1636,0 & 233,1 & 240 & 0,0 & 255,3 & 201,0 & 1636,0 & 213,5 & ,000 \\
\hline Crio_IOP & 103 & 0,0 & 0,0 & 0,0 & 0,0 & 0,0 & 137 & 0,0 & 0,5 & 0,0 & 70,0 & 5,9 & 240 & 0,0 & 0,3 & 0,0 & 70,0 & 4,5 & 387 \\
\hline PFC_IOP & 103 & 0,0 & 0,0 & 0,0 & 0,0 & 0,0 & 137 & 0,0 & 15,6 & 0,0 & 458,0 & 63,3 & 240 & 0,0 & 8,9 & 0,0 & 458,0 & 48,5 & ,003 \\
\hline Plaq_IOP & 103 & 0,0 & 0,0 & 0,0 & 0,0 & 0,0 & 137 & 0,0 & 4,9 & 0,0 & 272,0 & 26,2 & 240 & 0,0 & 2,8 & 0,0 & 272,0 & 20,0 & ,013 \\
\hline CHDI_Pós (ate 48h) & 103 & 0,0 & 15,6 & 0,0 & 180,0 & 41,1 & 137 & 0,0 & 94,7 & 60,0 & 1008,0 & 135,1 & 240 & 0,0 & 60,9 & 0,0 & 1008,0 & 112,6 & ,000 \\
\hline Crio_Pós & 103 & 0,0 & 0,0 & 0,0 & 0,0 & 0,0 & 137 & 0,0 & 0,8 & 0,0 & 108,0 & 9,2 & 240 & 0,0 & 0,4 & 0,0 & 108,0 & 6,9 & ,387 \\
\hline PFC_Pós & 103 & 0,0 & 0,0 & 0,0 & 0,0 & 0,0 & 137 & 0,0 & 12,1 & 0,0 & 494,0 & 55,4 & 240 & 0,0 & 6,9 & 0,0 & 494,0 & 42,3 & ,005 \\
\hline Plaq_Pós & 103 & 0,0 & 0,0 & 0,0 & 0,0 & 0,0 & 137 & 0,0 & 4,2 & 0,0 & 307,0 & 29,9 & 240 & 0,0 & 2,4 & 0,0 & 307,0 & 22,7 & 082 \\
\hline $\begin{array}{l}\text { CHDI_Per } \\
\text { (pre+intra+pos) }\end{array}$ & 103 & 0,0 & 154,6 & 150,0 & 400,0 & 97,4 & 137 & 150,0 & 447,9 & 350,0 & 2287,0 & 298,2 & 240 & 0,0 & 322,4 & 300,0 & 2287,0 & 275,5 &, 000 \\
\hline Crio_Per & 103 & 0,0 & 0,0 & 0,0 & 0,0 & 0,0 & 137 & 0,0 & 1,3 & 0,0 & 108,0 & 10,9 & 240 & 0,0 & 0,7 & 0,0 & 108,0 & 8,2 & ,220 \\
\hline PFC_Per & 103 & 0,0 & 0,0 & 0,0 & 0,0 & 0,0 & 137 & 0,0 & 27,7 & 0,0 & 648,0 & 98,4 & 240 & 0,0 & 15,9 & 0,0 & 648,0 & 75,6 & ,001 \\
\hline Plaq_Per & 103 & 0,0 & 0,0 & 0,0 & 0,0 & 0,0 & 137 & 0,0 & 9,1 & 0,0 & 372,0 & 43,2 & 240 & 0,0 & 5,2 & 0,0 & 372,0 & 32,9 & ,005 \\
\hline $\begin{array}{l}\text { CHDI_Per_Ind } \\
\text { (volume//_eso) }\end{array}$ & 103 & 0,0 & 15,3 & 16,7 & 27,4 & 8,6 & 137 & 27,8 & 58,0 & 48,0 & 305,5 & 35,7 & 240 & 0,0 & 39,7 & 31,3 & 305,5 & 34,8 &, 000 \\
\hline Crio_Per_Ind & 103 & 0,0 & 0,0 & 0,0 & 0,0 & 0,0 & 137 & 0,0 & 0,1 & 0,0 & 14,0 & 1,2 & 240 & 0,0 & 0,1 & 0,0 & 14,0 & 0,9 & 220 \\
\hline PFC_Per_Ind & 103 & 0,0 & 0,0 & 0,0 & 0,0 & 0,0 & 137 & 0,0 & 3,2 & 0,0 & 79,0 & 11,4 & 240 & 0,0 & 1,9 & 0,0 & 79,0 & 8,8 & ,001 \\
\hline Plaq_Per_Ind & 103 & 0,0 & 0,0 & 0,0 & 0,0 & 0,0 & 137 & 0,0 & 1,2 & 0,0 & 50,0 & 5,9 & 240 & 0,0 & 0,7 & 0,0 & 50,0 & 4,5 & ,005 \\
\hline ?T UTI & 99 & 1,0 & 3,5 & 2 & 36 & 5,2 & 134 & 1 & 7,7 & 3 & 77 & 12,9 & 236 & 1,0 & 6 & 2 & 77 & 11 & ,001 \\
\hline ?T Hosp & 100 & 5,0 & 17,3 & 14 & 93 & 12,7 & 134 & 6 & 22,9 & 17 & 174 & 21,0 & 234 & 5,0 & 21 & 15 & 174 & 18 & ,010 \\
\hline Dias PNF_Pós & 103 & & & & & & 137 & 1 & 2,3 & 2,00 & 4 & 1,5 & 240 & 1,0 & 2,25 & 2,00 & 4 & 1,500 & ,430 \\
\hline Dias FB_Pós & 3 & 1,0 & 4,7 & 5,00 & 8 & 3,5 & 11 & 1 & 248,7 & 7,00 & 2648 & 795,8 & 14 & 1,0 & 196,43 & 7,00 & 2648 & 705,645 & ,957 \\
\hline Dias EB_Pós & 13 & 24,0 & 1020,1 & 962,00 & 2347 & 835,9 & 12 & 28 & 1019,8 & 507,00 & 2885 & 1016,5 & 25 & 24,0 & 1019,96 & 757,00 & 2885 & 907,135 & ,033 \\
\hline Dias TAH_Pós & 2 & 0,0 & 0,0 & 00 & 0 & 0,0 & 9 & 4 & 61,2 & 11,00 & 365 & 117,7 & 11 & 0,0 & 50,09 & 9,00 & 365 & 108,164 & ,967 \\
\hline Dias TVP_Pós & 9 & 0,0 & 397,8 & 6,00 & 2879 & 942,6 & 24 & 0 & 575,0 & 3,00 & 2832 & 923,0 & 33 & 0,0 & 526,67 & 6,00 & 2879 & 916,953 & ,771 \\
\hline Dias Neopl_Pós & 12 & 7,0 & $\begin{array}{l}904,7 \\
\end{array}$ & 873,50 & 1894 & 751,8 & 25 & 61 & 852,5 & 882,00 & 2401 & 613,5 & 37 & 7,0 & 869,41 & 882,00 & 2401 & 651,327 & 871 \\
\hline Contagem de óbitos & 8 & 1,0 & 12,9 & 12,50 & 29 & 9,9 & 35 & 2 & 24,1 & 24,00 & 43 & 12,3 & 43 & 1,0 & 22,00 & 22,00 & 43 & 12,557 & 023 \\
\hline Dias Óbito_Pós & 8 & 61,0 & 1118,4 & 672,50 & 2827 & $\begin{array}{l}1033, \\
1\end{array}$ & 35 & 5 & 384,3 & 235,00 & 1699 & 475,5 & 43 & 5,0 & 520,88 & 320,00 & 2827 & 666,699 & 029 \\
\hline Dias ReTx_Pós & 2 & 473,0 & 907,5 & 907,50 & 1342 & 614,5 & 7 & 7 & 263,0 & 44,00 & 1176 & 434,0 & 9 & 7,0 & 406,22 & 112,00 & 1342 & 518,889 & ,079 \\
\hline Dias PT Prova & 56 & 4,0 & 25,9 & 5,00 & 1100 & 146,2 & 45 & 2 & 10,4 & 5,00 & 116 & 21,4 & 101 & 2,0 & 19,00 & 5,00 & 1100 & 109,630 & 600 \\
\hline
\end{tabular}


Anexo I. Análise univariada dos grupos de menor $(\mathrm{BCH})$ e maior $(\mathrm{ACH})$ volume transfusional perioperatório de concentrado de hemácias indexado pelo peso corporeo (continuação)

\begin{tabular}{|c|c|c|c|c|c|c|c|c|c|c|c|c|c|c|c|c|c|c|c|}
\hline \multirow{2}{*}{ CHDI_Per_Ind_ROC } & \multicolumn{6}{|c|}{$\mathrm{BCH}<=27,5$} & \multicolumn{6}{|c|}{$\mathrm{ACH}>27,5$} & \multicolumn{6}{|c|}{ Total } & \multirow[t]{2}{*}{ Valor $p$} \\
\hline & $\mathrm{N}$ & Minimum & Mean & Median & Maximum & SD & $\mathrm{N}$ & Minimum & Mean & Median & Maximum & SD & $\mathrm{N}$ & Minimum & Mean & Median & Maximum & SD & \\
\hline Dias RAC1_Pós & 14 & 18,0 & 699,9 & 547,50 & 1910 & 630,0 & 22 & 8 & 488,5 & 356,00 & 1593 & 486,3 & 36 & 8,0 & 570,67 & 398,00 & 1910 & 547,938 & ,364 \\
\hline Dias RAC2_Pós & 24 & 5,0 & 342,1 & 229,50 & 1243 & 390,9 & 39 & 7 & 825,1 & 437,00 & 3552 & 945,0 & 63 & 5,0 & 641,13 & 279,00 & 3552 & 812,372 & ,118 \\
\hline Dias RAC3_Pós & 28 & 5,0 & 478,9 & 114,00 & 1916 & 597,2 & 26 & 4 & 464,5 & 58,50 & 3250 & 793,4 & 54 & 4,0 & 471,93 & 109,00 & 3250 & 691,855 & ,421 \\
\hline HbO_Pré & 101 & 7,0 & 10,2 & 10,5 & 13,5 & 1,5 & 133 & 7,0 & 9,3 & 9,1 & 14,5 & 1,5 & 234 & 7,0 & 9,72 & 9,50 & 14,50 & 1,5 & ,000 \\
\hline Hb1_IOP & 80 & 5,8 & 8,6 & 8,7 & 13,6 & 1,5 & 105 & 5,2 & 7,6 & 7,4 & 11,1 & 1,2 & 185 & 5,2 & 8,0 & 7,9 & 13,60 & 1,4 & ,000 \\
\hline Hb7_Pós & 90 & 6,4 & 9,1 & 8,9 & 12,5 & 1,3 & 116 & 2,4 & 8,7 & 8,7 & 14,5 & 1,7 & 206 & 2,4 & 8,85 & 8,83 & 14,50 & 1,57 & ,064 \\
\hline Hb8_Pós & 44 & 7,1 & 9,2 & 9,0 & 12,0 & 1,1 & 59 & 6,6 & 9,0 & 9,0 & 11,8 & 1,3 & 103 & 6,6 & 9,08 & 9,00 & 12,00 & 1,20 & ,300 \\
\hline Htc0_Pré & 101 & 20,0 & 30,6 & 31,0 & 40,0 & 4,5 & 133 & 21,0 & 28,0 & 27,0 & 44,0 & 4,3 & 234 & 20,0 & 29,11 & 28,00 & 44,00 & 4,56 & ,000 \\
\hline Htc1_IOP & 80 & 18,0 & 25,5 & 25,0 & 35,0 & 4,1 & 105 & 14,0 & 22,9 & 23,0 & 33,0 & 3,6 & 185 & 14,0 & 23,98 & 24,00 & 35,00 & 4,03 & ,000 \\
\hline Htc7_Pós & 89 & 20,0 & 27,0 & 26,0 & 36,0 & 3,5 & 116 & 7,0 & 25,8 & 26,0 & 42,0 & 5,1 & 205 & 7,0 & 26,29 & 26,00 & 42,00 & 4,54 & ,048 \\
\hline Htc8_Pós & 44 & 20,0 & 27,1 & 27,0 & 37,0 & 3,5 & 58 & 20,0 & 26,6 & 26,0 & 37,0 & 3,8 & 102 & 20,0 & 26,84 & 26,00 & 37,00 & 3,63 & ,354 \\
\hline Plq0_Pré & 55 & 34000,0 & 195127,3 & 157000 & 521000 & \begin{tabular}{|l|l}
11332,0 \\
\end{tabular} & 95 & 30000 & 192621,1 & 184000 & 584000 & 118232,9 & 150 & 30000,0 & 193540,0 & 167000,0 & 584000,0 & 115379,9 & ,789 \\
\hline Plq1_IOP & 73 & 35000,0 & 157986,3 & 132000 & 670000 & \begin{tabular}{|l}
98726,1 \\
\end{tabular} & 99 & 18000 & 153282,8 & 136000 & 584000 & \begin{tabular}{|l|}
92188,4 \\
\end{tabular} & 172 & 18000,0 & 155279,07 & 135000,00 & 670000 & 94762,695 & ,863 \\
\hline Plq7_Pós & 90 & 37000,0 & 132711,1 & 108500 & 428000 & \begin{tabular}{|l}
78342,3 \\
\end{tabular} & 108 & 17000 & 106231,5 & 97500 & 397000 & 62340,1 & 198 & 17000,0 & 118267,68 & 103500,00 & 428000 & 71122,002 & ,021 \\
\hline Plq8_Pós & 43 & 8400,0 & 141451,2 & 121000 & 329000 & 78527,0 & 57 & 17000 & 100850,9 & 92000 & 289000 & \begin{tabular}{|l|}
49849,8 \\
\end{tabular} & 100 & 8400,0 & 118309,00 & 103500,00 & 329000 & 66557,059 & ,007 \\
\hline Na0_Pré & 99 & 131,0 & 136,9 & 137 & 149 & 2,6 & 130 & 108 & 134,8 & 135 & 145 & 4,4 & 229 & 108,0 & 136 & 136 & 149 & 3,8 & ,000 \\
\hline $\mathrm{Na1}$ _IOP & 76 & 66,0 & 134,7 & 136 & 141 & 8,4 & 105 & 106 & 133,9 & 134 & 143 & 4,9 & 181 & 66,0 & 134 & 135 & 143 & 7 & ,002 \\
\hline Na7_Pós & 91 & 132,0 & 139,1 & 139,00 & 151 & 3,7 & 105 & 125 & 140,0 & 139 & 158 & 5,0 & 196 & 125,0 & 140 & 139 & 158 & 4 & 131 \\
\hline Na8_Pós & 43 & 129,0 & 137,7 & 138,00 & 144 & 3,3 & 57 & 124 & 135,9 & 137,00 & 142 & 4,1 & 100 & 124,0 & 136,68 & 138,00 & 144 & 3,910 & ,046 \\
\hline KO_Pré & 48 & 3,2 & 4,3 & 4,3 & 5,7 & 0,5 & 83 & 2,9 & 4,4 & 4,4 & 5,9 & 0,6 & 131 & 2,9 & 4,4 & 4,3 & 5,9 & 0,5 & ,331 \\
\hline K1_IOP & 77 & 1,0 & 3,6 & 4,00 & 5 & 0,6 & 105 & 2 & 3,7 & 4,00 & 5 & 0,6 & 182 & 1,0 & 3,69 & 4,00 & 5 & ,625 & ,431 \\
\hline K7_Pós & 90 & 2,0 & 3,8 & 4,00 & 5 & 0,6 & 107 & 3 & 3,7 & 4,00 & 6 & 0,6 & 197 & 2,0 & 3,74 & 4,00 & 6 & 614 & ,368 \\
\hline K8_Pós & 42 & 2,0 & 4,0 & 4,00 & 6 & 0,8 & 59 & 3 & 4,2 & 4,00 & 6 & 0,6 & 101 & 2,0 & 4,11 & 4,00 & 6 & ,677 & ,064 \\
\hline Glio_Pré & 22 & 58,0 & 103,8 & 78 & 271 & 59,2 & 50 & 19 & 92,4 & 76 & 378 & 60,4 & 72 & 19,0 & 96 & 76 & 378 & 60 & 0 \\
\hline Gli1_IOP & 62 & 34,0 & 88,0 & 88 & 168 & 25,4 & 97 & 20 & 104,8 & 97 & 319 & 54,0 & 159 & 20,0 & 98 & 92 & 319 & 46 & 0 \\
\hline Gli7_IOP & 57 & 76,0 & 155,1 & 139 & 404 & 64,7 & 82 & 32 & 145,6 & 137 & 374 & 51,8 & 139 & 32,0 & 149 & 137 & 404 & 57 & 1 \\
\hline Gli8_IOP & 26 & 91,0 & 178,8 & 153 & 820 & 140,0 & 30 & 46 & 155,1 & 141 & 295 & 62,9 & 56 & 46,0 & 166 & 144 & 820 & 106 & 1 \\
\hline La1_IOP & 63 & 0,8 & 11,1 & 11,0 & 24,3 & 5,7 & 94 & 0,9 & 12,0 & 11,1 & 42,0 & 5,9 & 157 & 0,8 & 11,6 & 11,0 & 42,0 & 5,8 & , 439 \\
\hline La7_Pós & 77 & 0,0 & 22,7 & 13,0 & 407,0 & 54,2 & 89 & 3 & 18,6 & 14,00 & 227 & 25,7 & 166 & 0,0 & 20,51 & 13,00 & 407 & 41,387 & ,577 \\
\hline
\end{tabular}

(continua) 
Anexo I. Análise univariada dos grupos de menor $(\mathrm{BCH})$ e maior $(\mathrm{ACH})$ volume transfusional perioperatório de concentrado de hemácias indexado pelo peso corporeo (conclusão)

\begin{tabular}{|c|c|c|c|c|c|c|c|c|c|c|c|c|c|c|c|c|c|c|c|}
\hline \multirow{2}{*}{ CHDI_Per_Ind_ROC } & \multicolumn{6}{|c|}{$\mathrm{BCH}<=27,5$} & \multicolumn{6}{|c|}{$\mathrm{ACH}>27,5$} & \multicolumn{6}{|c|}{ Total } & \multirow[t]{2}{*}{ Valor $p$} \\
\hline & $\mathrm{N}$ & Minimum & Mean & Median & Maximum & SD & $\mathrm{N}$ & Minimum & Mean & Median & Maximum & SD & $\mathrm{N}$ & Minimum & Mean & Median & Maximum & SD & \\
\hline La8_Pós & 23 & 3,0 & 15,5 & 12,00 & 32 & 9,2 & 39 & 2 & 15,9 & 16,00 & 35 & 8,6 & 62 & 2,0 & 15,76 & 15,00 & 35 & 8,736 & ,798 \\
\hline RNIO_Pré & 94 & 0,7 & 1,2 & 1,17 & 2,13 & 0,2 & 123 & ,82 & 1,5 & 1,32 & 3,86 & 0,6 & 217 & 0,7 & 1,3812 & 1,2500 & 3,86 & 46667 & ,000 \\
\hline RNI1_IOP & 71 & 1,0 & 1,2 & 1,00 & 2 & 0,4 & 98 & 1 & 1,7 & 2,00 & 5 & 0,8 & 169 & 1,0 & 1,49 & 1,00 & 5 & ,674 & ,000 \\
\hline RNI7_Pós & 84 & 1,0 & 2,4 & 2,00 & 4 & 0,6 & 92 & 1 & 2,4 & 2,00 & 6 & 0,8 & 176 & 1,0 & 2,39 & 2,00 & 6 & ,684 & 895 \\
\hline RNI8_Pós & 30 & 1,0 & 1,8 & 2,00 & 4 & 0,7 & 43 & 1 & 2,1 & 2,00 & 5 & 0,9 & 73 & 1,0 & 1,95 & 2,00 & 5 & 832 & , 109 \\
\hline Rel0_Pré & 40 & 1,0 & 1,3 & 1,00 & 2 & 0,4 & 69 & 1 & 1,4 & 1,00 & 7 & 0,9 & 109 & 1,0 & 1,35 & 1,00 & 7 &, 750 & ,545 \\
\hline Rel1_IOP & 69 & 1,0 & 1,3 & 1,00 & 5 & 0,6 & 90 & 1 & 1,6 & 1,00 & 7 & 0,9 & 159 & 1,0 & 1,48 & 1,00 & 7 & ,794 & ,009 \\
\hline Rel7_Pós & 72 & 1,0 & 2,0 & 2,00 & 5 & 0,9 & 87 & 1 & 2,8 & 2,00 & 50 & 5,2 & 159 & 1,0 & 2,42 & 2,00 & 50 & 3,905 & ,067 \\
\hline Rel8_Pós & 31 & 1,0 & 1,6 & 1,00 & 4 & 1,0 & 38 & 1 & 2,4 & 1,00 & 37 & 5,8 & 69 & 1,0 & 2,07 & 1,00 & 37 & 4,360 & ,647 \\
\hline Cai0_Pré & 22 & 1,0 & 1,0 & 1,00 & 1 & 0,0 & 50 & 1 & 1,0 & 1,00 & 1 & 0,0 & 72 & 1,0 & 1,00 & 1,00 & 1 & ,000 & 1,000 \\
\hline Cai1_IOP & 73 & 1,0 & 1,0 & 1,00 & 1 & 0,0 & 101 & 1 & 1,0 & 1,00 & 3 & 0,3 & 174 & 1,0 & 1,03 & 1,00 & 3 & ,199 & ,086 \\
\hline Cai7_Pós & 35 & 0,0 & 1,0 & 1,00 & 2 & 0,2 & 47 & 1 & 3,4 & 1,00 & 112 & 16,2 & 82 & 0,0 & 2,35 & 1,00 & 112 & 12,259 & ,614 \\
\hline Cai8_Pós & 11 & 1,0 & 1,0 & 1,00 & 1 & 0,0 & 13 & 1 & 1,0 & 1,00 & 1 & 0,0 & 24 & 1,0 & 1,00 & 1,00 & 1 & ,000 & 1,000 \\
\hline Alb0_Pré & 95 & 1,0 & 2,9 & 3,0 & 5,0 & 0,9 & 122 & 1 & 2,5 & 2,0 & 5,0 & 0,8 & 217 & 1,0 & 2,70 & 3,00 & 5 & ,857 & ,002 \\
\hline Alb1_IOP & 66 & 2,0 & 2,6 & 2,0 & 4,0 & 0,7 & 92 & 1 & 2,3 & 2,0 & 4,0 & 0,7 & 158 & 1,0 & 2,43 & 2,00 & 4 & ,735 & , 070 \\
\hline Alb7_Pós & 77 & 1,2 & 2,8 & 2,8 & 4,8 & 0,7 & 83 & 1,50 & 2,8 & 2,8 & 4,6 & 0,7 & 160 & 1,2 & 2,82 & 2,80 & 4,85 & ,68 & ,836 \\
\hline Alb8_Pós & 15 & 1,3 & 2,6 & 2,8 & 3,9 & 0,6 & 28 & 1,20 & 2,6 & 2,5 & 6,5 & 1,0 & 43 & 1,2 & 2,60 & 2,60 & 6,50 & ,85 & ,459 \\
\hline ASTO_Pré & 36 & 45,0 & 255,1 & 240,50 & 637 & 155,6 & 54 & 29 & 323,6 & 237,0 & 2965,0 & 412,9 & 90 & 29,0 & 296,2 & 237,5 & 2965,0 & 335,0 & ,814 \\
\hline AST7_Pós & 83 & 50,0 & 4415,1 & 335,00 & 2705,00 & 341,0 & 84 & 20,0 & 485,7 & 335,5 & 5627,0 & 728,9 & 167 & 20,0 & 4450,6 & 335,0 & 5627,0 & 569,5 & ,690 \\
\hline AST8_Pós & 40 & 78,0 & 241,6 & 162,00 & 1213,00 & 241,7 & 53 & 20,0 & 349,7 & 171,0 & 3398,0 & 670,1 & 93 & 20,0 & 303,2 & 170,0 & 3398,0 & 530,5 & ,950 \\
\hline ALTO_Pré & 35 & 36,0 & 184,5 & 153,00 & 577,00 & 120,1 & 55 & 13,0 & 194,2 & 125,0 & 1268,0 & 206,0 & 90 & 13,0 & $\begin{array}{l}190,4 \\
\end{array}$ & 140,0 & 1268,0 & $\begin{array}{l}176,9 \\
\end{array}$ & ,358 \\
\hline ALT7_Pós & 83 & 64,0 & 463,8 & 372,00 & 3746,00 & 444,1 & 85 & 54,0 & 565,2 & 382,0 & 7561,0 & 921,8 & 168 & 54,0 & 515,1 & 379,0 & 7561,0 & 725,8 & ,898 \\
\hline ALT8_Pós & 40 & 133,0 & 379,6 & 318,00 & 1703,00 & 257,1 & 53 & 54,0 & 559,5 & 282,0 & 5233,0 & 989,2 & 93 & 54,0 & 4882,1 & 300,0 & 5233,0 & 767,5 & 311 \\
\hline BT0_Pré & 89 & 0,2 & 11,8 & 11,9 & 32,2 & 7,3 & 114 & , 2 & 13,4 & 13,5 & 38,4 & 8,9 & 202 & 0,2 & 12,7 & 12,6 & 38,4 & 8,2 & 304 \\
\hline BT7_Pós & 86 & 0,4 & 4,9 & 4,3 & 33,0 & 4,2 & 90 & 3 & 4,8 & 3,6 & 18,8 & 3,7 & 176 & 0,3 & 4,8 & 3,9 & 33,0 & 4,0 & ,583 \\
\hline BT8_Pós & 43 & 0,6 & 3,7 & 2,8 & 31,1 & 4,7 & 55 &, 4 & 3,8 & 2,8 & 22,2 & 3,4 & 98 & 0,4 & 3,7 & 2,8 & 31,1 & 4,0 & ,824 \\
\hline Cro_Pré & 92 & 0,0 & 0,0 & 0 & 1,0 & 0,1 & 123 & 0 & 0,0 & 0 & 1,0 & 0,1 & 215 & 0,0 & 0 & 0 & 1,0 & , 1 & ,743 \\
\hline Cl Cro_Pré(DCr) & 92 & 0,0 & 229,2 & 197 & 567 & 121,0 & 123 & & 188,3 & 151 & 542 & 104,8 & 215 & 0,0 & 206 & 158 & 567 & 114 & , 006 \\
\hline $\begin{array}{l}\text { Menor Grau de } \\
\text { Complicação }\end{array}$ & 103 & 0,0 & 1,6 & 2,0 & 6,0 & 0,8 & 137 & 0,0 & 1,7 & 2,0 & 7,0 & 1,1 & 240 & 0,0 & 1,7 & 2,0 & 7,0 & 1,0 & 0,67 \\
\hline $\begin{array}{l}\text { Maior Grau de } \\
\text { Complicação }\end{array}$ & 103 & 0,0 & 3,1 & 2,0 & 6,0 & 1,8 & 137 & 0,0 & 4,2 & 5,0 & 7,0 & 2,0 & 240 & 0,0 & 3,7 & 4,0 & 7,0 & 2,0 & 0,00 \\
\hline
\end{tabular}


1. Ferreira CT, Vieira SM, Silveira TR. [Liver transplantation]. Jornal de pediatria. 2000;76 Suppl 1:S198-208.

2. Welch CS. [Liver graft]. Maroc Medical. 1955;34(359):514-5.French

3. Starzl TE, Bernhard VM, Benvenuto R, Cortes N. A new method for onestage hepatectomy for dogs. Surgery. 1959;46:880-6.

4. Wall WJ, Calne RY, Herbertson BM, Baker PG, Smith DP, Underwood J, Kostakis A, Williams R. Simple hypothermic preservation for transporting human livers long distances for transplantation. Report of 12 cases. Transplantation. 1977;23(3):210-6.

5. Jamieson NV, Sundberg R, Lindell S, Claesson K, Moen J, Vreugdenhil PK, Wight DG, Southard JH, Belzer FO. Preservation of the canine liver for 2448 hours using simple cold storage with UW solution. Transplantation. 1988;46(4):517-22.

6. Jamieson $\mathrm{NV}$, Sundberg $\mathrm{R}$, Lindell $\mathrm{S}$, Southard $\mathrm{JH}$, Belzer FO. A comparison of cold storage solutions for hepatic preservation using the isolated perfused rabbit liver. Cryobiology. 1988;25(4):300-10.

7. Starzl TE, Marchioro TL, Vonkaulla KN, Hermann G, Brittain RS, Waddell WR. Homotransplantation of the Liver in Humans. Surg Gynecol Obstet. 1963;117:659-76.

8. Starzl TE, Fung JJ. Themes of liver transplantation. Hepatology. 2010;51(6):1869-84.

9. Bennett J, Bromley P. Perioperative issues in pediatric liver transplantation. Int Anesthesiology Clin. 2006;44(3):125-47.

10. Starzl TE, Iwatsuki S, Shaw BW, Jr., Van Thiel DH, Gartner JC, Zitelli BJ, Malatack JJ, Schade RR. Analysis of liver transplantation. Hepatology. 1984;4(1 Suppl):47S-9S.

11. Pichlmayr R, Brolsch $C$, Wonigeit $K$, Neuhaus $P$, Siegismund $S$, Schmidt FW, Burdelski M. Experiences with liver transplantation in Hannover. Hepatology. 1984;4(1 Suppl):56S-60S. 
12. Calne RY. The present position and future prospects of organ transplantation. Ann R Coll Surg Engl. 1968;42(5):283-306.

13. Starzl TE, Groth CG, Brettschneider L, Penn I, Fulginiti VA, Moon JB, Blanchard H, Martin AJ, Jr., Porter KA. Orthotopic homotransplantation of the human liver. Ann Surg. 1968;168(3):392-415.

14. Starzl TE, Koep LJ, Schroter GP, Halgrimson CG, Porter KA, Weil R, 3rd. Liver replacement for pediatric patients. Pediatrics. 1979;63(6):825-9.

15. Steadman RH. Anesthesia for liver transplant surgery. Anesthesiol Clin North America. 2004;22(4):687-711.

16. Calne RY, White DJ, Pentlow BD, Rolles K, Syrakos T, Ohtawa T, Smith DP, McMaster P, Evans DB, Herbertson BM, Thiru S. Cyclosporin A: preliminary observations in dogs with pancreatic duodenal allografts and patients with cadaveric renal transplants. Transplant Proc. 1979;11(1):8604.

17. Calne RY, Williams R. Liver transplantation. Curr Probl Surg. 1979;16(1):144.

18. Starzl TE, Klintmalm GB, Porter KA, Iwatsuki S, Schroter GP. Liver transplantation with use of cyclosporin a and prednisone. $\mathrm{N}$ Engl J Med. $1981 ; 305(5): 266-9$.

19. Mies S. [Liver transplantation]. Rev Assoc Med Bras. 1998;44(2):127-34.

20. National Institutes of Health Consensus Development Conference Statement: Liver transplantation. Jan-Feb 1984; Washington USA1983. p. 107S-10S.

21. Bacchella T, Machado MC. The first clinical liver transplantation of Brazil revisited. Transplant Proc. 2004;36(4):929-30.

22. Raia S, Nery JR, Mies S. Liver transplantation from live donors. Lancet. 1989;2(8661):497.

23. Andraus W, Canedo BF, D'Alburquerque LA. Living donor liver transplantation in Brazil-current state. Hepatobiliary Surg Nutr. 2016;5(2):176-82.

24. Fisher RA. Living donor liver transplantation: eliminating the wait for death in end-stage liver disease? Nat Rev Gastroenterol Hepatol. 2017;14(6):37382. 
25. Registro Brasileiro de Transplantes [RBT] veículo oficial da Associação Brasileira de Transplante de Órgãos. Revista Jan/Set 2017 .

26. Walia A, Schumann R. The evolution of liver transplantation practices. Curr Opin Organ Transplant. 2008;13(3):275-9.

27. Lisman T, Leebeek FW. Hemostatic alterations in liver disease: a review on pathophysiology, clinical consequences, and treatment. Dig Surg. $2007 ; 24(4): 250-8$.

28. Registro Brasileiro de Transplantes [RBT] veículo oficial da Associação Brasileira de Transplante de Órgãos - Edição comemorativa. Dez 2006.

29. Montano-Loza AJ. Clinical relevance of sarcopenia in patients with cirrhosis. World J Gastroenterol. 2014;20(25):8061-71.

30. Barash PG CB, Stoelting RK. Clinical Anesthesia. 5a ed. Philadelphia: Lippincot Williams \& Walkins; 2002.

31. Muiesan P VD, Mieli-Vergani G. Liver Transplantation in children. J Hepatol. 2007;46(2):340-8.

32. Luca L, Westbrook R, Tsochatzis EA. Metabolic and cardiovascular complications in the liver transplant recipient. Ann Gastroenterol. 2015;28(2):183-92.

33. Hackl C, Schlitt HJ, Melter M, Knoppke B, Loss M. Current developments in pediatric liver transplantation. World J Hepatol. 2015;7(11):1509-20.

34. Kim JJ, Marks SD. Long-term outcomes of children after solid organ transplantation. Clinics (São Paulo) . 2014;69 Suppl 1:28-38.

35. Abramson O, Rosenthal P. Current status of pediatric liver transplantation. Clin Liver Dis. 2000;4(3):533-52.

36. Yazigi NA. Long term outcomes after pediatric liver transplantation. Pediatr Gastroenterol Hepatol Nutr. 2013;16(4):207-18.

37. Rawal N, Yazigi NA. Pediatric Liver Transplantation. Pediatr Clin North Am. 2017;64(3):677-84.

38. Austin MT, Feurer ID, Chari RS, Gorden DL, Wright JK, Pinson CW. Survival after pediatric liver transplantation: why does living donation offer an advantage? Arch Surg. 2005;140(5):465-70; discussion 70-1. 
39. McDiarmid SV, Anand R, Lindblad AS, Group SR. Studies of Pediatric Liver Transplantation: 2002 update. An overview of demographics, indications, timing, and immunosuppressive practices in pediatric liver transplantation in the United States and Canada. Pediatr Transplant. 2004;8(3):284-94.

40. Abt PL, Rapaport-Kelz R, Desai NM, Frank A, Sonnad S, Rand E, Markmann JF, Shaked A, Olthoff KM. Survival among pediatric liver transplant recipients: impact of segmental grafts. Liver transplantation : official publication of the American Association for the Study of Liver Diseases and the International Liver Transpl. 2004;10(10):1287-93.

41. Farmer DG, Yersiz H, Ghobrial RM, McDiarmid SV, Gornbein J, Le H, Schlifke A, Amersi F, Maxfield A, Amos N, Restrepo GC, Chen P, Dawson S, 3rd, Busuttil RW. Early graft function after pediatric liver transplantation: comparison between in situ split liver grafts and living-related liver grafts. Transplantation. 2001;72(11):1795-802.

42. Sandhu L, Sandroussi C, Guba M, Selzner M, Ghanekar A, Cattral MS, McGilvray ID, Levy G, Greig PD, Renner EL, Grant DR. Living donor liver transplantation versus deceased donor liver transplantation for hepatocellular carcinoma: comparable survival and recurrence. Liver Transplant. 2012;18(3):315-22.

43. Spada M, Riva S, Maggiore G, Cintorino D, Gridelli B. Pediatric liver transplantation. World J Gastroenterol. 2009;15(6):648-74.

44. Govindarajan KK. Biliary atresia: Where do we stand now? World J of Hepatol. 2016;8(36):1593-601.

45. Fischler B, Ehrnst A, Forsgren $M$, Orvell $C$, Nemeth $A$. The viral association of neonatal cholestasis in Sweden: a possible link between cytomegalovirus infection and extrahepatic biliary atresia. J Pediatr Gastroenterol Nutr. 1998;27(1):57-64.

46. Morecki R, Glaser JH, Cho S, Balistreri WF, Horwitz MS. Biliary atresia and reovirus type 3 infection. N Engl J of Med. 1982;307(8):481-4.

47. Riepenhoff-Talty M, Gouvea V, Evans MJ, Svensson L, Hoffenberg E, Sokol RJ, Uhnoo I, Greenberg SJ, Schakel K, Zhaori G, Fitzgerald J, Chong S, el-Yousef M, Nemeth A, Brown M, Piccoli D, Hyams J, Ruffin D, Rossi T. Detection of group $\mathrm{C}$ rotavirus in infants with extrahepatic biliary atresia. $\mathrm{J}$ Infect Dis. 1996;174(1):8-15.

48. Sokol RJ, Mack C. Etiopathogenesis of biliary atresia. Semin Liver Dis. $2001 ; 21(4): 517-24$. 
49. Davenport M, Gonde C, Redkar R, Koukoulis G, Tredger M, Mieli-Vergani G, Portmann B, Howard ER. Immunohistochemistry of the liver and biliary tree in extrahepatic biliary atresia. J Pediatric Surg. 2001;36(7):1017-25.

50. Bezerra JA, Tiao G, Ryckman FC, Alonso M, Sabla GE, Shneider B, Sokol RJ, Aronow BJ. Genetic induction of proinflammatory immunity in children with biliary atresia. Lancet. 2002;360(9346):1653-9.

51. Carmi R, Magee CA, Neill CA, Karrer FM. Extrahepatic biliary atresia and associated anomalies: etiologic heterogeneity suggested by distinctive patterns of associations. Am J Medical Genet. 1993;45(6):683-93.

52. Mack CL, Sokol RJ. Unraveling the pathogenesis and etiology of biliary atresia. Pediatr Res. 2005;57(5 Pt 2):87R-94R.

53. Chardot C, Carton M, Spire-Bendelac N, Le Pommelet C, Golmard J, Reding R, Auvert B. Is the Kasai operation still indicated in children older than 3 months diagnosed with biliary atresia? J Pediatr. 2001;138(2):224-8.

54. Karrer FM, Price MR, Bensard DD, Sokol RJ, Narkewicz MR, Smith DJ, Lilly JR. Long-term results with the Kasai operation for biliary atresia. Arch Surg. 1996;131(5):493-6.

55. de Carvalho E, Ivantes CA, Bezerra JA. Extrahepatic biliary atresia: current concepts and future directions. J Pediatric (Rio J). 2007;83(2):105-20.

56. Boyd SD, Stenard F, Lee DK, Goodnough LT, Esquivel CO, Fontaine MJ. Alloimmunization to red blood cell antigens affects clinical outcomes in liver transplant patients. Liver transpl. 2007;13(12):1654-61.

57. Boin Ide F, Leonardi MI, Udo EY, Seva-Pereira T, Stucchi RS, Leonardi LS. [The application of MELD score in patients submitted to liver transplantation: a retrospective analysis of survival and the predictive factors in the short and long term]. Arq Gastroenterol. 2008;45(4):275-83.

58. Ghaffaripour S, Mahmoudi H, Khosravi MB, Sahmeddini MA, Eghbal H, Sattari H, Kazemi K, Malekhosseini SA. Preoperative factors as predictors of blood product transfusion requirements in orthotopic liver transplantation. Prog Transplant. 2011;21(3):254-9.

59. Neto JS, Pugliese R, Fonseca EA, Vincenzi R, Pugliese V, Candido H, Stein AB, Benavides M, Ketzer B, Teng H, Porta G, Miura IK, Baggio V, Guimaraes T, Porta A, Rodrigues CA, Carnevale FC, Carone E, Kondo M, Chapchap $P$. Four hundred thirty consecutive pediatric living donor liver 
transplants: variables associated with posttransplant patient and graft survival. Liver Transpl. 2012;18(5):577-84.

60. Castañeda-Martinez PD, Alcaide-Ortega RI, Fuentes-Garcia VE, Hernandez-Plata JA, Nieto-Zermeno J, Reyes-Lopez A, Varela-Fascinetto G. Anesthetic risk factors associated with early mortality in pediatric liver transplantation. Transplant Proc. 2010;42(6):2383-6.

61. Schiergens TS, Rentsch M, Kasparek MS, Frenes K, Jauch KW, Thasler WE. Impact of perioperative allogeneic red blood cell transfusion on recurrence and overall survival after resection of colorectal liver metastases. Dis Colon Rectum. 2015;58(1):74-82.

62. Spahn DR, Casutt M. Eliminating blood transfusions: new aspects and perspectives. Anesthesiology. 2000;93(1):242-55.

63. Glance LG, Dick AW, Mukamel DB, Fleming FJ, Zollo RA, Wissler R, Salloum R, Meredith UW, Osler TM. Association between intraoperative blood transfusion and mortality and morbidity in patients undergoing noncardiac surgery. Anesthesiology. 2011;114(2):283-92.

64. Shiba $H$, Ishida $Y$, Wakiyama $S$, lida $T$, Matsumoto $M$, Sakamoto $T$, Ito $R$, Gocho T, Furukawa K, Fujiwara Y, Hirohara S, Misawa T, Yanaga K. Negative impact of blood transfusion on recurrence and prognosis of hepatocellular carcinoma after hepatic resection. J Gastrointest Surg. 2009;13(9):1636-42.

65. Nosotti M, Rebulla P, Riccardi D, Baisi A, Bellaviti N, Rosso L, Santambrogio L. Correlation between perioperative blood transfusion and prognosis of patients subjected to surgery for stage I lung cancer. Chest. 2003;124(1):102-7.

66. Hallet J, Tsang M, Cheng ES, Habashi R, Kulyk I, Hanna SS, Coburn NG, Lin Y, Law CH, Karanicolas PJ. The Impact of Perioperative Red Blood Cell Transfusions on Long-Term Outcomes after Hepatectomy for Colorectal Liver Metastases. Ann Surg Oncol. 2015;22(12):4038-45.

67. Reim D, Strobl AN, Buchner C, Schirren R, Mueller W, Luppa P, Ankerst DP, Friess $H$, Novotny A. Perioperative transfusion of leukocyte depleted blood products in gastric cancer patients negatively influences oncologic outcome: A retrospective propensity score weighted analysis on 610 curatively resected gastric cancer patients. Medicine (Baltimore). 2016;95(29):e4322. 
68. Snyder GL, Greenberg S. Effect of anaesthetic technique and other perioperative factors on cancer recurrence. Br J Anaesth. 2010;105(2):10615.

69. Li C, Mi K, Wen TF, Yan LN, Li B, Wei YG, Yang JY, Xu MQ, Wang WT. Risk factors and outcomes of massive red blood cell transfusion following living donor liver transplantation. J Dig Dis. 2012;13(3):161-7.

70. Lopez-Plaza I. Transfusion guidelines and liver transplantation: time for consensus. Liver Transplant. 2007;13(12):1630-2.

71. Yao HS, Wang Q, Wang WJ, Hu ZQ. Intraoperative allogeneic red blood cell transfusion in ampullary cancer outcome after curative pancreatoduodenectomy: a clinical study and meta-analysis. World J Surg. 2008;32(9):2038-46.

72. Buddeberg F, Schimmer BB, Spahn DR. Transfusion-transmissible infections and transfusion-related immunomodulation. Best Pract Res Clin Anaesthesiol. 2008;22(3):503-17.

73. Jabbour N, Gagandeep S, Shah H, Mateo R, Stapfer M, Genyk Y, Sher L, Zwierzchoniewska M, Selby R, Zeger G. Impact of a transfusion-free program on non-Jehovah's Witness patients undergoing liver transplantation. Arch Surg. 2006;141(9):913-7.

74. Ozier Y, Tsou MY. Changing trends in transfusion practice in liver transplantation. Curr Opin Organ Transplant. 2008;13(3):304-9.

75. Trzebicki J, Flakiewicz E, Kosieradzki M, Blaszczyk B, Kolacz M, Jureczko L, Pacholczyk M, Chmura A, Lagiewska B, Lisik W, Wasiak D, Kosson D, Kwiatkowski A, Lazowski T. The use of thromboelastometry in the assessment of hemostasis during orthotopic liver transplantation reduces the demand for blood products. Ann Transplant. 2010;15(3):19-24.

76. Molenaar IQ, Warnaar N, Groen H, Tenvergert EM, Slooff MJ, Porte RJ. Efficacy and safety of antifibrinolytic drugs in liver transplantation: a systematic review and meta-analysis. Am J Transplant. 2007;7(1):185-94.

77. Gurusamy KS, Pissanou T, Pikhart H, Vaughan J, Burroughs AK, Davidson BR. Methods to decrease blood loss and transfusion requirements for liver transplantation. Cochrane Database Syst Rev. 2011(12):CD009052.

78. Clevenger B, Mallett SV. Transfusion and coagulation management in liver transplantation. World J Gastroenterol. 2014;20(20):6146-58. 
79. Greiff G, Pleym H, Stenseth R, Berg KS, Wahba A, Videm V. Prediction of bleeding after cardiac surgery: comparison of model performances: a prospective observational study. J Cardiothorac Vas Anesth. 2015;29(2):311-9.

80. Vassal O, Desgranges FP, Tosetti S, Burgal S, Dailler F, Javouhey E, Mottolese C, Chassard D. Risk factors for intraoperative allogeneic blood transfusion during craniotomy for brain tumor removal in children. Paediatr Anaesth. 2016;26(2):199-206.

81. Jackson BL, Fowler S, Williams ST, British Association of Urological Surgeons - Section of $O$. Perioperative outcomes of cytoreductive nephrectomy in the UK in 2012. BJU Int. 2015;116(6):905-10.

82. David JS, Voiglio EJ, Cesareo E, Vassal O, Decullier E, Gueugniaud PY, Peyrefitte S, Tazarourte K. Prehospital parameters can help to predict coagulopathy and massive transfusion in trauma patients. Vox Sang. 2017.

83. Nunez TC, Voskresensky IV, Dossett LA, Shinall R, Dutton WD, Cotton BA. Early prediction of massive transfusion in trauma: simple as $A B C$ (assessment of blood consumption)? J Trauma. 2009;66(2):346-52.

84. McCluskey SA, Karkouti K, Wijeysundera DN, Kakizawa K, Ghannam M, Hamdy A, Grant D, Levy G. Derivation of a risk index for the prediction of massive blood transfusion in liver transplantation. Liver Transplant. 2006;12(11):1584-93.

85. Massicotte L, Sassine MP, Lenis S, Roy A. Transfusion predictors in liver transplant. Anesth Analg. 2004;98(5):1245-51, table of contents.

86. Massicotte L, Beaulieu D, Roy JD, Marleau D, Vandenbroucke F, Dagenais M, Lapointe R, Roy A. MELD score and blood product requirements during liver transplantation: no link. Transplantation. 2009;87(11):1689-94.

87. Rana A, Petrowsky H, Hong JC, Agopian VG, Kaldas FM, Farmer D, Yersiz $\mathrm{H}$, Hiatt JR, Busuttil RW. Blood transfusion requirement during liver transplantation is an important risk factor for mortality. J Am Coll Surg. 2013;216(5):902-7.

88. Mangus RS, Kinsella SB, Nobari MM, Fridell JA, Vianna RM, Ward ES, Nobari R, Tector AJ. Predictors of blood product use in orthotopic liver transplantation using the piggyback hepatectomy technique. Transplant Proc. 2007;39(10):3207-13. 
89. Fernandes DS, Pereira Real CC, Sa Couto Romao PA, Marcos Correia De Barros FB, Marques Aragao IM, Guimaraes Fonseca LF, Goncalves Aguiar JM, Costa Branco TM, Fernandes Moreira ZM, Barros Esteves SM. Preoperative predictors of red blood cell transfusion in liver transplantation. Blood Transfus. 2016;15(1):53-6.

90. Bang SR, Ahn HJ, Kim GS, Yang M, Gwak MS, Ko JS, Kim SH, Lee SK. Predictors of high intraoperative blood loss derived by simple and objective method in adult living donor liver transplantation. Transplant Proc. 2010;42(10):4148-50.

91. de Boer MT, Christensen MC, Asmussen M, van der Hilst CS, Hendriks HG, Slooff MJ, Porte RJ. The impact of intraoperative transfusion of platelets and red blood cells on survival after liver transplantation. Anesth Analg. 2008;106(1):32-44, table of contents.

92. Ramos E, Dalmau A, Sabate A, Lama C, Llado L, Figueras J, Jaurrieta E. Intraoperative red blood cell transfusion in liver transplantation: influence on patient outcome, prediction of requirements, and measures to reduce them. Liver Transplant. 2003;9(12):1320-7.

93. Massicotte L, Sassine MP, Lenis S, Seal RF, Roy A. Survival rate changes with transfusion of blood products during liver transplantation. Can $\mathrm{J}$ Anaesth. 2005;52(2):148-55.

94. Nacoti M, Cazzaniga S, Lorusso F, Naldi L, Brambillasca P, Benigni A, Corno V, Colledan M, Bonanomi E, Vedovati S, Buoro S, Falanga A, Lussana F, Barbui T, Sonzogni V. The impact of perioperative transfusion of blood products on survival after pediatric liver transplantation. Pediatric Transplant. 2012;16(4):357-66.

95. Steib A, Freys G, Lehmann C, Meyer C, Mahoudeau G. Intraoperative blood losses and transfusion requirements during adult liver transplantation remain difficult to predict. Can J Anaesth. 2001;48(11):1075-9.

96. Nacoti M, Corbella D, Fazzi F, Rapido F, Bonanomi E. Coagulopathy and transfusion therapy in pediatric liver transplantation. World J Gastroenterol. 2016;22(6):2005-23.

97. Gelb B, Feng S. Management of the liver transplant patient. Expert Rev of Gastroenterol Hepatol. 2009;3(6):631-47.

98. Ng VL, Alonso EM, Bucuvalas JC, Cohen G, Limbers CA, Varni JW, Mazariegos G, Magee J, McDiarmid SV, Anand R, Studies of Pediatric Liver Transplantation Research $\mathrm{G}$. Health status of children alive 10 years after 
pediatric liver transplantation performed in the US and Canada: report of the studies of pediatric liver transplantation experience. J Pediatr. 2012;160(5):820-6 e3.

99. Dindo D DN, Clavien PA. Classification of surgical complications : a new proposal with evaluation in a cohort of 6336 patients and results of a survey. Ann Surg. 2004;240(2):205-13.

100.Beck-Schimmer B, Bonvini JM, Schadde E, Dutkowski P, Oberkofler CE, Lesurtel M, DeOliveira ML, Figueira ER, Rocha Filho JA, Auler JO, Jr., D'Albuquerque LA, Reyntjens K, Wouters P, Rogiers X, Debaerdemaeker L, Ganter MT, Weber A, Puhan MA, Clavien PA, Breitenstein S. Conditioning With Sevoflurane in Liver Transplantation: Results of a Multicenter Randomized Controlled Trial. Transplantation. 2015;99(8):1606-12.

101.Tsampalieros A, Lepage N, Feber J. Intraindividual variability of the modified Schwartz and novel CKiD GFR equations in pediatric renal transplant patients. Pediatr Transplant. 2011;15(7):760-5.

102.Zachwieja K, Korohoda P, Kwinta-Rybicka J, Miklaszewska M, Moczulska A, Bugajska J, Berska J, Drozdz D, Pietrzyk JA. Which equations should and which should not be employed in calculating eGFR in children? Adv Med Sci. 2015;60(1):31-40.

103.Staples A, LeBlond R, Watkins S, Wong C, Brandt J. Validation of the revised Schwartz estimating equation in a predominantly non-CKD population. Pediatr Nephrol. 2010;25(11):2321-6.

104.Warady BA, Chadha V. Chronic kidney disease in children: the global perspective. Pediatr Nephrol. 2007;22(12):1999-2009.

105.Alqahtani SA. Update in liver transplantation. Discov Med. 2012;14(75):133-41.

106.López Santamaria M GM, Murcia J, Diez Pardo JA,Leal N; Frauca E, Camarena $C$, Hierro $L$, dela Vega $A$, Díaz MC, Jara $P$, Tovar J. [Prognostic factors in pediatric liver transplantation. Multivariate analysis]. Cir Pediatr 2003;38(8):2465-7.

107. Pereboom IT, de Boer MT, Haagsma EB, Hendriks HG, Lisman T, Porte RJ. Platelet transfusion during liver transplantation is associated with increased postoperative mortality due to acute lung injury. Anesth Analg. 2009;108(4):1083-91. 
108.Clavien PA, Sanabria JR, Strasberg SM. Proposed classification of complications of surgery with examples of utility in cholecystectomy. Surgery. 1992;111(5):518-26.

109.Clavien PA, Camargo CA, Jr., Croxford R, Langer B, Levy GA, Greig PD. Definition and classification of negative outcomes in solid organ transplantation. Application in liver transplantation. Ann Surg. 1994;220(2):109-20.

110.Broering DC, Wilms C, Bok P, Fischer L, Mueller L, Hillert C, Lenk C, Kim JS, Sterneck M, Schulz KH, Krupski G, Nierhaus A, Ameis D, Burdelski M, Rogiers $X$. Evolution of donor morbidity in living related liver transplantation: a single-center analysis of 165 cases. Ann Surg. 2004;240(6):1013-24; discussions 24-6.

111.al CDLMMAOBe. Predictos of major posoperative complications in neonatal surgery. Rev Col Bras Cir. 2013;40 (5):363-69.

112.Sethi MV, Zimmer J, Ure B, Lacher M. Prospective assessment of complications on a daily basis is essential to determine morbidity and mortality in routine pediatric surgery. J Pediatr Surg. 2016;51(4):630-3.

113.Kazaryan AM, Rosok BI, Edwin B. Morbidity assessment in surgery: refinement proposal based on a concept of perioperative adverse events. ISRN Surg. 2013;2013:625093.

114.Panwar R, Pal S, Dash NR, Shalimar, Sahni P, Acharya SK, Pande GK, Chattopadhyay TK, Nundy S. Hepatic resection for predominantly large size hepatocellular carcinoma: Early and long-term results from a tertiary care center in India. Indian J Gastroenterol. 2016;35(4):280-6.

115.Mokart D, Giaoui E, Barbier L, Lambert J, Sannini A, Chow-Chine L, Brun JP, Faucher M, Guiramand J, Ewald J, Bisbal M, Blache JL, Delpero JR, Leone $\mathrm{M}$, Turrini $\mathrm{O}$. Postoperative sepsis in cancer patients undergoing major elective digestive surgery is associated with increased long-term mortality. J Crit Care. 2016;31(1):48-53.

116.Bekker J, Ploem S, de Jong KP. Early hepatic artery thrombosis after liver transplantation: a systematic review of the incidence, outcome and risk factors. Am Journal of Transplant. 2009;9(4):746-57.

117.Fanna M, Baptiste A, Capito C, Ortego R, Pacifico R, Lesage F, Moulin F, Debray D, Sissaoui S, Girard M, Lacaille F, Telion C, Elie C, Aigrain Y, Chardot $\mathrm{C}$. Preoperative risk factors for intra-operative bleeding in pediatric liver transplantation. Pediatr Transplant. 2016;20(8):1065-71. 
118.Roullet S, Biais M, Millas E, Revel P, Quinart A, Sztark F. Risk factors for bleeding and transfusion during orthotopic liver transplantation. Ann Fr Anesth Reanim. 2011;30(4):349-52.

119.De Santis GC, Brunetta DM, Nardo M, Oliveira LC, Souza FF, Cagnolati D, Mente ED, Sankarankutty AK, Covas DT, de Castro e Silva O. Preoperative variables associated with transfusion requirements in orthotopic liver transplantation. Transfus Apher Sci. 2014;50(1):99-105.

120.Benson AB, Burton JR, Jr., Austin GL, Biggins SW, Zimmerman MA, Kam I, Mandell S, Silliman CC, Rosen H, Moss M. Differential effects of plasma and red blood cell transfusions on acute lung injury and infection risk following liver transplantation. Liver Transplant. 2011;17(2):149-58.

121.Feltracco P, Carollo C, Barbieri S, Pettenuzzo T, Ori C. Early respiratory complications after liver transplantation. World J Gastroenterol. 2013;19(48):9271-81.

122.Chappell D, Jacob M, Hofmann-Kiefer K, Conzen P, Rehm M. A rational approach to perioperative fluid management. Anesthesiology. 2008;109(4):723-40.

123.Gelman S, Mushlin PS. Catecholamine-induced changes in the splanchnic circulation affecting systemic hemodynamics. Anesthesiology. 2004;100(2):434-9.

124.Laster ML, Fine RN. Growth following solid organ transplantation in childhood. Pediatr Transplant. 2014;18(2):134-41.

125.Issa DH, Alkhouri N. Long-term management of liver transplant recipients: A review for the internist. Cleve Clin J Med. 2015;82(6):361-72.

126.Fonseca-Aten M, Michaels MG. Infections in pediatric solid organ transplant recipients. Semin Pediatr Surg. 2006;15(3):153-61.

127.LaRosa C, Baluarte HJ, Meyers KE. Outcomes in pediatric solid-organ transplantation. Pediatr Transplant. 2011;15(2):128-41.

128.Gladdy RA, Richardson SE, Davies HD, Superina RA. Candida infection in pediatric liver transplant recipients. Liver Transpl Surg. 1999;5(1):16-24.

129.Madan RP, Herold BC. Viral infections in pediatric solid organ transplantation recipients and the impact of molecular diagnostic testing. Curr Opin Organ Transplant. 2010;15(3):293-300. 
130.Fisher RA. Cytomegalovirus infection and disease in the new era of immunosuppression following solid organ transplantation. Transpl Infect Dis. 2009;11(3):195-202.

131. Oliveira RA, Turrini RNT, Poveda VB. Risk factors for development of surgical site infections among liver transplantation recipients: An integrative literature review. Am J Infect Control. 2017.

132.Starczewska MH, Giercuszkiewicz D, Niewinski G, Kanski A. Perioperative bleeding in patients undergoing liver transplantation. Anaesthesiol Intensive Ther. 2016;48(1):34-40.

133.Corradini SG, Elisei W, De Marco R, Siciliano M, lappelli $M$, Pugliese $F$, Ruberto F, Nudo F, Pretagostini R, Bussotti A, Mennini G, Eramo A, Liguori F, Merli M, Attili AF, Muda AO, Natalizi S, Berloco P, Rossi M. Preharvest donor hyperoxia predicts good early graft function and longer graft survival after liver transplantation. Liver Transplant. 2005;11(2):140-51.

134.Li J, Wang K. Application of elderly donor for liver transplantation. Int J Clin Exp Med. 2015;8(7):10315-20.

135. Hayashi M, Fujii K, Kiuchi T, Uryuhara K, Kasahara M, Takatsuki M, Takeichi T, Kitade H, Sugimoto T, Uemoto S, Asonuma K, Egawa H, Fujita $\mathrm{S}$, Inomata Y, Tanaka K. Effects of fatty infiltration of the graft on the outcome of living-related liver transplantation. Transplant Proc. 1999;31(12):403.

136.Cameron AM, Ghobrial RM, Yersiz H, Farmer DG, Lipshutz GS, Gordon SA, Zimmerman M, Hong J, Collins TE, Gornbein J, Amersi F, Weaver M, Cao C, Chen T, Hiatt JR, Busuttil RW. Optimal utilization of donor grafts with extended criteria: a single-center experience in over 1000 liver transplants. Ann Surg. 2006;243(6):748-53; discussion 53-5.

137.Sirivatanauksorn Y, Taweerutchana V, Limsrichamrern S, Kositamongkol $\mathrm{P}$, Mahawithitwong $\mathrm{P}$, Asavakarn S, Tovikkai C. Recipient and perioperative risk factors associated with liver transplant graft outcomes. Transplant Proc. 2012;44(2):505-8.

138.Sabra TA, Okajima H, Yoshizawa A, Okamoto T, Anazawa T, Ygi S, Hata K, Yasuchika K, Taura K, Hatano E, Kaido T, Uemoto S. Portal vein reconstruction using vein grafts in pediatric living donor liver transplantation: Current status. Pediatr Transplant. 2017;21(3). 
139.Lodhi SA, Lamb KE, Meier-Kriesche HU. Solid organ allograft survival improvement in the United States: the long-term does not mirror the dramatic short-term success. Am J Transplant. 2011;11(6):1226-35.

140.Dreyzin A, Lunz J, Venkat V, Martin L, Bond GJ, Soltys KA, Sindhi R, Mazariegos GV. Long-term outcomes and predictors in pediatric liver retransplantation. Pediatr Transplant. 2015;19(8):866-74.

141.Stabler B, Clopper RR, Siegel PT, Stoppani C, Compton PG, Underwood LE. Academic achievement and psychological adjustment in short children. The National Cooperative Growth Study. J Dev Behav Pediatr. 1994;15(1):1-6.

142.Stewart SM, Uauy R, Kennard BD, Waller DA, Benser M, Andrews WS. Mental development and growth in children with chronic liver disease of early and late onset. Pediatrics. 1988;82(2):167-72.

143.Krull K, Fuchs C, Yurk H, Boone P, Alonso E. Neurocognitive outcome in pediatric liver transplant recipients. Pediatr Transplant. 2003;7(2):111-8.

144.Schulz KH, Wein C, Boeck A, Rogiers X, Burdelski M. Cognitive performance of children who have undergone liver transplantation. Transplantation. 2003;75(8):1236-40.

145.Guest Je HJ. Nutritional aspects of Pediatric Liver Transplantation. Transplantation of the Liver. Philadelphia: WB Sauders; 1996. p. 227-35.

146.Matinlauri IH, Nurminen MM, Hockerstedt KA, Isoniemi HM. Risk factors predicting survival of liver transplantation. Transplant Proc. 2005;37(2):1155-60.

147.Lee DS, Gil WH, Lee HH, Lee KW, Lee SK, Kim SJ, Choi SH, Heo JS, Hyon WS, Kim GS, Paik SW, Koh KC, Joh JW. Factors affecting graft survival after living donor liver transplantation. Transplant Proc. 2004;36(8):2255-6.

148.Wilson AC, Greenbaum LA, Barletta GM, Chand D, Lin JJ, Patel HP, Mitsnefes M. High prevalence of the metabolic syndrome and associated left ventricular hypertrophy in pediatric renal transplant recipients. Pediatr Transplant. 2010;14(1):52-60.

149.Madhwal S, Atreja A, Albeldawi M, Lopez R, Post A, Costa MA. Is liver transplantation a risk factor for cardiovascular disease? A meta-analysis of observational studies. Liver Transplant. 2012;18(10):1140-6. 
150.Abbas A LA, PillaiS, . Cellular and Molecular Immunology: Saunders Elsevier; 2011.

151.Banff schema for grading liver allograft rejection: an international consensus document. Hepatology. 1997;25(3):658-63.

152.Neil DA, Hubscher SG. Current views on rejection pathology in liver transplantation. Transplant Int. 2010;23(10):971-83.

153. Nacif LS, Pinheiro RS, Pecora RA, Ducatti L, Rocha-Santos V, Andraus W, D'Albuquerque LC. Late acute rejection in liver transplant: a systematic review. Arq Bras Cir Dig. 2015;28(3):212-5.

154.Chen W, Lee S, Colby J, Kluger J, Ashaye A, Tongbram V, Baker E, Mather J, Coleman Cl, White CM. The Impact of Pre-Transplant Red Blood Cell Transfusions in Renal Allograft Rejection. The Impact of PreTransplant Red Blood Cell Transfusions in Renal Allograft Rejection. AHRQ Technology Assessments. Rockville (MD)2012.

155.Wang FS, Yamaguchi Y, Furuhashi T, Uchino S, Kihara S, Yamada S, Mori $\mathrm{K}$, Ogawa M. Recipient blood pre-transplant transfusion prolongs hepatic allograft survival in rats. J Surg Res. 2006;135(1):52-60.

156.Kamdar KY, Rooney CM, Heslop HE. Posttransplant lymphoproliferative disease following liver transplantation. Curr Opin Organ Transplant. 2011;16(3):274-80.

157.Cata JP, Wang H, Gottumukkala V, Reuben J, Sessler DI. Inflammatory response, immunosuppression, and cancer recurrence after perioperative blood transfusions. Br J Anaesth. 2013;110(5):690-701.

158.van de Watering LM, Brand A, Houbiers JG, Klein Kranenbarg WM, Hermans J, van de Velde C, Cancer R, Blood transfusion study $g$. Perioperative blood transfusions, with or without allogeneic leucocytes, relate to survival, not to cancer recurrence. Br J Surg. 2001;88(2):267-72.

159.Sabate A, Dalmau A, Koo M, Aparicio I, Costa M, Contreras L. Coagulopathy management in liver transplantation. Transplant Proc. 2012;44(6):1523-5.

160.Massicotte L, Denault AY, Beaulieu D, Thibeault L, Hevesi Z, Nozza A, Lapointe R, Roy A. Transfusion rate for 500 consecutive liver transplantations: experience of one liver transplantation center. Transplantation. 2012;93(12):1276-81. 
161.Jawan B, de Villa V, Luk HN, Wang CS, Huang CJ, Chen YS, Wang CC, Cheng YF, Huang TL, Eng HL, Liu PP, Chiu KW, Chen CL. Perioperative normovolemic anemia is safe in pediatric living-donor liver transplantation. Transplantation. 2004;77(9):1394-8.

162.Chen CL, Concejero A, Wang CC, Wang SH, Lin CC, Liu YW, Yong CC, Yang $\mathrm{CH}$, Lin TS, Chiang YC, Jawan B, Huang TL, Cheng YF, Eng HL. Living donor liver transplantation for biliary atresia: a single-center experience with first 100 cases. Am J Transplant. 2006;6(11):2672-9.

163.Mizuta K, Sanada Y, Wakiya T, Urahashi T, Umehara M, Egami S, Hishikawa S, Okada N, Kawano Y, Saito T, Hayashida M, Takahashi S, Yoshino H, Shimizu A, Takatsuka Y, Kitamura T, Kita Y, Uno T, Yoshida Y, Hyodo M, Sakuma Y, Fujiwara T, Ushijima K, Sugimoto K, Ohmori M, Ohtomo S, Sakamoto K, Nakata M, Yano T, Yamamoto H, Kobayashi E, Yasuda $\mathrm{Y}$, Kawarasaki H. Living-donor liver transplantation in 126 patients with biliary atresia: single-center experience. Transplant Proc. 2010;42(10):4127-31.

164. Yuasa T, Niwa N, Kimura S, Tsuji H, Yurugi K, Egawa $H$, Tanaka K, Asano $\mathrm{H}$, Maekawa $\mathrm{T}$. Intraoperative blood loss during living donor liver transplantation: an analysis of 635 recipients at a single center. Transfusion. 2005;45(6):879-84.

165.Huang CJ, Cheng KW, Chen CL, Wu SC, Shih TH, Yang SC, Jawan B, Wang $\mathrm{CH}$. Predictive factors for pediatric patients requiring massive blood transfusion during living donor liver transplantation. Ann Transplant. 2013;18:443-7.

166.Jin SJ, Kim SK, Choi SS, Kang KN, Rhyu CJ, Hwang S, Lee SG, Namgoong JM, Kim YK. Risk factors for intraoperative massive transfusion in pediatric liver transplantation: a multivariate analysis. Int $\mathrm{J}$ Med Sci. 2017;14(2):173-80.

167.Deakin M, Gunson BK, Dunn JA, McMaster P, Tisone G, Warwick J, Buckels JA. Factors influencing blood transfusion during adult liver transplantation. Ann R Coll Surg Engl. 1993;75(5):339-44.

168.Diab YA, Wong EC, Luban NL. Massive transfusion in children and neonates. Br J Haematol. 2013;161(1):15-26.

169.Inghilleri G. Prediction of transfusion requirements in surgical patients: a review. [Transfusion Alternatives in Transfusion Medicine]. 2009;11:10-9. 
170.Garcia-Gil FA, Luque P, Ridruejo R, Tome-Zelaya E, Guemes A, Serrano MT, Barrao ME. Liver transplant, in emergency 0 (UNOS Status 1). Transplant Proc. 2006;38(8):2465-7.

171.Boin IF, Leonardi MI, Luzo AC, Cardoso AR, Caruy CA, Leonardi LS. Intraoperative massive transfusion decreases survival after liver transplantation. Transplant Proc. 2008;40(3):789-91.

172.Pereboom IT, Lisman T, Porte RJ. Platelets in liver transplantation: friend or foe? Liver Transplant. 2008;14(7):923-31.

173. Ulukaya S, Acar L, Ayanoglu HO. Transfusion requirements during cadaveric and living donor pediatric liver transplantation. Pediatr Transplant. 2005;9(3):332-7.

174.Barcelona SL, Thompson AA, Cote CJ. Intraoperative pediatric blood transfusion therapy: a review of common issues. Part II: transfusion therapy, special considerations, and reduction of allogenic blood transfusions. Paediatr Anaesth. 2005;15(10):814-30.

175. Kim SJ, Lee HH, Lee DS, Lee KW, Joh JW, Woo DH, Kwon GY, Oh HY, Kim YG, Huh WS, Kim DJ, Kim GS, Lee SK, Lee BB. Prognostic factors affecting graft and patient survival in cadaveric and living kidney transplantation. Transplant Proc. 2004;36(7):2038-9. 